\title{
Experimental Evaluation of Refrigerant Leak Characteristics for Different HVAC\&R Equipment Types
}

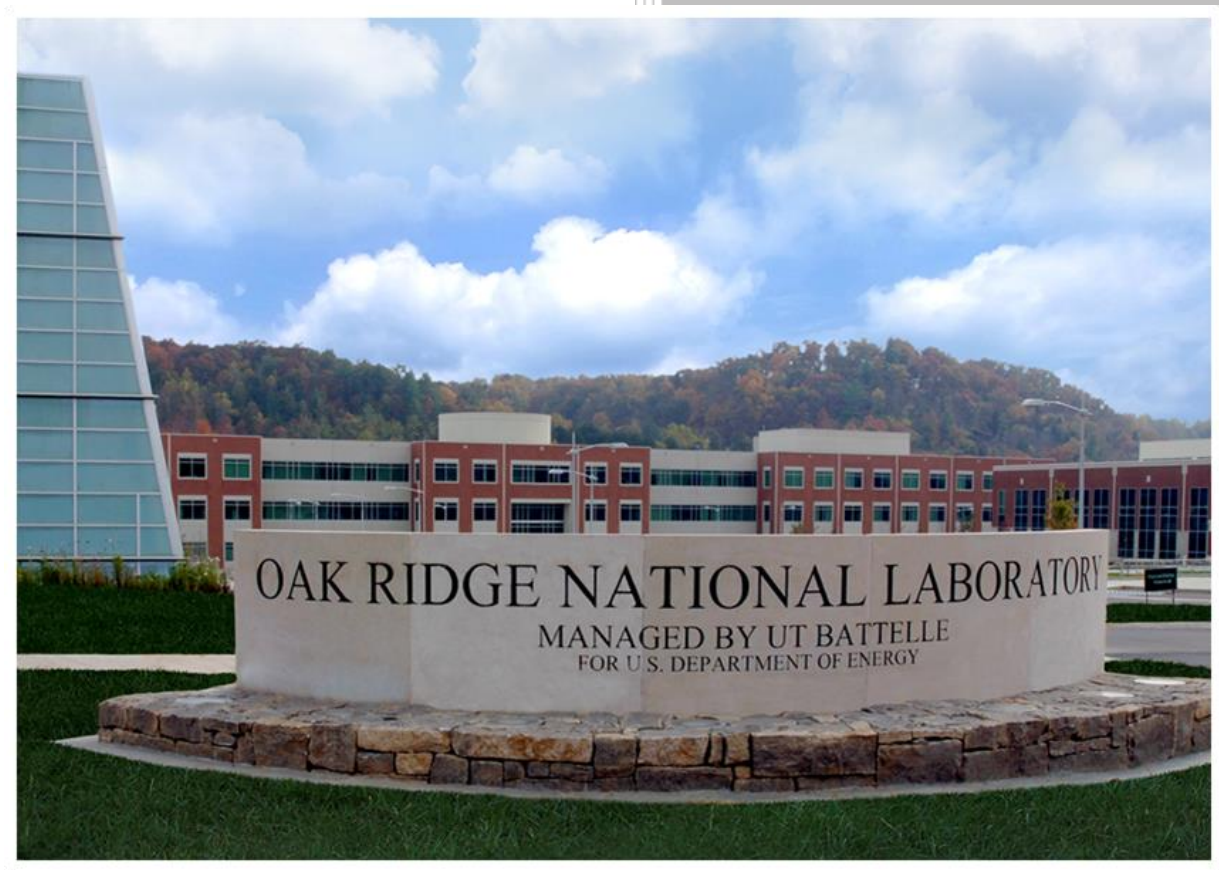

Approved for public release. Distribution is unlimited.
Van Baxter Viral K. Patel Ahmad Abu-Heiba William A. Miller Randall Linkous Geoff Ormston

March 2019 


\title{
DOCUMENT AVAILABILITY
}

Reports produced after January 1, 1996, are generally available free via US Department of Energy (DOE) SciTech Connect.

Website www.osti.gov

Reports produced before January 1, 1996, may be purchased by members of the public from the following source:

\author{
National Technical Information Service \\ 5285 Port Royal Road \\ Springfield, VA 22161 \\ Telephone 703-605-6000 (1-800-553-6847) \\ TDD 703-487-4639 \\ Fax 703-605-6900 \\ E-mail info@ntis.gov \\ Website http://classic.ntis.gov/
}

Reports are available to DOE employees, DOE contractors, Energy Technology Data Exchange representatives, and International Nuclear Information System representatives from the following source:

Office of Scientific and Technical Information

PO Box 62

Oak Ridge, TN 37831

Telephone 865-576-8401

Fax 865-576-5728

E-mail reports@osti.gov

Website http://www.osti.gov/contact.html

This report was prepared as an account of work sponsored by an agency of the United States Government. Neither the United States Government nor any agency thereof, nor any of their employees, makes any warranty, express or implied, or assumes any legal liability or responsibility for the accuracy, completeness, or usefulness of any information, apparatus, product, or process disclosed, or represents that its use would not infringe privately owned rights. Reference herein to any specific commercial product, process, or service by trade name, trademark, manufacturer, or otherwise, does not necessarily constitute or imply its endorsement, recommendation, or favoring by the United States Government or any agency thereof. The views and opinions of authors expressed herein do not necessarily state or reflect those of the United States Government or any agency thereof. 
Energy and Transportation Science Division

\title{
EXPERIMENTAL EVALUATION OF REFRIGERANT LEAK CHARACTERISTICS FOR DIFFERENT HVAC\&R EQUIPMENT TYPES
}

\author{
Van Baxter \\ Viral K. Patel \\ Ahmad Abu-Heiba \\ William A. Miller \\ Randall Linkous \\ Geoff Ormston
}

Date Published: March 2019

Prepared by

OAK RIDGE NATIONAL LABORATORY

Oak Ridge, TN 37831-6283

managed by

UT-BATTELLE, LLC

for the

US DEPARTMENT OF ENERGY

under contract DE-AC05-00OR22725 



\section{CONTENTS}

CONTENTS

iii

TABLE OF FIGURES IN EXECUTIVE SUMMARY...

TABLE OF FIGURES IN MAIN BODY OF REPORT …........................................................... iv

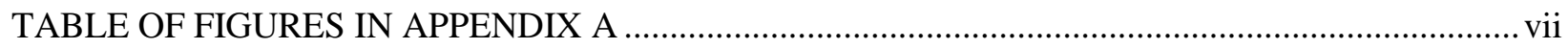

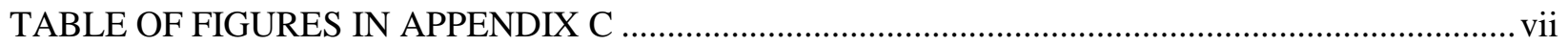

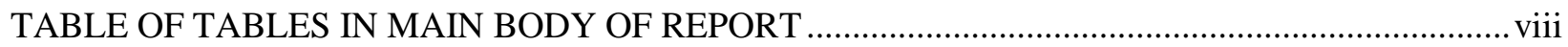

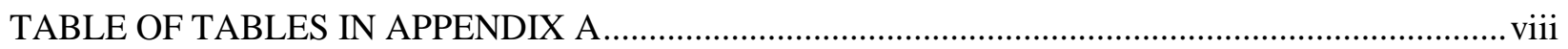

TABLE OF TABLES IN APPENDIX C ................................................................................ viii

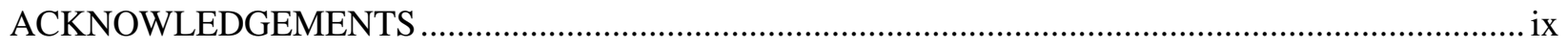

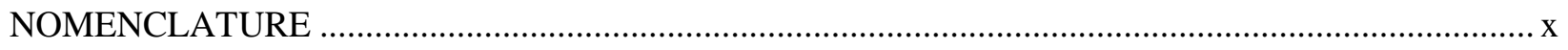

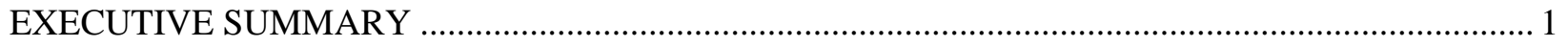

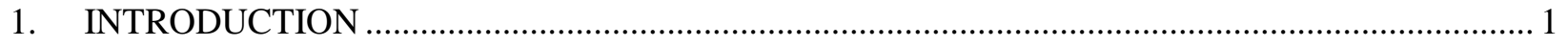

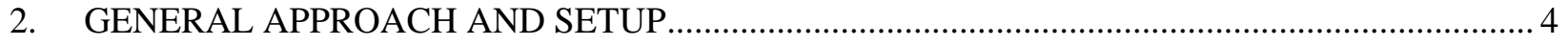

2.1 GENERAL REQUIREMENTS FROM AHRTI 9012 WORK STATEMENT ........................ 4

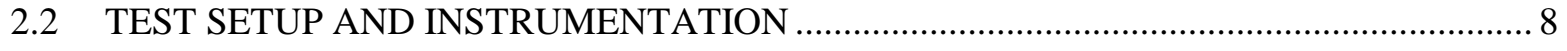

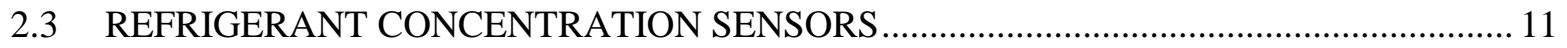

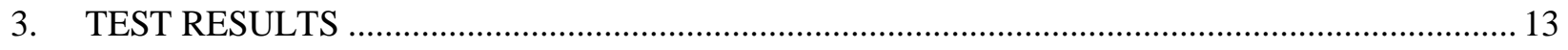

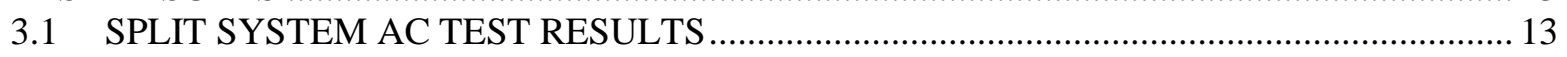

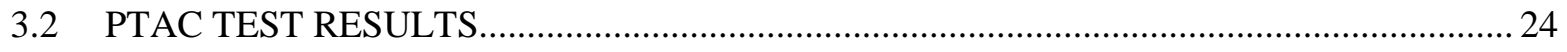

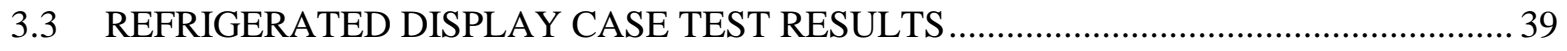

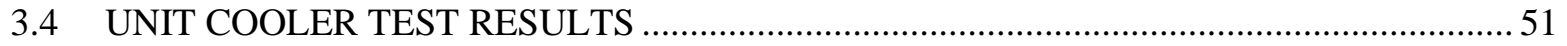

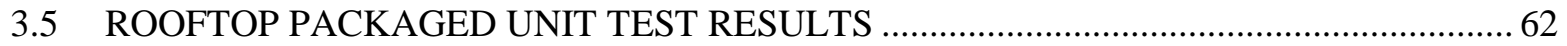

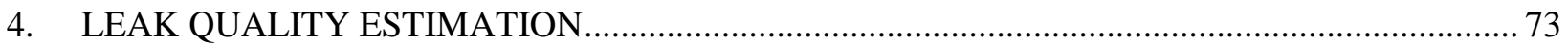

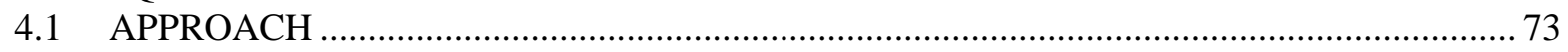

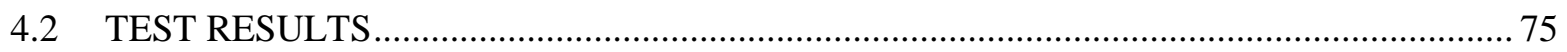

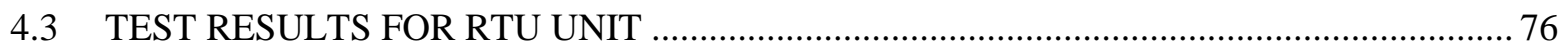

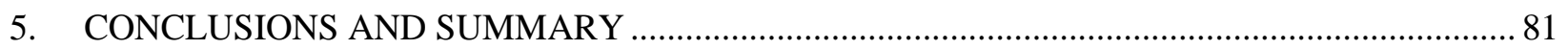

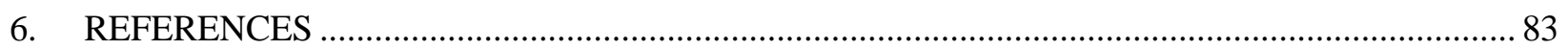

APPENDIX A. INSTRUMENTATION, DAS, AND TEST UNITS …….......................................... A-2

APPENDIX B. EXPERIMENTAL PROCEDURES ................................................................... $\mathrm{B}-2$

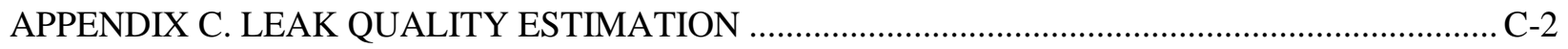




\section{TABLE OF FIGURES IN EXECUTIVE SUMMARY}

Figure ES 1. Average leak rates for $80 \%$ of total charge released for split AC system tests..................... 2

Figure ES 2. Average leak rates for $80 \%$ of total charge released for PTAC tests................................... 2

Figure ES 3. Average leak rates for $80 \%$ of total charge released for display case tests........................... 3

Figure ES 4. Average leak rates for $80 \%$ of total charge released for RTU AC tests................................ 3

Figure ES 5. Average leak rates for $80 \%$ of total charge released for unit cooler system tests................... 4

\section{TABLE OF FIGURES IN MAIN BODY OF REPORT}

Figure 1. Split AC unit tested. Left is the condensing unit and right is the evaporator unit (air handler)

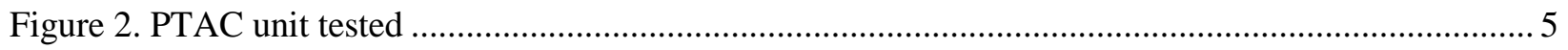

Figure 3. Packaged rooftop AC unit tested ....................................................................................... 5

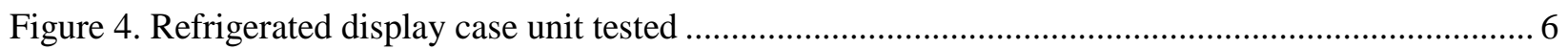

Figure 5. Unit cooler unit tested. Left is the condensing unit and right is the evaporator unit ................... 6

Figure 6. Split AC test unit conceptual set up in test chamber (not to scale) .......................................... 9

Figure 7. (a.) Refrigerant leak capture box schematic and (b.) photo; box mounted on precision weigh scale.

Figure 8. Deconvolved concentration signal vs. actual concentration. The deconvolved signal is obtained using a non-linear dynamic model of the sensor. The dynamic model was estimated using sensor output voltage response to concentration dataset collected experimentally

Figure 9. (a.) Split AC installed in chamber and (b.) close-up of leak release control system (pneumatically controlled, fast opening ball valve) ............................................................................. 13

Figure 10. Refrigerant and room temperature sensor support rig ........................................................ 14

Figure 11. Initial shakedown test with split AC unit charged with nitrogen ......................................... 15

Figure 12. Shakedown test with split AC unit charged with R-410A................................................... 16

Figure 13. "Catch" box/drip pan weight gain during tests G1 (115), left, and G2, right......................... 17

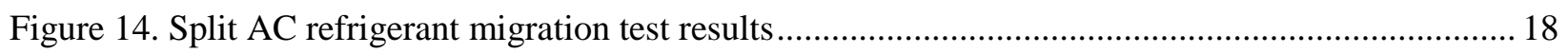

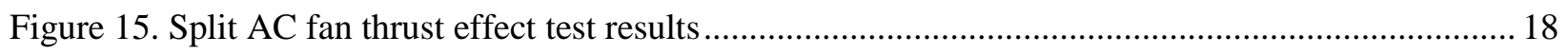

Figure 16. (a.) High- and low-side pressure decay, (b.) percent charge released and (c.) system diagram for split AC test 109 (4.11 mm orifice).

Figure 17. (a.) High- and low-side pressure decay, (b.) percent charge released and (c.) system diagram for split AC test 110 (4.11 mm orifice).

Figure 18. (a.) High- and low-side pressure decay, (b.) percent charge released and (c.) system diagram for split AC test 111 (4.11 mm orifice)..

Figure 19. (a.) High- and low-side pressure decay, (b.) percent charge released and (c.) system diagram for split AC test 112 (4.11 mm orifice).

Figure 20. (a.) High- and low-side pressure decay, (b.) percent charge released and (c.) system diagram for split AC test 113 (7.03 $\mathrm{mm}$ orifice) 
Figure 21. (a.) High- and low-side pressure decay, (b.) percent charge released and (c.) system diagram for split AC test 114 (7.03 $\mathrm{mm}$ orifice)

Figure 22. (a.) High- and low-side pressure decay, (b.) percent charge released and (c.) system diagram for split AC test 115 (same as G1, $7.03 \mathrm{~mm}$ orifice) ...

Figure 23. (a.) High- and low-side pressure decay, (b.) percent charge released and (c.) system diagram for split AC test 116 (7.03 mm orifice)....

Figure 24. PTAC test unit showing process tubes used as leak sources ................................................. 24

Figure 25. PTAC with leak control system installed ......................................................................... 25

Figure 26. PTAC leak release point with cap and 0.041 " $(1.04 \mathrm{~mm})$ orifice for low leak rate tests .......... 26

Figure 27. PTAC test 103 leak back pressure and mass flux (measured and calculated with Eqs.

(1) \& (2)) vs. leak time 28

Figure 28. PTAC fan thrust effect test results.

Figure 29. (a.) High- and low-side pressure decay, (b.) percent charge released (c.) power consumption and (d.) system diagram for PTAC test 101 (1.04 mm orifice).

Figure 30. (a.) High- and low-side pressure decay, (b.) percent charge released (c.) power consumption and (d.) system diagram for PTAC test 102 (1.04 mm orifice).

Figure 31. (a.) High- and low-side pressure decay, (b.) percent charge released (c.) power consumption and (d.) system diagram for PTAC test 103 (1.04 mm orifice).

Figure 32. (a.) High- and low-side pressure decay, (b.) percent charge released (c.) power consumption and (d.) system diagram for PTAC test 104 (1.04 mm orifice).

Figure 33. (a.) High- and low-side pressure decay, (b.) percent charge released (c.) power consumption and (d.) system diagram for PTAC test 105 (4.39 $\mathrm{mm}$ orifice).

Figure 34. (a.) High- and low-side pressure decay, (b.) percent charge released (c.) power consumption and (d.) system diagram for PTAC test 106 (4.39 mm orifice).

Figure 35. (a.) High- and low-side pressure decay, (b.) percent charge released (c.) power consumption and (d.) system diagram for PTAC test 107 (4.39 mm orifice).

Figure 36. (a.) High- and low-side pressure decay, (b.) percent charge released (c.) power consumption and (d.) system diagram for PTAC test 108 (4.39 mm orifice).

Figure 37. Display case test unit: (left) view of compressor, condenser, and control section; (right) leak control system mounted in compressor compartment. 39

Figure 38. Display case fan operation impact test results

Figure 39. (a.) High- and low-side pressure decay, (b.) percent charge released (c.) power consumption and (d.) system diagram for display case test 125 (2.03 $\mathrm{mm}$ orifice). 41

Figure 40. (a.) High- and low-side pressure decay, (b.) percent charge released (c.) power consumption and (d.) system diagram for display case test 126 (2.03 $\mathrm{mm}$ orifice).

Figure 41. (a.) High- and low-side pressure decay, (b.) percent charge released (c.) power consumption and (d.) system diagram for display case test 127 (2.03 $\mathrm{mm}$ orifice).

Figure 42. (a.) High- and low-side pressure decay, (b.) percent charge released (c.) power consumption and (d.) system diagram for display case test 128 (2.03 $\mathrm{mm}$ orifice).

Figure 43. (a.) High- and low-side pressure decay, (b.) percent charge released (c.) power consumption and (d.) system diagram for display case test 129 (4.39 $\mathrm{mm}$ orifice). 45

Figure 44. (a.) High- and low-side pressure decay, (b.) percent charge released (c.) power consumption and (d.) system diagram for display case test 130 (4.39 $\mathrm{mm}$ orifice). 
Figure 45. (a.) High- and low-side pressure decay, (b.) percent charge released (c.) power consumption and (d.) system diagram for display case test 131 (4.39 $\mathrm{mm}$ orifice).

Figure 46. (a.) High- and low-side pressure decay, (b.) percent charge released (c.) power consumption and (d.) system diagram for display case test 132 (4.39 $\mathrm{mm}$ orifice).

Figure 47. Display case test 129: low-side pressure (corrected) vs. barometric pressure at site; last

$\sim 17$ minutes of test period. 49

Figure 48. Display case test 129: high-side pressure vs. time; last $\sim 17$ minutes of test period... 49

Figure 49. Display case test 129: actual system mass vs. time; last $\sim 17$ minutes of test period 50

Figure 50. Unit cooler outdoor condensing section .51

Figure 51. Unit cooler indoor evaporator section; leak control system mounted on top of evaporator unit.

Figure 52. (a.) High- and low-side pressure decay, (b.) percent charge released (c.) power consumption and (d.) system diagram for unit cooler test 133 (2.03 mm orifice).

Figure 53. (a.) High- and low-side pressure decay, (b.) percent charge released (c.) power consumption and (d.) system diagram for unit cooler test 134 (2.03 mm orifice).

Figure 54. (a.) High- and low-side pressure decay, (b.) percent charge released (c.) power consumption and (d.) system diagram for unit cooler test 135 (2.03 mm orifice).

Figure 55. (a.) High- and low-side pressure decay, (b.) percent charge released (c.) power consumption and (d.) system diagram for unit cooler test 136 (2.03 mm orifice).

Figure 56. (a.) High- and low-side pressure decay, (b.) percent charge released (c.) power consumption and (d.) system diagram for unit cooler test 137 (7.03 mm orifice).

Figure 57. (a.) High- and low-side pressure decay, (b.) percent charge released (c.) power consumption and (d.) system diagram for unit cooler test 138 (7.03 $\mathrm{mm}$ orifice).

Figure 58. (a.) High- and low-side pressure decay, (b.) percent charge released (c.) power consumption and (d.) system diagram for unit cooler test 139 (7.03 $\mathrm{mm}$ orifice).

Figure 59. (a.) High- and low-side pressure decay, (b.) percent charge released (c.) power consumption and (d.) system diagram for unit cooler test 140 (7.03 mm orifice). 61

Figure 60. RTU test unit showing process tubes used as leak sources

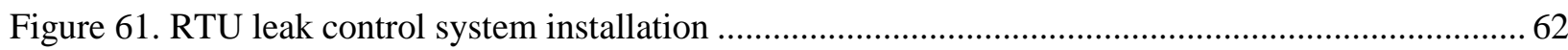

Figure 62. RTU leak release point with cap and 0.125 " $(3.175 \mathrm{~mm})$ orifice for low leak rate tests........... 63

Figure 63. RTU fan thrust effect test results

Figure 64. (a.) High- and low-side pressure decay, (b.) percent charge released (c.) power consumption and (d.) system diagram for RTU test 117 (3.175 mm orifice).

Figure 65. (a.) High- and low-side pressure decay, (b.) percent charge released (c.) power consumption and (d.) system diagram for RTU test 118 (3.175 mm orifice).

Figure 66. (a.) High- and low-side pressure decay, (b.) percent charge released (c.) power consumption and (d.) system diagram for RTU test 119 (3.175 mm orifice).

Figure 67. (a.) High- and low-side pressure decay, (b.) percent charge released (c.) power consumption and (d.) system diagram for RTU test 120 (3.175 mm orifice)

Figure 68. (a.) High- and low-side pressure decay, (b.) percent charge released (c.) power consumption and (d.) system diagram for RTU test 121 (7.03 mm orifice).

Figure 69. (a.) High- and low-side pressure decay, (b.) percent charge released (c.) power consumption and (d.) system diagram for RTU test 122 (7.03 $\mathrm{mm}$ orifice).... 
Figure 70. (a.) High- and low-side pressure decay, (b.) percent charge released (c.) power consumption and (d.) system diagram for RTU test 123 (7.03 mm orifice) .....

Figure 71. (a.) High- and low-side pressure decay, (b.) percent charge released (c.) power consumption and (d.) system diagram for RTU test 124 (7.03 mm orifice) ........................................... 72

Figure 72 . Tank used for leak quality estimation tests....................................................................... 73

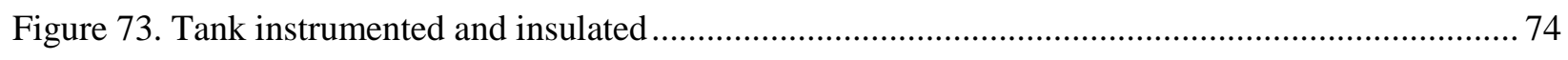

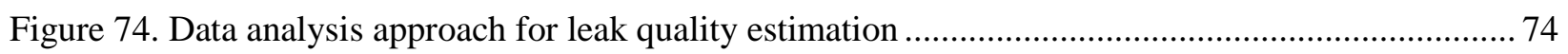

Figure 75. Leak quality estimates (in plastic container and refrigerant cylinder) for $0.5 \mathrm{~g} / \mathrm{s}$ leak............. 75

Figure 76. Leak quality estimates (in plastic container and refrigerant cylinder) for $0.5 \mathrm{~g} / \mathrm{s}$ leak............. 76

Figure 77. RTU and container weights showing the movement of refrigerant during the low-side

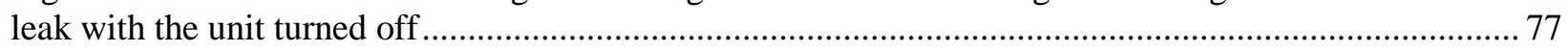

Figure 78. Leak quality estimates for low-side tests of the RTU turned off after running at steadystate .78

Figure 79. RTU and container weights showing the movement of refrigerant during the high-side leak with the unit running .79

Figure 80. Leak quality estimates for high-side tests of the RTU running at steady-state

\section{TABLE OF FIGURES IN APPENDIX A}

Figure A 1. Calibration curve for leak pan scale A-3

Figure A 2. Snapshots of different camera angles captured during a typical display case test. A-5

Figure A 3. Screenshot of NI LabVIEW VI used for unit cooler tests

\section{TABLE OF FIGURES IN APPENDIX C}

Figure $\mathrm{C}$ 1. Container and RTU weights measured during refrigerant leaking from the high-side with the RTU deenergized

Figure C 2. Refrigerant quality computed upstream the orifice during refrigerant leaking from the high-side with the RTU deenergized . C-6 Figure $C$ 3. Container pressure measured during refrigerant leaking from the high-side with the RTU deenergized 


\section{TABLE OF TABLES IN MAIN BODY OF REPORT}

Table 1. Safety classification of refrigerants as outlined in ISO 817:2014 and Addendum g to ANSI/ASHRAE 34

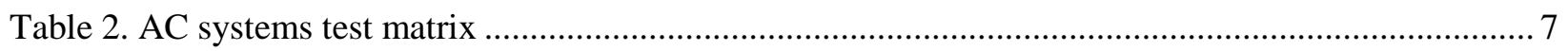

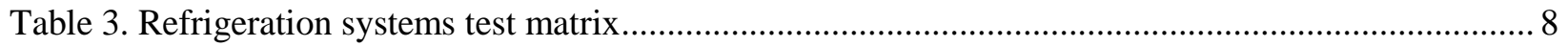

Table 4. High-speed camera recording time, capacity and resolution vs. record speed ........................... 10

Table 5. Split AC unit leak test results summary ............................................................................... 17

Table 6. PTAC test 103 leak flux; measured vs. calculated vapor mass flux from Eq. (1) ....................... 27

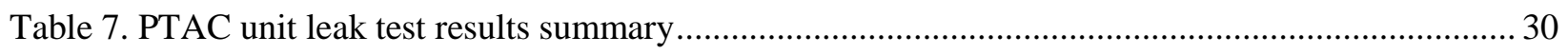

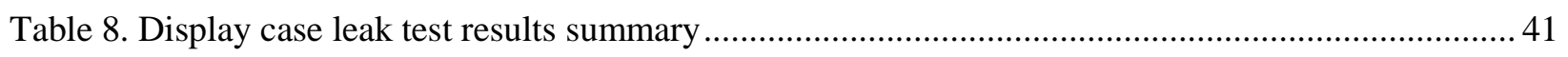

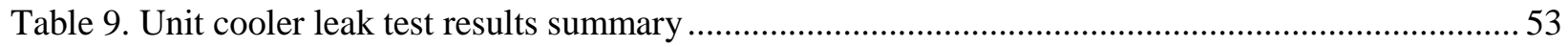

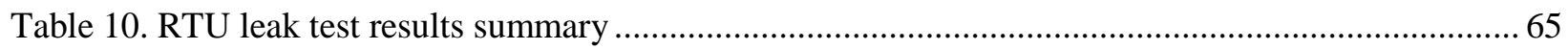

TABLE OF TABLES IN APPENDIX A

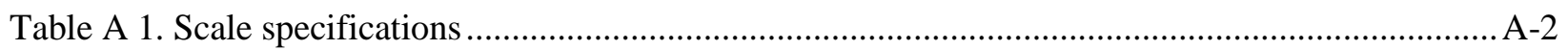

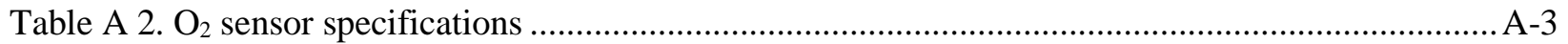

Table A 3. Nominal-speed camera specifications .............................................................................. A

Table A 4. Data acquisition hardware specifications ......................................................................

Table A 5. Refrigerant release valve specifications .......................................................................... A

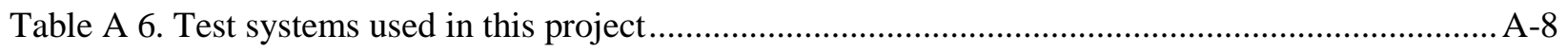

TABLE OF TABLES IN APPENDIX C

Table C 1. Salient Results of Quality Estimation Tests .................................................................... 


\section{ACKNOWLEDGEMENTS}

The authors gratefully acknowledge the advice and guidance offered over the course of the project by the members of the AHRTI-9012 Project Monitoring Subcommittee (PMS) - Dutch Uselton (Lennox, chair), Phillip Johnson (Daikin), Warren Clough (Carrier), Jim Vershaw (Trane), Samuel Yana Motta (Honeywell), Tom Watson (Daikin), Roy Crawford (Johnson Controls), Jay Kohler (Johnson Controls), Xudong Wang (AHRTI), and Antonio Bouza (DOE). We particularly acknowledge the industry members' efforts to provide the HVAC\&R units used in the leak testing. We also particularly thank Phil Johnson for his advice in formatting the charts used in the report Executive Summary.

This work was sponsored by Antonio Bouza, HVAC\&R leader, Emerging Technologies program of the Building Technologies Office of the U.S. Department of Energy (DOE/BTO), under Contract No. DEAC05-00OR22725 with UT-Battelle, LLC. 


\section{NOMENCLATURE}

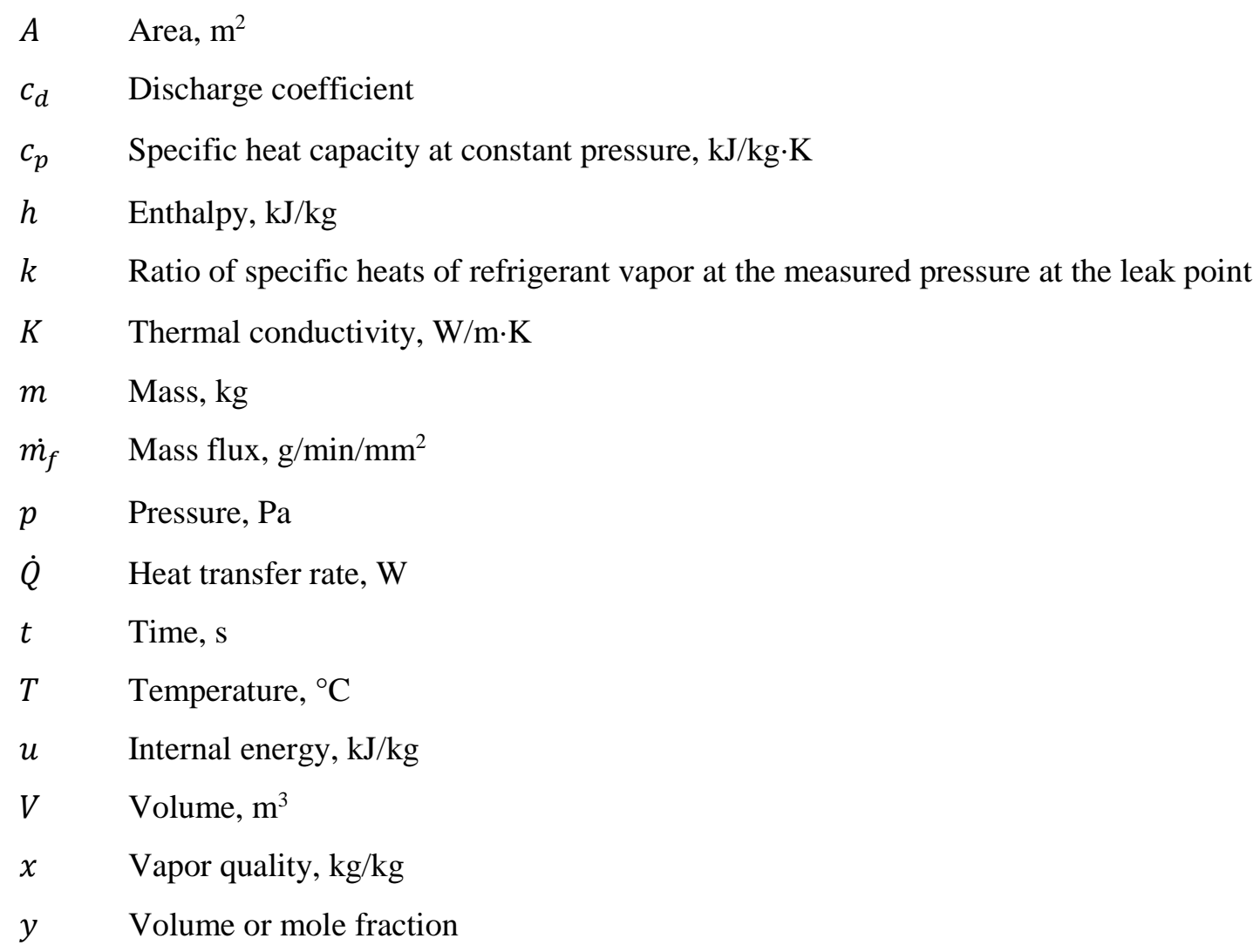

\section{Greek symbols}
$\Delta \quad$ Difference
$\eta \quad$ Number of moles, kmol
$\rho \quad$ Density, $\mathrm{kg} / \mathrm{m}^{3}$

\section{Subscripts}

$\begin{array}{ll}\text { atm } & \text { Atmospheric } \\ \text { cont } & \text { Container } \\ \text { Cond } & \text { Conduction } \\ c v & \text { Control volume } \\ e & \text { Exterior } \\ f & \text { Final } \\ \text { HDPE } & \text { High-density polyethylene } \\ i & \text { Initial } \\ \text { int } & \text { Interior }\end{array}$


$l \quad$ Liquid

ref Refrigerant

$v \quad$ Vapor 


\section{EXECUTIVE SUMMARY}

The US Department of Energy (DOE) Building Technology Office (BTO) and the Air-conditioning, Heating \& Refrigeration Technology Institute (AHRTI) collaborated to sponsor an experimental study of refrigerant leak characteristics at ORNL; AHRTI project 9012. The original objectives were to conduct refrigerant leak tests on several heating, ventilating, air conditioning and refrigeration (HVAC\&R) systems under operating conditions representative of actual applications to document the pressure decay rate and the mass flow rate of leaked refrigerant as a function of time. Estimates of the quality (vapor versus liquid) of the leaking refrigerant and oil escaping with the leak were also desired. The project involved imposing refrigerant leaks on five systems and collecting data to meet the project objectives. Systems chosen covered three air-conditioning (AC) applications (packaged terminal AC or PTAC, 3-ton residential split system AC, and 5-ton packaged rooftop AC) and two refrigeration applications (split system unit cooler, and standalone display case). AHRTI members donated the test systems used for the project. The systems were to be tested at two different leak rates (catastrophic high rate simulating full line break and a lower flow rate), two leak locations (high-pressure side and low-pressure side), and two operating conditions (compressor on or off).

This project was intended to simulate failures resulting in much more rapid charge releases than the more typical, much slower rates seen in practice that would take days, weeks, or months to empty a system of its entire charge. Thus, the high leak rate case used for our tests was meant to simulate a "maximum possible" worst case refrigerant release scenario (e.g., full line break or other rupture resulting in an orifice diameter equal to the liquid line of the system under test). For the low leak rate case, the intent was to simulate a refrigerant leak (or release) rate that would result in a total loss of system charge in "roughly" four minutes. Given the wide variation between the two leak rates, the low rate was not expected to be exactly four minutes for the specific systems tested. The choice of the 4-minute rate was intended to represent a "reasonable" worst case release scenario to match the refrigerant leak rate assumption used in the International Electrotechnical Commission standard IEC 60335-2-40 (2016 version, [1]).

\section{General observations from leak tests}

Figures ES1-ES4 illustrate the average leak rates (for $80 \%$ of total charge released) for the split AC, PTAC, the standalone display case, and RTU AC case, respectively. The horizontal dashed (red) line in each figure represents the leak rate required to release the entire system charge in four minutes. 


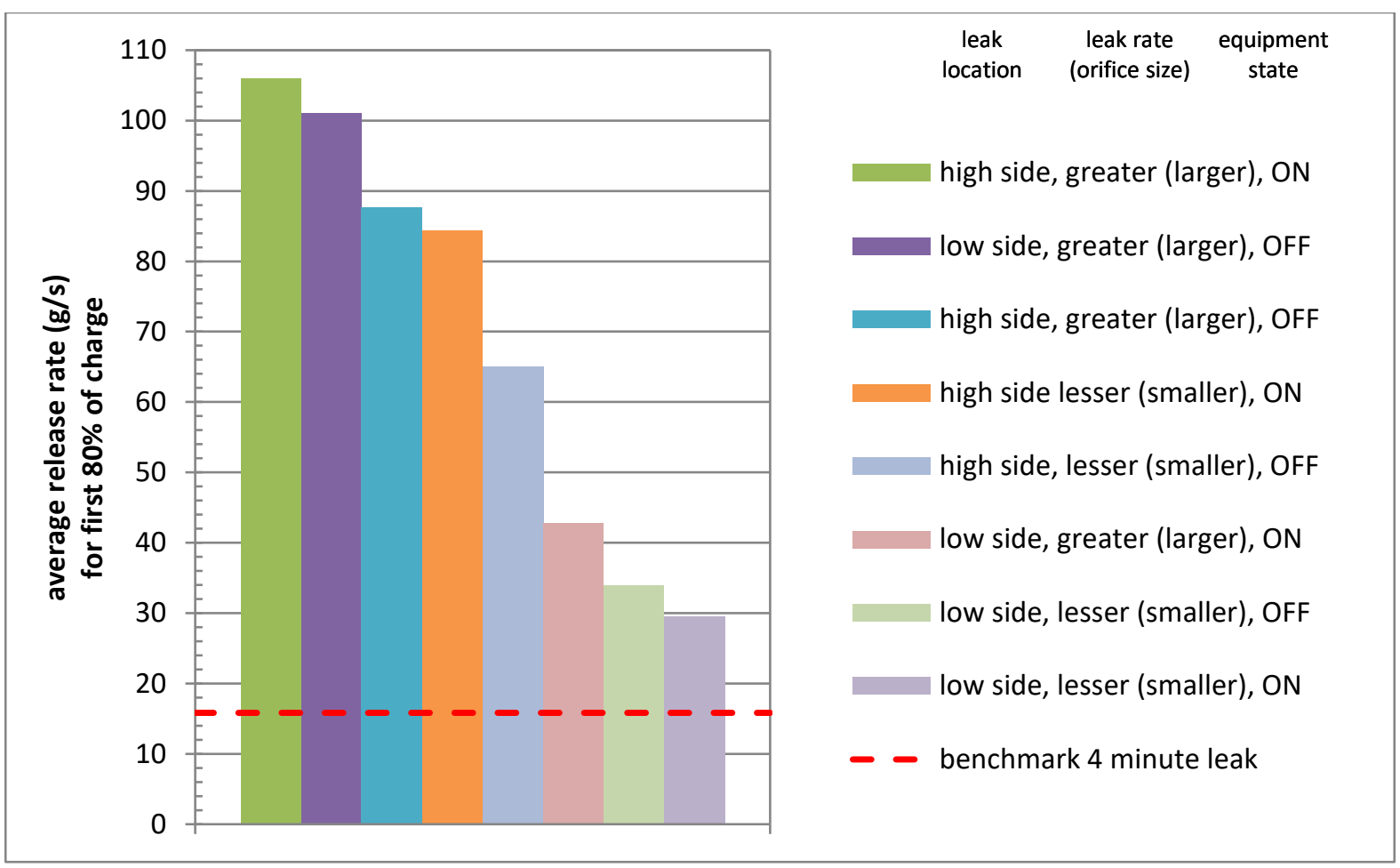

Figure ES 1. Average leak rates for $80 \%$ of total charge released for split AC system tests.

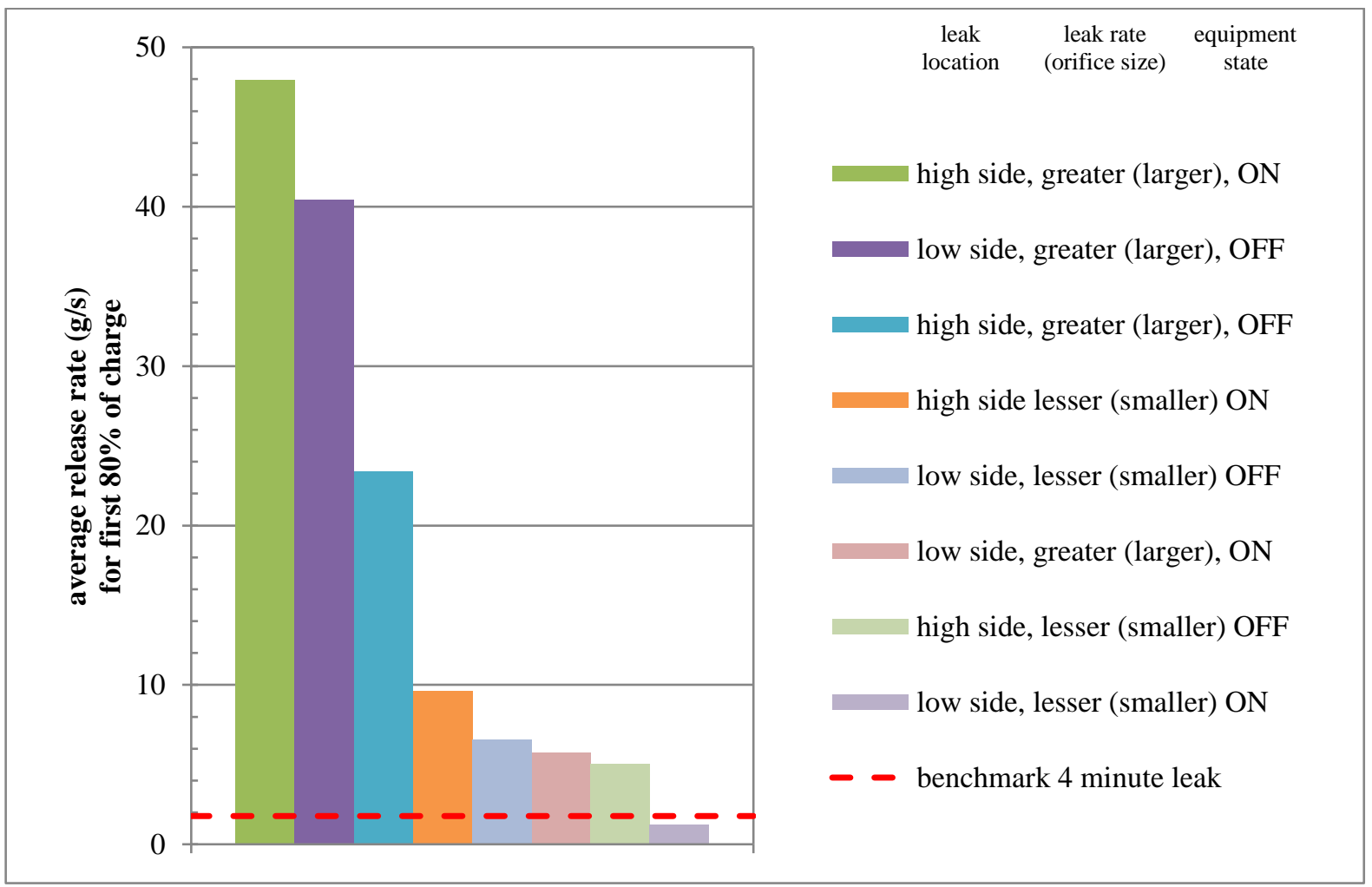

Figure ES 2. Average leak rates for $80 \%$ of total charge released for PTAC tests. 


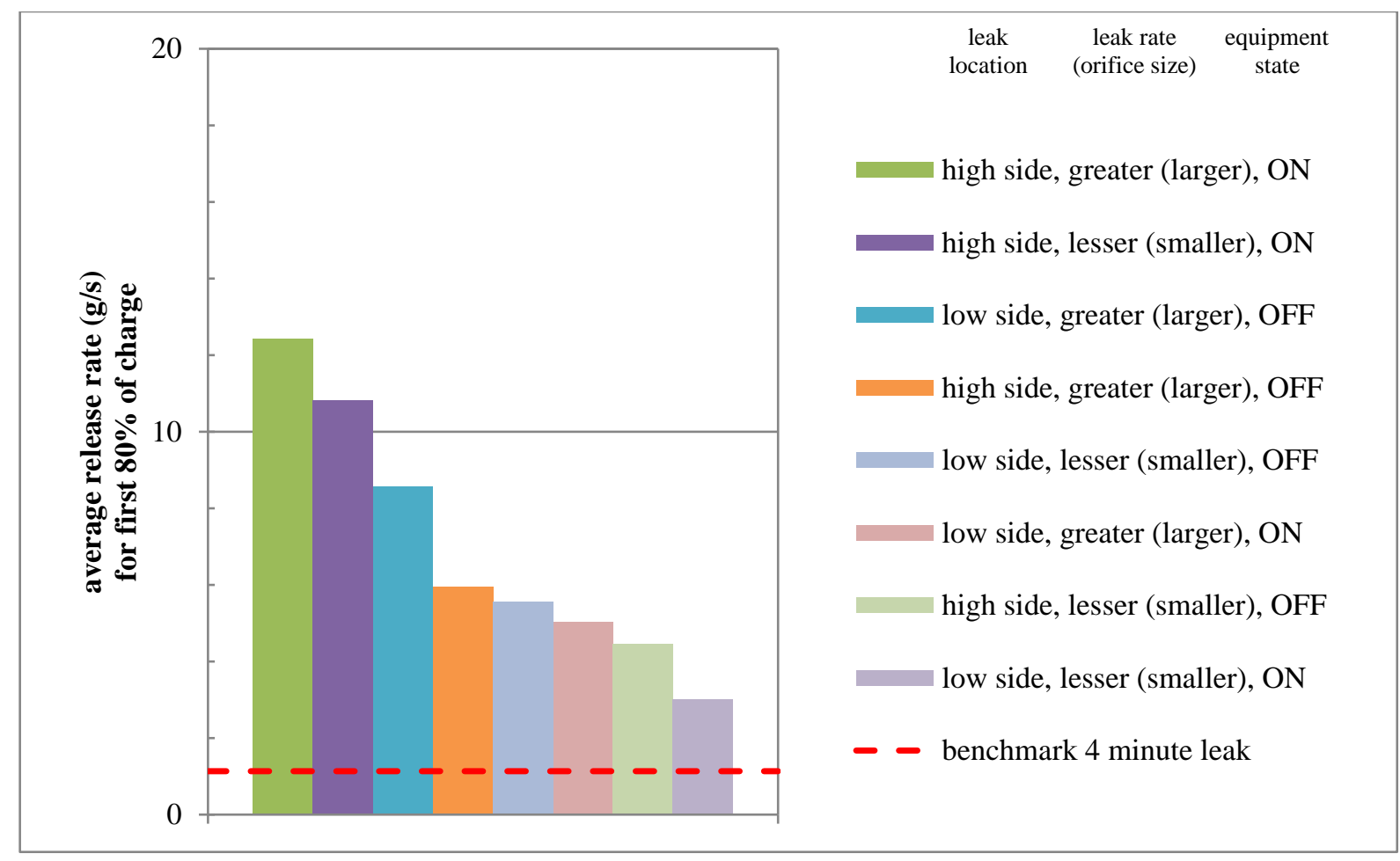

Figure ES 3. Average leak rates for $80 \%$ of total charge released for display case tests.

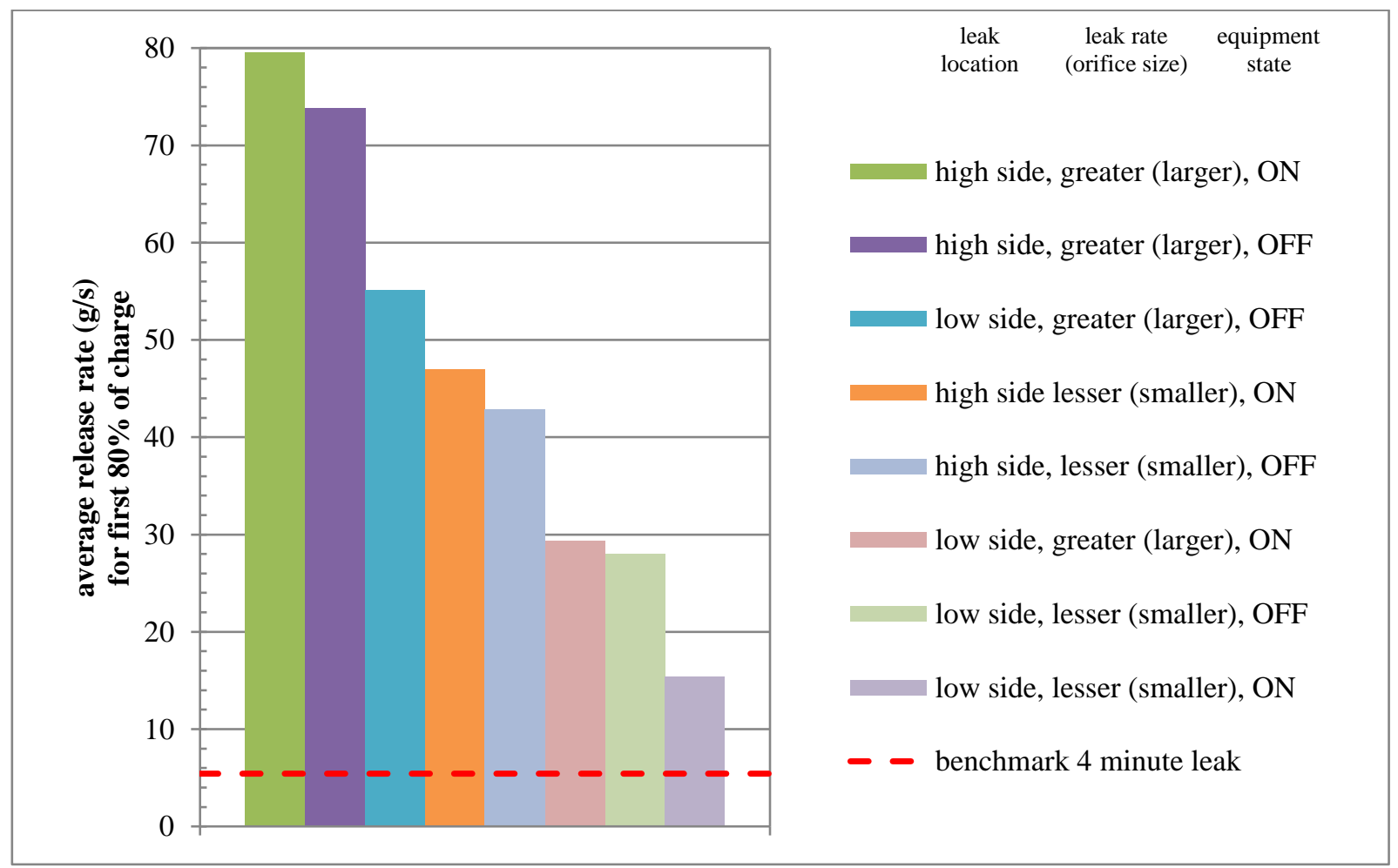

Figure ES 4. Average leak rates for $80 \%$ of total charge released for RTU AC tests.

Based on the information in Figures ES1-ES4, for all four systems: 
- The compressor on, high side release, larger orifice showed the fastest leak flow rate

- The compressor on, low side release, smaller orifice showed the slowest leak flow

- In general - with compressor on the high side leak rates are greater than the low side rates (higher pressure and density at the leak location); with the compressor off high side leak rates are lesser than the low side rates (larger line size, less flow resistance to leak location on compressor suction line)

In the unit cooler system case general test result trends were different. The refrigeration circuit for this system included a normally closed solenoid valve in the liquid line upstream of the thermostatic expansion valve (TXV). When the room temperature control thermostat is satisfied this valve closes, isolating the evaporator from the condensing unit. The system also uses a pump down cycle at thermostat shut down to move most of the refrigerant in the evaporator to the condensing unit. As a result, low-side leaks with the unit off resulted in only very small refrigerant loss $(4 \%$ of the charge for the low leak rate or smaller orifice case and $6 \%$ for the high leak rate case), therefore they are not included in the leak rate summary Figure ES 5.

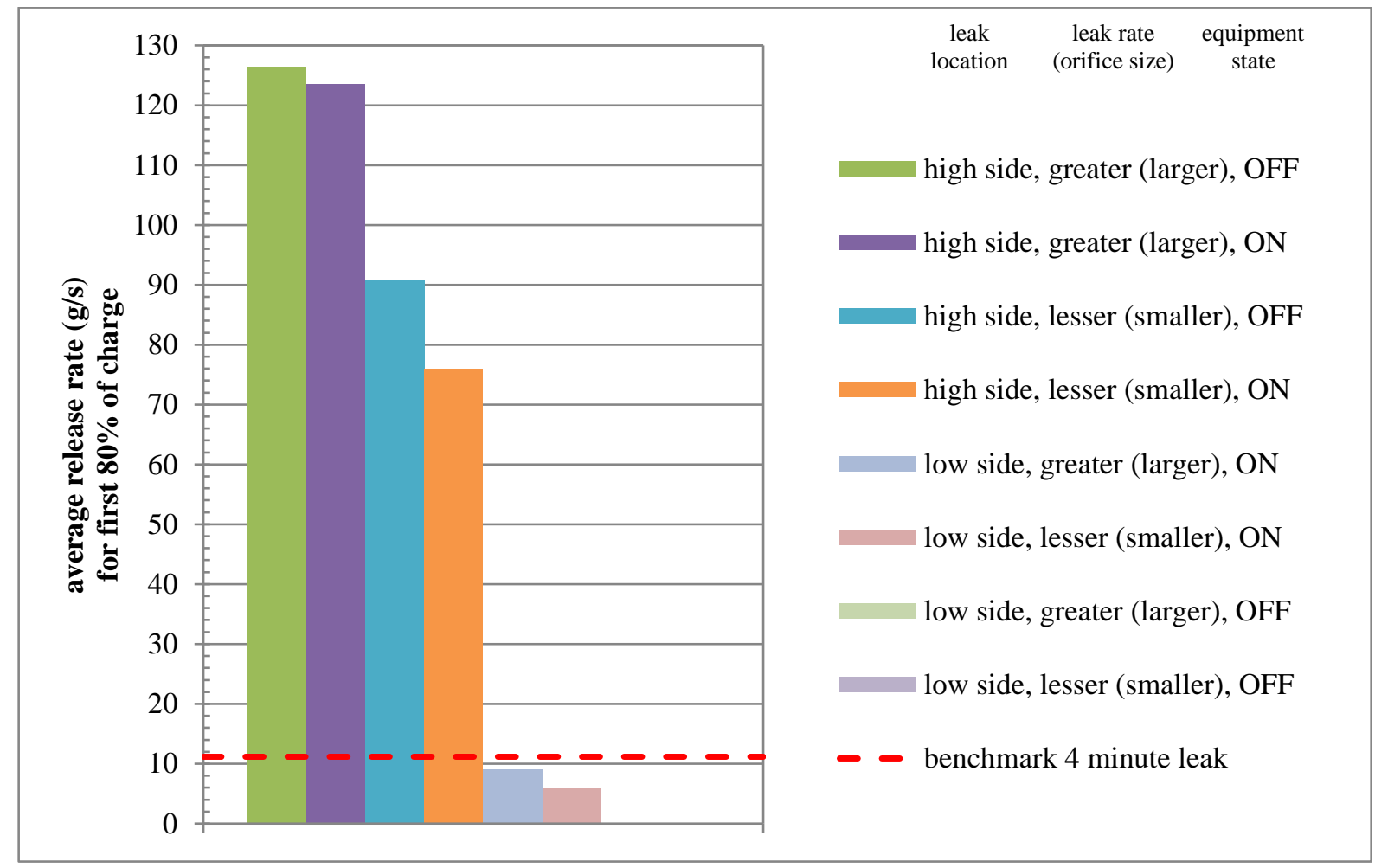

Figure ES 5. Average leak rates for $80 \%$ of total charge released for unit cooler system tests.

Other general observations based on the information in Figure ES 5:

- For the high side leak tests, rates with compressor off are somewhat greater than for compressor on, opposite the trend seen with the other units tested

- For compressor off cases, the liquid line solenoid valve is closed and the system pump down cycle had moved most of the refrigerant to the condensing unit; in the compressor on cases, the solenoid valve remained open and no pump down cycle occurred before the leak

Additional highlights: 
- Split AC system leak test results

○ Nearly all the system charge was released (96-100\%) for all eight test scenarios

$\circ$ For the two compressor-off and low side leak tests, about $0.17 \mathrm{lb}(0.077 \mathrm{~kg})$ of oil is estimated to have been ejected with the refrigerant; there was no measurable oil release for any of the other tests.

- $\quad$ PTAC leak test results

○ $\sim 100 \%$ of charge was released for all tests except the two compressor-on tests at the low leak flow (the low side leak for this case retained $\sim 8 \%$ of the charge and the high side leak retained $\sim 4 \%$ )

○ There was no measurable oil release during any of the tests

- Display case leak test results

$\circ$ The only test condition to show $100 \%$ charge release was the compressor on, high side leak

- All other cases showed 2-5\% charge retention

- There was no measurable oil release during any of the tests

- Unit cooler leak test results (high leak rate)

$\circ$ No measurable oil release during any of the tests

- $\quad$ RTU AC leak test results

- No significant oil release observed during any of the tests (oil catch/weigh system not used for the RTU tests)

- All of RTU test results showed some refrigerant retention at the end of the 20-min test period, ranging from $3.3 \%$ to $12.1 \%$; generally, the compressor "on" cases retained more refrigerant at test end than did the corresponding compressor "off" cases (low side leak, lower rate cases (117 and 119) are the only exceptions).

- A testing procedure was developed, and an algorithm formulated that estimates the quality of a refrigerant leak upstream the point of leakage.

○ Proof-of-concept tests shows the procedure yields results consistent with thermodynamic principals for isenthalpic flow across a throttle

- Tests conducted on the RTU (with a $1 \mathrm{~mm}$ leak orifice) showed the following results:

- Low-side leak, unit on: Vapor leak, quality $(x)=1$

- Low-side leak, unit off: Two-phase leak quality, $\mathrm{x}=\sim 0.85$

- High-side leak, unit on: Rapid drop in leak quality from 1 to 0 (all liquid) in $\sim 35 \mathrm{~s}$

- High-side leak, unit off: Rapid drop in leak quality from 1 to 0 (all liquid) in $\sim 55 \mathrm{~s}$ 


\section{INTRODUCTION}

Environmental protection goals are becoming progressively stricter to reduce negative environmental impacts of refrigerants. The Montréal Protocol has in the past required phase-outs of chlorofluorocarbons (CFCs, completed in 2010) and hydrochlorofluorocarbons (HCFCs, expected to be complete by 2030 in developed countries). Hydrofluorocarbons (HFCs) like R-410A and R-134a have been used as alternatives to HCFCs for many HVAC\&R applications but have relatively high global warming potentials (GWP). In October 2016, the Kigali Amendment to the Montréal Protocol was adopted to phase-down the use of HFCs. For developed countries the Kigali Amendment requires the carbon dioxide equivalent $\left(\mathrm{CO}_{2 \mathrm{e}}\right)$ emissions from HFC consumption to be reduced to $15 \%$ of the average for 2011-2013 by 2036 [2]. Proposed lower GWP alternatives to replace high-GWP HFCs include low-GWP HFCs, hydrofluoroolefins (HFO), hydrochlorofluoroolefins (HCFO), hydrocarbons (HC), ammonia (R-717), $\mathrm{CO} 2$ (R-744), or blends containing low-GWP HFCs and other low-GWP fluids. Most of the lower toxicity (class A) low-GWP alternatives are flammable to some degree according to Addendum g to ANSI/ASHRAE 34 [3] and ISO 817:2014 [4], which designate toxicity and flammability of refrigerants as follows:

Table 1. Safety classification of refrigerants as outlined in ISO 817:2014 and Addendum g to ANSI/ASHRAE 34

\begin{tabular}{|l|c|c|}
\cline { 2 - 3 } \multicolumn{1}{c|}{} & \multicolumn{2}{c|}{ Safety group } \\
\hline $\begin{array}{l}\text { Higher } \\
\text { flammability }\end{array}$ & A3 & B3 \\
\hline Flammable & A2 & B2 \\
\hline $\begin{array}{l}\text { Lower } \\
\text { flammability }\end{array}$ & A2L & B2L \\
\hline $\begin{array}{l}\text { No flame } \\
\text { propagation }\end{array}$ & A1 & B1 \\
\cline { 2 - 3 } & $\begin{array}{c}\text { Lower } \\
\text { toxicity }\end{array}$ & $\begin{array}{c}\text { Higher } \\
\text { toxicity }\end{array}$ \\
\hline
\end{tabular}

Refrigerant flammability introduces challenges to the usage of low global warming potential (Low GWP) refrigerants in real life applications. Those challenges are centered around the deflagration risk associated with their use and its implications on personal and property safety. Standards have been developed to systematically set maximum allowable flammable refrigerant charges to ensure safety in case of refrigerant leakage. These standards were initially based on limited testing [5-7] and numerical analyses of refrigerant leakage into confined spaces. Currently published general safety standards include International Standards Organization (ISO) 5149 [8], and its relative counterpart ANSI/ASHRAE 15 [9].

Equipment standards include the International Electrotechnical Commission (IEC) standard suite, IEC 60335-2-24 [10], IEC 60335-2-40 [11] and IEC 60335-2-89 [12]. The corresponding CANENA standards are Underwriter's Laboratories (UL) UL 60335-2-24 [13], UL 60335-2-40 [14] and UL 60335-2-89 [15], along with UL 471 [16], UL 563 [17], etc.

These standards were developed based on non-flammable and flammable refrigerant categories. Flammable refrigerants have been included in the relevant international and North American standards for over two decades. The cognizant bodies for these standards are continually engaged in revision/update processes.

Most low GWP refrigerant options are either class A2L (lower flammability) or A3 (higher flammability). While expanded use of such refrigerants is generally seen as a key to reducing the global environmental impact of HVAC\&R equipment and systems, current codes significantly restrict the use of all flammable 
refrigerants, including lower flammability A2L types. A2L refrigerants are treated at the same risk level as those in the A2 category in many standards and in some cases, there is no discrimination between any level of flammability. There is, therefore, a need to revise the relevant safety standards and codes to facilitate wider use of low-GWP but flammable refrigerant alternatives; especially A2L refrigerants. However, the bodies responsible for maintaining and updating these standards and codes must have credible, publicly available, science-based knowledge about the safe use of these refrigerants. Currently, there are significant gaps in this information.

Recognizing this global challenge, the Alliance for Responsible Atmospheric Policy, the AirConditioning, Heating \& Refrigeration Institute (AHRI), ASHRAE, the U.S. Department of Energy (DOE), and the State of California together with the White House committee for environmental quality (CEQ) began coordination to develop an effective and efficient program to facilitate development of this information. In 2016, $\$ 5.8$ million was committed by the following organizations to a collaborative effort to cover the highest priority research needs: AHRI- (\$1 million), ASHRAE ( $\$ 1.3$ million), DOE ( $\$ 3.0$ million), and the State of California (\$0.5 million).

In support of this effort, Air-conditioning, Heating \& Refrigeration Technology Institute's (AHRTI) Flammable Refrigerants Subcommittee (FRS) conducted a survey to committees and working groups working on flammable refrigerants related standards. The survey was focused on identify existing knowledge gaps of using flammable refrigerants. Among the survey responses, the FRS identified top priority research needs below:

- Whole room or real-life leaks, with ignition sources present, are needed to validate or re-calibrate current AHRI and OEM risk assessments.

- The HVAC industry needs to understand the risk/consequence after refrigerant ignition, in order to establish quantified risk tolerance limits for severity of event rather than just probability of ignition.

- The HVAC industry needs to assess the ability of $2 \mathrm{~L}$ refrigerants to sustain an ignition (with \% oil included), and possibly cause a secondary combustion event compared to current refrigerant/lubricant systems which are proven in use.

AHRTI initiated research project 9007 in 2016 to begin to address these knowledge gaps and the final report was released in June 2017 [18]. The report presented some new findings on the dynamics of moderate and large refrigerant leakage rates. From the preface to the report:

"Depending upon the operating state of the equipment and the location of the leakage point within the refrigerant circuit, the release may be mainly vapor or a vapor/liquid mixture. The CFD studies that have been used to guide the industry do not consider the possibility of a mechanism that can pool liquid refrigerant at the floor or droplet formation suspended in the air (refrigerant fog). This, of course, significantly changes the refrigerant concentration regime. Further work done by an AHRI member with R-410A liquid refrigerant leaks similar to what was done in this work confirmed refrigerant liquid could remain for hours depending on the leak methodology. Further work would be warranted to understand the two-phase and time factor dynamics of various liquid refrigerant leak scenarios. CFD models would need to be updated to accurately reflect the correct release phenomena. Product risk assessments would also need to be reassessed with this new information."

Based on the above observations from AHRTI 9007, a test program was proposed to document the dynamics of "real-life" refrigerant leak events of varying severity (e.g., leak flow rate, etc.). The testing was to be done using actual equipment under realistic conditions and using a refrigerant or a range of refrigerants that are representative of $\mathrm{A} 2 \mathrm{~L}$ and $\mathrm{A} 3$ refrigerants. In order to reduce risks assumed by 
testing labs in conducting the requested work, it was decided that the refrigerants used for the testing need not be flammable.

Calculations of maximum flammable refrigerant charge limits in IEC 60335-2-40 [11] have generally assumed a fixed leak time of 4 minutes. This was originally meant to represent a catastrophic leak and was based on the time taken to leak $150 \mathrm{~g}$ of $\mathrm{CO}_{2}$ through a capillary tube (about 3.5 minutes), defined (at that time) in IEC 60335-2-24 [7, 19]. As such, the 4-minute leak time is embedded into the global IEC standard and into all subsequent standards which are based on it. Although the above assumptions were reasonable and necessary at the time, the actual leak rate and duration for new and existing flammable refrigerants in actual HVAC\&R applications have not been adequately quantified to update the standard. The leak rate is known to depend strongly on the equipment type, leak location (e.g. evaporator or condenser leak), refrigerant type (i.e. lower- or higher-pressure), leak orifice diameter and equipment operation condition (i.e. on or off). For these reasons, it is imperative to quantify the actual leak rates and duration for various pieces of equipment and account for slow, medium, rapid and catastrophic leaks.

The US Department of Energy (DOE) Building Technology Office (BTO) and AHRTI collaborated to sponsor an experimental study of refrigerant leak characteristics at ORNL; AHRTI project 9012. The original objectives were to conduct refrigerant leak testing under conditions representative of those seen by actual equipment to document the pressure decay rate, the mass flow rate of leaked refrigerant, and the quality (vapor versus liquid) of the leaking refrigerant as a function of time. When liquid remains in the leaking refrigerant after the initial process of flashing to atmospheric pressure, a determination of the amount of liquid that "rains out" versus the small droplets that remain suspended (as a fog) as a function of time is also of interest as these phenomena will affect refrigerant concentration profiles. It is also important to know what fraction of the total charge remains in the equipment due to self-chilling from system pressure reduction. This could have implications for calculation of maximum allowable charge in systems with A2L refrigerants.

This project was intended to simulate massive failures resulting in much more rapid charge releases than the more typical, much slower rates seen in practice that would take days, weeks, or months to empty a system of its entire charge. Thus, the high leak rate chosen was meant to simulate a "maximum possible" worst case refrigerant release scenario (e.g., full line break or other rupture resulting in an orifice diameter equal to the liquid line of the system under test). For the low leak rate cases, the intent was to simulate a refrigerant leak (or release) rate that would result in a total loss of system charge in "roughly" four minutes. Given the wide variation between the two leak rates, the low rate was not expected to be exactly four minutes for the specific systems tested. The choice of the 4-minute rate was intended to represent a "reasonable" worst case release scenario to match the refrigerant leak rate assumption used in IEC 603352-40 (2016 version) [1].

The results will be used to help update the safety standards and will be part of the national and international research effort to enable the widespread use of environmentally preferred, higher-efficiency refrigerants for different applications. They will also contribute to update the following standards: UL 60335-2-40, ISO 5149, ASHRAE 15, ASHRAE 15.2, UL 471, UL 60335-2-24, UL 60335-2-89, UL 563, etc.

This report describes the scope, tasks, and relevant results of the project. Section 2 provides a general description of the test approach along with descriptions of the test equipment and planned setup (instrumentation, DAS, etc.). Section 3 provides a discussion of key results from tests of the various units. Section 4 describes the approach, set up, and test results for leak quality estimation. Finally, the project conclusions and summary are given in Section 5. 


\section{GENERAL APPROACH AND SETUP}

\subsection{GENERAL REQUIREMENTS FROM AHRTI 9012 WORK STATEMENT}

The project involved imposing refrigerant leaks on five systems and conducting tests to obtain data to meet the project objectives. Systems chosen covered three air-conditioning (AC) applications (packaged terminal AC or PTAC, 3-ton residential split system AC, and 5-ton packaged rooftop AC) and two refrigeration applications (split system unit cooler, and standalone display case). AHRTI members donated the test systems used for the project. Figures 1 - 5 illustrate each of the test systems.

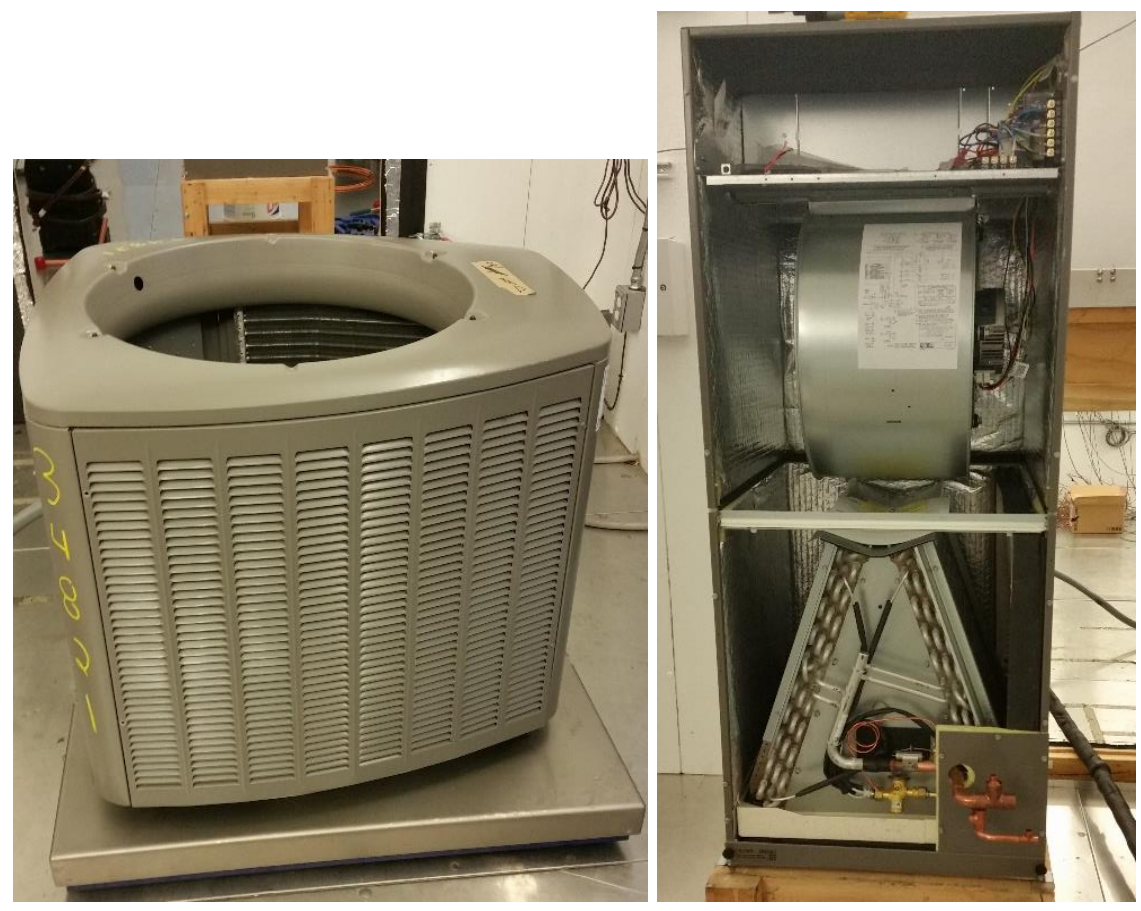

Figure 1. Split AC unit tested. Left is the condensing unit and right is the evaporator unit (air handler) 


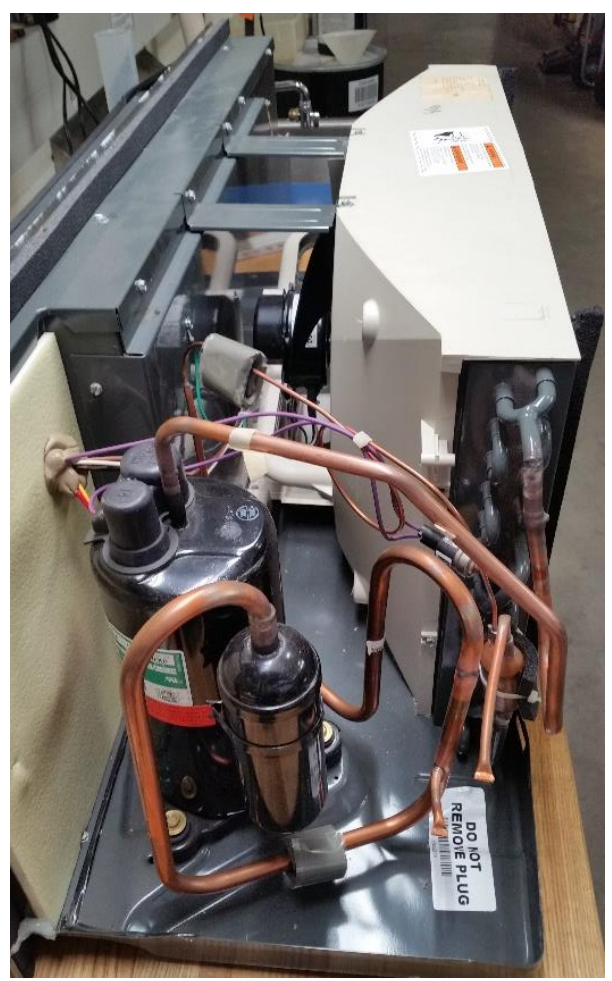

Figure 2. PTAC unit tested

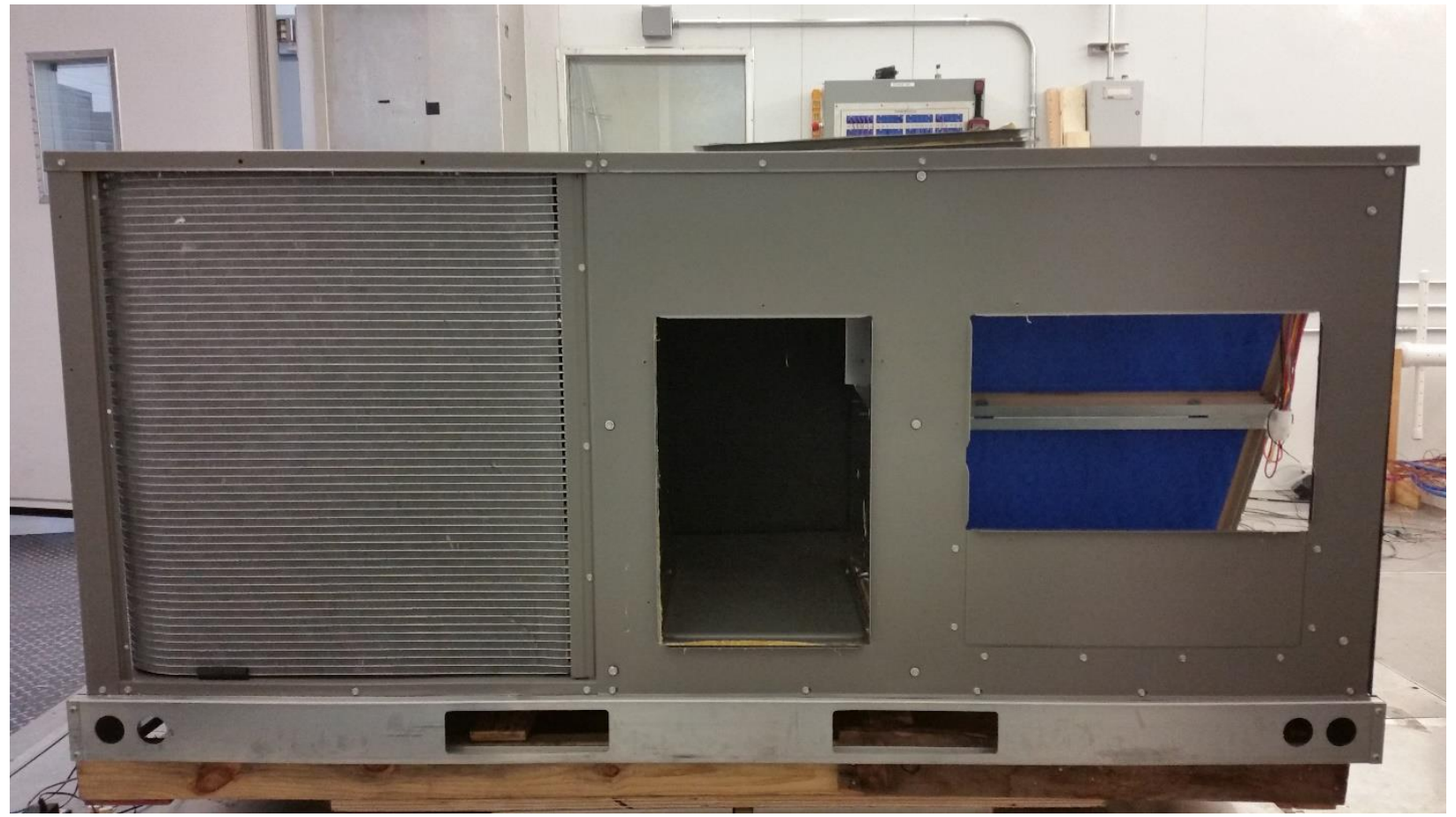

Figure 3. Packaged rooftop AC unit tested 


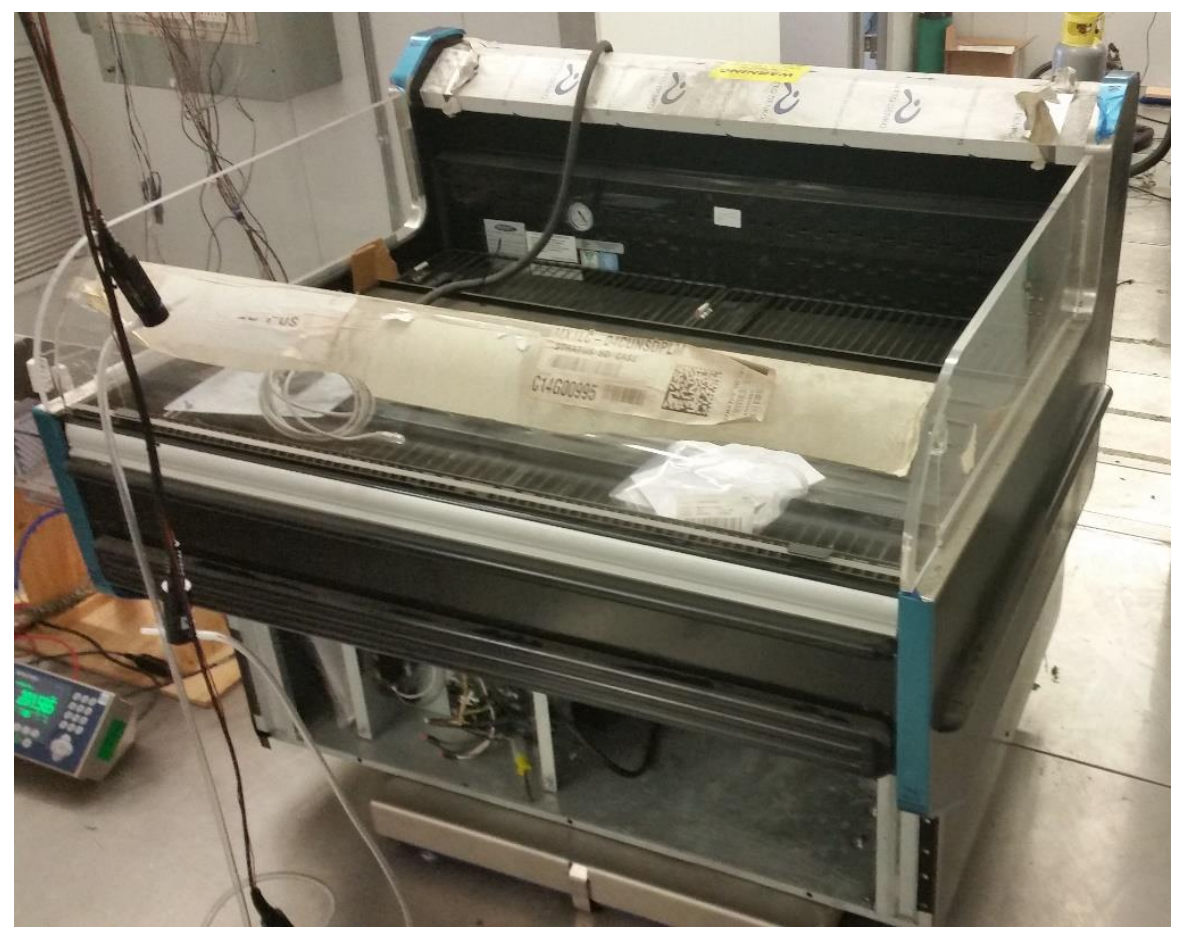

Figure 4. Refrigerated display case unit tested
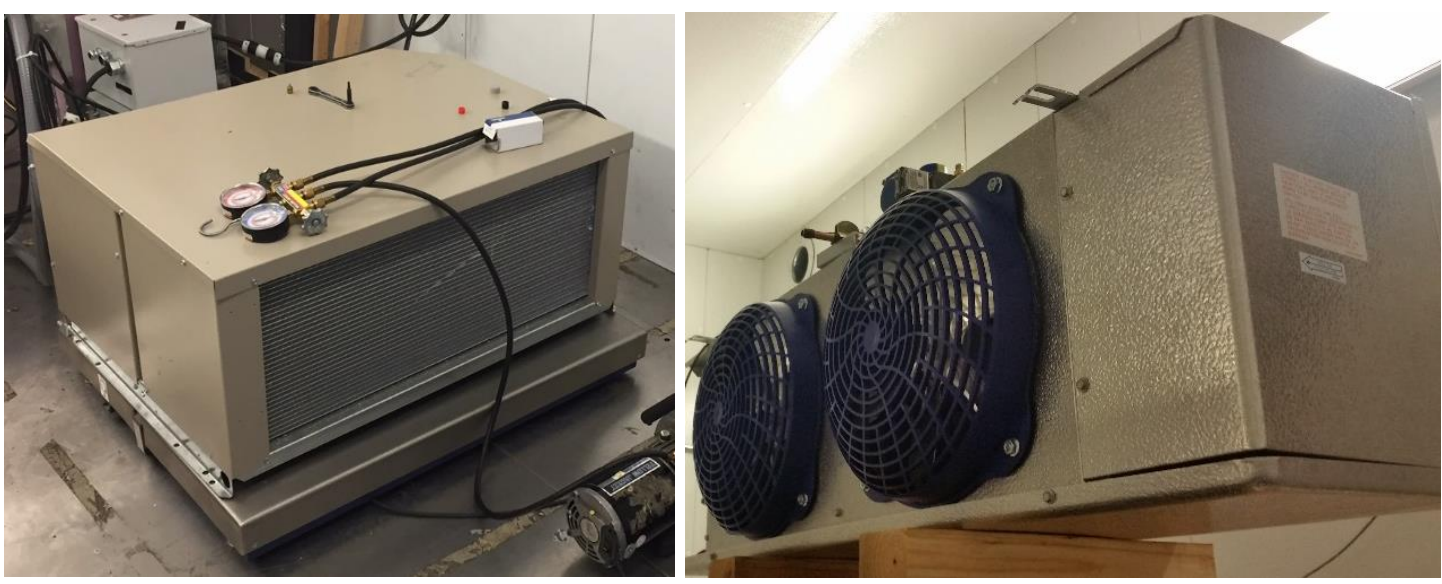

Figure 5. Unit cooler unit tested. Left is the condensing unit and right is the evaporator unit

Tables 2 and 3, below, list the AC and refrigeration systems, respectively, and tests to be run on each. 
Table 2. AC systems test matrix

\begin{tabular}{|c|c|c|c|c|c|c|c|c|}
\hline Test \# & Equipment & Refrigerant & $\begin{array}{c}\text { Low leak } \\
\text { rate }\end{array}$ & $\begin{array}{c}\text { High leak } \\
\text { rate }\end{array}$ & $\begin{array}{c}\text { Equipment } \\
\text { ON }\end{array}$ & $\begin{array}{c}\text { Equipment } \\
\text { OFF }\end{array}$ & $\begin{array}{c}\text { Low side } \\
\text { leak }\end{array}$ & $\begin{array}{c}\text { High side } \\
\text { leak }\end{array}$ \\
\hline 101 & PTAC & $\mathrm{R}-410 \mathrm{~A}$ & $\mathrm{x}$ & & $\mathrm{x}$ & & $\mathrm{x}$ & \\
\hline 102 & PTAC & $\mathrm{R}-410 \mathrm{~A}$ & $\mathrm{x}$ & & $\mathrm{x}$ & & & $\mathrm{x}$ \\
\hline 103 & PTAC & $\mathrm{R}-410 \mathrm{~A}$ & $\mathrm{x}$ & & & $\mathrm{x}$ & $\mathrm{x}$ & \\
\hline 104 & PTAC & $\mathrm{R}-410 \mathrm{~A}$ & $\mathrm{x}$ & & & $\mathrm{x}$ & & $\mathrm{x}$ \\
\hline 105 & PTAC & $\mathrm{R}-410 \mathrm{~A}$ & & $\mathrm{x}$ & $\mathrm{x}$ & & $\mathrm{x}$ & \\
\hline 106 & PTAC & $\mathrm{R}-410 \mathrm{~A}$ & & $\mathrm{x}$ & $\mathrm{x}$ & & & $\mathrm{x}$ \\
\hline 107 & PTAC & R-410A & & $\mathrm{x}$ & & $\mathrm{x}$ & $\mathrm{x}$ & \\
\hline 108 & PTAC & $\mathrm{R}-410 \mathrm{~A}$ & & $\mathrm{x}$ & & $\mathrm{x}$ & & $\mathrm{x}$ \\
\hline 109 & Split-System & $\mathrm{R}-410 \mathrm{~A}$ & $\mathrm{x}$ & & $\mathrm{x}$ & & $\mathrm{x}$ & \\
\hline 110 & Split-System & $\mathrm{R}-410 \mathrm{~A}$ & $\mathrm{x}$ & & $\mathrm{x}$ & & & $\mathrm{x}$ \\
\hline 111 & Split-System & $\mathrm{R}-410 \mathrm{~A}$ & $\mathrm{x}$ & & & $\mathrm{x}$ & $\mathrm{x}$ & \\
\hline 112 & Split-System & $\mathrm{R}-410 \mathrm{~A}$ & $\mathrm{x}$ & & & $\mathrm{x}$ & & $\mathrm{x}$ \\
\hline 113 & Split-System & R-410A & & $\mathrm{x}$ & $\mathrm{x}$ & & $\mathrm{x}$ & \\
\hline 114 & Split-System & $\mathrm{R}-410 \mathrm{~A}$ & & $\mathrm{x}$ & $\mathrm{x}$ & & & $\mathrm{x}$ \\
\hline 115 & Split-System & $\mathrm{R}-410 \mathrm{~A}$ & & $\mathrm{x}$ & & $\mathrm{x}$ & $\mathrm{x}$ & \\
\hline 116 & Split-System & $\mathrm{R}-410 \mathrm{~A}$ & & $\mathrm{x}$ & & $\mathrm{x}$ & & $\mathrm{x}$ \\
\hline 117 & Packaged RTU & $\mathrm{R}-410 \mathrm{~A}$ & $\mathrm{x}$ & & $\mathrm{x}$ & & $\mathrm{x}$ & \\
\hline 118 & Packaged RTU & $\mathrm{R}-410 \mathrm{~A}$ & $\mathrm{x}$ & & $\mathrm{x}$ & & & $\mathrm{x}$ \\
\hline 119 & Packaged RTU & $\mathrm{R}-410 \mathrm{~A}$ & $\mathrm{x}$ & & & $\mathrm{x}$ & $\mathrm{x}$ & \\
\hline 120 & Packaged RTU & $\mathrm{R}-410 \mathrm{~A}$ & $\mathrm{x}$ & & & $\mathrm{x}$ & & $\mathrm{x}$ \\
\hline 121 & Packaged RTU & $\mathrm{R}-410 \mathrm{~A}$ & & $\mathrm{x}$ & $\mathrm{x}$ & & $\mathrm{x}$ & \\
\hline 122 & Packaged RTU & $\mathrm{R}-410 \mathrm{~A}$ & & $\mathrm{x}$ & $\mathrm{x}$ & & & $\mathrm{x}$ \\
\hline 123 & Packaged RTU & $\mathrm{R}-410 \mathrm{~A}$ & & $\mathrm{x}$ & & $\mathrm{x}$ & $\mathrm{x}$ & \\
\hline 124 & Packaged RTU & $\mathrm{R}-410 \mathrm{~A}$ & & $\mathrm{x}$ & & $\mathrm{x}$ & & $\mathrm{x}$ \\
\hline G1* & Split-System & $\mathrm{R}-410 \mathrm{~A}$ & & $\mathrm{x}$ & blower only & & $\mathrm{x}$ & \\
\hline G2* & Split-System & $\mathrm{R}-410 \mathrm{~A}$ & & $\mathrm{x}$ & & $\mathrm{x}$ & $\mathrm{x}$ & \\
\hline
\end{tabular}

*G1 and G2 were gate tests to determine whether equipment "off” tests for all AC units should be done with blower on or off. 
Table 3. Refrigeration systems test matrix

\begin{tabular}{|c|c|c|c|c|c|c|c|c|}
\hline Test \# & Equipment & Refrigerant & $\begin{array}{c}\text { Low leak } \\
\text { rate }\end{array}$ & $\begin{array}{c}\text { High leak } \\
\text { rate }\end{array}$ & $\begin{array}{c}\text { Equipment } \\
\text { ON }\end{array}$ & $\begin{array}{l}\text { Equipment } \\
\text { OFF }\end{array}$ & $\begin{array}{c}\text { Low side } \\
\text { leak }\end{array}$ & $\begin{array}{c}\text { High side } \\
\text { leak }\end{array}$ \\
\hline 125 & Display Case & R-404A & $\mathrm{x}$ & & $\mathrm{x}$ & & $\mathrm{x}$ & \\
\hline 126 & Display Case & R-404A & $\mathrm{x}$ & & $\mathrm{x}$ & & & $\mathrm{x}$ \\
\hline 127 & Display Case & R-404A & $\mathrm{x}$ & & & $\mathrm{x}$ & $\mathrm{x}$ & \\
\hline 128 & Display Case & R-404A & $\mathrm{x}$ & & & $\mathrm{x}$ & & $\mathrm{x}$ \\
\hline 129 & Display Case & R-404A & & $\mathrm{x}$ & $\mathrm{x}$ & & $\mathrm{x}$ & \\
\hline 130 & Display Case & $\mathrm{R}-404 \mathrm{~A}$ & & $\mathrm{x}$ & $\mathrm{x}$ & & & $\mathrm{x}$ \\
\hline 131 & Display Case & $\mathrm{R}-404 \mathrm{~A}$ & & $\mathrm{x}$ & & $\mathrm{x}$ & $\mathrm{x}$ & \\
\hline 132 & Display Case & $\mathrm{R}-404 \mathrm{~A}$ & & $\mathrm{x}$ & & $\mathrm{x}$ & & $\mathrm{x}$ \\
\hline 133 & Unit Cooler & R-404A & $\mathrm{x}$ & & $\mathrm{x}$ & & $\mathrm{x}$ & \\
\hline 134 & Unit Cooler & R-404A & $\mathrm{x}$ & & $\mathrm{x}$ & & & $\mathrm{x}$ \\
\hline 135 & Unit Cooler & R-404A & $\mathrm{x}$ & & & $\mathrm{x}$ & $\mathrm{x}$ & \\
\hline 136 & Unit Cooler & $\mathrm{R}-404 \mathrm{~A}$ & $\mathrm{x}$ & & & $\mathrm{x}$ & & $\mathrm{x}$ \\
\hline 137 & Unit Cooler & $\mathrm{R}-404 \mathrm{~A}$ & & $\mathrm{x}$ & $\mathrm{x}$ & & $\mathrm{x}$ & \\
\hline 138 & Unit Cooler & $\mathrm{R}-404 \mathrm{~A}$ & & $\mathrm{x}$ & $\mathrm{x}$ & & & $\mathrm{x}$ \\
\hline 139 & Unit Cooler & $\mathrm{R}-404 \mathrm{~A}$ & & $\mathrm{x}$ & & $\mathrm{x}$ & $\mathrm{x}$ & \\
\hline 140 & Unit Cooler & R-404A & & $\mathrm{x}$ & & $\mathrm{x}$ & & $\mathrm{x}$ \\
\hline
\end{tabular}

As noted, the refrigerants used for the testing program were R-410A for the AC systems and R-404A for the refrigeration systems. The AHRTI project monitoring subcommittee (PMS) for this project felt that these refrigerants (both A1 per ASHRAE Standard 34) could be used to provide valid test results at a much-reduced hazard level.

For the high-pressure side leaks at high leak rate, the PMS recommended a tube the size of the test system's liquid line with no restriction be used for the release point. The same tube size was recommended for low-pressure side and high leak rate since it is unlikely that a suction line would be completely severed. For "low leak rate", the PMS originally recommended restricting the release area to $1 / 2$ the cross-sectional area of the release tube. However, after reviewing results of the first system tested (split AC) this recommendation changed to use an orifice diameter for the other four units to closely approach a total leak time (for $99 \%$ of the total refrigerant released to exit the unit) of about 4 minutes for the "equipment off," and "low side leak" test cases. See further discussion in Section 3.

\subsection{TEST SETUP AND INSTRUMENTATION}

Figure 6 illustrates the general test chamber setup arrangement as used for the split AC unit and illustrates the approximate positioning of test visualization, concentration, and space temperature instrumentation. This positioning was basically similar for all the test units. 


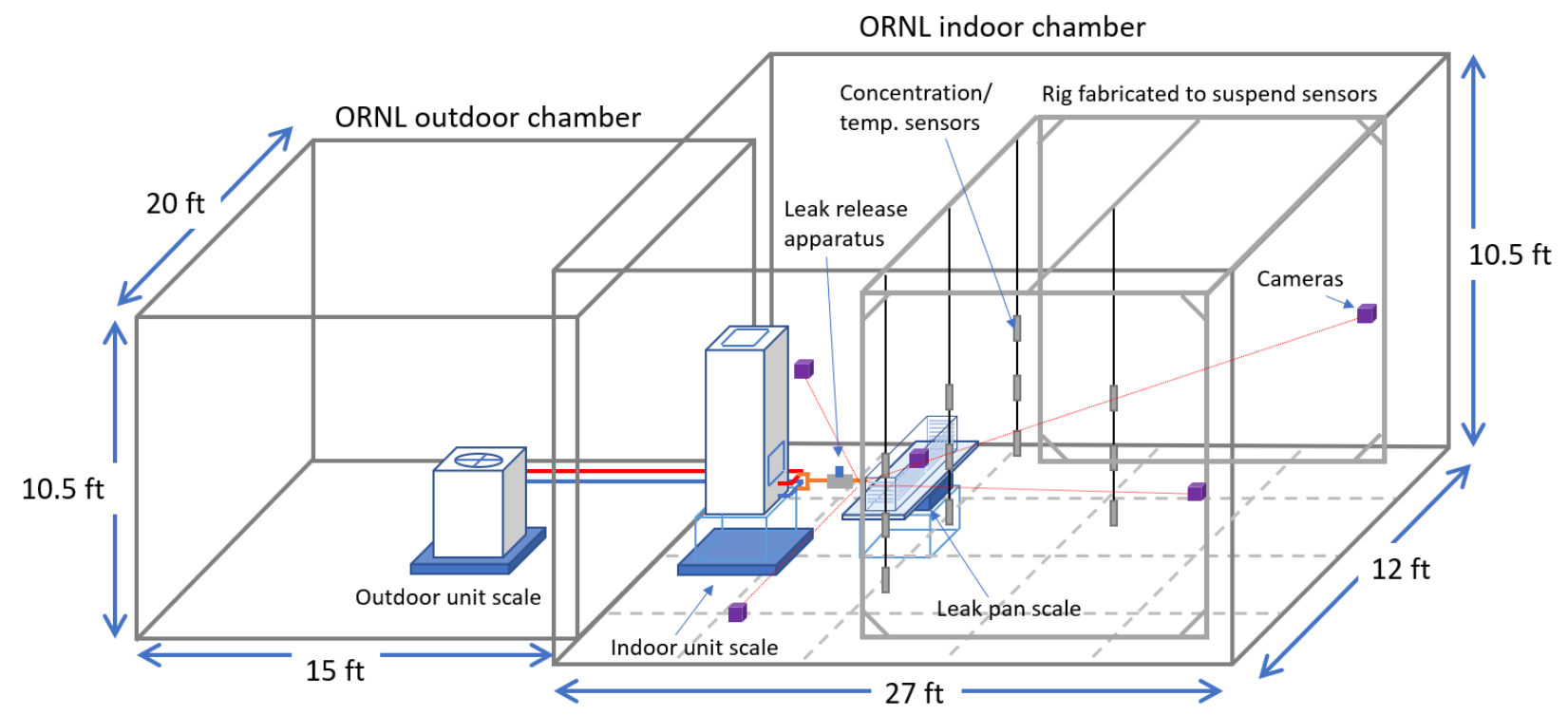

Figure 6. Split AC test unit conceptual set up in test chamber (not to scale)

The AHRTI 9012 work statement specified a number of data needs as noted in the list below. Details on instrumentation (measurement range, accuracy, precision, etc.) and the data acquisition and control (DAQ) system are given in APPENDIX A.

- Video recording from multiple angles

○ Five GoPro HERO5 Session ${ }^{\mathrm{TM}}$ cameras used for each system (positioned just under, above, to left of, to right of, and looking directly at the leak release point)

- A high speed (HS) camera was originally planned to be used as well. The recording capacity of the HS camera available was only sufficient to capture about 2-3 seconds of real time action with maximum resolution (see Table 4 below). So, it was decided to focus this recording time on the first few seconds of a leak release. However, due to set up issues (light needs, mounting difficulties, etc.) the HS camera was not used on any leak test.

- 12 or more concentration measurements arrayed in the room

$\circ$ Apogee ${ }^{\circledR} \mathrm{SO}-220 \mathrm{O}_{2}$ sensors used (e.g., sensing Oxygen concentration as surrogate for refrigerant concentration). See further discussion below.

- 24 or more temperature measurements arrayed in the room (type T thermocouples)

- Pressure decay recording within the high and low-pressure sides of the equipment

- High-accuracy pressure gages located just upstream of the leak locations were used to measure high and low side pressures during each leak event. Type $\mathrm{T}$ thermocouples were co-located with each pressure sensor and a third TC was located at the leak release point

- Mass flow rate measurement of the released refrigerant mass vs. time.

- High-precision scales used to track unit weight vs. time to provide refrigerant loss rate measure. Two scales used for split AC and unit cooler systems, one scale used for all other systems.

- Quality measurement of the leak over time.

- A separate test approach using a closed capture tank was developed in an attempt to provide an estimate of this parameter. See discussion in Section 4. 
- Oil loss for each test and/or oil sump monitoring with a sight glass to enable returning the system oil level to nominal before each test.

○ Some test systems (e.g., split AC) included means (sight glass or external refrigerant/oil level tube) for direct monitoring of compressor sump oil level, but not all. A leak "capture" box was fabricated and mounted on a separate weigh scale. Refrigerant releases were directed into this box to obtain a secondary estimate of any oil and/or liquid refrigerant release during the leak tests (see Figure 7). The box would also be able to record any liquid refrigerant droplets collected in the drip pan during leak tests.

- Ambient temperature conditions of $95^{\circ} \mathrm{F} \pm 2^{\circ} \mathrm{F}$ for the "outdoor portion" and $75^{\circ} \mathrm{F} \pm 2^{\circ} \mathrm{F}$ for the "indoor portion" of the equipment were specified for the AC test units. For the display case unit, a $75^{\circ} \mathrm{F} \pm 2^{\circ} \mathrm{F}$ operating condition was specified. For the split unit cooler, ambient temperature conditions of $95^{\circ} \mathrm{F} \pm 2^{\circ} \mathrm{F}$ for the "outdoor portion" and $20^{\circ} \mathrm{F} \pm 2^{\circ} \mathrm{F}$ for the "indoor portion" of the equipment were specified.

○ For all equipment "on" tests, the systems were allowed to reach steady operation at the noted conditions prior to initiating a refrigerant leak event - approximately 20 minutes.

- Compressor and unit power were measured during each "on" test to provide a direct indication of compressor shut off during the test (e.g., due to low pressure cut out or other system safety controls).

- The work statement specified that low-side leak tests done with the equipment "off" should have provision for transfer of refrigerant from the high side to the low side. This represents a worst case: refrigerant having migrated to the indoor unit due to cooler temperatures. This condition was only achieved for the AC systems and the display case unit. The split unit cooler system tested included a solenoid valve and pump down cycle to isolate the refrigerant in the condenser section when there is no call for cooling.

Table 4. High-speed camera recording time, capacity and resolution vs. record speed

\begin{tabular}{|c|c|c|c|}
\hline $\begin{array}{c}\text { Frames per } \\
\text { Second }\end{array}$ & $\begin{array}{c}\text { Resolution } \\
\text { (pixels) }\end{array}$ & $\begin{array}{c}\text { Frames in } \\
\text { memory }\end{array}$ & $\begin{array}{c}\text { Record } \\
\text { time (s) }\end{array}$ \\
\hline 1 & $1280 \times 1024$ & 2,447 & 2447.0 \\
\hline 100 & $1280 \times 1024$ & 2,447 & 24.470 \\
\hline 200 & $1280 \times 1024$ & 2,447 & 12.235 \\
\hline 1,000 & $1280 \times 1024$ & 2,447 & 2.447 \\
\hline 5,000 & $804 \times 600$ & 6,672 & 1.334 \\
\hline 10,000 & $528 \times 396$ & 15,390 & 1.539 \\
\hline
\end{tabular}




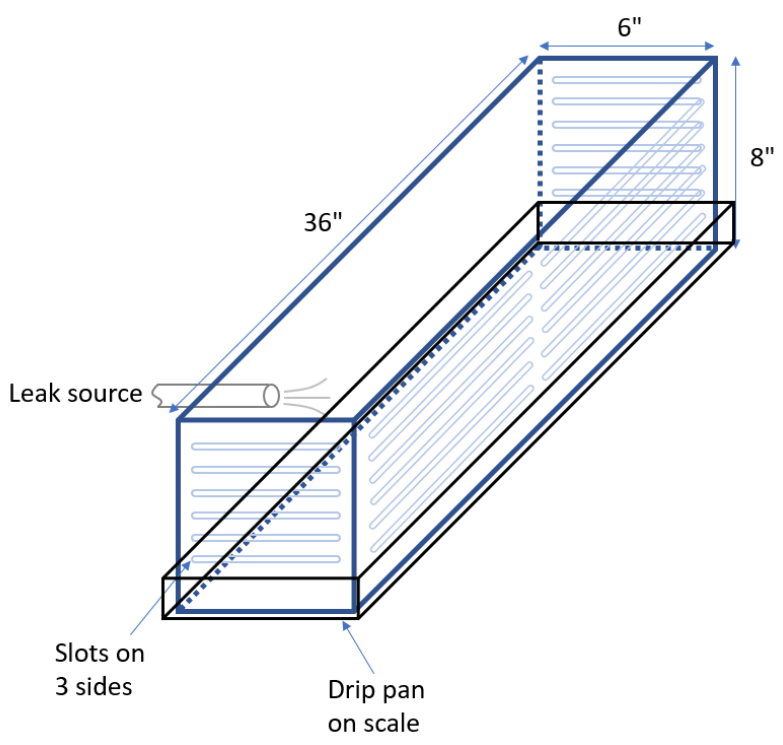

(a.)

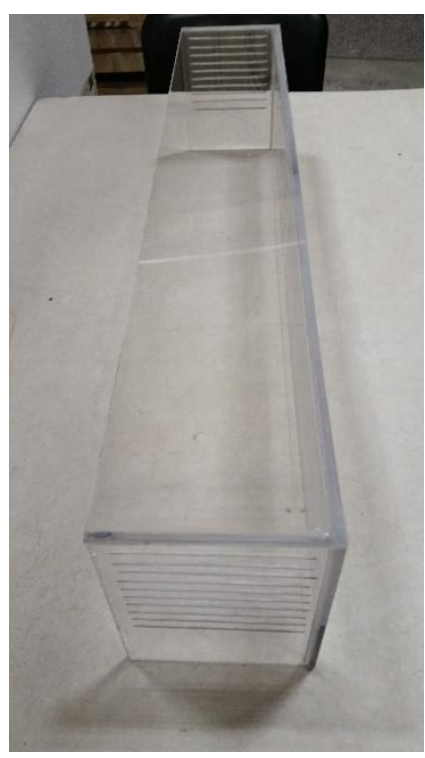

(b.)

Figure 7. (a.) Refrigerant leak capture box schematic and (b.) photo; box mounted on precision weigh scale

\subsection{REFRIGERANT CONCENTRATION SENSORS}

As noted above, for refrigerant concentration measurement the plan was to use Apogee ${ }^{\circledR}$ brand $\mathrm{O}_{2}$ deprivation sensors. These provide a direct measure of $\mathrm{O}_{2}$ concentration. With careful calibration, the refrigerant concentration can be determined based on $\mathrm{O}_{2}$ reduction from normal atmospheric concentration $(\sim 21 \%)$. The purpose of the concentration measurements was to provide a data resource that could be utilized for future calibration of computational fluid dynamics (CFD) models of leak events.

An initial calibration exercise was conducted to verify the accuracy, utility, etc. of the Apogee ${ }^{\circledR}$ sensors. Tests were run with ambient air flowing over the sensor $\left(\sim 21 \% \mathrm{O}_{2}\right)$ and then with $\mathrm{N}_{2}$ and R-134a flowing over the sensor (nearly $0 \% \mathrm{O}_{2}$ ). Voltage output of the sensor was $\sim 12.6 \mathrm{mV}$ with air and $\sim 0.4-0.5 \mathrm{mV}$ with $\mathrm{N}_{2}$ and $\mathrm{R}-134 \mathrm{a}$. The $\mathrm{mV}$ outputs converted to $\mathrm{O}_{2}$ sensitivity were:

- Ambient air: $\mathrm{O}_{2}$ concentration $=20.94 \% \pm 0.0467 \%$

- $\mathrm{N}_{2}$ flowing over sensor: $\mathrm{O}_{2}$ concentration $=0.73 \% \pm 0.0203 \%$

- R-134a flowing over sensor: $\mathrm{O}_{2}$ concentration $=0.73 \% \pm 0.0056 \%$

Room concentration and temperature data was taken during the leak tests of each system. Upon examining the concentration data during the split AC tests, it became apparent that significant postprocessing of the data is required to deconvolve the actual instantaneous refrigerant concentration profiles in the test room. It was also noted that the sensors experienced repeatability issues between each test necessitating re-baselining prior to each test. Given the time constraints for the project it was decided to proceed with the primary leak tests and delay detailed concentration data analysis. The concentration sensors remained active during all leak tests, but only the raw data is stored for now.

Deconvolution of the sensor output is necessary because the instantaneous response of the sensor does not correspond to the real time refrigerant concentration at each sensor location. The instantaneous response is a resultant of the effect of the instantaneous concentration and the dynamic characteristics of the sensor (time constants for both rising and settling time, and frequency response). Deconvolution is usually performed by using the concentration-to-voltage dynamic model (transfer function) of the sensor to infer the instantaneous concentration from the convolved voltage response. The transfer function of the Apogee 
sensors turned out to be of high-order which complicates the mathematical manipulation needed to deconvolve the response. Therefore, a grey-box approach was investigated to assess its potential.

A series of concentration step changes was prepared and imposed on the sensor. The sensor's instantaneous output was recorded. The input and output data were then used to train a nonlinear model that predicts the instantaneous concentration given the convolved response. Several dynamic models were used, and training continued until a model could reasonably reproduce the instantaneous concentration from the convolved response. Figure 8 illustrates the results of this initial model development exercise; model estimates of concentration vs. the artificial step change concentration. Although this grey-box approach has shown promising results, additional analysis must be conducted with larger data sets and is left for future work.

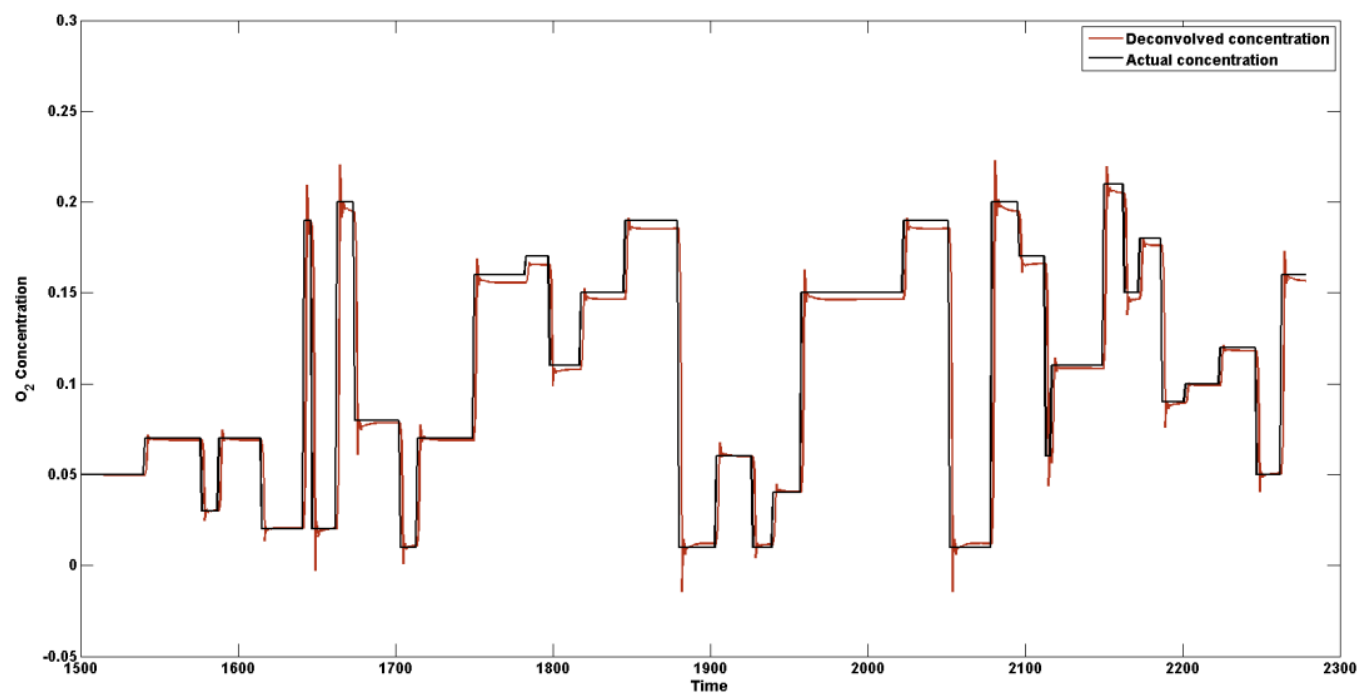

Figure 8. Deconvolved concentration signal vs. actual concentration. The deconvolved signal is obtained using a non-linear dynamic model of the sensor. The dynamic model was estimated using sensor output voltage response to concentration dataset collected experimentally 


\section{TEST RESULTS}

\subsection{SPLIT SYSTEM AC TEST RESULTS}

Figure 9a shows the indoor and outdoor sections of the AC unit as connected in the chamber. Each is supported by a precision weigh scale. The partition wall opening was closed with plywood and insulated during tests with care taken to make sure the connecting lines could move freely so as not to impede the weigh scale measurement. The refrigerant "catch box" can be seen in the foreground sitting on a third scale. Its purpose was to mimic release as it would occur inside the AC air handler and to capture and weigh any liquid refrigerant and/or oil expelled during the leak tests. Figure $9 \mathrm{~b}$ provides a close-up view of the leak release control system; a pneumatically operated, fast-acting, full-port ball valve which was controlled by the DAQ system through a PC used for data acquisition and supervisory control. Two hand-operated ball valves (just to the right of the automatic valve controller) are included to enable the test operator to select the high or low side leak point as required for each test. Pressure and temperature instrumentation for the high and low side are visible in the back of the photo (refer to Figure 9). An additional thermocouple to measure temperature at the leak point is positioned under a tape and insulation wrap just behind the leak release point at the extreme lower left corner. The leak release in the photo is set up for the high leak rate (full line rupture) cases. For the low leak tests a orifice with smaller diameter (having about $34 \%$ of the flow area) was attached to the leak release point.

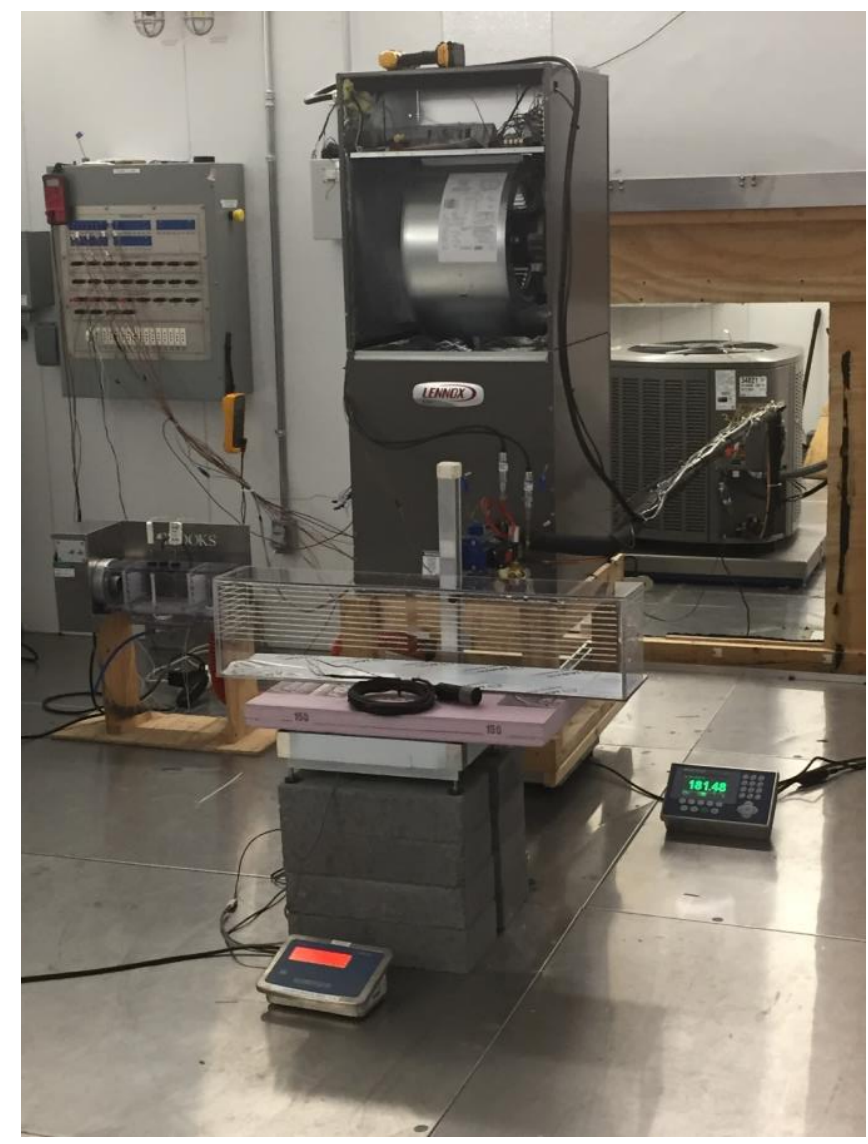

(a.)

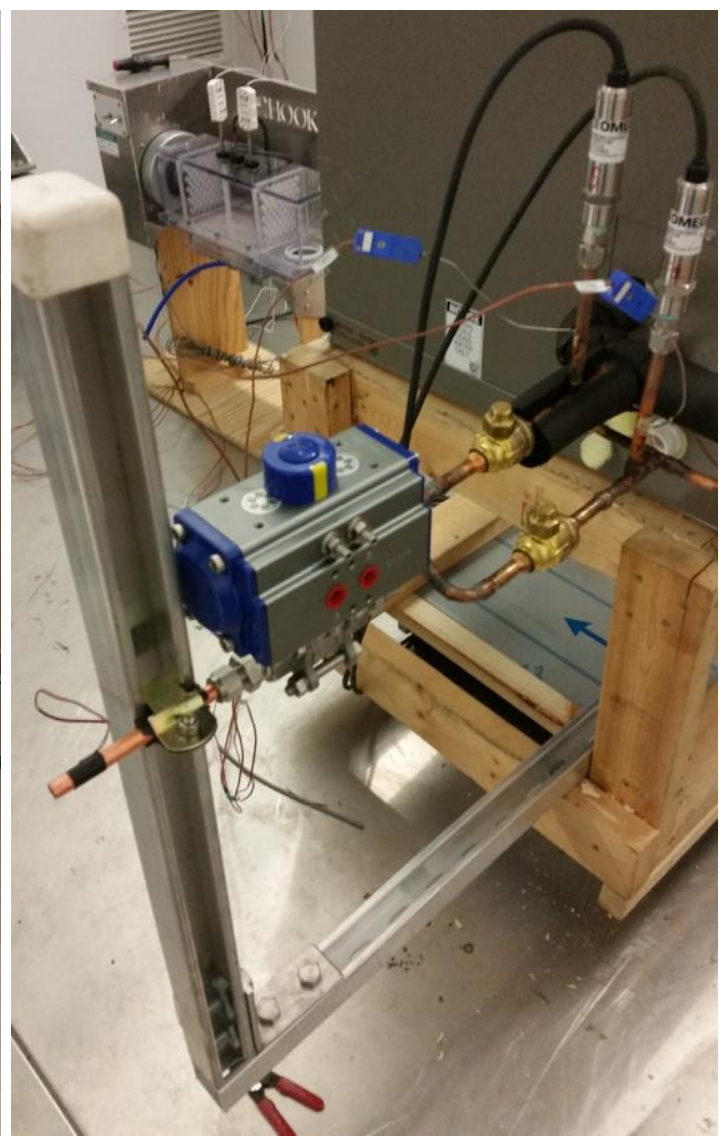

(b.)

Figure 9. (a.) Split AC installed in chamber and (b.) close-up of leak release control system (pneumatically controlled, fast opening ball valve) 
Figure 10 shows a concentration/temperature $(\mathrm{C} / \mathrm{T})$ sensor support frame to which the $\mathrm{C} / \mathrm{T}$ trees were attached during the tests. AC setup progress was discussed with the AHRTI PMS at a web meeting on April 17, 2018. Major suggestions coming from the meeting were 1) conduct shake down tests to make sure the weigh scale signal noise will not impact measurement of refrigerant loss, and 2) perhaps start the $\mathrm{AC}$ tests immediately and only include $\mathrm{C} / \mathrm{T}$ data as soon as the support frame and $\mathrm{C} / \mathrm{T}$ trees could be installed (some tests will be without C/T data, as the PMS agreed with this).

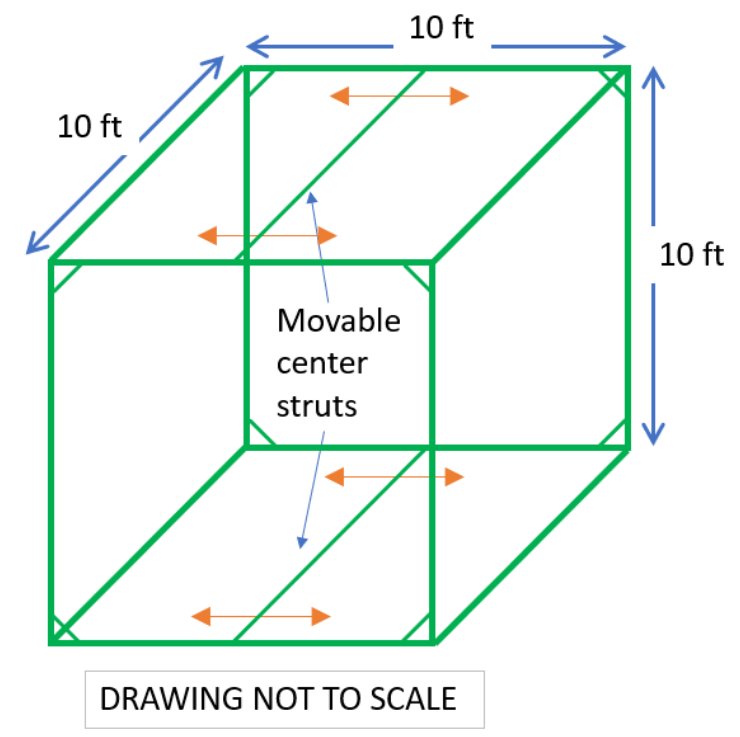

Figure 10. Refrigerant and room temperature sensor support rig

Prior to initiation of system testing, two shakedown tests were performed to make sure that the refrigerant weight loss would be discernable from the weigh scale signal noise. The first, using nitrogen gas as system charge, confirmed the stability of the system weight instrumentation; results plotted in Figure 11 indicated that the scale output signal was very stable. A second shakedown test using R-410A under test 106 conditions (system on, high-side leak, high leak rate) was run subsequently. Figure 12 illustrates the system weight loss and pressure vs. time; all the refrigerant was released within 1-2 minutes. The sudden additional drop in the air handler (ID unit) weight at about the 3-minute mark was attributed to some loose item falling from the test unit based on video footage.

The following general procedure was used for each system, with some differences for the unit cooler system (detailed test procedures are given in APPENDIX B):

- Test unit charged to "nameplate" specifications per manufacturer recommendation.

- Test chambers operated to establish steady ambient control at the specified temperature conditions (NOTE: indoor wet bulb condition was maintained $<50^{\circ} \mathrm{F}$ to assure no water would condense in the unit and impose uncertainty on the system weight measurement; this approach worked well for the three AC test units but some frost accumulation was observed on the evaporators of the refrigeration test units; NOTE --- the frost accumulation was judged not to have impacted the refrigerant leak measurements as discussed in the relevant sections following.)

- System was operated for at least 20 minutes to distribute refrigerant to steady-state locations.

- Data collection initiated.

- Manual ball valves were set to required position for high or low side leak as required.

- For "unit off" tests, system was turned off and refrigerant allowed to migrate to final locations for at least 20 minutes. 
- System leak initiated by control PC sending "open" signal to automatic ball valve.

- Data collection continues for at least 20 minutes.

- Test chambers evacuated of refrigerant and preparation for next test begins

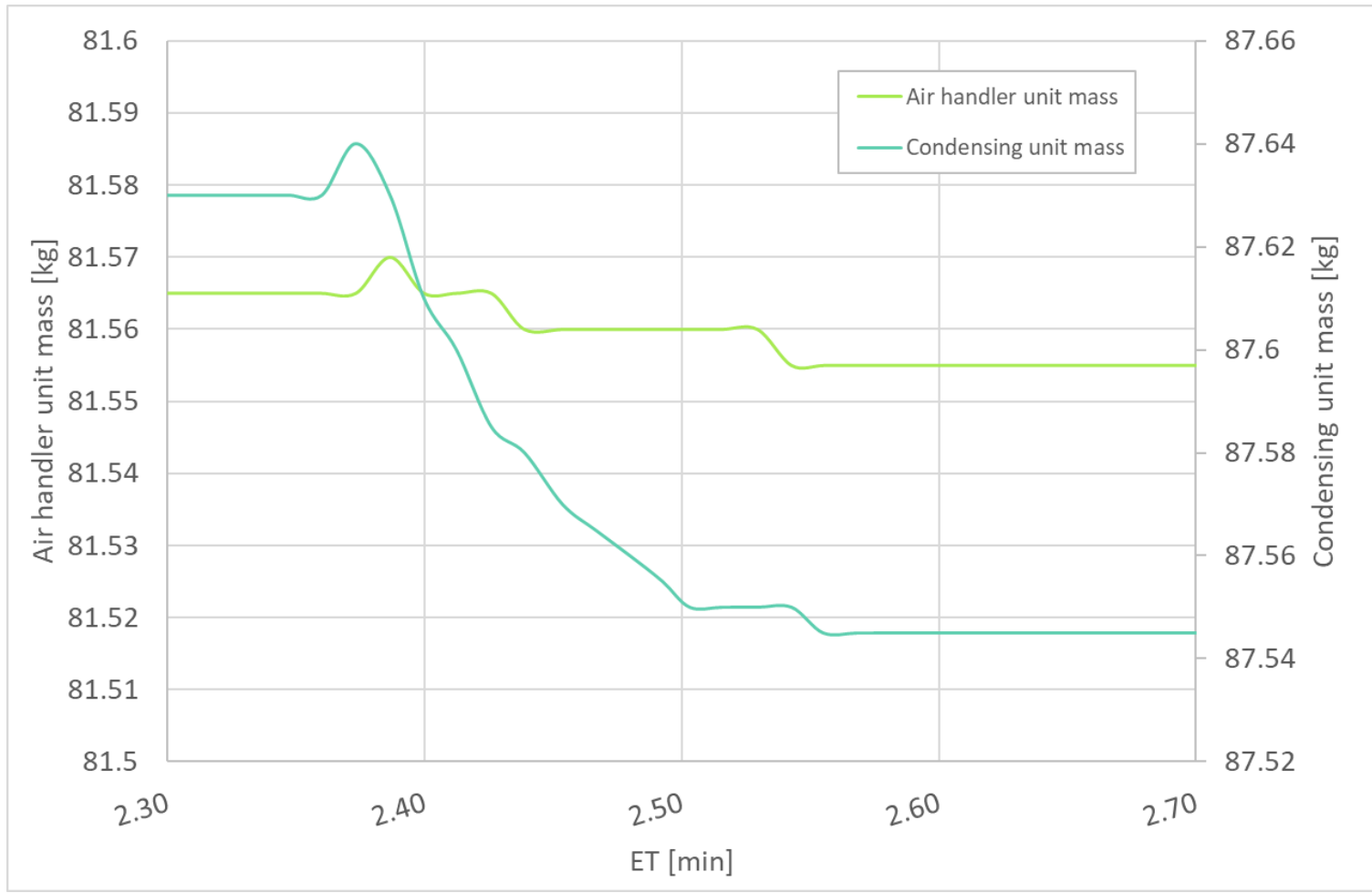

Figure 11. Initial shakedown test with split AC unit charged with nitrogen 


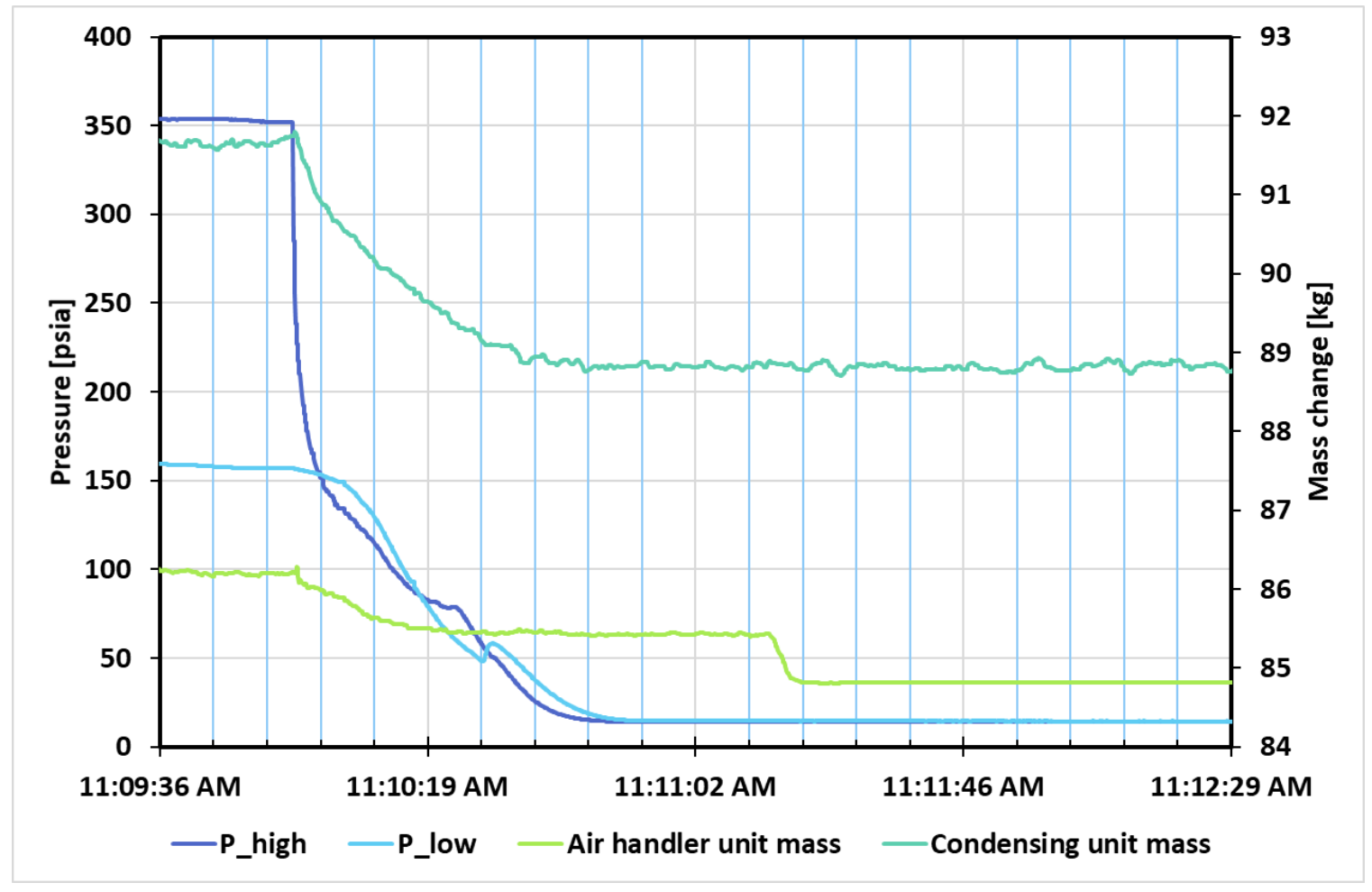

Figure 12. Shakedown test with split AC unit charged with R-410A

Table 5 provides a summary of all the split AC unit tests (NOTE: test no. 110 results highlighted because the first test at this condition was faulty. The test was repeated and the results that are highlighted in the table are of the repeated test). Leak location, hole size, and compressor on/off status can be determined by referring to Figures 16-23. For all the tests, $96-100 \%$ of unit charge $(8.375 \mathrm{lb})$ was released within the 20-min test period. Only the two "gate" tests, G1 (same as no. 115) and G2 (unit off, low-side leak, high leak rate) showed any significant change in the "catch" box drip pan mass $(0.15-0.17 \mathrm{lb})$. Figure 13 shows the change in "catch" box \& drip pan mass during tests G1 (115) and G2. The total mass gain in the drip pan was about $0.18 \mathrm{lb}(0.08 \mathrm{~kg})$ and about $0.17 \mathrm{lb}(0.075 \mathrm{~kg})$ for G1 and G2, respectively. By the end of the test the pan weight had dropped slightly reducing the total weight gain to about $0.17 \mathrm{lb}(0.7 \mathrm{~kg})$. We believe this weight drop is due to evaporation of liquid refrigerant entrained in the oil, so most of the weight gain was due to oil expelled along with the refrigerant. A similar trend is observed for the G2 test.

The "gate" tests were run to determine whether to keep the indoor blower on (G1) or off (G2) during unit off tests. Since the total refrigerant release was slightly greater for the G1 case, all future unit off (e.g. compressor off) tests for all test units will be run with the ID blower on. Note that while the total charge released was very similar in all cases, the time required to leak $80 \%$ of the total refrigerant release varied from $\sim 28 \mathrm{~s}$ to $>102 \mathrm{~s}$. 
Table 5. Split AC unit leak test results summary

\begin{tabular}{|c|c|c|c|c|c|c|c|c|}
\hline Test \# & $\begin{array}{c}\text { System } \\
\text { charge } \\
{[\mathrm{lb}]}\end{array}$ & $\begin{array}{c}\text { OD unit } \\
\text { mass } \\
\text { change } \\
{[\mathrm{lb}]}\end{array}$ & $\begin{array}{c}\text { ID unit } \\
\text { mass } \\
\text { change } \\
{[\mathrm{lb}]}\end{array}$ & $\begin{array}{c}\text { Total } \\
\text { charge } \\
\text { released } \\
{[\mathrm{lb}]}\end{array}$ & $\begin{array}{c}\text { Time to } \\
\text { release } \\
80 \% \text { of } \\
\text { total }[\mathrm{s}]\end{array}$ & $\begin{array}{c}\text { Average } \\
\text { leak rate } \\
\text { for } 80 \% \\
\text { release } \\
{[\mathrm{lb} / \mathrm{min}]}\end{array}$ & $\begin{array}{c}\text { Charge } \\
\text { left in } \\
\text { system } \\
{[\mathrm{lb}]}\end{array}$ & $\begin{array}{c}\text { Collector } \\
\text { pan mass } \\
\text { change } \\
{[\mathrm{lb}]}\end{array}$ \\
\hline $\mathrm{G} 1(115)$ & 8.38 & 4.98 & 3.29 & 8.27 & 29.70 & 13.36 & 0.11 & 0.17 \\
\hline $\mathrm{G} 2$ & 8.38 & 5.92 & 2.09 & 8.01 & 74.70 & 5.38 & 0.36 & 0.15 \\
\hline 109 & 8.38 & 6.48 & 1.84 & 8.32 & 102.40 & 3.90 & 0.05 & -0.01 \\
\hline 110 & 8.38 & 6.49 & 1.74 & 8.23 & 35.40 & 11.36 & 0.14 & -0.02 \\
\hline 111 & 8.38 & 6.65 & 1.46 & 8.11 & 86.60 & 4.64 & 0.27 & 0.00 \\
\hline 112 & 8.38 & 6.68 & 1.49 & 8.17 & 45.58 & 8.82 & 0.21 & -0.00 \\
\hline 113 & 8.38 & 6.45 & 2.21 & 8.65 & 73.35 & 5.66 & -0.28 & -0.02 \\
\hline 114 & 8.38 & 6.43 & 1.66 & 8.09 & 27.70 & 14.00 & 0.28 & 0.01 \\
\hline $115(\mathrm{G} 1)$ & 8.38 & 4.98 & 3.29 & 8.27 & 29.70 & 13.36 & 0.11 & 0.17 \\
\hline 116 & 8.38 & 6.80 & 1.52 & 8.32 & 34.40 & 11.60 & 0.05 & -0.00 \\
\hline
\end{tabular}

*Nameplate charge was $81 \mathrm{~b}, 6 \mathrm{oz}$ or $\sim 8.38 \mathrm{lb}$.
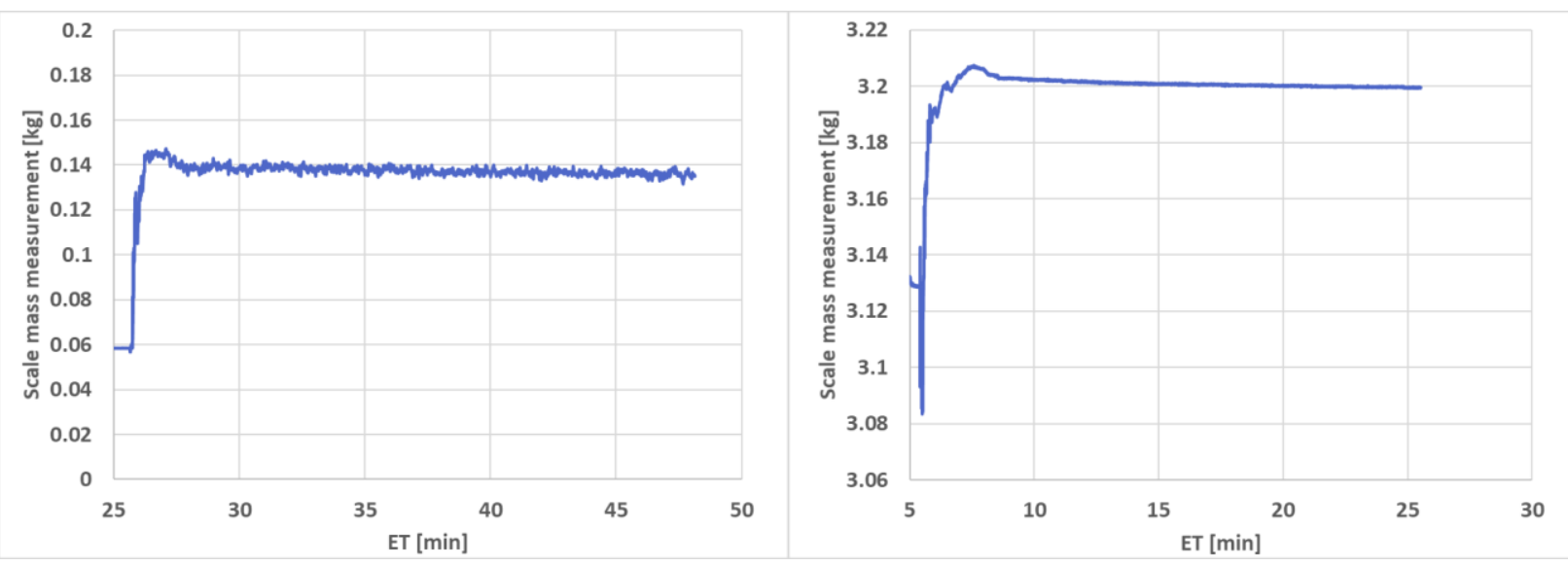

Figure 13. "Catch" box/drip pan weight gain during tests G1 (115), left, and G2, right

In addition to the planned split AC leak tests summarized above, two additional tests were run at AHRTI request to track refrigerant migration after compressor and blower shut off (Figure 14, below) and to determine the impact of fan thrust on the unit weight data (Figure 15, below). Results from the refrigerant migration test show a slight movement of charge between ID and OD units due to the ambient temperature difference between the ID and OD rooms $\left(\sim 20^{\circ} \mathrm{F}\right)$. The total magnitude of migration was about $0.22 \mathrm{lb}(0.1 \mathrm{~kg})$ or less at the 100 -min point when data taking stopped; this was much less in magnitude than the measured refrigerant loss during tests, $\sim 8.0-8.4 \mathrm{lb}(3.6-3.8 \mathrm{~kg})$. Figure 15 indicates that the OD fan adds about $2 \mathrm{lb}(0.9 \mathrm{~kg})$ to the OD unit scale output while the ID blower adds about $1 \mathrm{lb}$ $(0.45 \mathrm{~kg})$ to the ID unit indicated weight. Data from the fan thrust tests were used to correct the refrigerant loss data from the leak tests. Figures 16 - 23 provide graphical summaries of the normalized refrigerant loss data along with pressure decay vs. time for each test. The leak start point is seen as a vertical dashed line for each plot set and data collection continued for 20 minutes after leak start in each test. Note that some of the plots show more data preceding the leak start than others. 


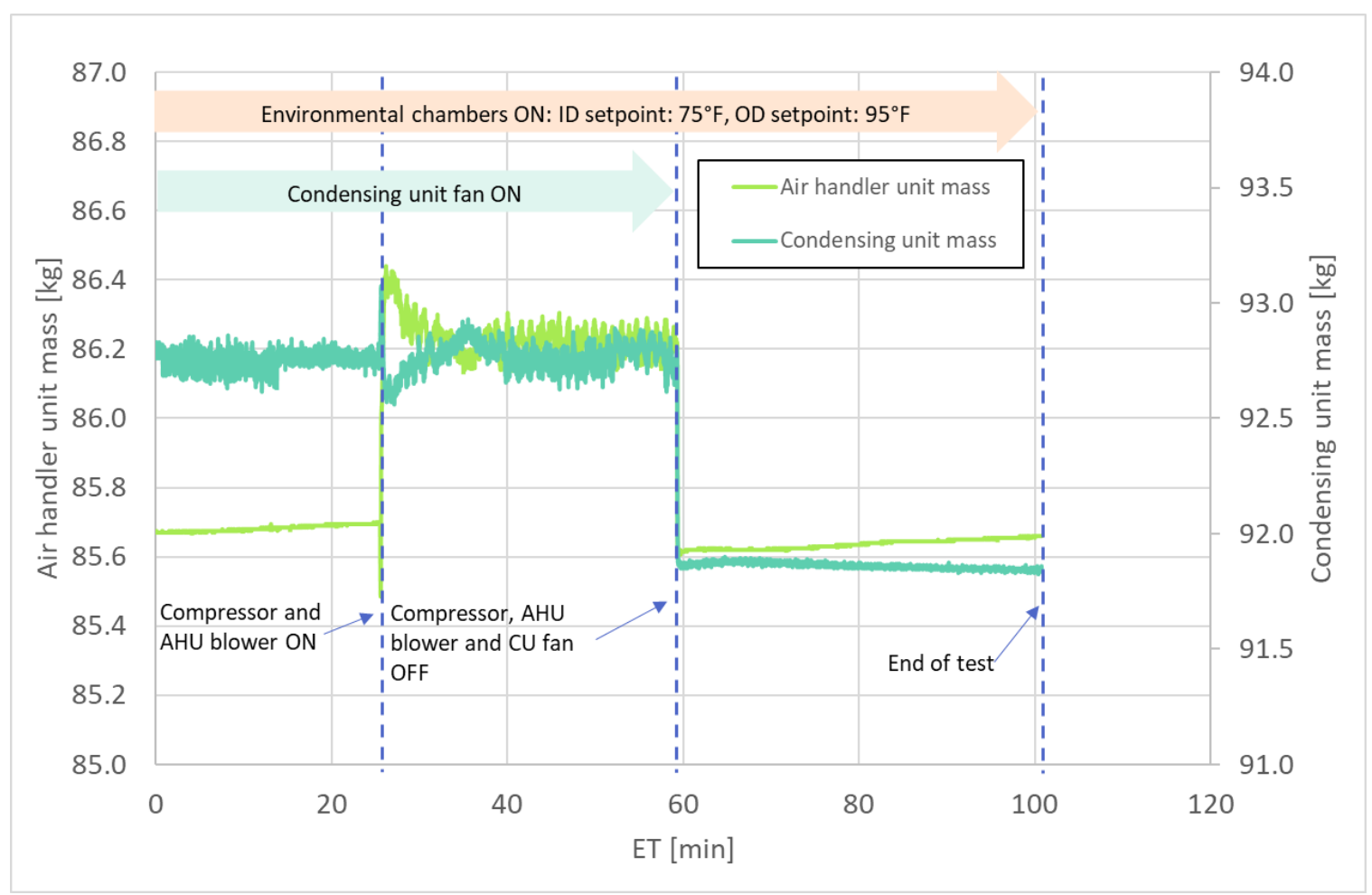

Figure 14. Split AC refrigerant migration test results

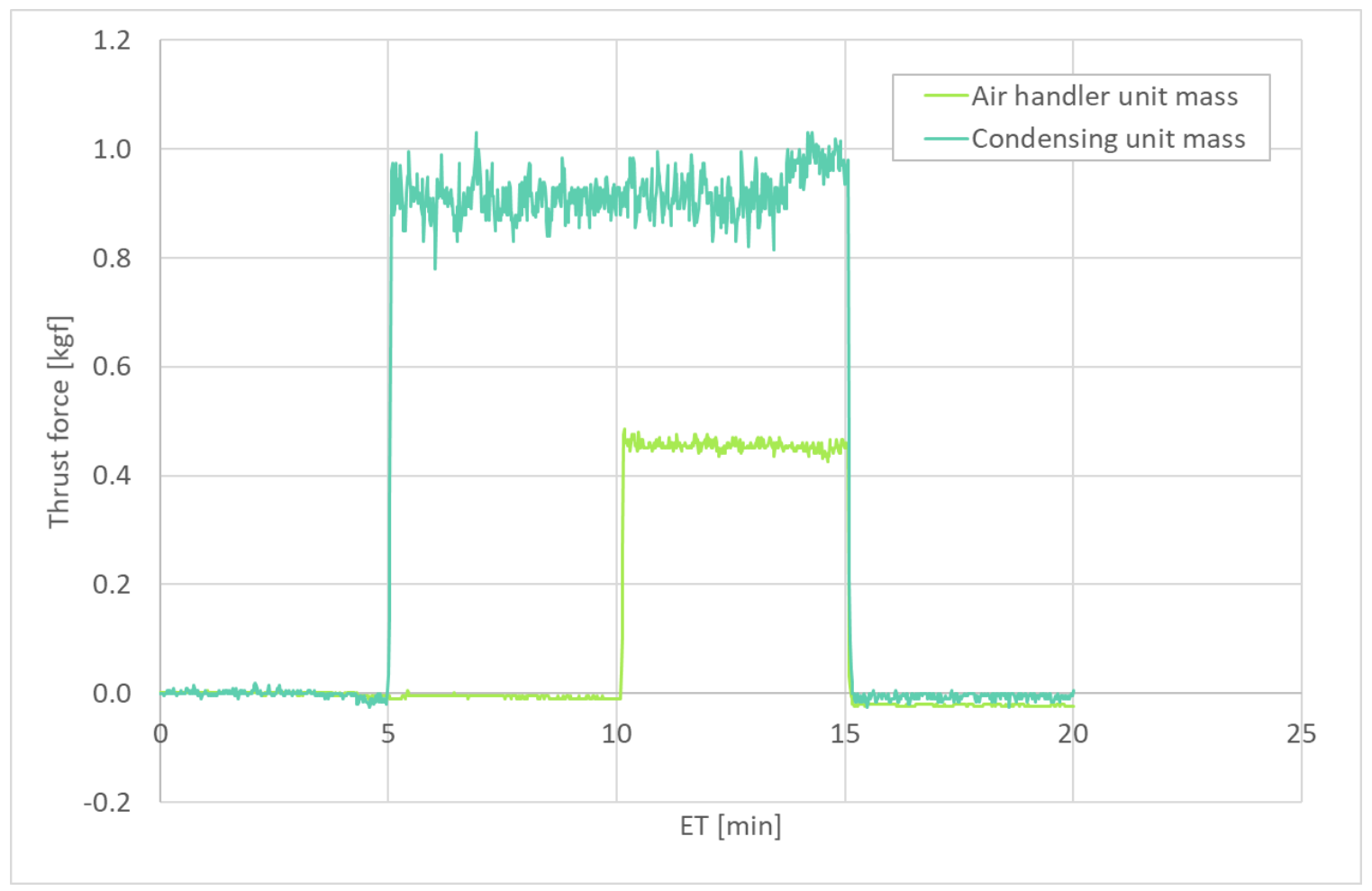

Figure 15. Split AC fan thrust effect test results 


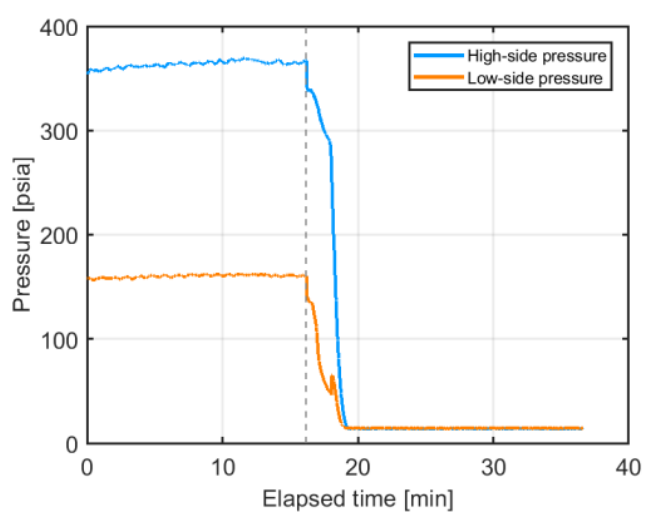

(а.)

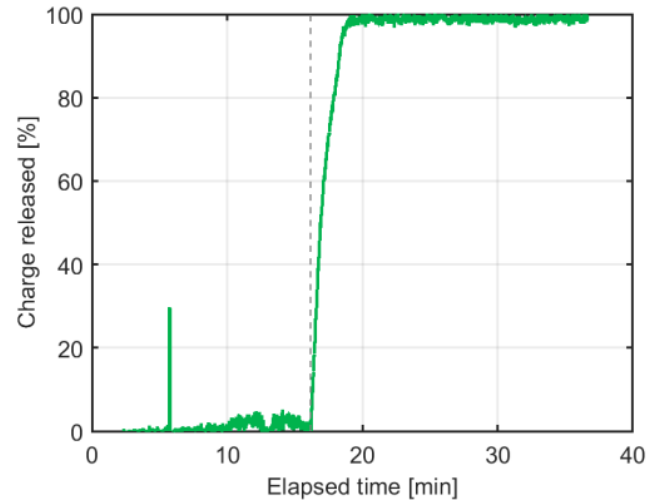

(b.)

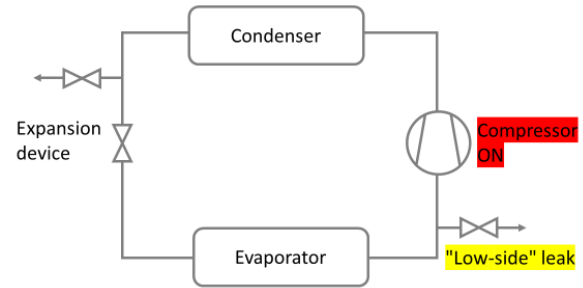

(c.)

Figure 16. (a.) High- and low-side pressure decay, (b.) percent charge released and (c.) system diagram for split AC test 109 (4.11 mm orifice)

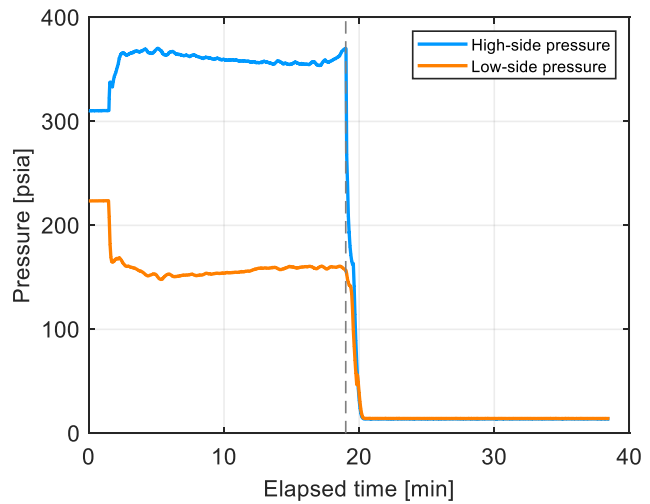

(а.)

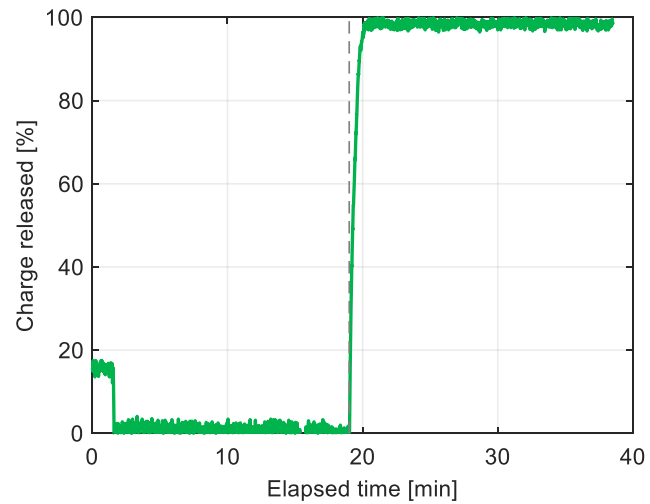

(b.)

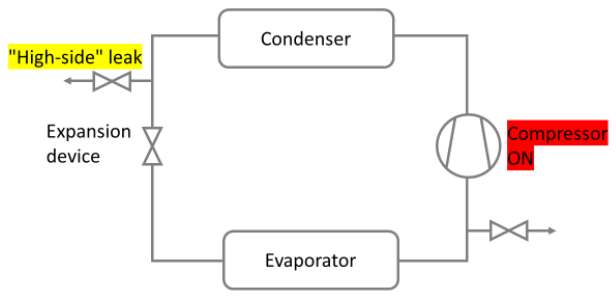

(c.)

Figure 17. (a.) High- and low-side pressure decay, (b.) percent charge released and (c.) system diagram for split AC test 110 (4.11 mm orifice) 


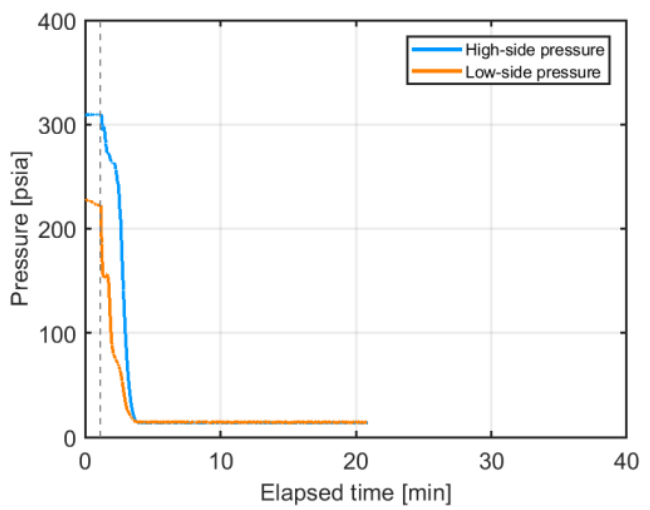

(a.)

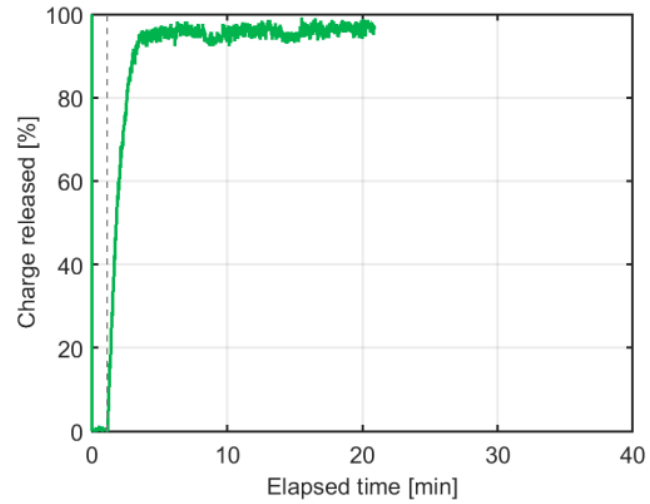

(b.)

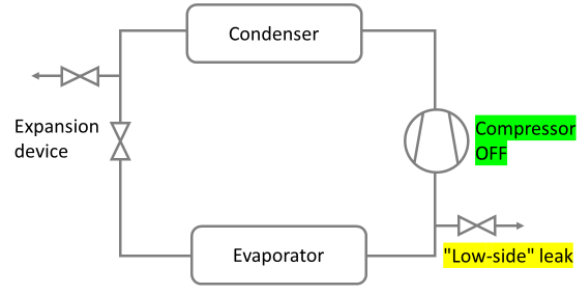

(c.)

Figure 18. (a.) High- and low-side pressure decay, (b.) percent charge released and (c.) system diagram for split AC test 111 (4.11 mm orifice)

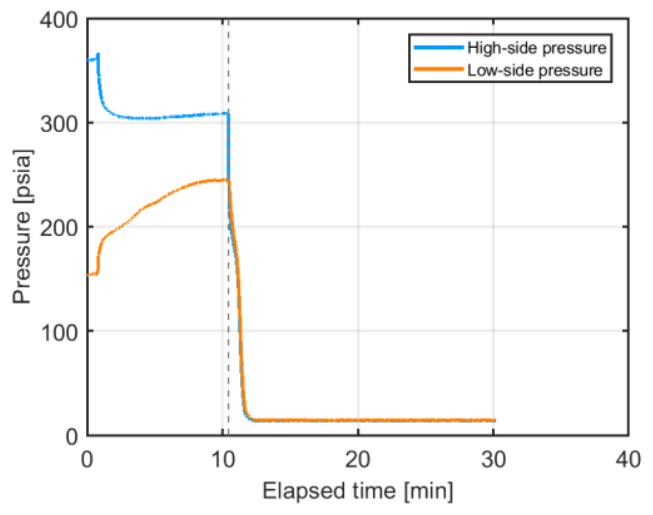

(а.)

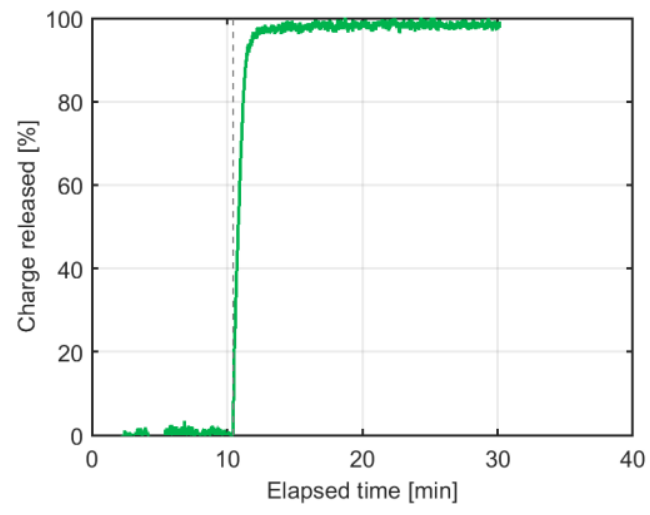

(b.)

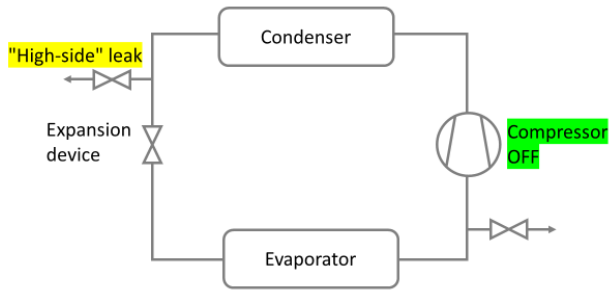

(c.)

Figure 19. (a.) High- and low-side pressure decay, (b.) percent charge released and (c.) system diagram for split AC test 112 (4.11 mm orifice) 


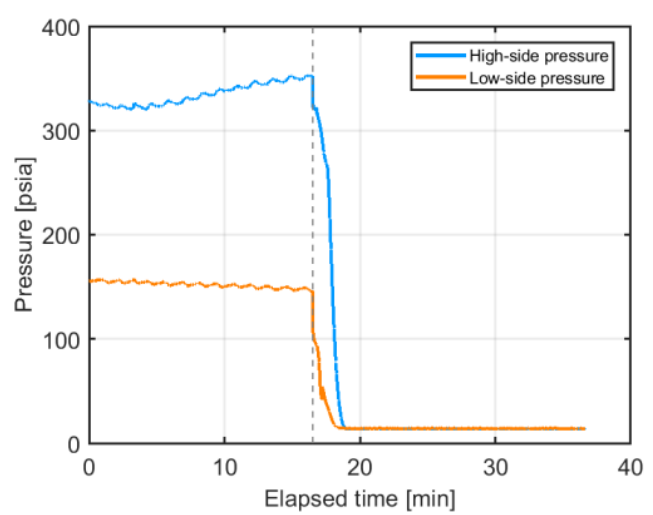

(a.)

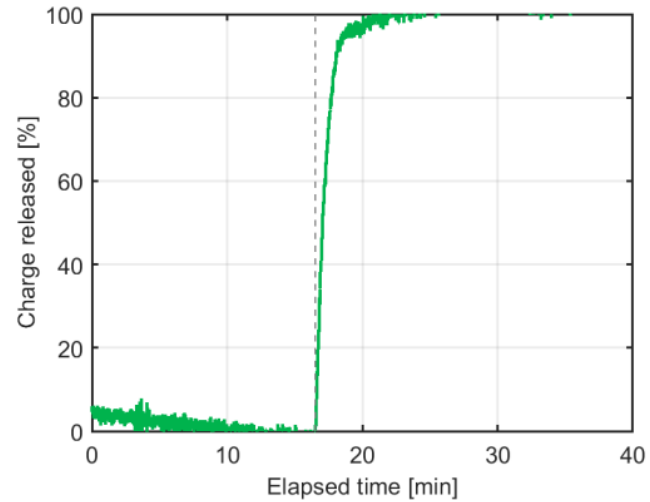

(b.)

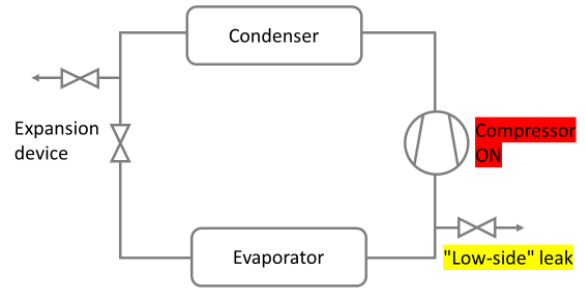

(c.)

Figure 20. (a.) High- and low-side pressure decay, (b.) percent charge released and (c.) system diagram for split AC test 113 ( $7.03 \mathrm{~mm}$ orifice)

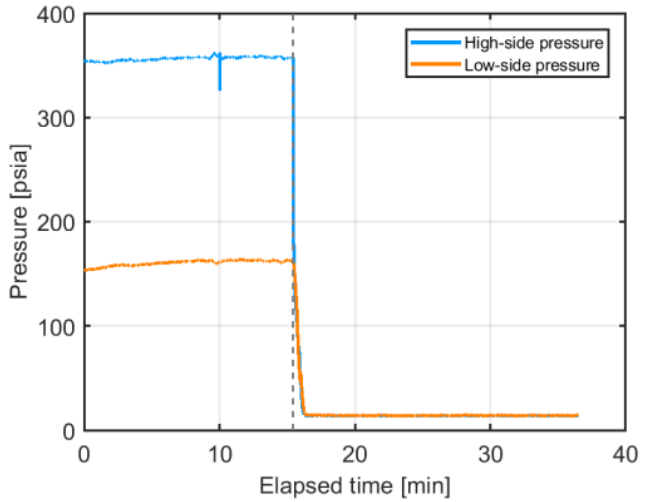

(a.)

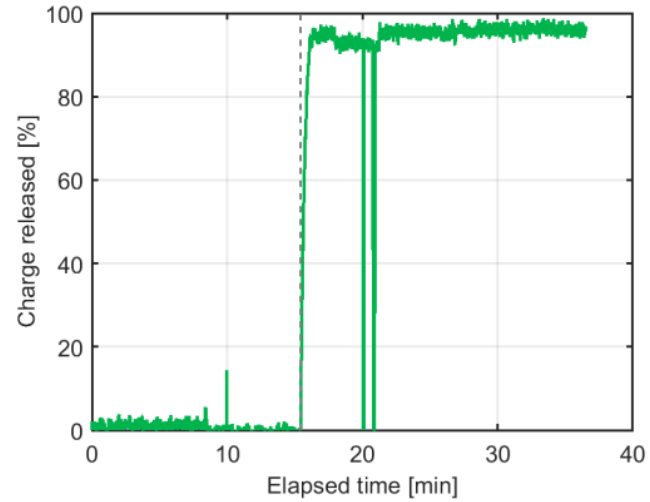

(b.)

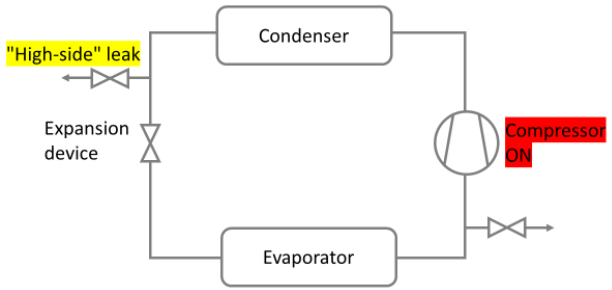

(c.)

Figure 21. (a.) High- and low-side pressure decay, (b.) percent charge released and (c.) system diagram for split AC test 114 ( $7.03 \mathrm{~mm}$ orifice) 


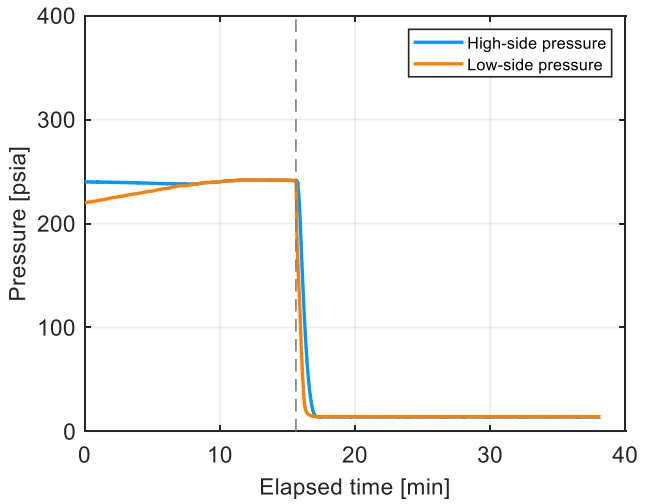

(а.)

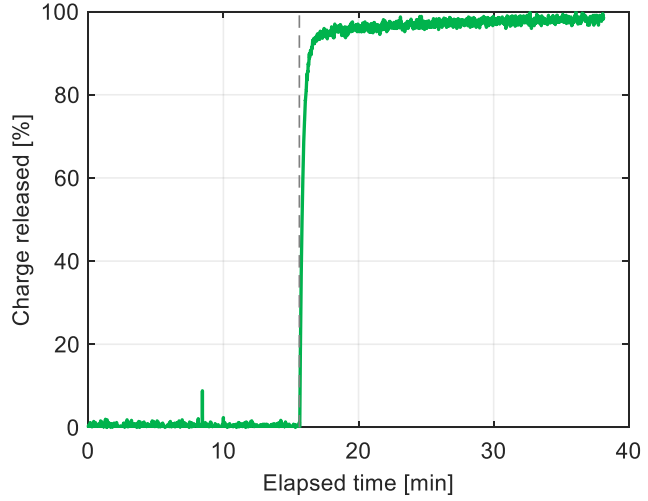

(b.)

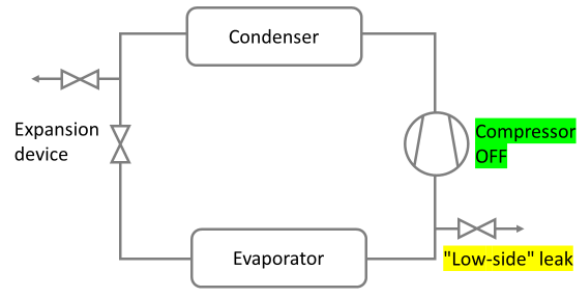

(c.)

Figure 22. (a.) High- and low-side pressure decay, (b.) percent charge released and (c.) system diagram for split AC test 115 (same as G1, 7.03 mm orifice)

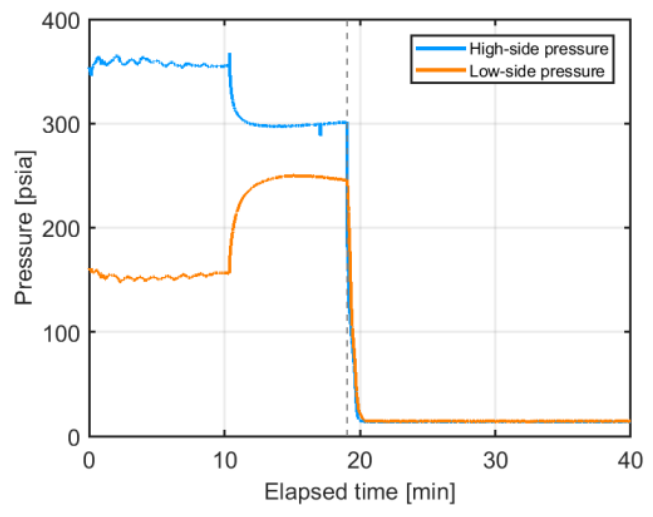

(а.)

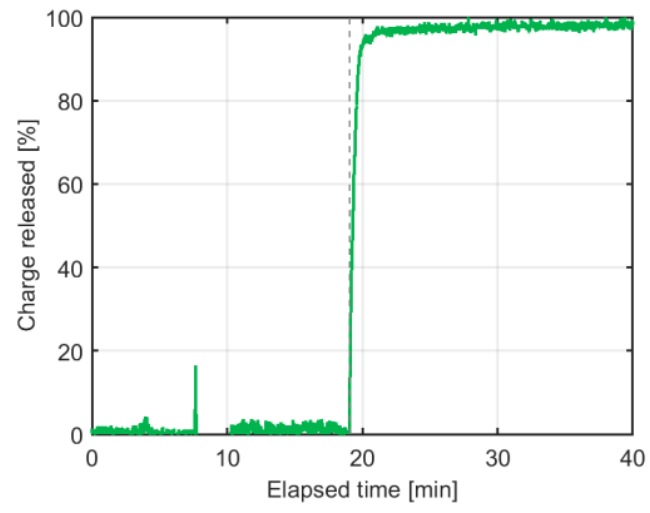

(b.)

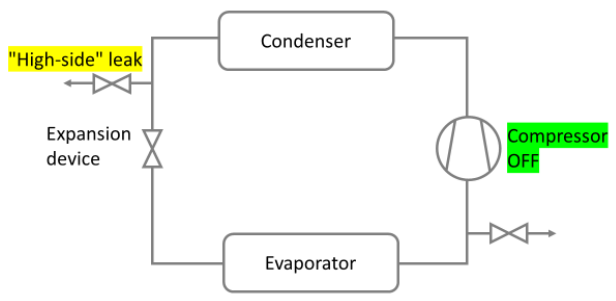

(c.)

Figure 23. (a.) High- and low-side pressure decay, (b.) percent charge released and (c.) system diagram for split AC test 116 (7.03 mm orifice) 
During a review of the split AC results with the PMS, they noted that for the low leak rate tests (tests 109112) the leak release times were not very much longer than those for the high leak rate cases. For the split AC tests the orifice size for cases 109-112 was about half the flow area used for the high rate cases. They requested that the low leak rate orifice area/diameter be resized for the remaining four systems so that their "low rate" charge release times would be closer to four minutes based on the system "off" and low side leak test condition. 


\subsection{PTAC TEST RESULTS}

Figure 24 is a photo of the packaged terminal air conditioner (PTAC) unit showing the two existing 1/4" OD process tubes used as the leak points. Figure 25 shows the PTAC modified to extend the process tubes through the evaporator compartment into the indoor test chamber with the leak control automatic ball valve and leak point selection manual ball valves installed. Essentially the same leak control system as used for the split AC was used with the PTAC, but with a smaller diameter tube.

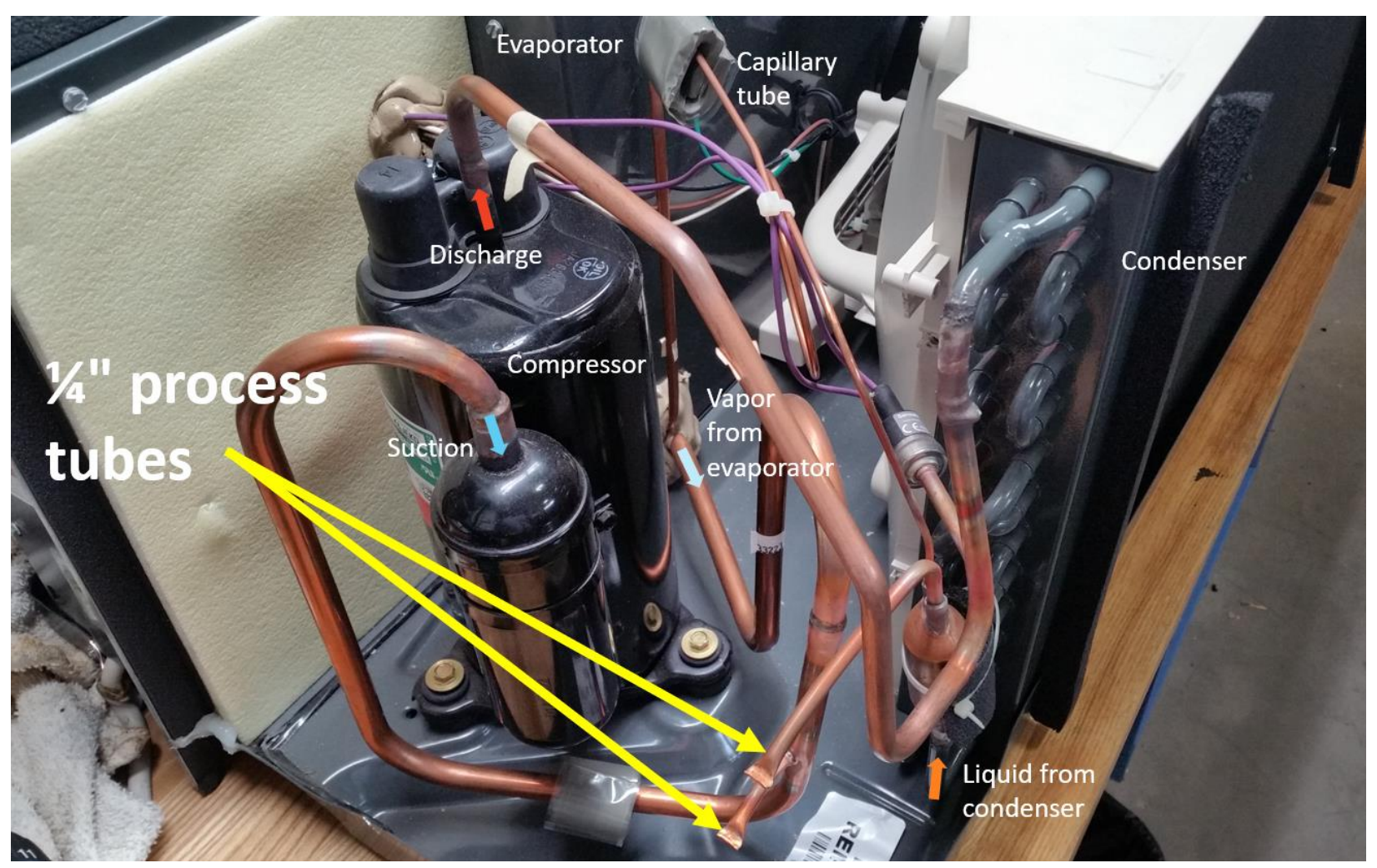

Figure 24. PTAC test unit showing process tubes used as leak sources 


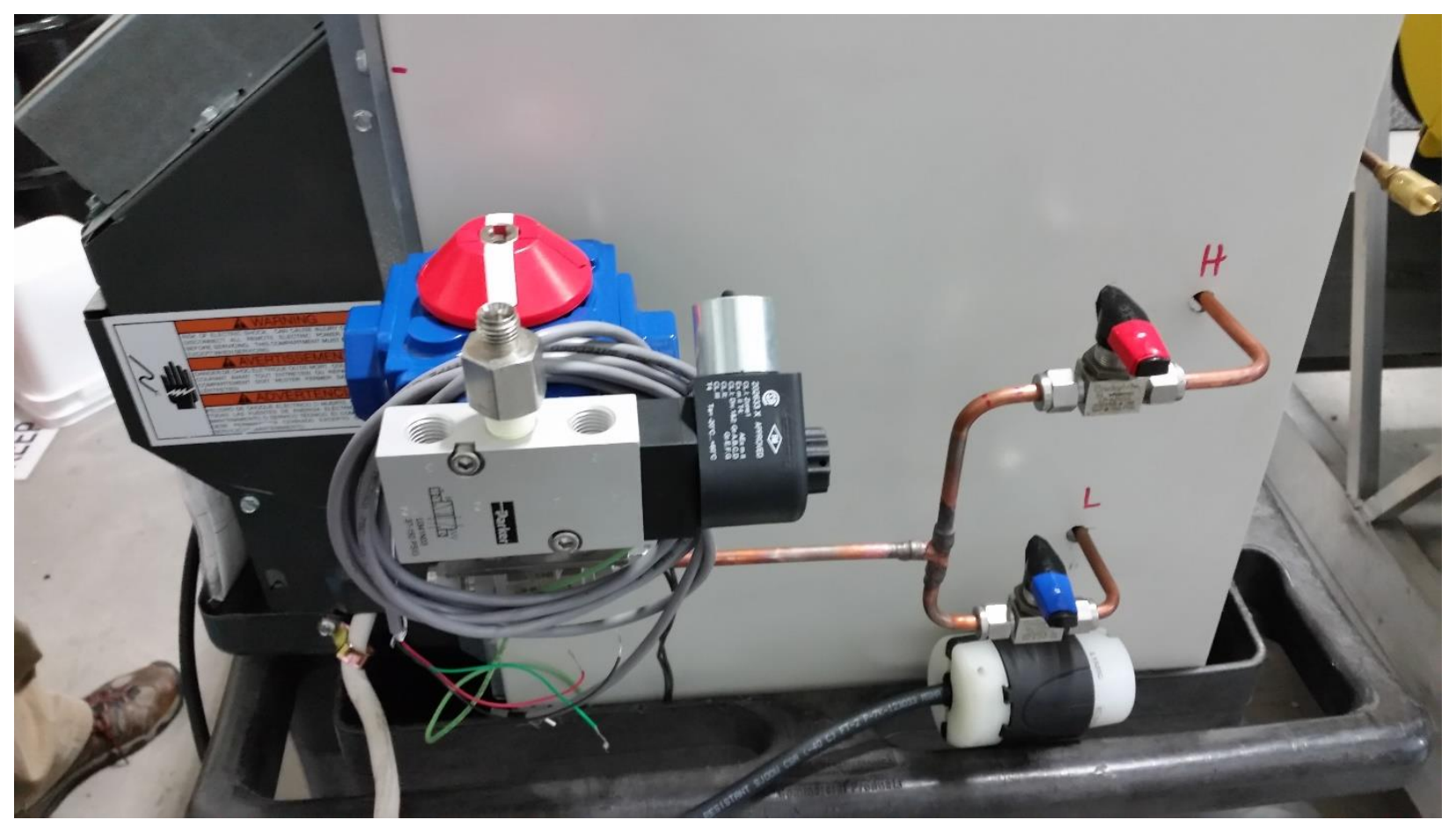

Figure 25. PTAC with leak control system installed

For the low leak rate PTAC tests (tests 101-104) a leak orifice diameter of 0.041" (1.04 mm) based on 4minute charge release period was selected. This orifice size resulted in a leak time of $\sim 250$ s to release $100 \%$ of the PTAC charge for test no. 103 (compressor off, low side leak, evaporator exit location). Figure 26 is a close-up photo of the leak release point with cap installed and 0.041 " hole drilled into the cap. 


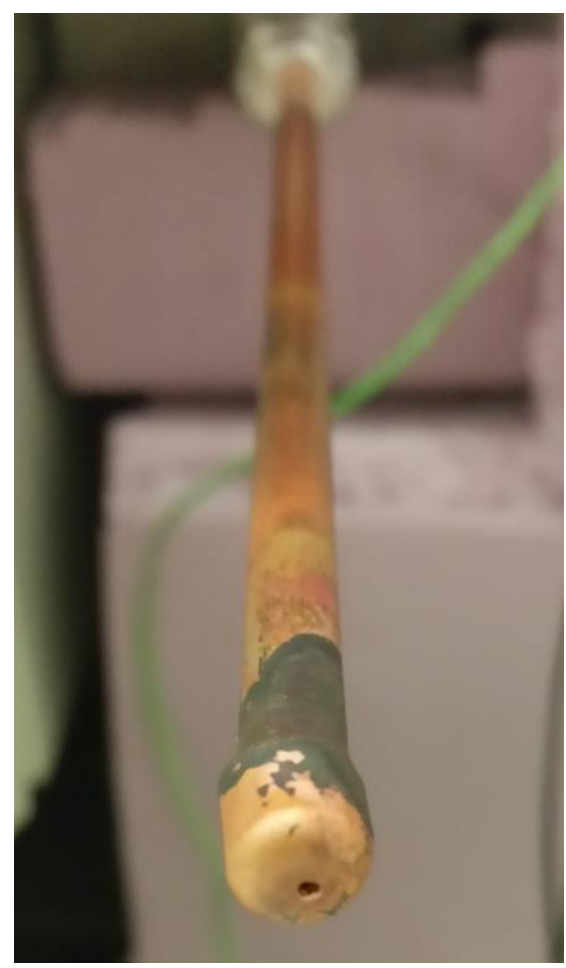

Figure 26. PTAC leak release point with cap and $0.041 "(1.04 \mathrm{~mm})$ orifice for low leak rate tests

Table 6 and Figure 27 provide results of a comparison between the measured leak mass flux and that calculated using the classical choked mass flux formula in Eq. (1) below [20] that is proposed in the new version of IEC standard 60335-2-89 [12].

$$
\dot{m}_{f}=0.06 \times c_{d} \sqrt{k \rho_{v}\left(p_{v}-p_{a t m}\right)\left(\frac{2}{k+1}\right)^{\frac{k+1}{k-1}}}
$$

where:

$\dot{m}_{f}$ is the mass flux in $\mathrm{g} / \mathrm{min} / \mathrm{mm}^{2}$, $c_{d}$ is the discharge coefficient (set to 0.61 ),

$k$ is the ratio of specific heats of refrigerant vapor at the measured pressure at the leak point, $\rho_{v}$ is the refrigerant vapor density in $\mathrm{kg} / \mathrm{m}^{3}$ at the measured pressure at the leak point, $p_{v}$ is the refrigerant vapor pressure in Pa measured at the leak point, and $p_{a t m}$ is the atmospheric pressure measured at the ORNL test site, 98,801.9 Pa.

Note that equation 1 is for single-phase vapor flow only. Further $k, \rho_{o}$ and $p_{o}$ are calculated at the specific percentage leak points in Table 6. A 5 s averaging time was used for all points except the $95 \%$ point; a 10s averaging time was used due to the very slow leak rate. The properties $k, \rho_{o}$, and saturated vapor sonic velocity are interpolated from the R-410A data table on page 30.31 of the 2017 ASHRAE Handbook of Fundamentals [21].

Mass flux at the beginning of the leak was also calculated assuming pure liquid flow using Eq. (2) below [22]. 


$$
\dot{m}_{f}=c_{d} \sqrt{2 \rho_{l}\left(p_{l}-p_{a t m}\right)}
$$

where:

$\dot{m}_{f}$ is the mass flux in $\mathrm{g} / \mathrm{min} / \mathrm{mm}^{2}$,

$c_{d}$ is the discharge coefficient,

$\rho_{l}$ is the refrigerant liquid density in $\mathrm{kg} / \mathrm{m}^{3}$ at the measured conditions at the leak point,

$p_{l}$ is the refrigerant liquid pressure in Pa measured at the leak point, and

$p_{a t m}$ is the atmospheric pressure measured at the ORNL test site, 98,801.9 Pa.

For $c_{d}$ ranging from 0.85 to 1 , the computed liquid mass flux ranges from $\sim 930$ to $1094 \mathrm{~g} / \mathrm{min} / \mathrm{mm}^{2}$ (only the value for $c_{d}$ of 1 is plotted in Figure 27). The measured mass flux at the beginning of the leak, based on a rough "eyeballed" curve fit of the data, appears to be $\sim 900 \mathrm{~g} / \mathrm{min} / \mathrm{mm}^{2}$ suggesting that the initial leak flow was nearly all liquid (quality of 0 ).

Table 6. PTAC test 103 leak flux; measured vs. calculated vapor mass flux from Eq. (1)

\begin{tabular}{|c|c|c|c|c|c|c|}
\hline $\begin{array}{c}\text { Leak } \\
\text { release } \\
\%\end{array}$ & $\begin{array}{c}\text { Leak } \\
\text { release } \\
\text { elapsed } \\
\text { time, s }\end{array}$ & $\begin{array}{c}\text { Mass flux } \\
\text { calculated } \\
\text { from test } \\
\text { data, } \\
\text { g/min/mm }\end{array}$ & $\begin{array}{c}\text { Mass flux } \\
\text { calculated } \\
\text { from Eq. } \\
1, \\
\mathrm{~g} / \mathrm{min} / \mathrm{mm}^{2}\end{array}$ & $\begin{array}{c}\text { System } \\
\text { pressure } \\
\text { just } \\
\text { upstream } \\
\text { of leak } \\
\text { point, } \mathrm{kPa}\end{array}$ & $\begin{array}{c}\text { Leak } \\
\text { velocity } \\
\text { calculated } \\
\text { from test } \\
\text { data, } / \mathrm{s}\end{array}$ & $\begin{array}{c}\text { Sat. vapor } \\
\text { sonic } \\
\text { velocity, } \\
\mathrm{m} / \mathrm{s}\end{array}$ \\
\hline $0 \%$ & 0.0 & 260.53 & 1634.27 & & 162.06 \\
\hline $5 \%$ & 5.9 & 706.53 & 248.90 & 1573.00 & 188.87 & 162.68 \\
\hline $15 \%$ & 14.4 & 776.99 & 244.28 & 1547.94 & 211.30 & 162.93 \\
\hline $25 \%$ & 23.5 & 635.78 & 238.03 & 1513.42 & 177.04 & 163.28 \\
\hline $35 \%$ & 33.8 & 635.49 & 232.95 & 1486.85 & 180.69 & 163.54 \\
\hline $45 \%$ & 46.3 & 441.46 & 222.52 & 1430.10 & 131.06 & 164.10 \\
\hline $50 \%$ & 54.6 & 353.23 & 219.98 & 1415.90 & 105.98 & 164.23 \\
\hline $55 \%$ & 62.7 & 423.89 & 217.13 & 1399.79 & 128.68 & 164.39 \\
\hline $65 \%$ & 83.6 & 353.28 & 206.45 & 1342.45 & 112.66 & 164.95 \\
\hline $75 \%$ & 108.2 & 282.38 & 174.86 & 1158.58 & 104.85 & 166.70 \\
\hline $85 \%$ & 140.2 & 211.81 & 116.12 & 804.86 & 114.59 & 173.40 \\
\hline $95 \%$ & 199.7 & 144.79 & 92.30 & 655.05 & 96.24 & 171.05 \\
\hline $100 \%$ & 253.1 & - & - & 132.59 & - & 162.06 \\
\hline
\end{tabular}




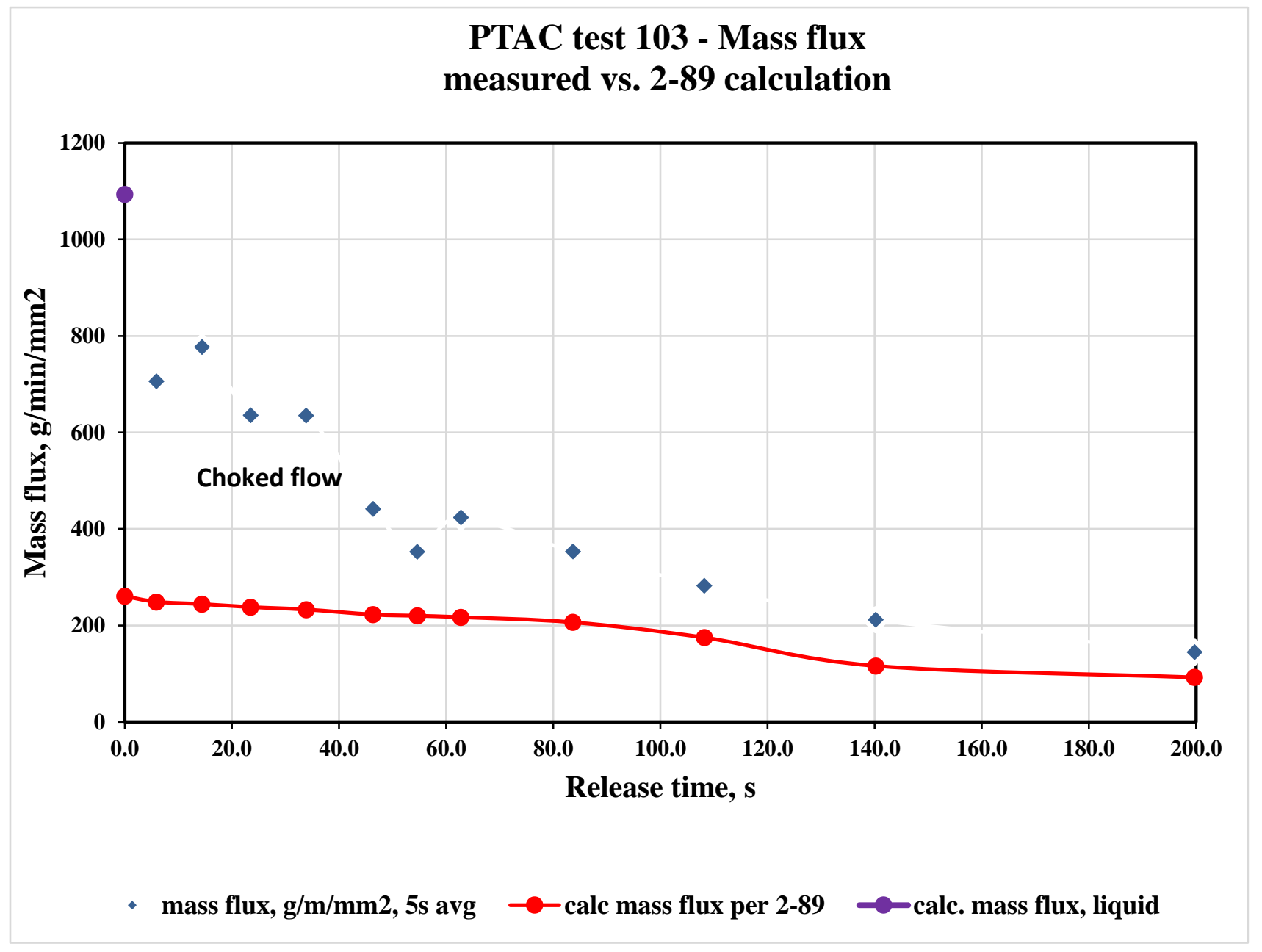

Figure 27. PTAC test 103 leak back pressure and mass flux (measured and calculated with Eqs. (1) \& (2)) vs. leak time

The calculated mass flux from the test data is about three times higher than that calculated with Eq. (1) for the first $\sim 40$ s of the leak release. For the remainder of the leak time the match is closer but measured values still exceed calculated by $\sim 1.5-2 \mathrm{x}$. The measured flux appears to lie between the calculated values for vapor (Eq. 1) and liquid Eq. (2) at the leak initiation point and appears much closer to the calculated liquid flux suggesting a high liquid fraction. Note, though, that the calculated liquid flux assumed $a c_{d}$ of 1 . Observation of video footage indicates that the leak flow emerges with a significant mist content indicating entrainment of refrigerant liquid (and perhaps some water vapor condensed from the ambient air (vapor quality <1.0). Eq. (1) is for choked flow of single-phase gas only through an orifice. Note that the estimated actual leak velocity only exceeds the saturated vapor sonic velocity for the measured pressures for about the first 40 s of the leak.

Further plans for correlating the leak flow results involve calculating the leak flow rate (or mass flux) from all the test results assuming $100 \%$ liquid and $100 \%$ vapor flow using various equations from relevant literature sources. The measured leak flow from the tests would be used to infer a correction factor (to be correlated with pressure, temperature, remaining charge and/or other parameters from the tests). This work will be documented in a separate follow-on report or paper. 
Results of tests to determine the impact of fan thrust on the unit weight data are given in Figure 28. The ID blower thrust added about $0.13 \mathrm{lb}(0.06 \mathrm{~kg})$ to the scale output while that of the OD fan added about an additional $0.07 \mathrm{lb}(0.03 \mathrm{~kg})$ to the indicated weight. Data from the fan thrust tests were used to correct the refrigerant loss data from the leak tests.

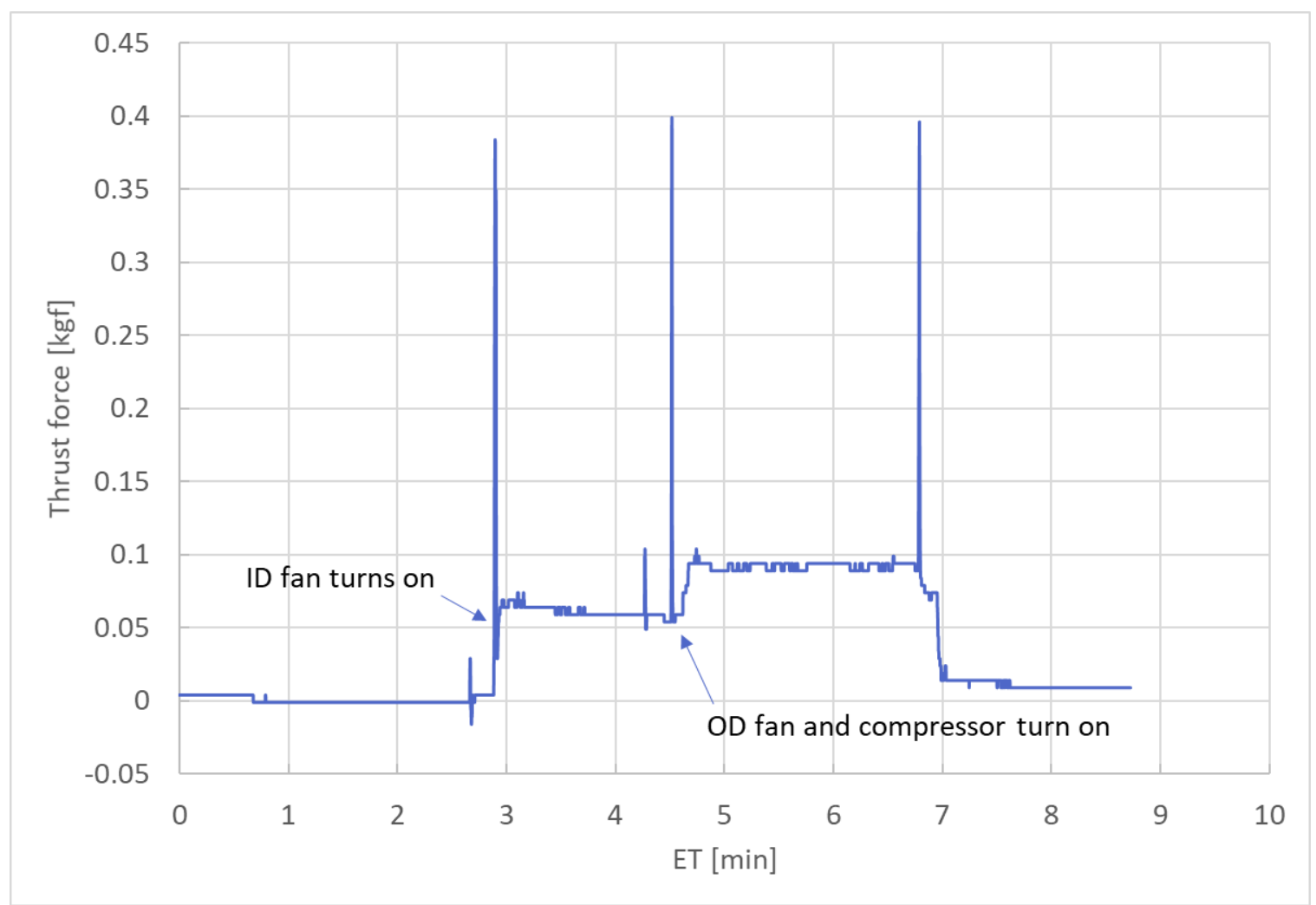

Figure 28. PTAC fan thrust effect test results

Table 7 provides a summary of the PTAC leak test results. Leak location, hole size, and compressor on/off status can be determined by referring to Figures 29-36. For six of the tests $>99 \%$ of unit charge ( $2.064 \mathrm{lb}$ ) was released within the 20-min test period. Test cases 101 and 102 (low leak rate, system on) showed $\sim 8 \%$ charge retention (low side leak) and $\sim 4 \%$ charge retention (high side leak), respectively, at test end. For test 103, compressor off and low side leak, the time required to release $80 \%$ of the total refrigerant loss was about 116 s compared to $\sim 220$ s for $99 \%$ of the total release to escape. 
Table 7. PTAC unit leak test results summary

\begin{tabular}{|c|c|c|c|c|c|c|}
\hline Test \# & $\begin{array}{c}\text { System } \\
\text { charge } \\
{[\mathrm{lb}]^{*}}\end{array}$ & $\begin{array}{c}\text { Total } \\
\text { charge } \\
\text { released } \\
{[\mathrm{lb}]}\end{array}$ & $\begin{array}{c}\text { Time to } \\
\text { release } \\
80 \% \text { of } \\
\text { total } \\
\text { charge [s] }\end{array}$ & $\begin{array}{c}\text { Average } \\
\text { leak rate } \\
\text { for 80\% } \\
\text { release } \\
{[\mathrm{lb} / \mathrm{min}]}\end{array}$ & $\begin{array}{c}\text { Charge left } \\
\text { in system } \\
{[\mathrm{lb}]}\end{array}$ & $\begin{array}{c}\text { Collector } \\
\text { pan mass } \\
\text { change [lb] }\end{array}$ \\
\hline 101 & 2.06 & 1.91 & 549.00 & 0.18 & 0.16 & -0.00 \\
\hline 102 & 2.06 & 1.97 & 74.50 & 1.33 & 0.09 & -0.00 \\
\hline 103 & 2.06 & 2.11 & 116.60 & 0.85 & -0.04 & -0.01 \\
\hline 104 & 2.06 & 2.04 & 146.10 & 0.68 & 0.02 & 0.00 \\
\hline 105 & 2.06 & 2.08 & 132.50 & 0.75 & -0.02 & 0.00 \\
\hline 106 & 2.06 & 2.06 & 15.70 & 6.31 & 0.00 & -0.01 \\
\hline 107 & 2.06 & 2.13 & 19.20 & 5.16 & -0.06 & -0.02 \\
\hline 108 & 2.06 & 2.11 & 32.80 & 3.02 & -0.04 & 0.000 \\
\hline
\end{tabular}

*Nameplate charge was $33 \mathrm{oz}$ or $\sim 2.06 \mathrm{lb}$.

Figures 29 - 36 provide graphical summaries of the normalized refrigerant loss data along with pressure decay vs. time for each test. 


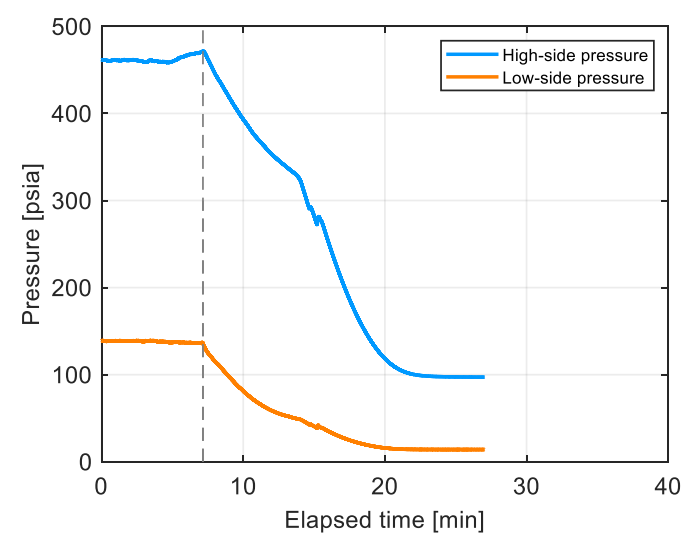

(a.)

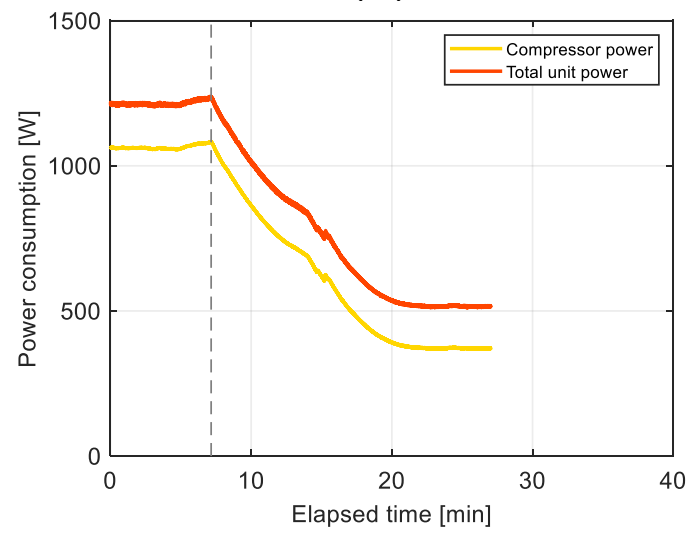

(c.)

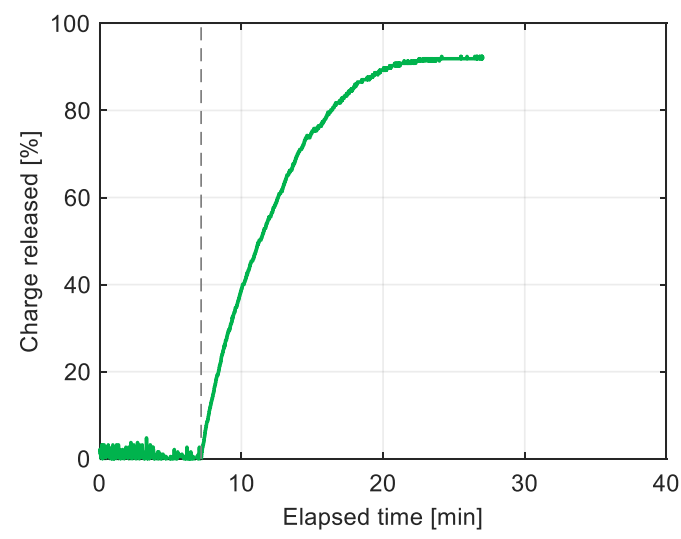

(b.)

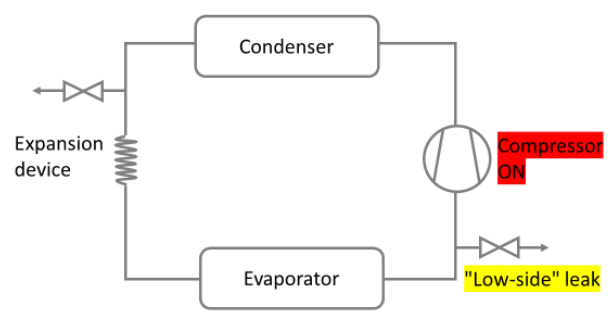

(d.)

Figure 29. (a.) High- and low-side pressure decay, (b.) percent charge released (c.) power consumption and (d.) system diagram for PTAC test 101 (1.04 mm orifice) 


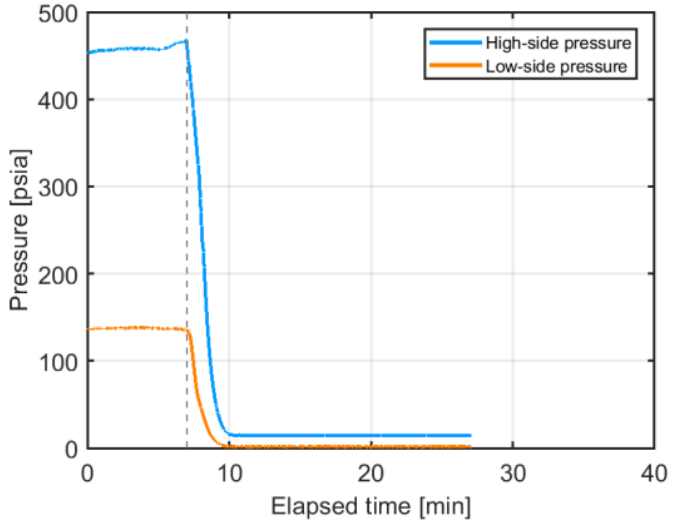

(а.)

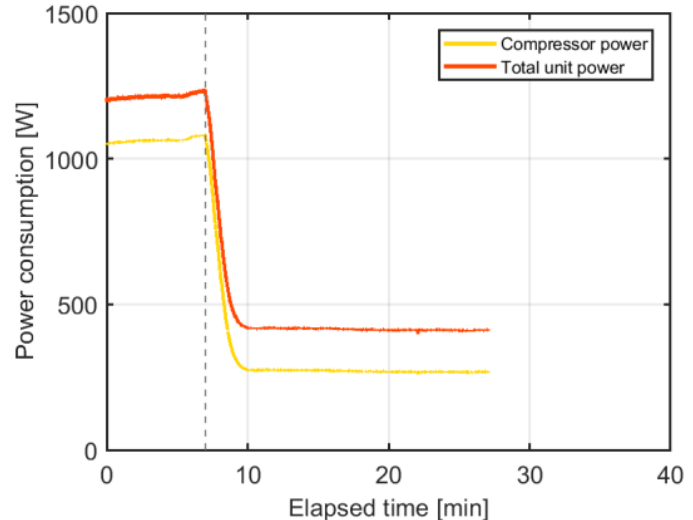

(c.)

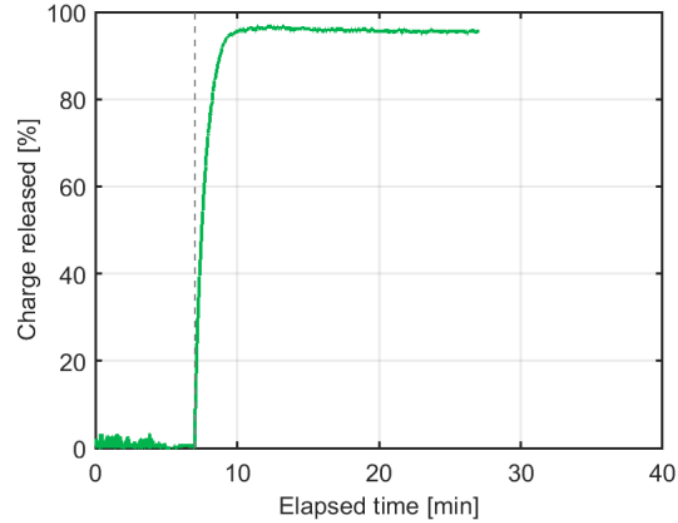

(b.)

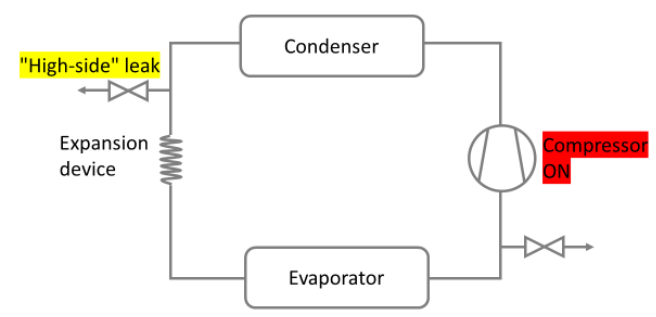

(d.)

Figure 30. (a.) High- and low-side pressure decay, (b.) percent charge released (c.) power consumption and (d.) system diagram for PTAC test 102 (1.04 mm orifice) 


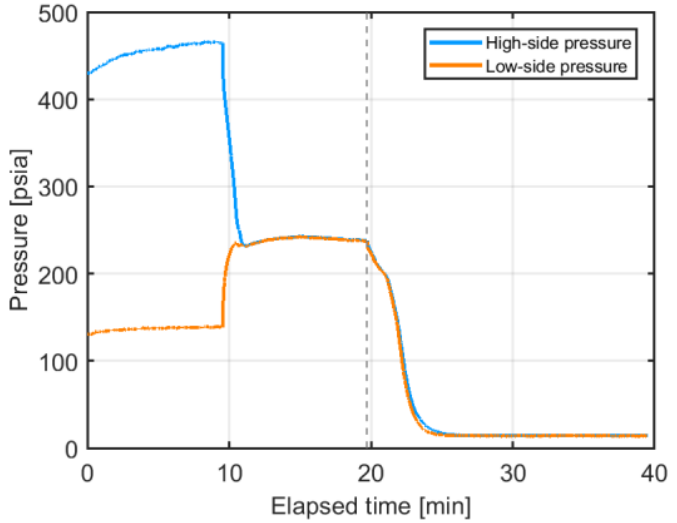

(а.)

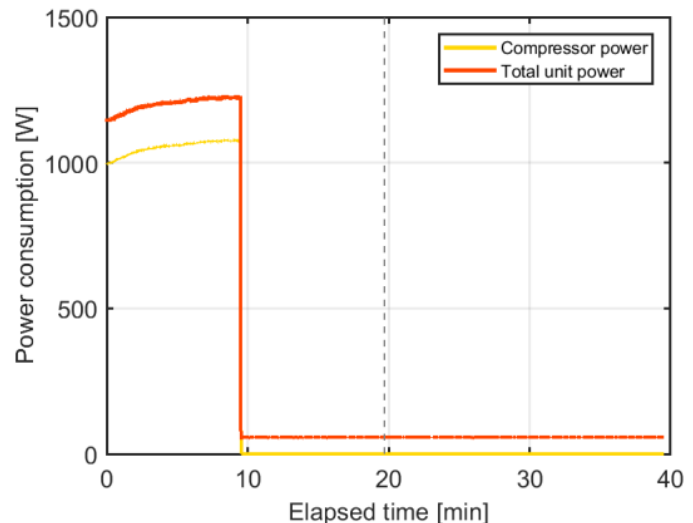

(c.)

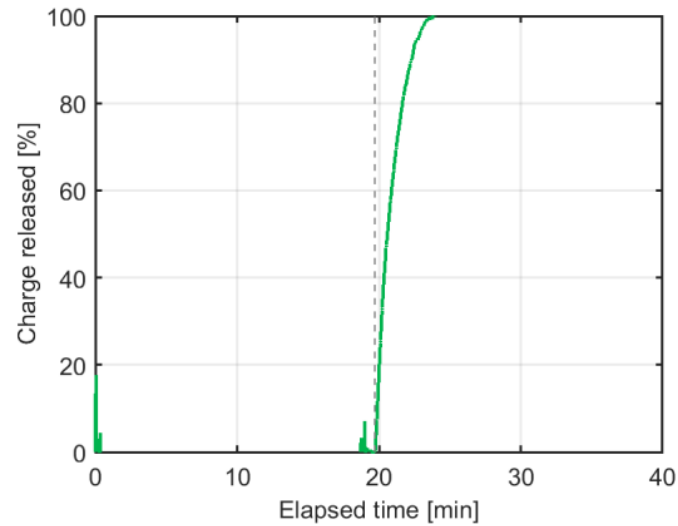

(b.)

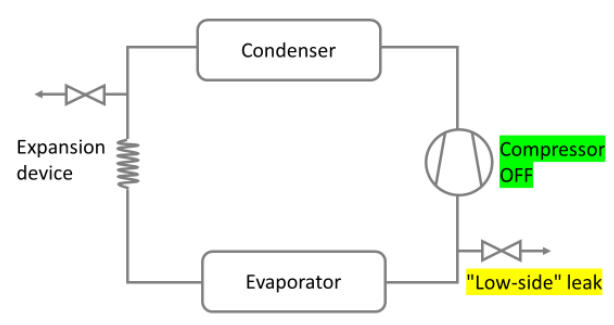

(d.)

Figure 31. (a.) High- and low-side pressure decay, (b.) percent charge released (c.) power consumption and (d.) system diagram for PTAC test 103 (1.04 mm orifice) 


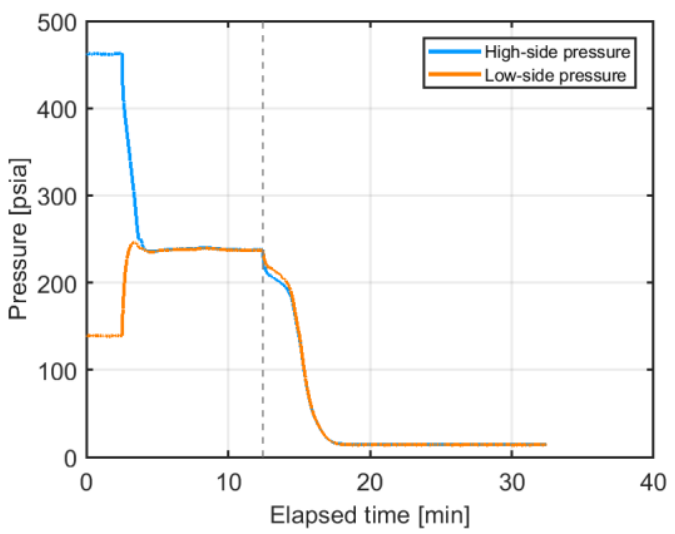

(а.)

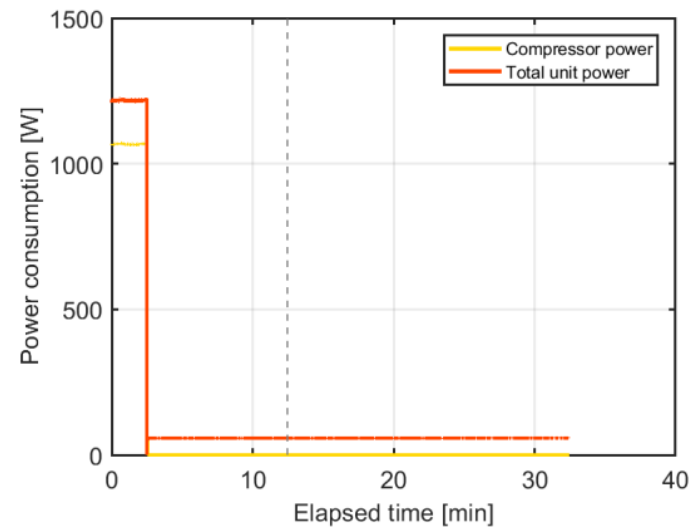

(c.)

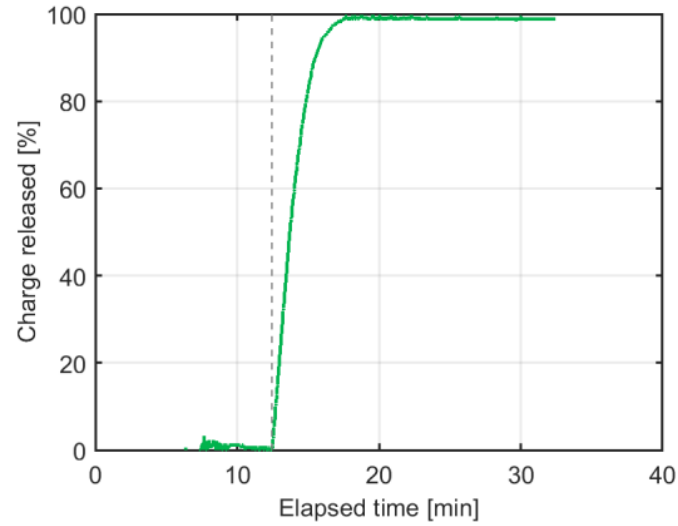

(b.)

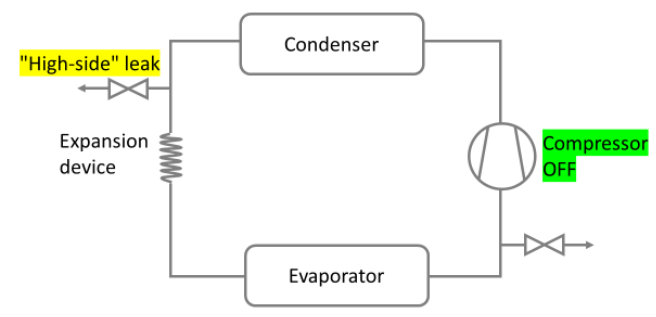

(d.)

Figure 32. (a.) High- and low-side pressure decay, (b.) percent charge released (c.) power consumption and (d.) system diagram for PTAC test 104 (1.04 mm orifice) 


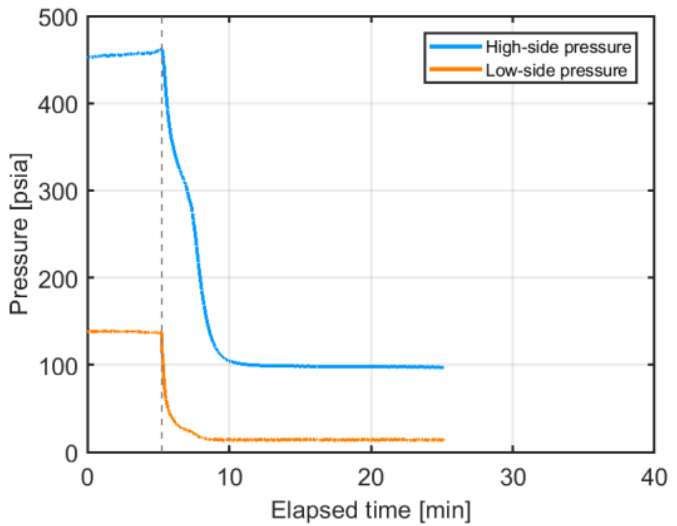

(a.)

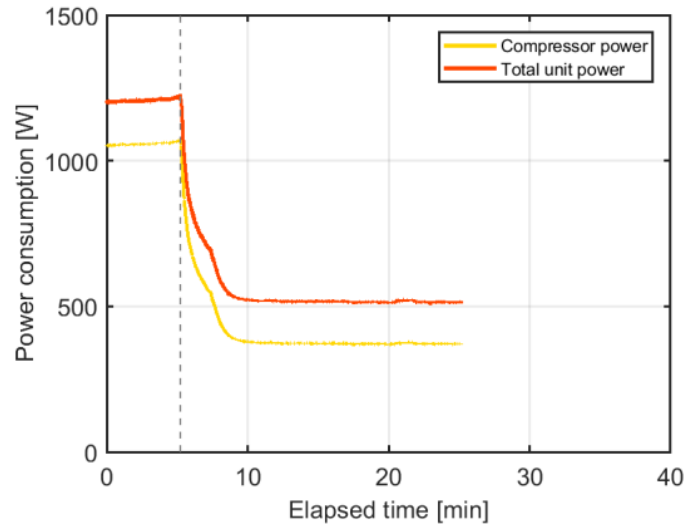

(c.)

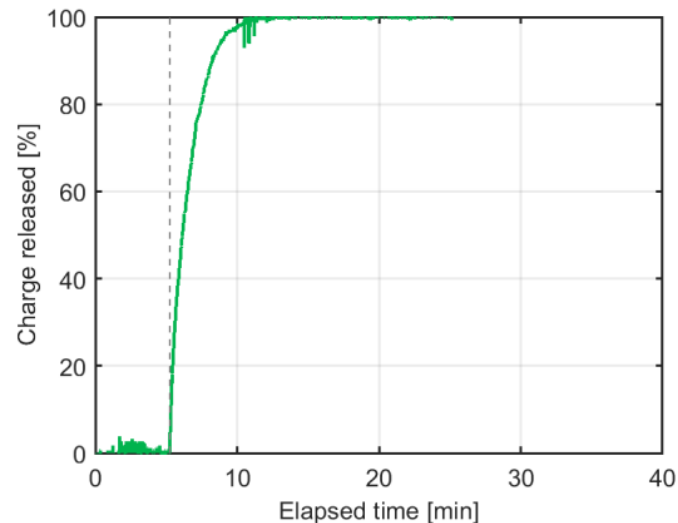

(b.)

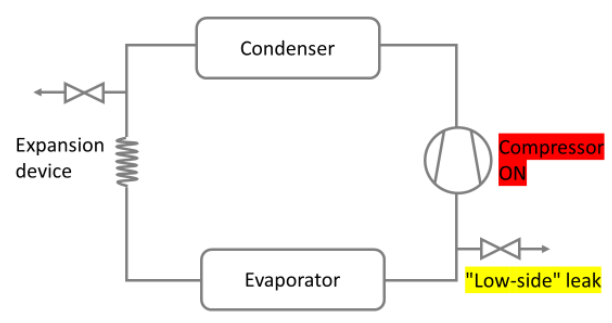

(d.)

Figure 33. (a.) High- and low-side pressure decay, (b.) percent charge released (c.) power consumption and (d.) system diagram for PTAC test 105 (4.39 $\mathrm{mm}$ orifice) 


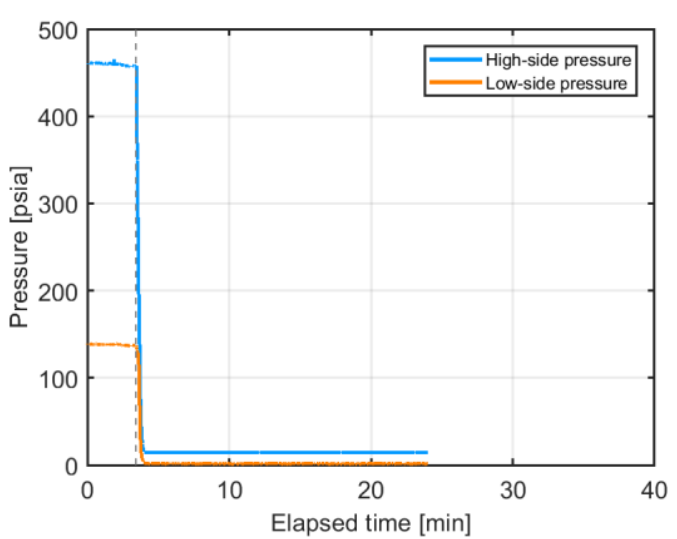

(а.)

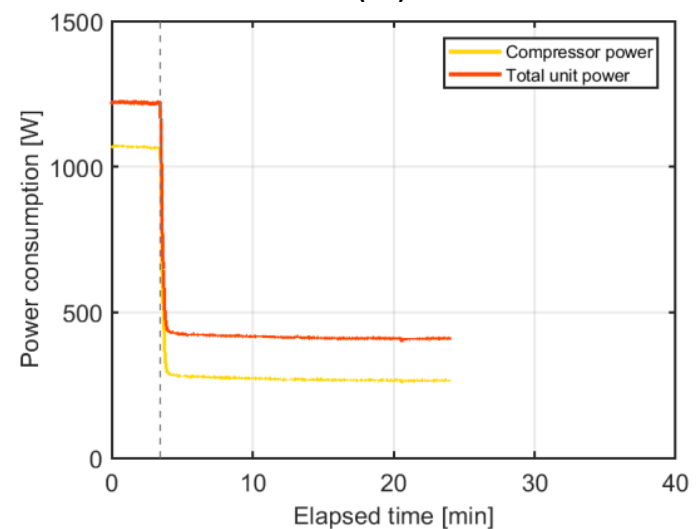

(c.)

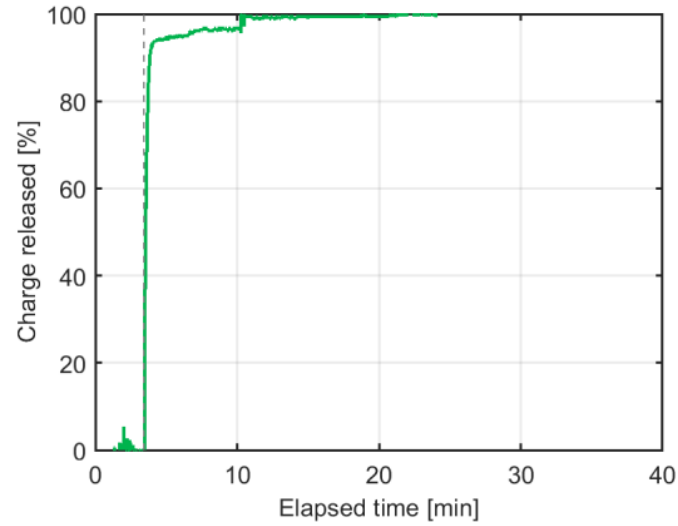

(b.)

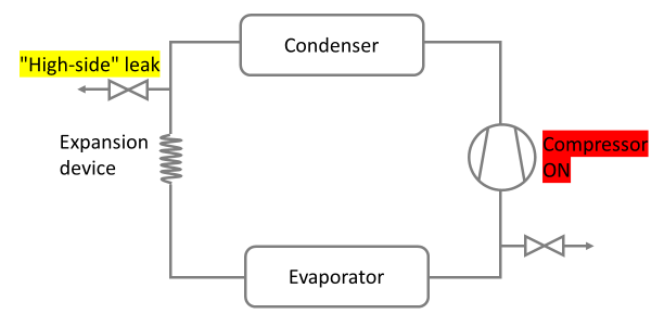

(d.)

Figure 34. (a.) High- and low-side pressure decay, (b.) percent charge released (c.) power consumption and (d.) system diagram for PTAC test $106(4.39 \mathrm{~mm}$ orifice $)$ 


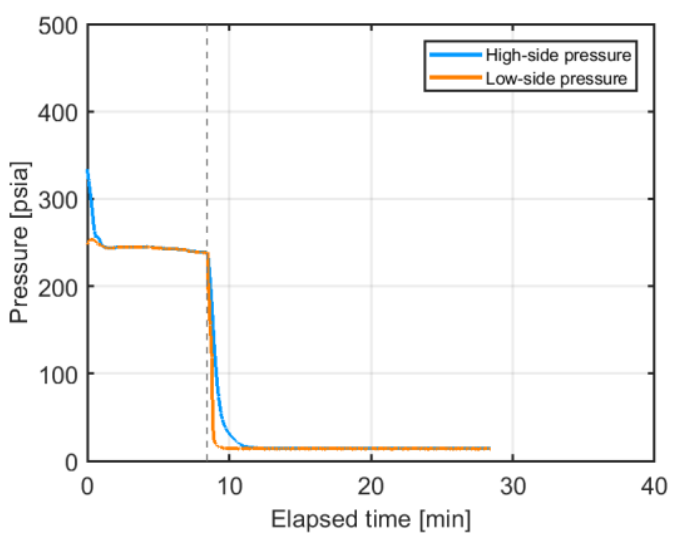

(а.)

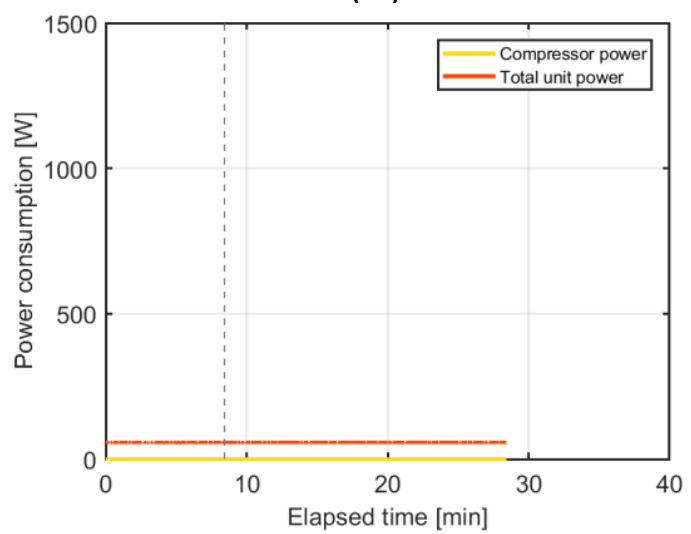

(c.)

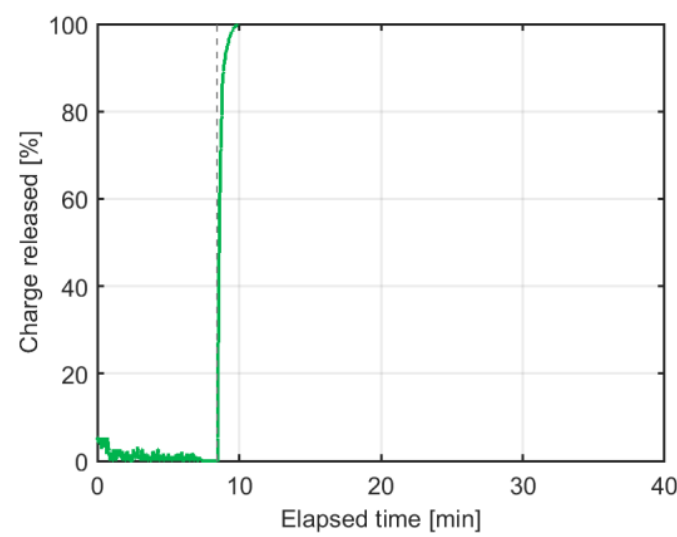

(b.)

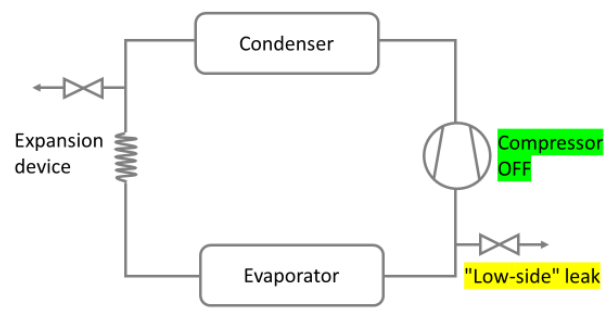

(d.)

Figure 35. (a.) High- and low-side pressure decay, (b.) percent charge released (c.) power consumption and (d.) system diagram for PTAC test 107 (4.39 mm orifice) 


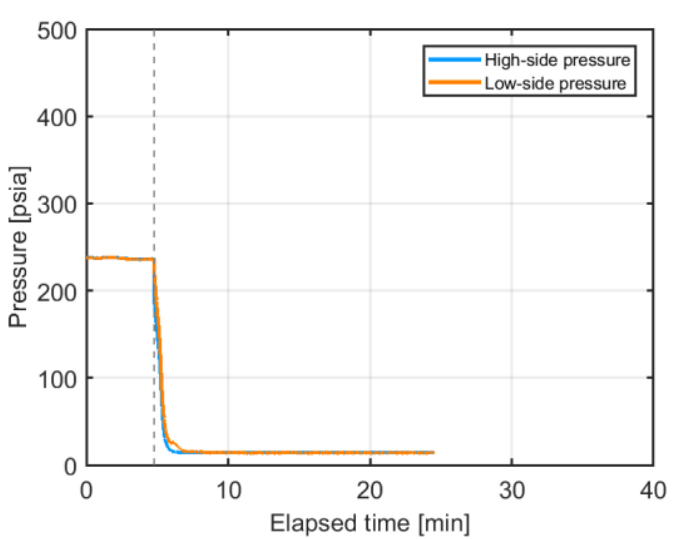

(а.)

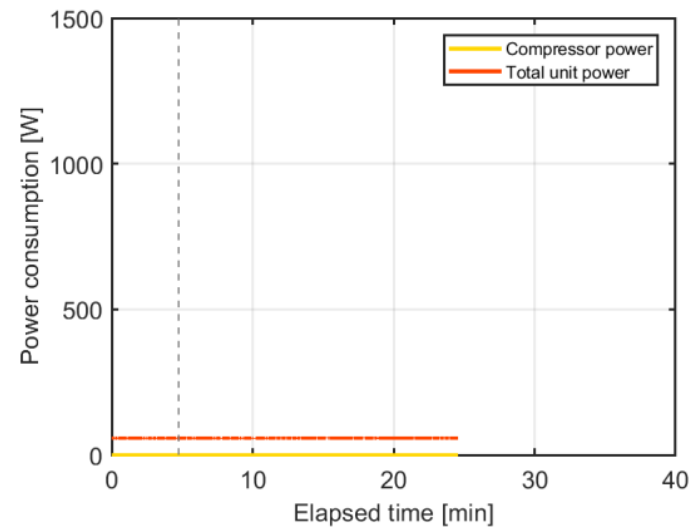

(c.)

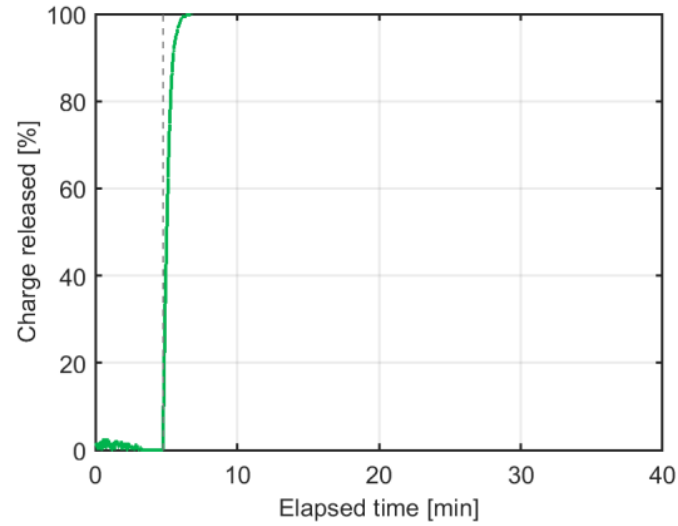

(b.)

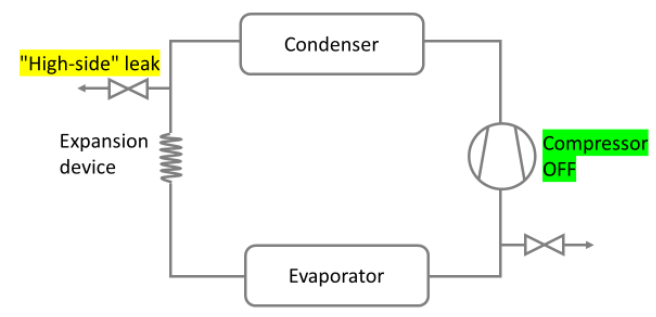

(d.)

Figure 36. (a.) High- and low-side pressure decay, (b.) percent charge released (c.) power consumption and (d.) system diagram for PTAC test 108 (4.39 mm orifice) 


\subsection{REFRIGERATED DISPLAY CASE TEST RESULTS}

After PTAC tests were complete, the standalone display case unit was installed in the test chamber. Figure 37 shows photos of the display case unit. On the left is a view of the case mounted on the weigh scale with front panel open showing the compressor and condenser. The right side of the photo shows the leak control automatic ball valve and leak point selection manual ball valves installed.
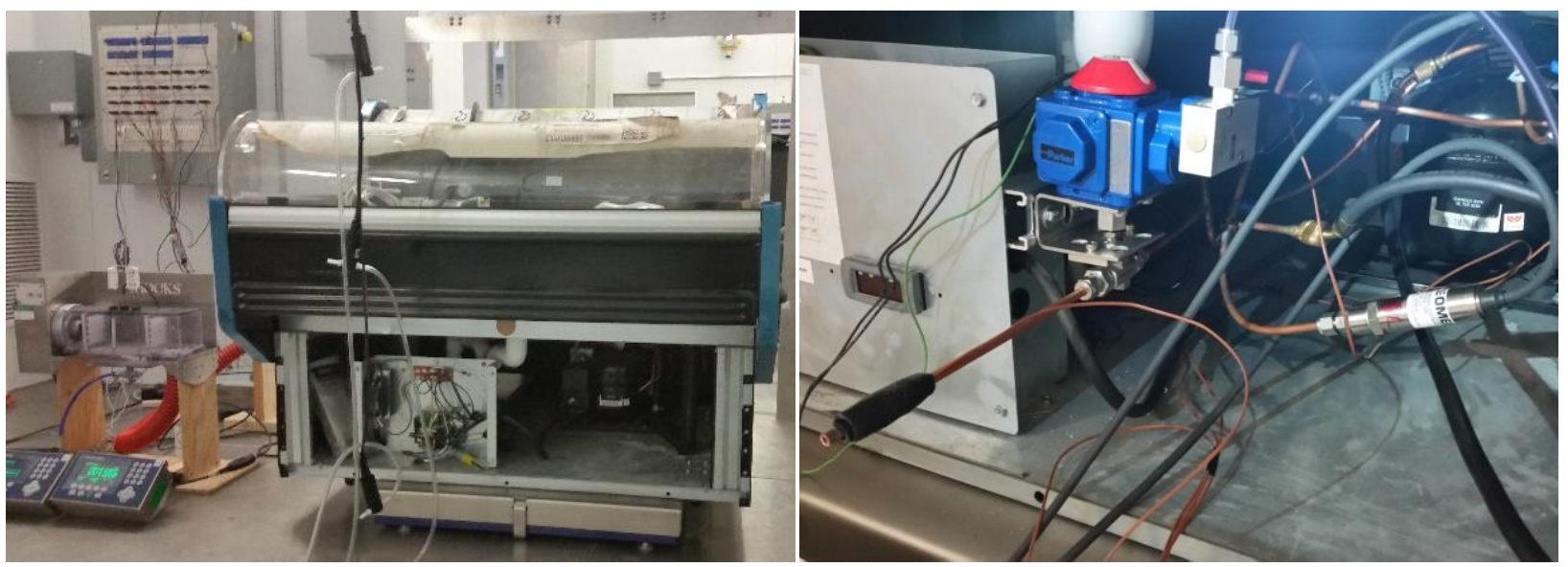

Figure 37. Display case test unit: (left) view of compressor, condenser, and control section; (right) leak control system mounted in compressor compartment

A test was run to determine the impact of fan operation on the unit weight data for the display case; results are shown in Figure 38. The mass curve indicates that the measured weight of the unit increased by $\sim 0.18-0.19 \mathrm{lb}(80-85 \mathrm{~g})$ while the compressor was on (about 18 minutes). Since the unit weight did not immediately return to the initial weight when the compressor was turned off, it is most likely that this was due to frost accumulation (rather than fan thrust) on the evaporator surfaces. Observation of the unit control panel's temperature indicator via video footage shows that the coil exit temperature dropped to $\sim 20^{\circ} \mathrm{F}$ with set point of $\left.0^{\circ} \mathrm{F}\right)$. The unit weight appears to asymptotically approach about a $0.03 \mathrm{lb}(15 \mathrm{~g})$ weight loss, perhaps due to frost sublimation, by 15 minutes after compressor shut off (note that the scale resolution is $\pm 0.01 \mathrm{lb}( \pm 5 \mathrm{~g})$. By comparison the time required to reach $80 \%$ of charge loss during the leak tests ranged from 1.5 to 6.25 minutes (Table 8). Observation of the coil exit temperature indicator from video footage during the leak events indicated that it stayed well below freezing for $90 \%+$ during each leak test. It is considered unlikely that the frost weight gain had any measurable impact on the refrigerant charge loss data. 


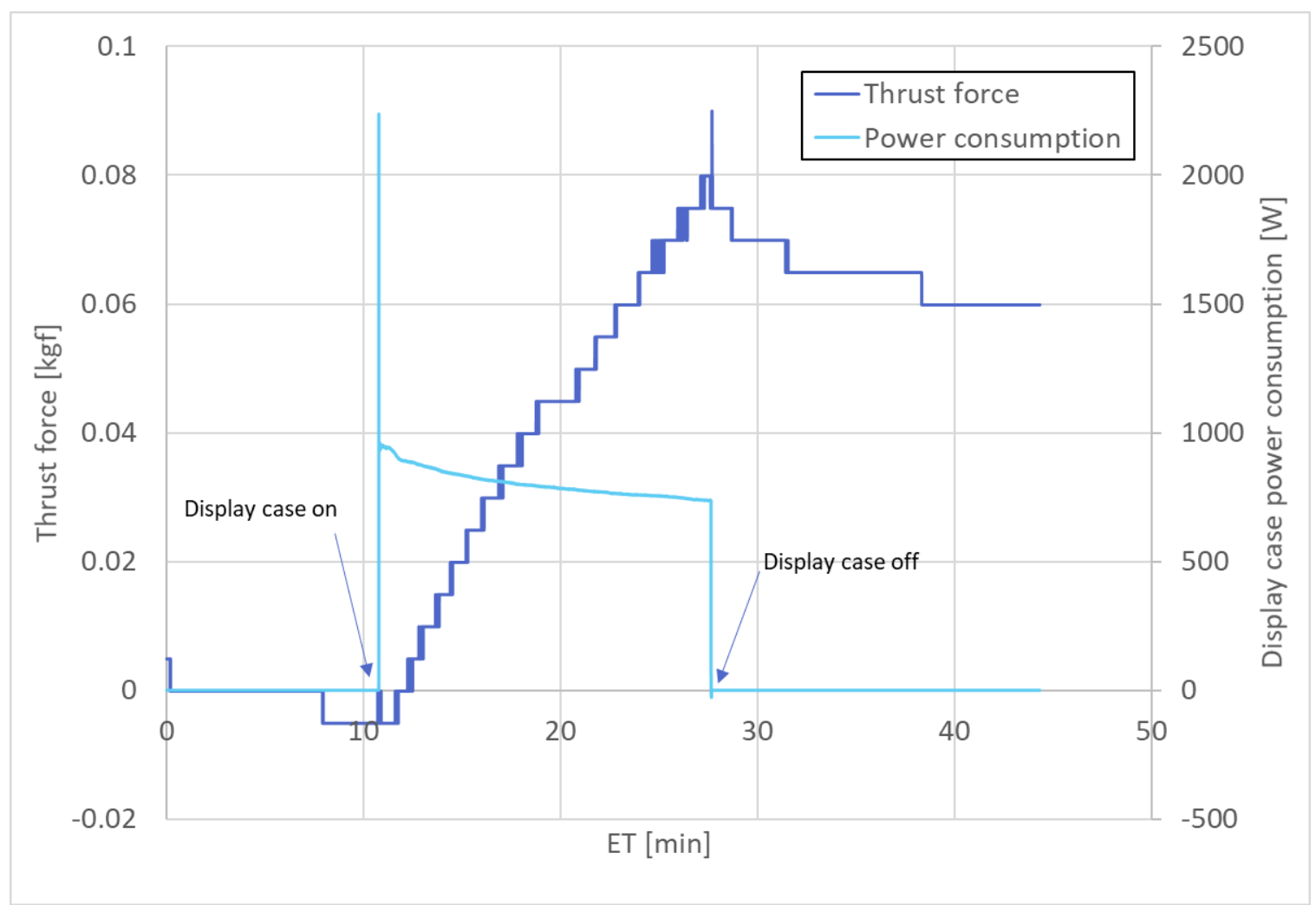

Figure 38. Display case fan operation impact test results

Table 8 provides a summary of the display case leak test results. Leak location, hole size, and compressor on/off status can be determined by referring to Figures 39-46. For the low leak rate test nos. 125-128 a 0.082 -inch $(2.03 \mathrm{~mm})$ diameter orifice was used. This size was found to give about a five-minute leak time for the total charge release ( $96 \%$ of the total unit charge) in test 127 (compressor off, low side leak). Unlike previous AC units tested, in most of the display case tests, a small amount of refrigerant was retained at test end.

- System "on" and high side leak (nos. 126 \& 130) - essentially all refrigerant was released

$\circ$ Compressor tended to push refrigerant into condenser \& out leak point

- System “off” and low side leak (nos. $127 \&$ 131) - 2-3\% refrigerant retained

$\circ$ Expansion device \& compressor impede flow of refrigerant from condenser to leak point

- All other cases - 4-5\% refrigerant retained

○ "on" \& low side leak (nos. 125 \& 129) - compressor competing with leak point for refrigerant flow

○ “off" \& high side leak (nos. 128 \& 132) - expansion device \& compressor impede refrigerant flow from evaporator to leak point

Figures 39-46 illustrate the total charge release (as \% of total charge). The unit weight scale data was set to 0 at the beginning of each leak event to normalize out weight gain due to frost accumulation. 
Table 8. Display case leak test results summary

\begin{tabular}{|c|c|c|c|c|c|c|}
\hline Test \# & $\begin{array}{c}\text { System } \\
\text { charge } \\
{[\mathrm{lb}]}\end{array}$ & $\begin{array}{c}\text { Total } \\
\text { charge } \\
\text { released } \\
{[\mathrm{lb}]}\end{array}$ & $\begin{array}{c}\text { Time to } \\
\text { release } \\
80 \% \text { of } \\
\text { total } \\
\text { charge [s] }\end{array}$ & $\begin{array}{c}\text { Average } \\
\text { leak rate } \\
\text { for } 80 \% \\
\text { release } \\
{[\mathrm{lb} / \mathrm{min}]}\end{array}$ & $\begin{array}{c}\text { Charge } \\
\text { left in } \\
\text { system } \\
{[\mathrm{lb}]}\end{array}$ & $\begin{array}{c}\text { Collector } \\
\text { pan mass } \\
\text { change } \\
{[\mathrm{lb}]}\end{array}$ \\
\hline 125 & 3.30 & 3.14 & 379.80 & 0.42 & 0.16 & -0.02 \\
\hline 126 & 3.30 & 3.33 & 111.70 & 1.42 & -0.03 & -0.01 \\
\hline 127 & 3.30 & 3.23 & 210.80 & 0.75 & 0.07 & -0.03 \\
\hline 128 & 3.30 & 3.15 & 256.40 & 0.62 & 0.15 & 0.00 \\
\hline 129 & 3.30 & 3.14 & 227.00 & 0.70 & 0.16 & -0.02 \\
\hline 130 & 3.30 & 3.31 & 96.70 & 1.64 & -0.01 & -0.00 \\
\hline 131 & 3.30 & 3.20 & 135.60 & 1.17 & 0.10 & -0.04 \\
\hline 132 & 3.30 & 3.14 & 191.10 & 0.83 & 0.16 & 0.00 \\
\hline
\end{tabular}

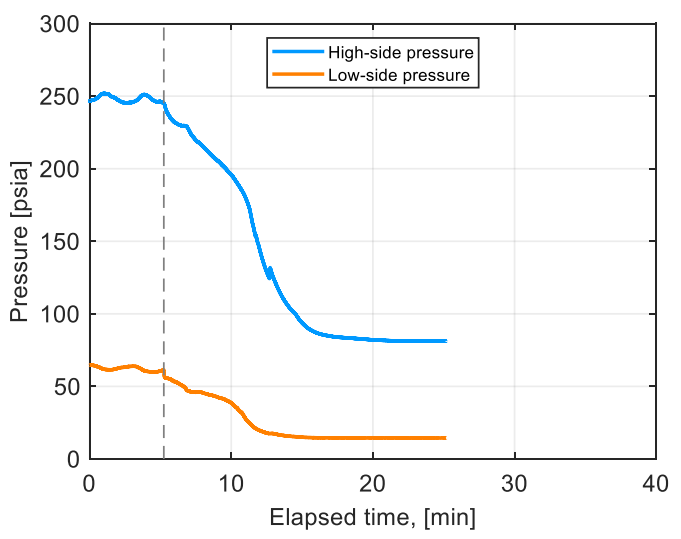

(a.)

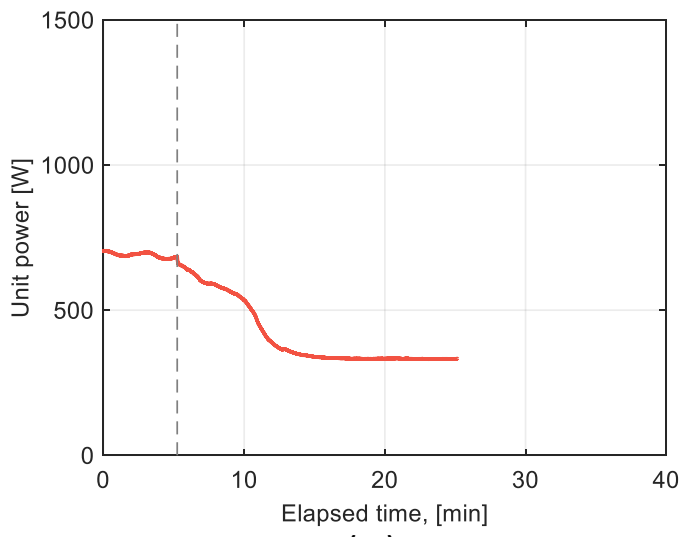

(c.)

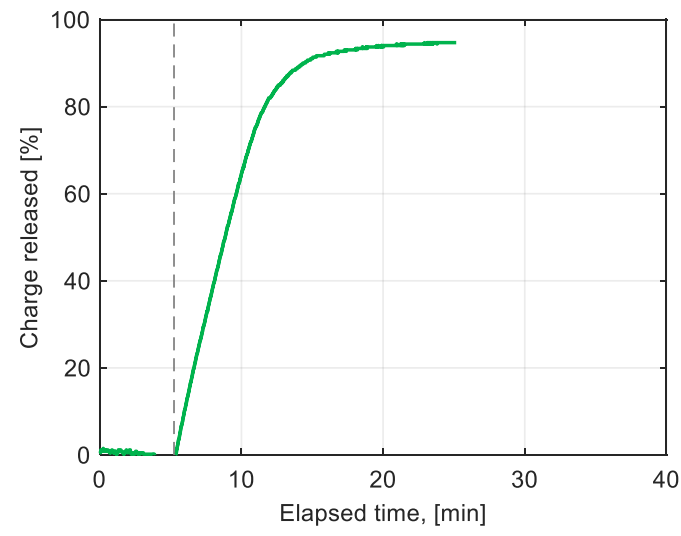

(b.)

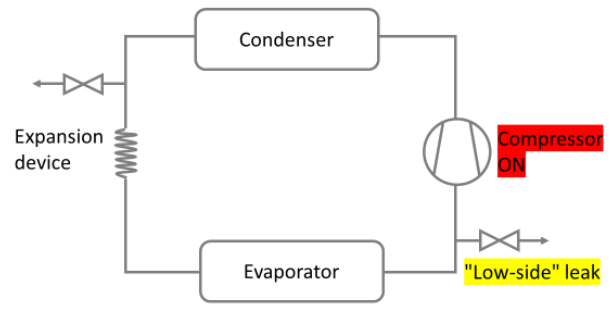

(d.)

Figure 39. (a.) High- and low-side pressure decay, (b.) percent charge released (c.) power consumption and (d.) system diagram for display case test $125(2.03 \mathrm{~mm}$ orifice) 


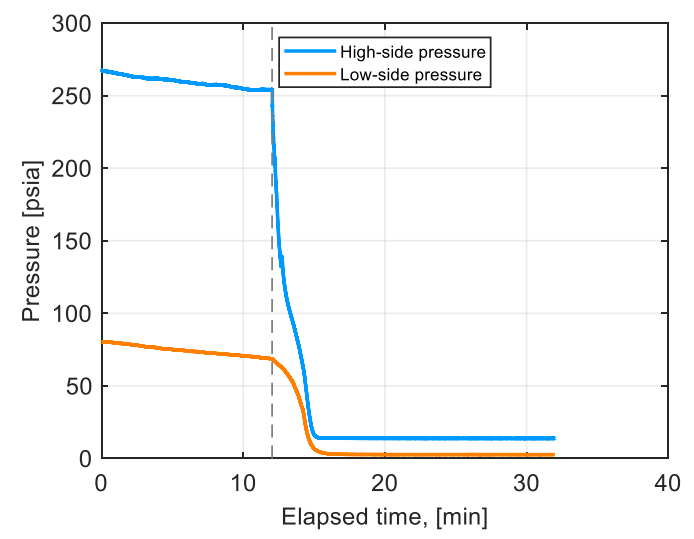

(а.)

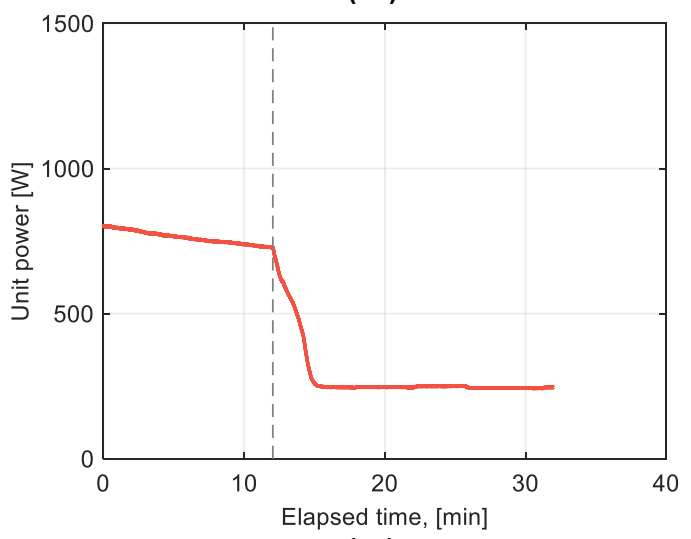

(c.)

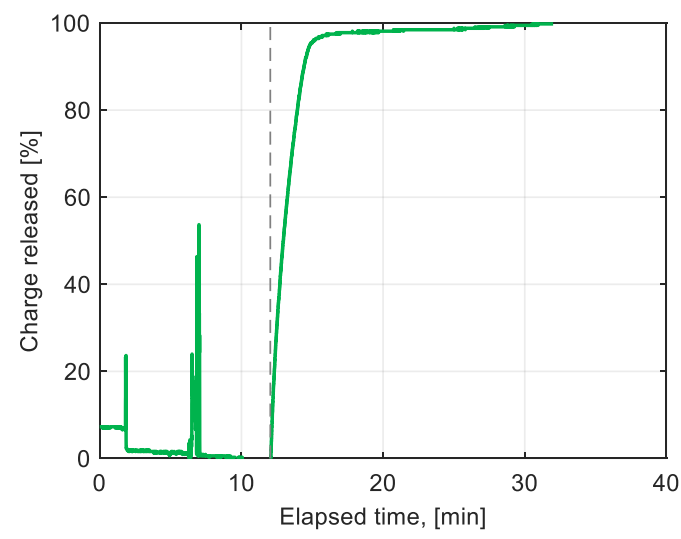

(b.)

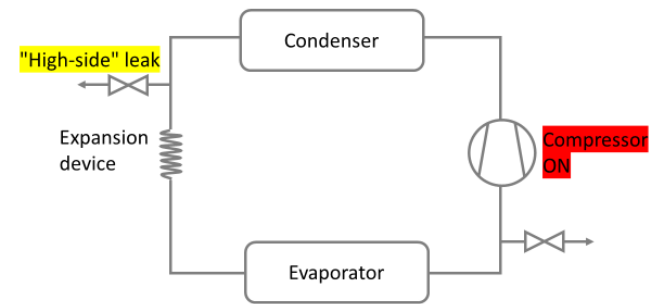

(d.)

Figure 40. (a.) High- and low-side pressure decay, (b.) percent charge released (c.) power consumption and (d.) system diagram for display case test 126 ( $2.03 \mathrm{~mm}$ orifice) 


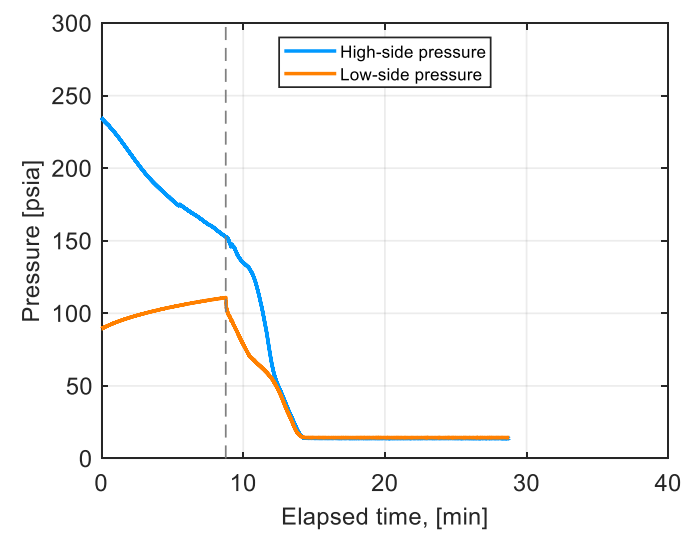

(а.)

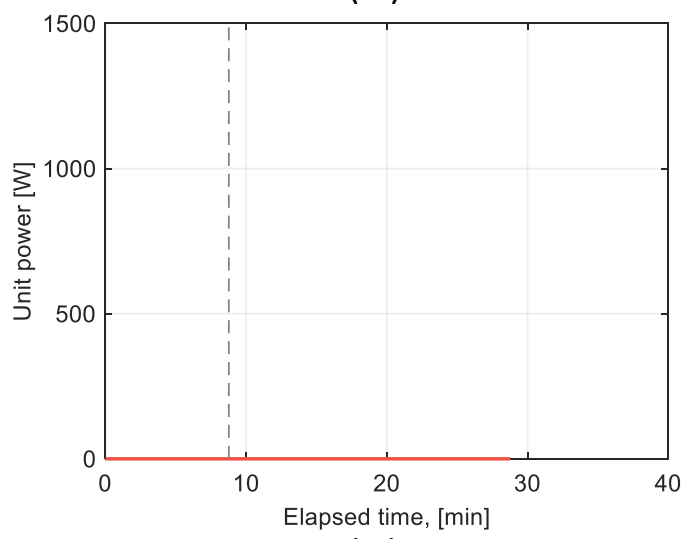

(c.)

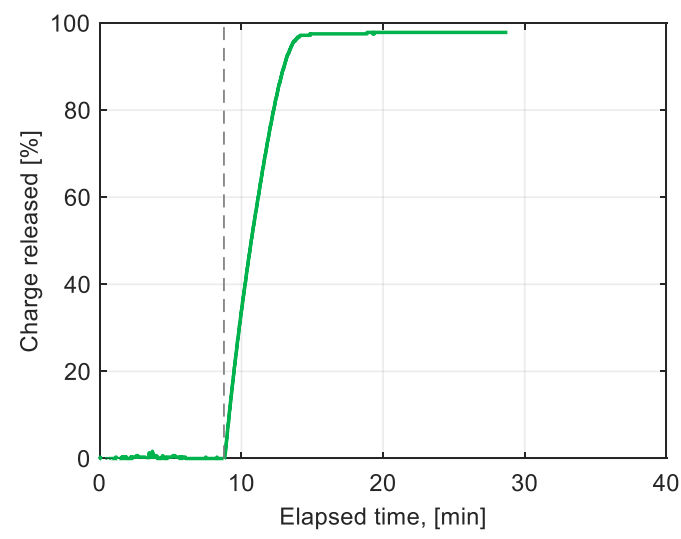

(b.)

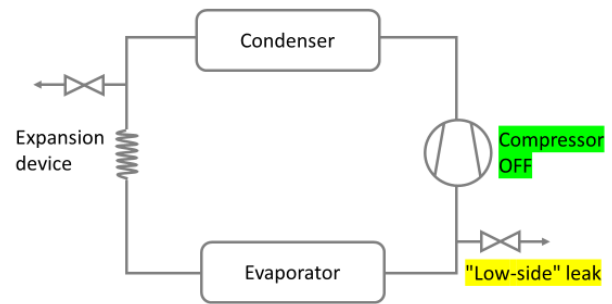

(d.)

Figure 41. (a.) High- and low-side pressure decay, (b.) percent charge released (c.) power consumption and (d.) system diagram for display case test $127(2.03 \mathrm{~mm}$ orifice $)$ 


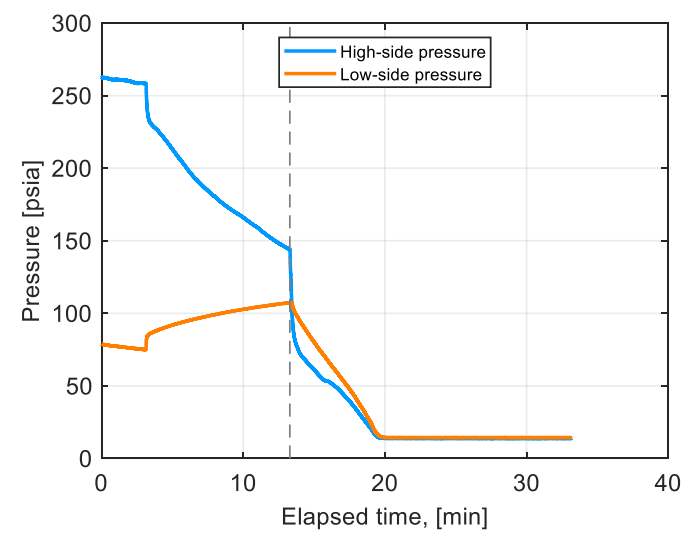

(а.)

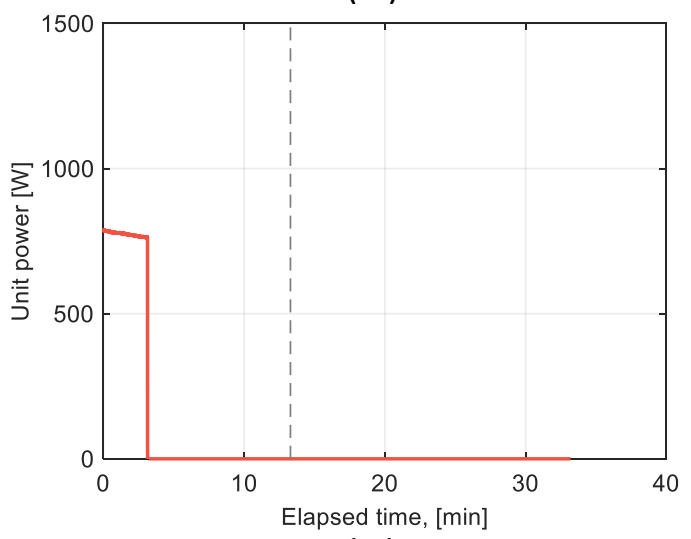

(c.)

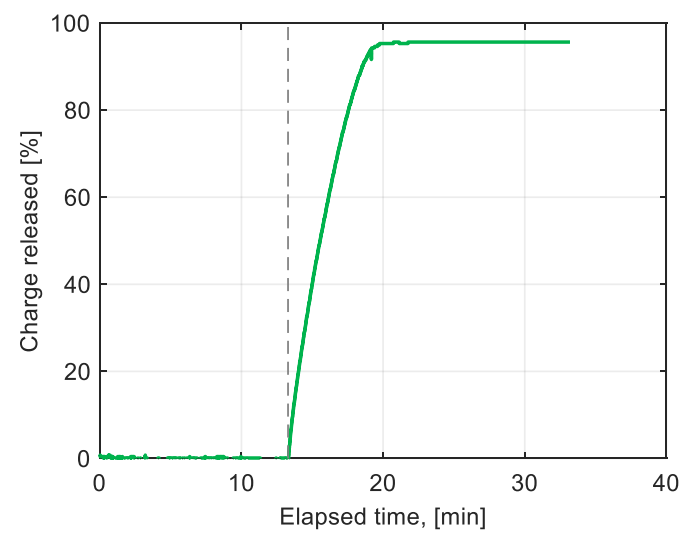

(b.)

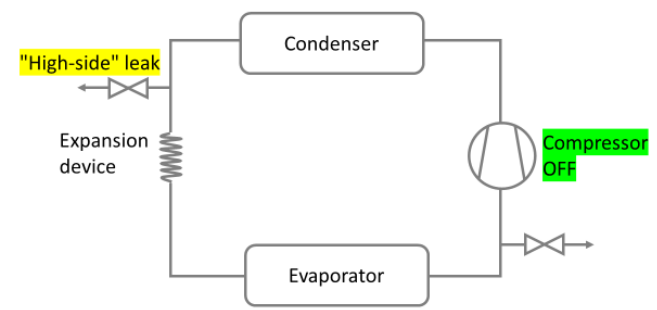

(d.)

Figure 42. (a.) High- and low-side pressure decay, (b.) percent charge released (c.) power consumption and (d.) system diagram for display case test 128 ( $2.03 \mathrm{~mm}$ orifice) 


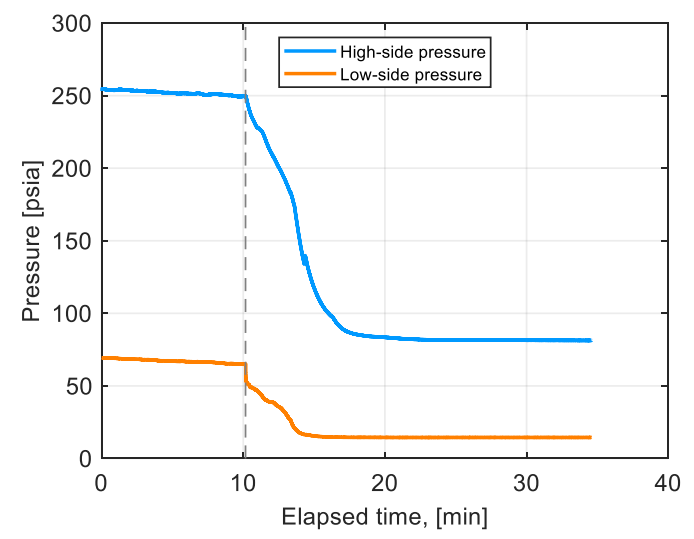

(а.)

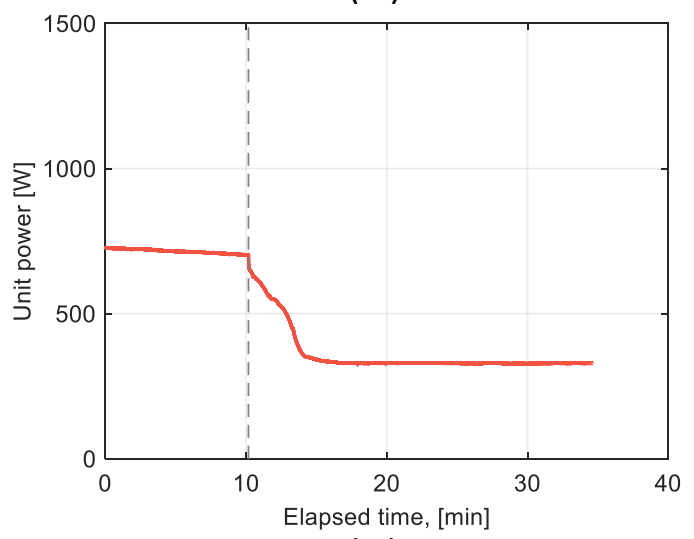

(c.)

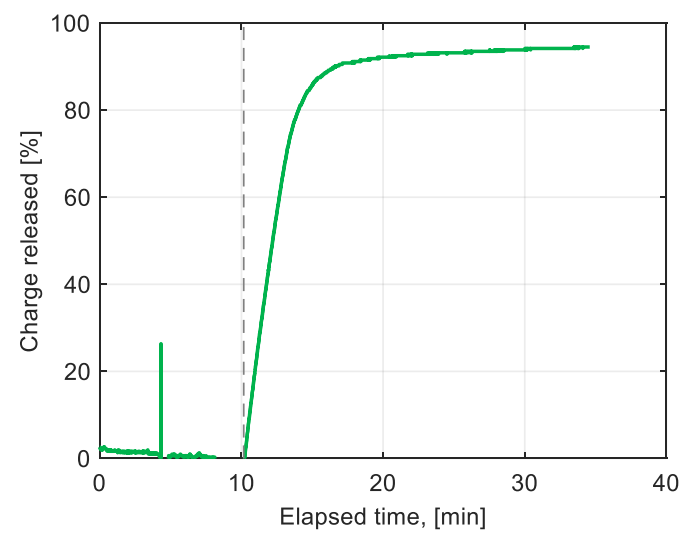

(b.)

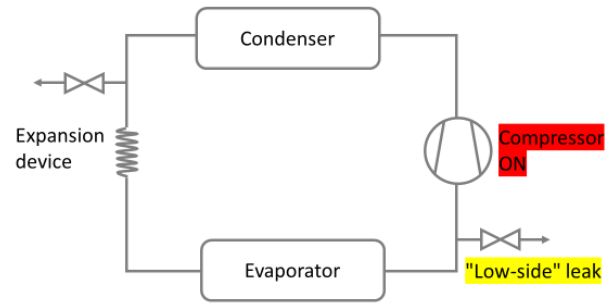

(d.)

Figure 43. (a.) High- and low-side pressure decay, (b.) percent charge released (c.) power consumption and (d.) system diagram for display case test $129(4.39 \mathrm{~mm}$ orifice $)$ 


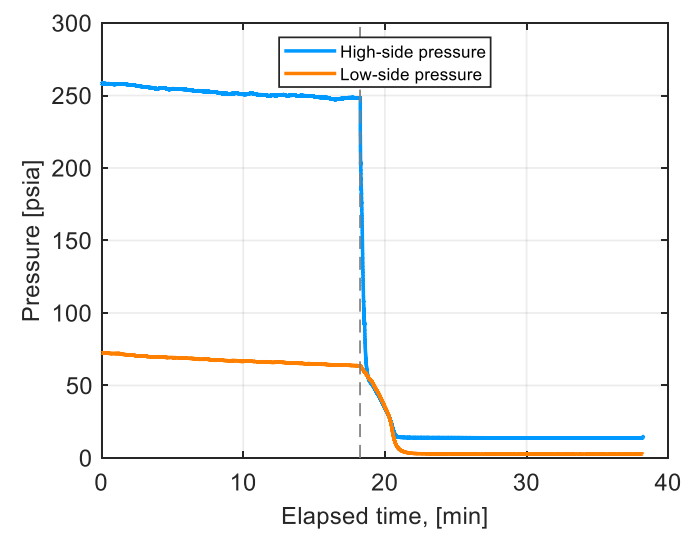

(а.)

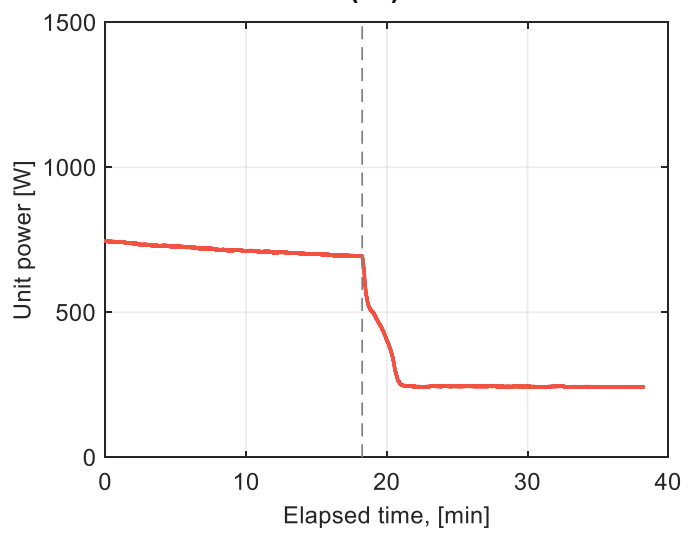

(c.)

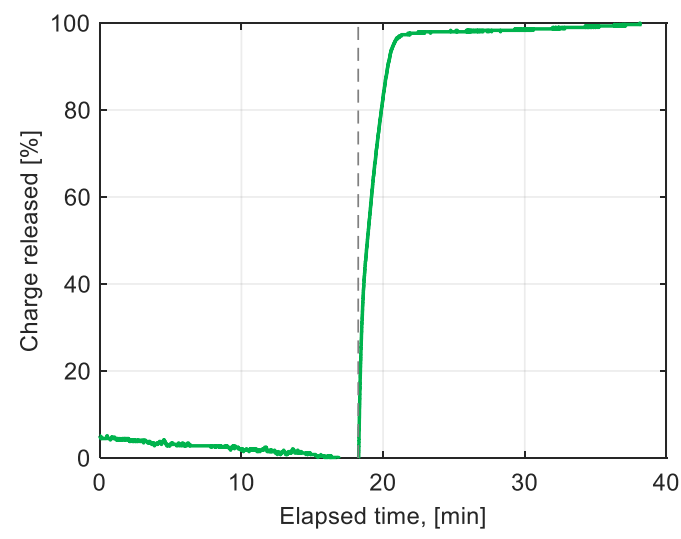

(b.)

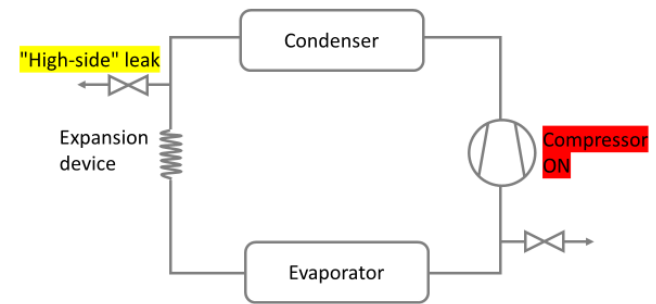

(d.)

Figure 44. (a.) High- and low-side pressure decay, (b.) percent charge released (c.) power consumption and (d.) system diagram for display case test 130 ( $4.39 \mathrm{~mm}$ orifice $)$ 


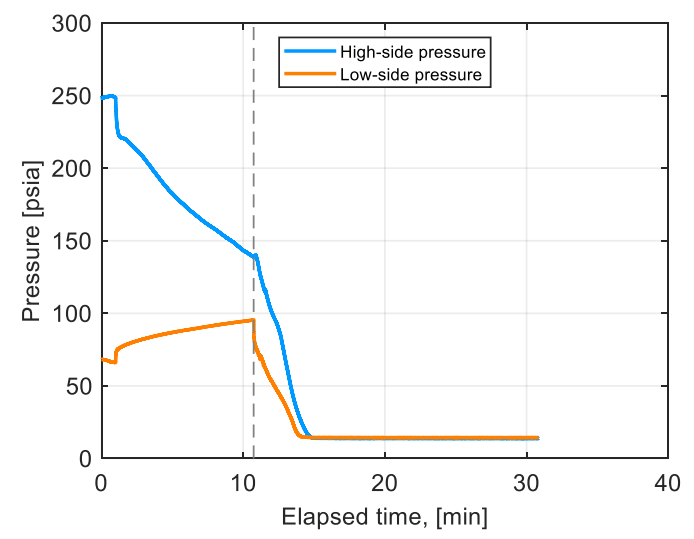

(a.)

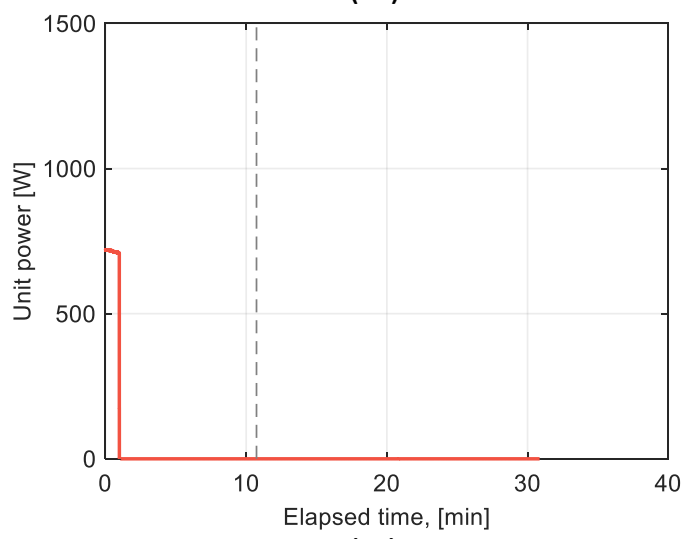

(c.)

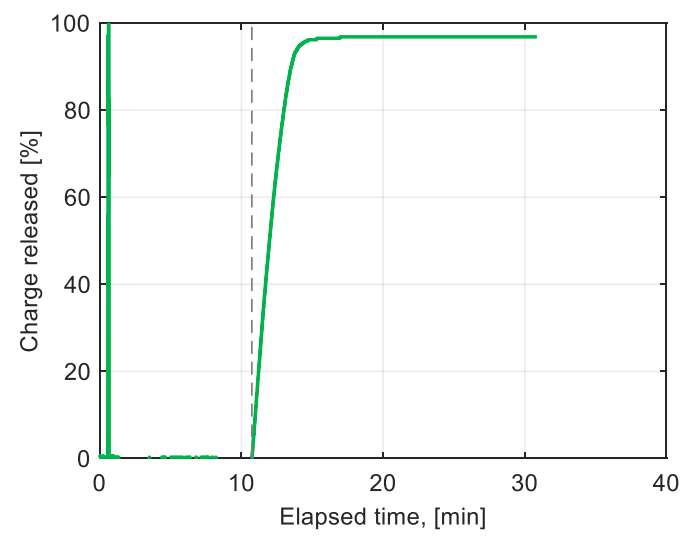

(b.)

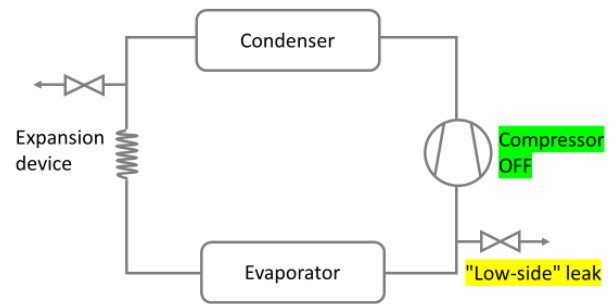

(d.)

Figure 45. (a.) High- and low-side pressure decay, (b.) percent charge released (c.) power consumption and (d.) system diagram for display case test $131(4.39 \mathrm{~mm}$ orifice $)$ 


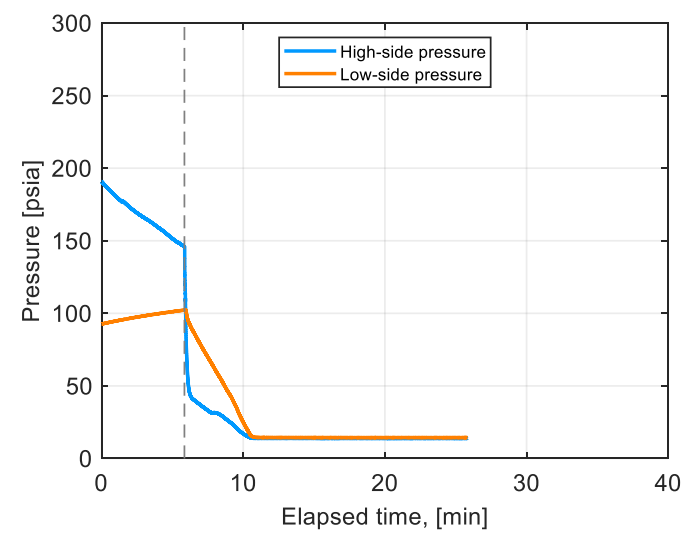

(а.)

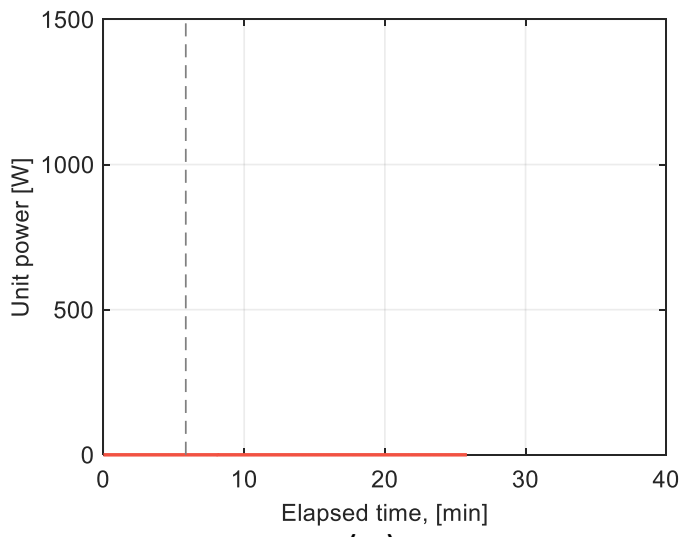

(c.)

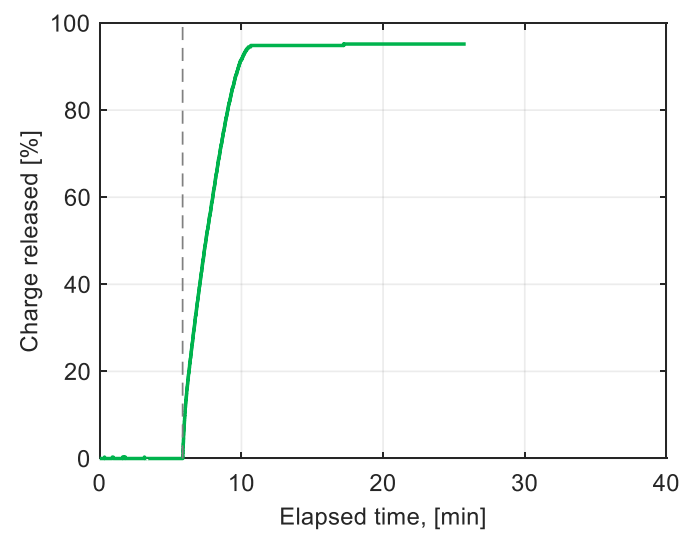

(b.)

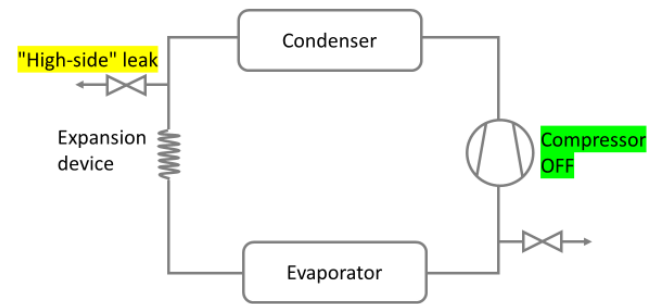

(d.)

Figure 46. (a.) High- and low-side pressure decay, (b.) percent charge released (c.) power consumption and (d.) system diagram for display case test $132(4.39 \mathrm{~mm}$ orifice $)$

Unlike the split AC and PTAC systems, the display case unit compressor never shut down during any of the leak events. Additionally, for the compressor "on" and low side leak tests 125 and 129, the low side pressure dropped to approximately atmospheric pressure, raising concerns that the compressor could be drawing air into the system and mixing with the remaining refrigerant (mostly in the condenser). Figures 47-49 below show the low-side pressure, high-side pressure, and system mass vs. time for the last approximately 10 minutes of test 129 . For the test period, it can be seen that the low-side pressure and barometric pressure (BP) were relatively equal within measurement uncertainty as seen in Figure 47 (Note: the BP was the average as measured on the roof of a separate building about 100 yards west of the test chamber (purple line in Figure 47) during the 1-hour test period). It is also apparent that the high-side pressure and system mass both continued to drop during the time period. For this particular test it appears unlikely that any air was entrained in the system. However, if such an incident happened in a field installation and the unit continued to run for several hours (or days) without detection of the problem it is possible that some air could be entrained into the system possibly resulting in a fire or explosion event. 


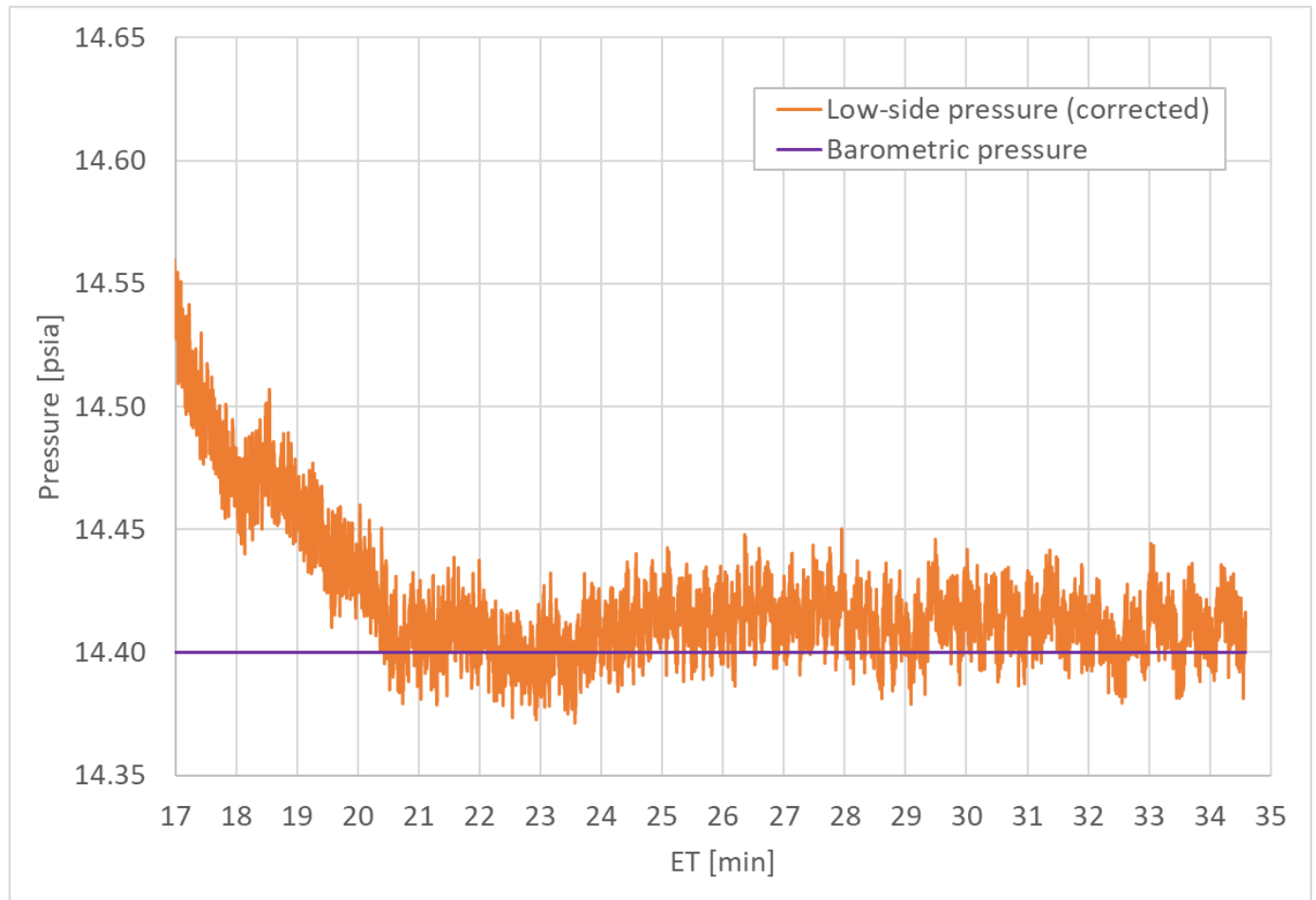

Figure 47. Display case test 129: low-side pressure (corrected) vs. barometric pressure at site; last $\sim 17$ minutes of test period

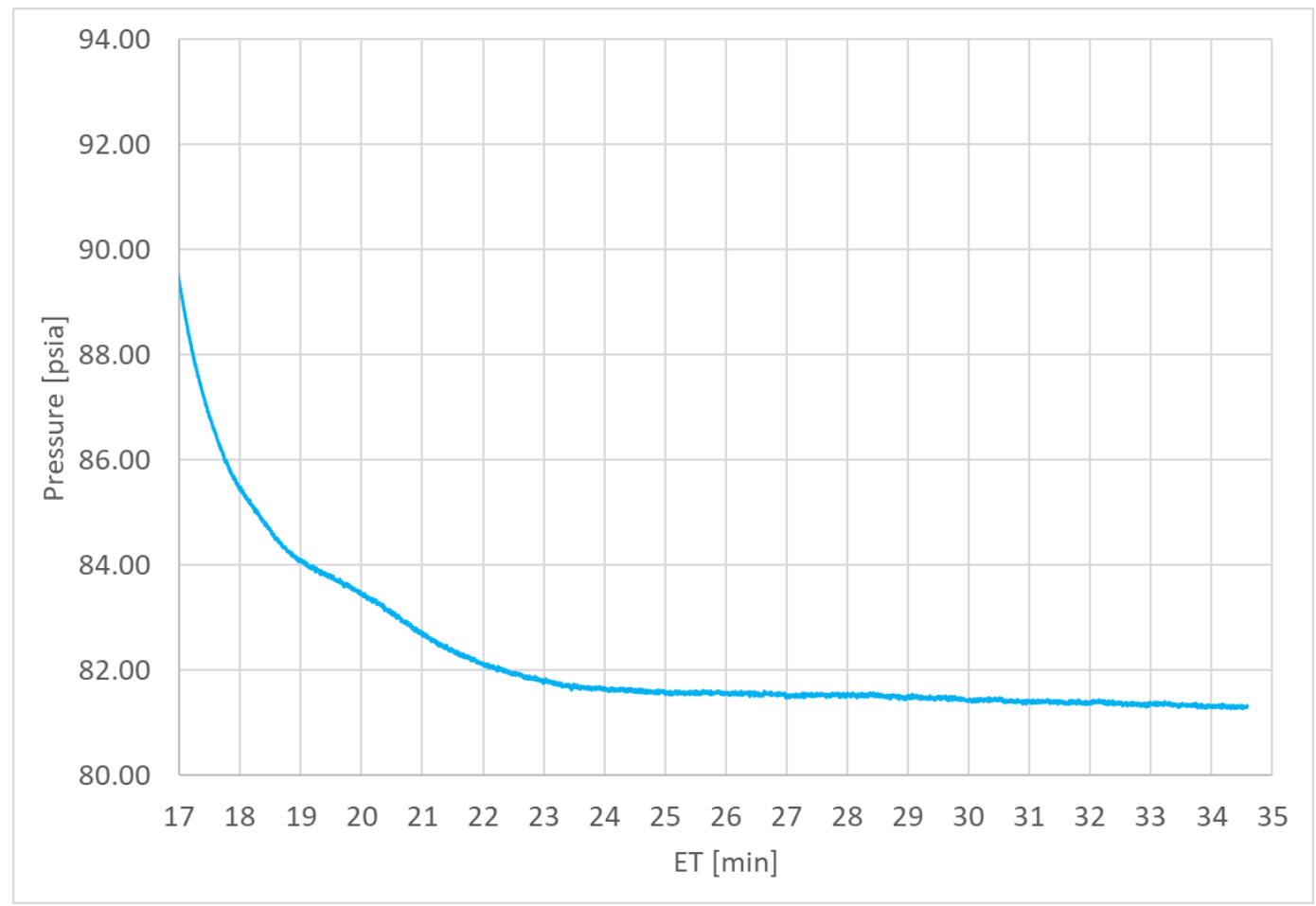

Figure 48. Display case test 129: high-side pressure vs. time; last $\sim 17$ minutes of test period 


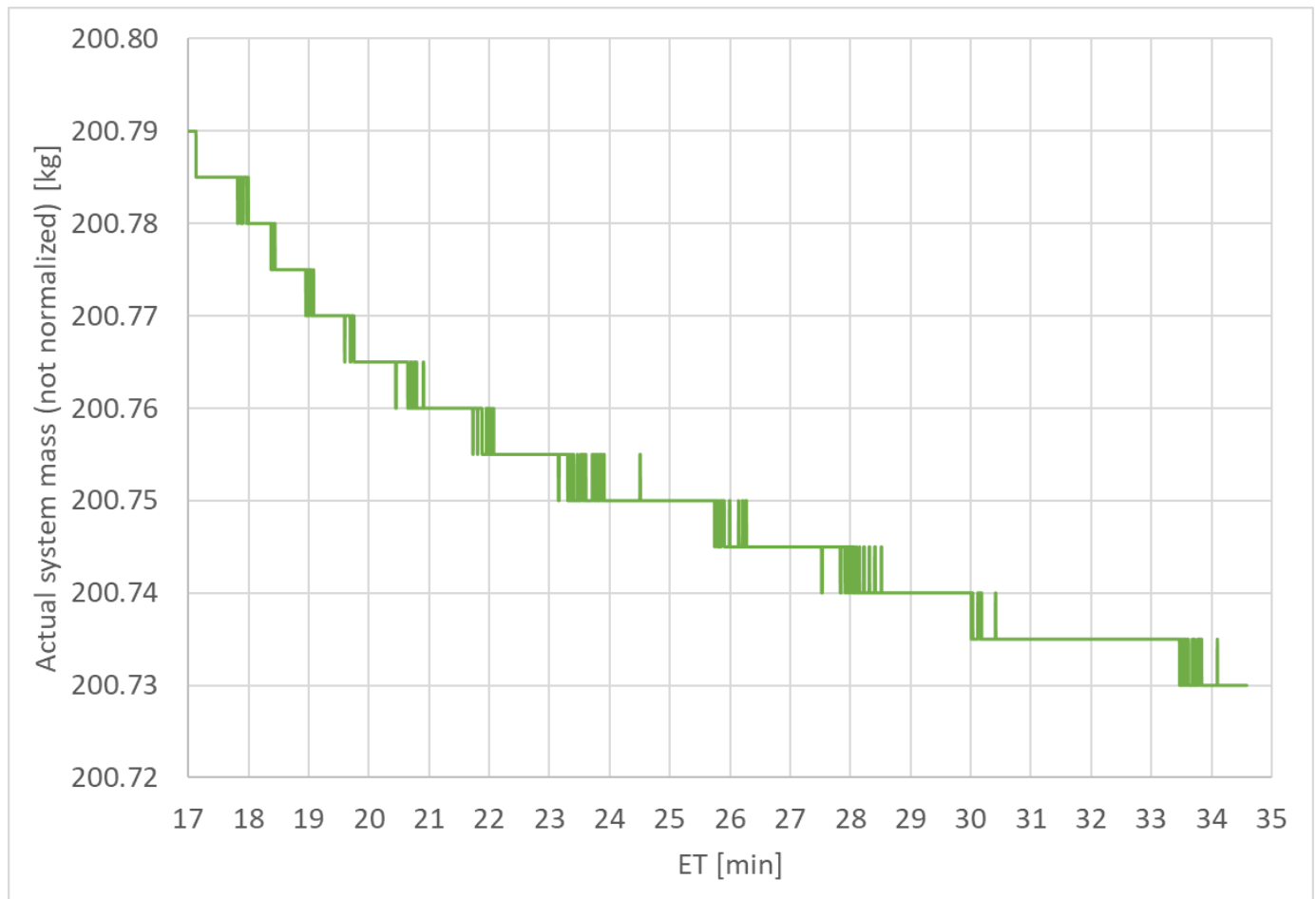

Figure 49. Display case test 129: actual system mass vs. time; last $\sim 17$ minutes of test period 


\subsection{UNIT COOLER TEST RESULTS}

The unit cooler system was installed in the chamber after display case tests were completed. Figures 50 and 51 illustrate the installation of the outdoor condensing unit and indoor evaporator unit. The indoor evaporator unit was elevated 6-7 ft above floor level and the leak control system was mounted on top of the unit. It was discovered that the evaporator section was missing its thermostatic expansion valve (TXV) and a solenoid valve. These were procured locally, and installation proceeded. As noted earlier, the solenoid valve is used to isolate the evaporator from the OD condenser section when the thermostat is satisfied. The system controls also included a pump-down cycle which, together with the solenoid valve, isolated most of the system refrigerant charge in the OD section when there is no call for room cooling.

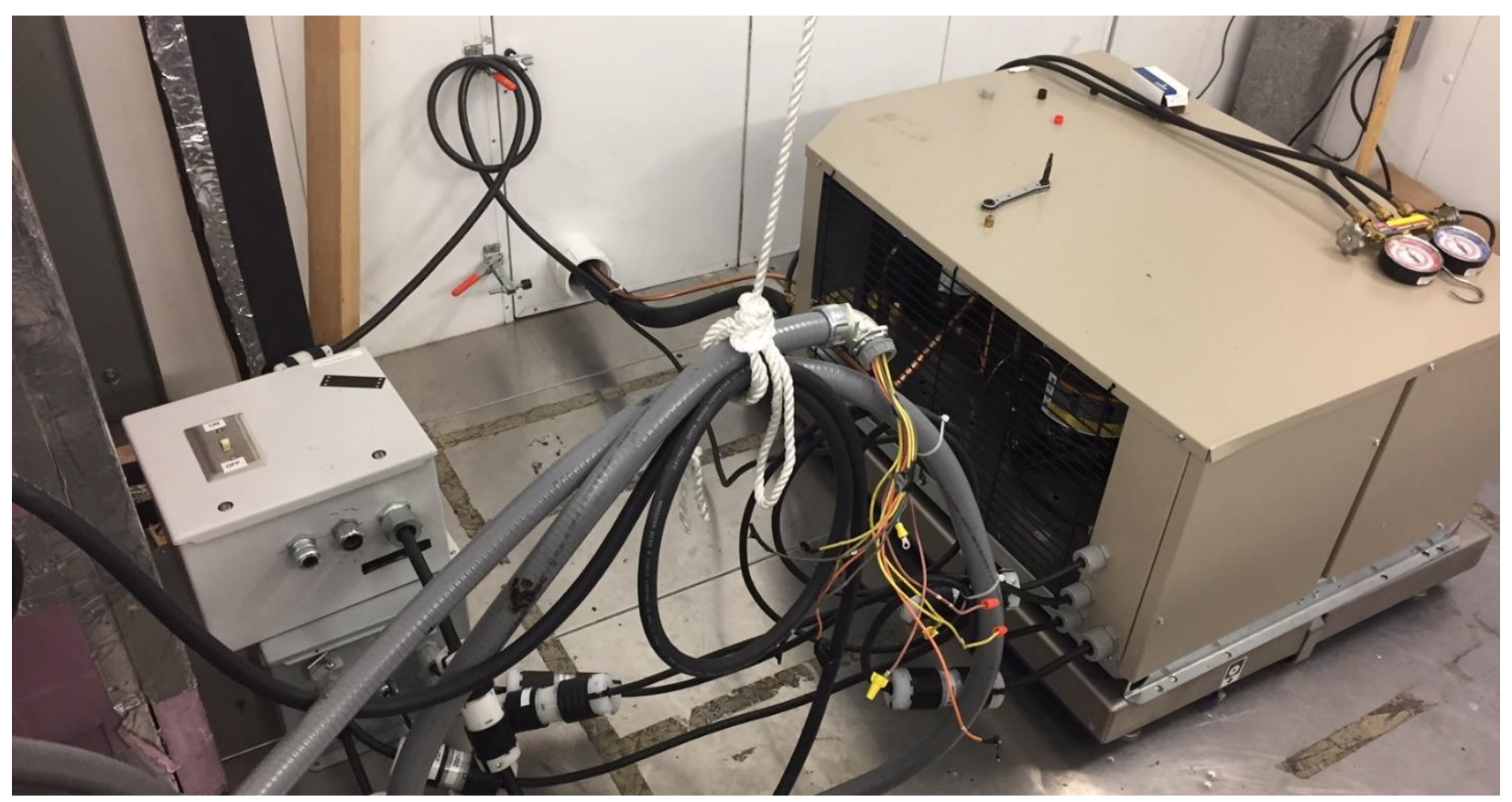

Figure 50. Unit cooler outdoor condensing section 


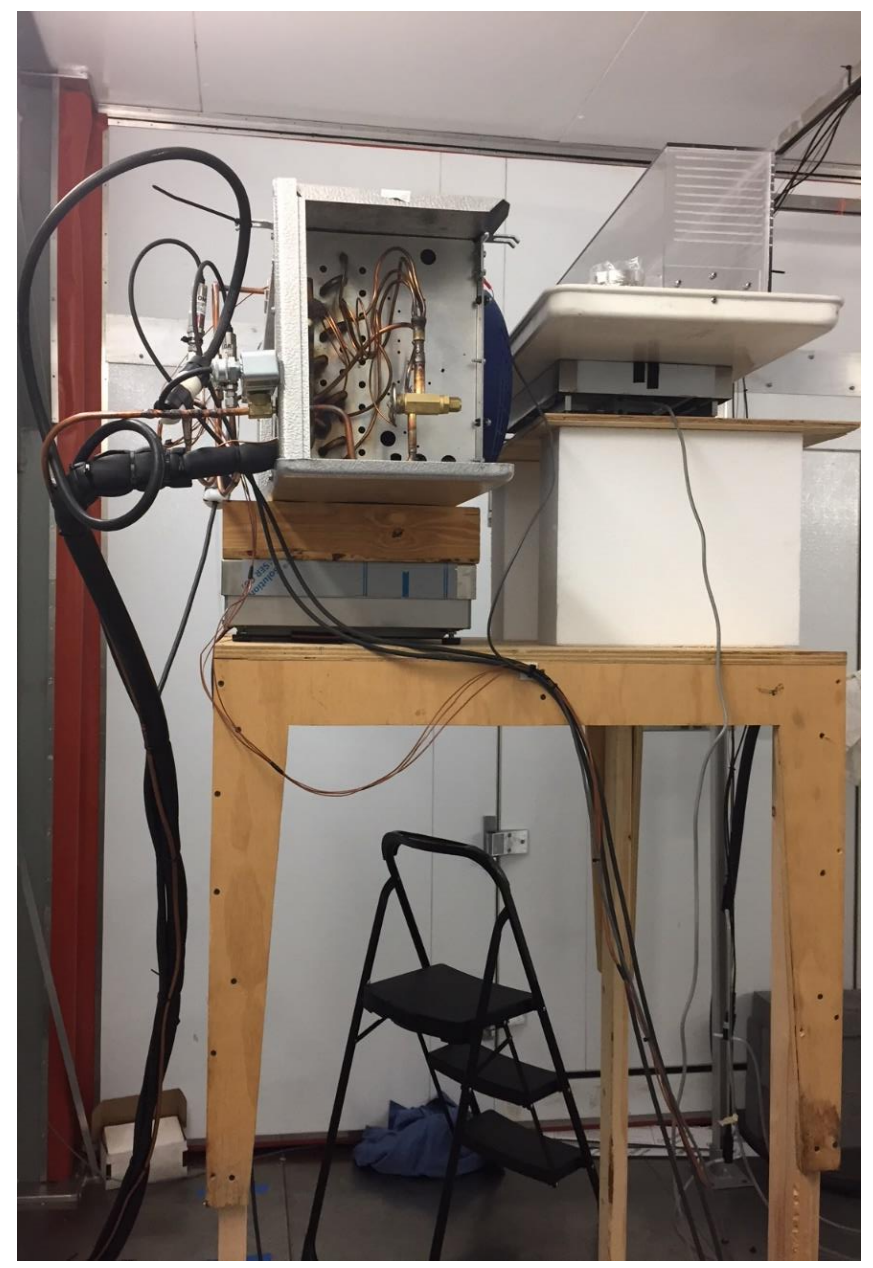

Figure 51. Unit cooler indoor evaporator section; leak control system mounted on top of evaporator unit

Tests for this system were run with ambient operating dry-bulb temperature of $95^{\circ} \mathrm{F}$ outdoor and $20^{\circ} \mathrm{F}$ indoor. For these tests, no correction was made for fan thrust or frost accumulation impacts on the evaporator unit weight for two reasons. First, the evaporator unit blowers run all the time whether the compressor is on or off. Secondly, any frost that accumulates on the evaporator surface is very unlikely to melt or sublimate during the test period since the ambient temperature is maintained at $20^{\circ} \mathrm{F}$.

Table 9 provides a summary of the unit cooler leak test results. Leak location, hole size, and compressor on/off status can be determined by referring to Figures 52-59.

- System "on" and high side leak tests $134 \& 138$ - nearly all refrigerant released

$\circ$ compressor shut off due to low pressure $\sim 13 \mathrm{~s}$ and $\sim 30$ s after leak was initiated for tests 138 and 134 , respectively

- $\sim 75 \%$ of charge was released while the compressor was running

- refrigerant release continued at very low rate after compressor shut off until end of test

- back pressure remained higher for test 134 (smaller leak orifice) than in test 138

- System "off" and low side leak tests 135 \& 139 - only 4-6\% of refrigerant charge released

$\circ$ Solenoid valve and pump-down cycle isolated refrigerant in condenser side

- Solenoid valve \& compressor severely restricted flow of refrigerant to leak point 
- System "on" and low side leak tests 133 \& 137 -

○ High leak rate (137)

- Compressor shut off $\sim 2$ minutes after leak initiation

- $\sim 50 \%$ of charge released while compressor running; another $\sim 40 \%$ released over next $\sim 5 \mathrm{~min} ; \sim 6-7 \%$ of additional charge released by test end ( $\sim 96-97 \%$ total charge released)

○ Low leak rate (133)

- Compressor shut off $\sim 2.5$ minutes after leak initiation

- $\sim 40 \%$ of charge released while compressor running; $~ 50 \%$ more released over next $\sim 5 \mathrm{~min} ; \sim 5-6 \%$ of additional charge released by test end ( $\sim 95-96 \%$ total charge released)

- $\quad$ System “off" \& high side leak tests $136 \& 140$

$\circ$ High leak rate (140) - 99\% of refrigerant charge released

- $\sim 95 \%$ of charge released in first 1-2 min of leak

- Continued slow release until end of test period

○ Low leak rate (136) - 96-97\% of charge released

- $~ 90 \%$ of charge released in first 1-2 min

Table 9. Unit cooler leak test results summary

\begin{tabular}{|c|c|c|c|c|c|c|c|c|}
\hline Test \# & $\begin{array}{c}\text { System } \\
\text { charge } \\
{[\mathrm{lb}]}\end{array}$ & $\begin{array}{c}\text { OD unit } \\
\text { mass } \\
\text { change } \\
{[\mathrm{lb}]}\end{array}$ & $\begin{array}{c}\text { ID unit } \\
\text { mass } \\
\text { change } \\
{[\mathrm{lb}]}\end{array}$ & $\begin{array}{c}\text { Total } \\
\text { charge } \\
\text { released } \\
{[\mathrm{lb}]}\end{array}$ & $\begin{array}{c}\text { Time to } \\
\text { release } \\
80 \% \text { of } \\
\text { total } \\
\text { charge }[\mathrm{s}]\end{array}$ & $\begin{array}{c}\text { Average } \\
\text { leak rate } \\
\text { for } 80 \% \\
\text { release } \\
{[\mathrm{lb} / \mathrm{min}]}\end{array}$ & $\begin{array}{c}\text { Charge } \\
\text { left in } \\
\text { system } \\
{[\mathrm{lb}]}\end{array}$ & $\begin{array}{c}\text { Collector } \\
\text { pan mass } \\
\text { change } \\
{[\mathrm{lb}]}\end{array}$ \\
\hline 133 & 5.00 & 4.00 & 0.76 & 4.76 & 294.70 & 0.81 & 0.24 & -0.01 \\
\hline 134 & 5.00 & 4.06 & 0.88 & 4.94 & 23.60 & $10.17^{1}$ & 0.06 & -0.00 \\
\hline 135 & 5.00 & 0.04 & 0.15 & 0.20 & -2 & - & 4.80 & -0.02 \\
\hline 136 & 5.00 & 4.22 & 0.61 & 4.83 & 19.30 & 12.44 & 0.17 & -0.00 \\
\hline 137 & 5.00 & 4.10 & 0.72 & 4.82 & 193.20 & 1.24 & 0.18 & 0.00 \\
\hline 138 & 5.00 & 4.12 & 0.92 & 5.04 & 14.80 & $16.22^{3}$ & -0.04 & 0.02 \\
\hline 139 & 5.00 & 0.10 & 0.20 & 0.30 & -4 & - & 4.70 & 0.01 \\
\hline 140 & 5.00 & 4.30 & 0.65 & 4.95 & 14.20 & 16.90 & 0.05 & -0.00 \\
\hline
\end{tabular}

${ }^{1}$ Leak rate was $\sim 12.6 \mathrm{lb} / \mathrm{min}$ while compressor running (about first $30 \mathrm{~s}$ of leak release).

${ }^{2}$ Only $\sim 4 \%$ of charge released during entire test period.

${ }^{3}$ Leak rate was $\sim 17.7 \mathrm{lb} / \mathrm{min}$ while compressor running (about first $13 \mathrm{~s}$ of leak release).

${ }^{4}$ Only $\sim 6 \%$ of charge released during entire test period.

Figures 52-59 illustrate the total charge release (as \% of total charge). The unit weight scale data was tared to 0 at the beginning of each leak event to normalize out weight gain due to frost accumulation and fan thrust impacts. 


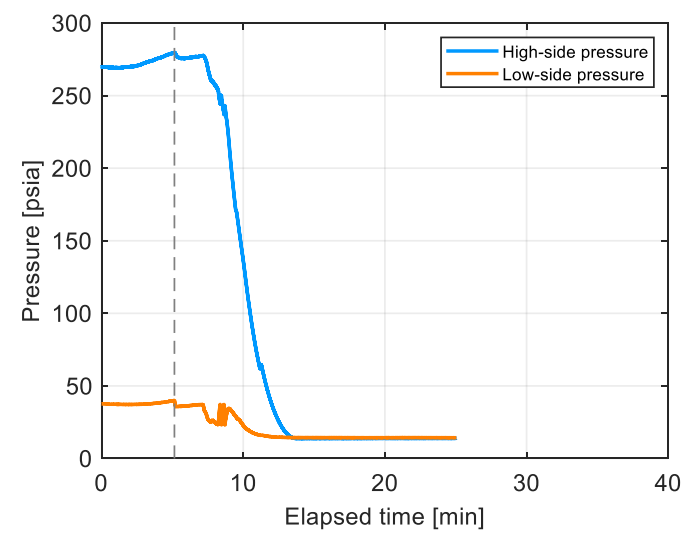

(a.)

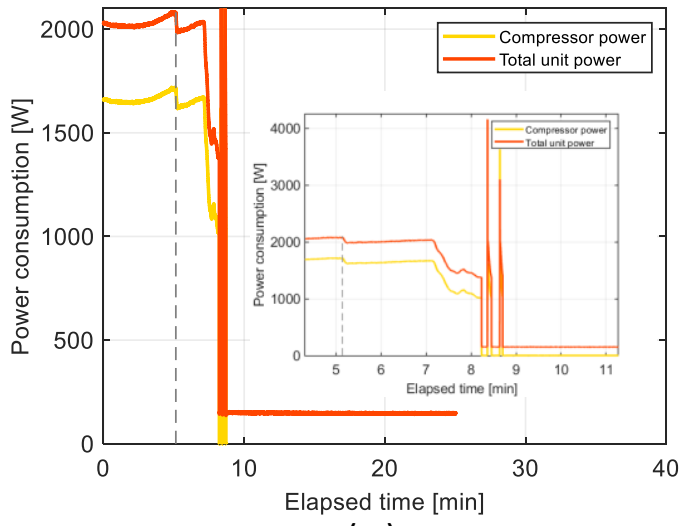

(c.)

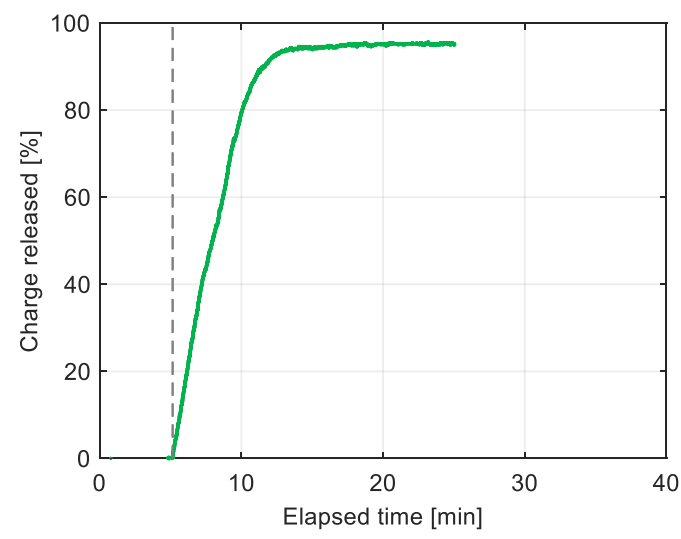

(b.)

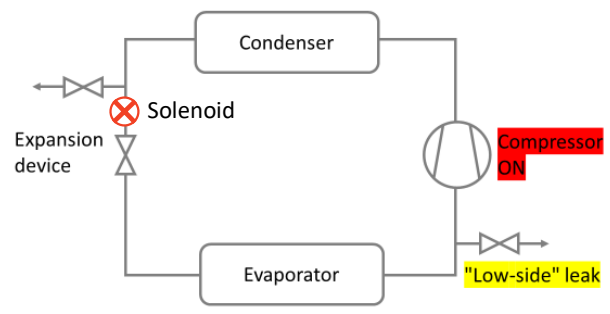

(d.)

Figure 52. (a.) High- and low-side pressure decay, (b.) percent charge released (c.) power consumption and (d.) system diagram for unit cooler test $133(2.03 \mathrm{~mm}$ orifice $)$ 


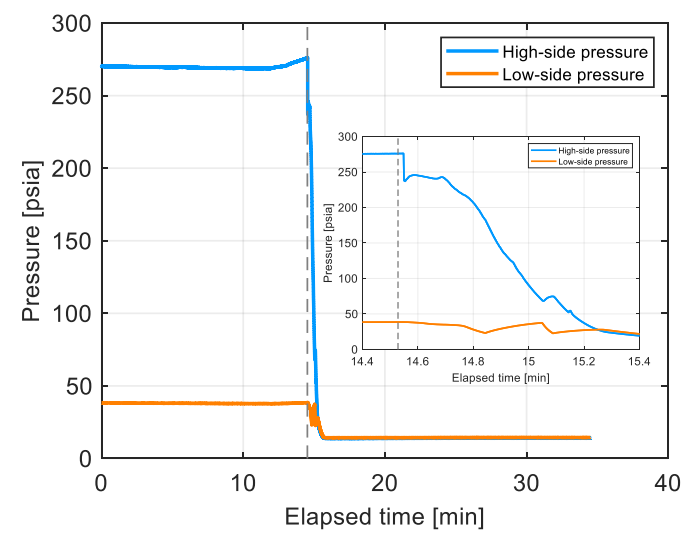

(а.)

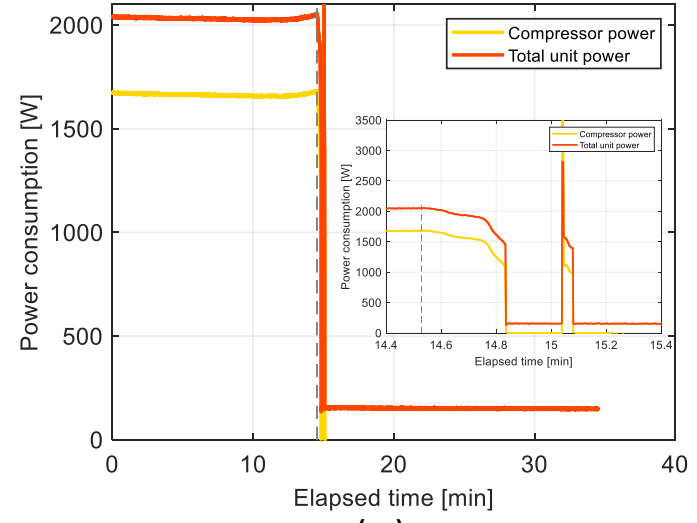

(c.)

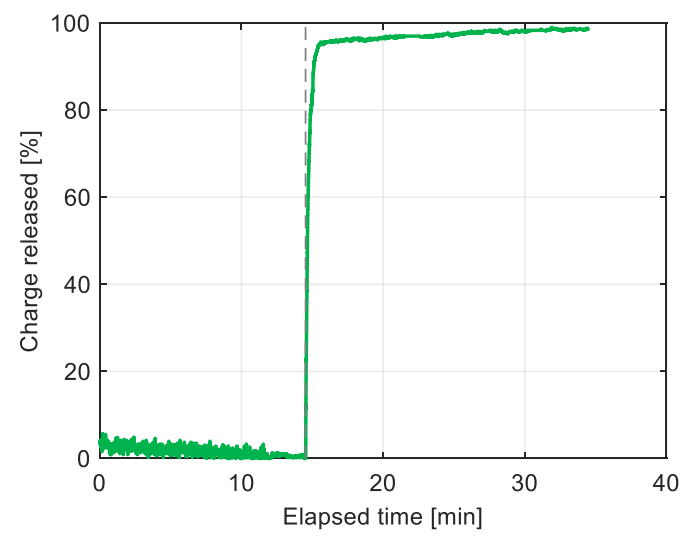

(b.)

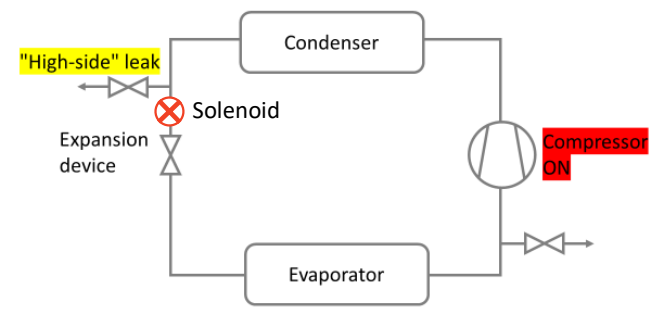

(d.)

Figure 53. (a.) High- and low-side pressure decay, (b.) percent charge released (c.) power consumption and (d.) system diagram for unit cooler test $134(2.03 \mathrm{~mm}$ orifice $)$ 


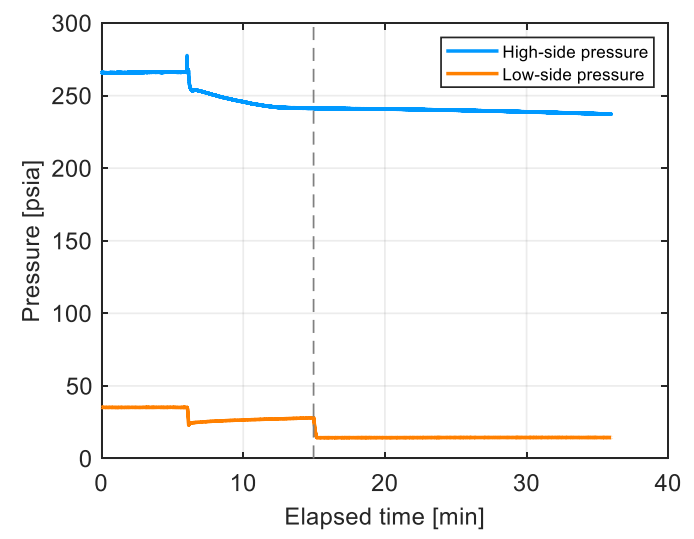

(a.)

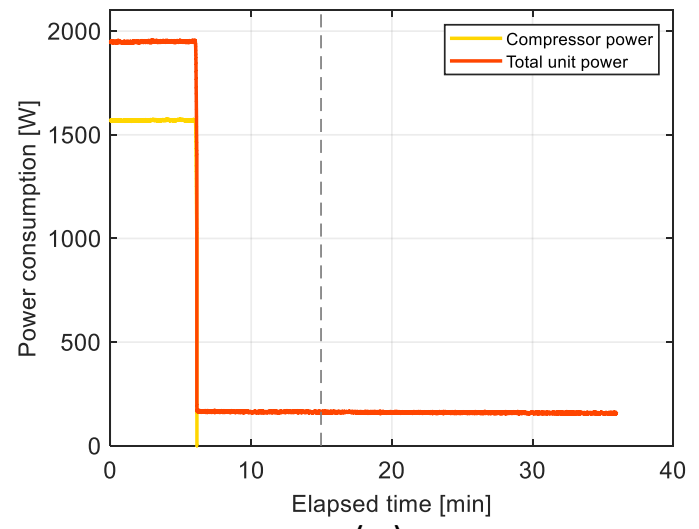

(c.)

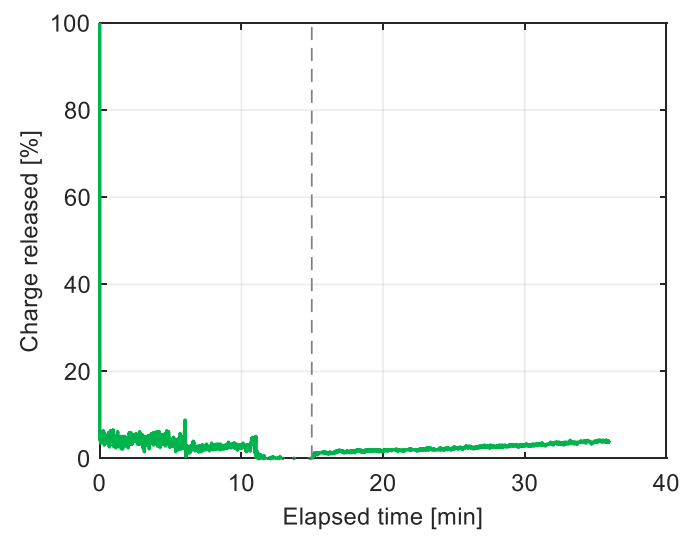

(b.)

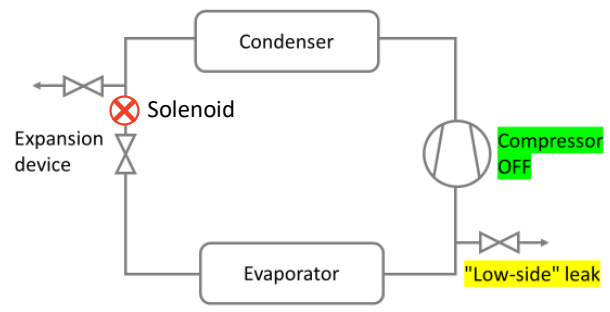

(d.)

Figure 54. (a.) High- and low-side pressure decay, (b.) percent charge released (c.) power consumption and (d.) system diagram for unit cooler test $135(2.03 \mathrm{~mm}$ orifice $)$ 


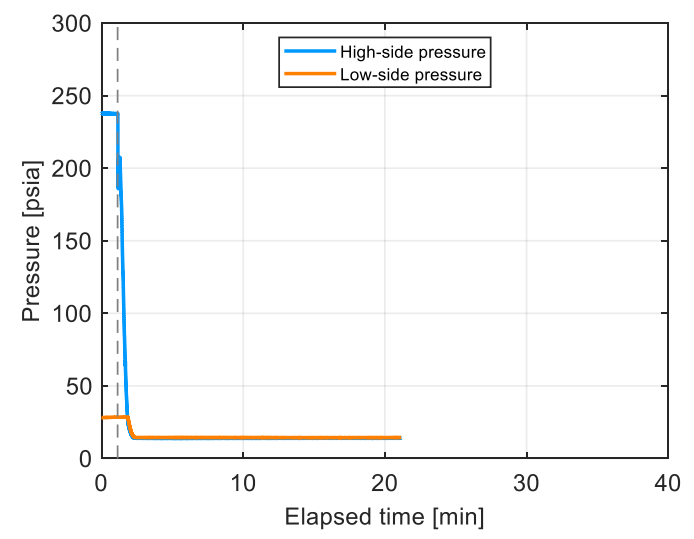

(а.)

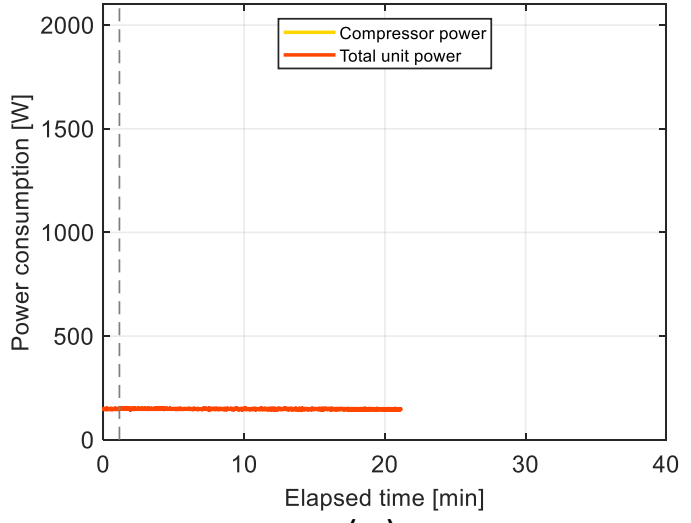

(c.)

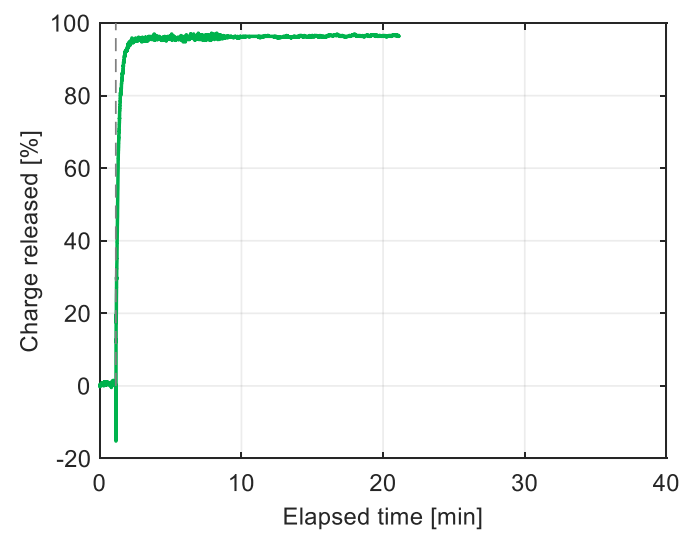

(b.)

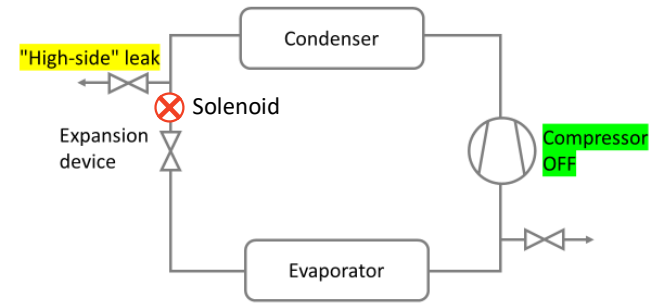

(d.)

Figure 55. (a.) High- and low-side pressure decay, (b.) percent charge released (c.) power consumption and (d.) system diagram for unit cooler test $136(2.03 \mathrm{~mm}$ orifice $)$ 


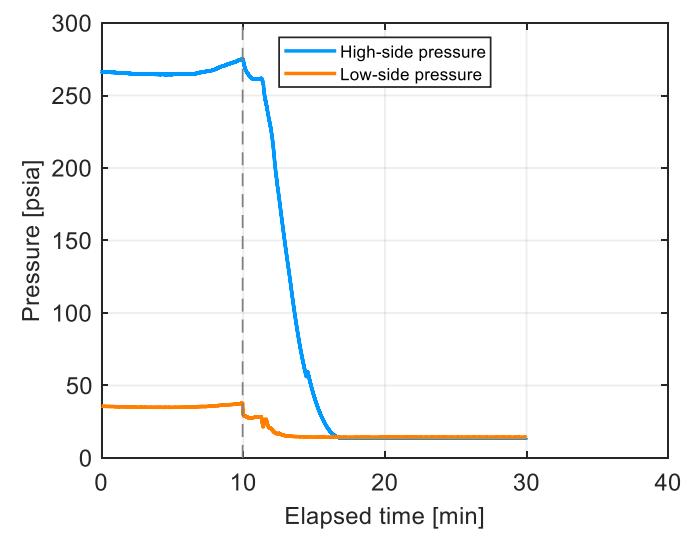

(а.)

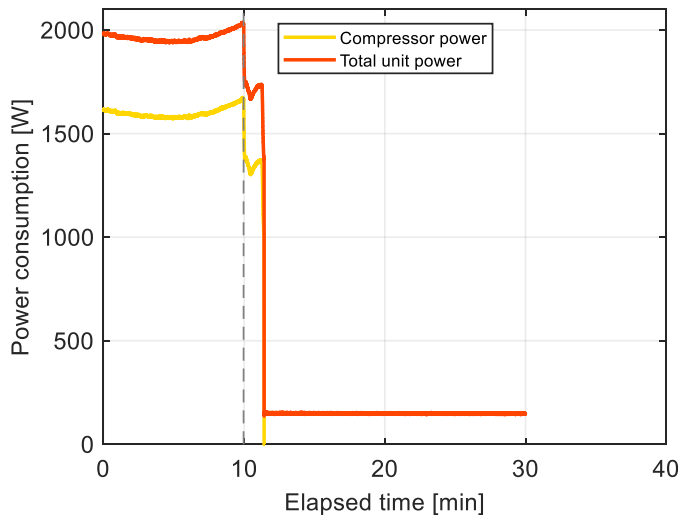

(c.)

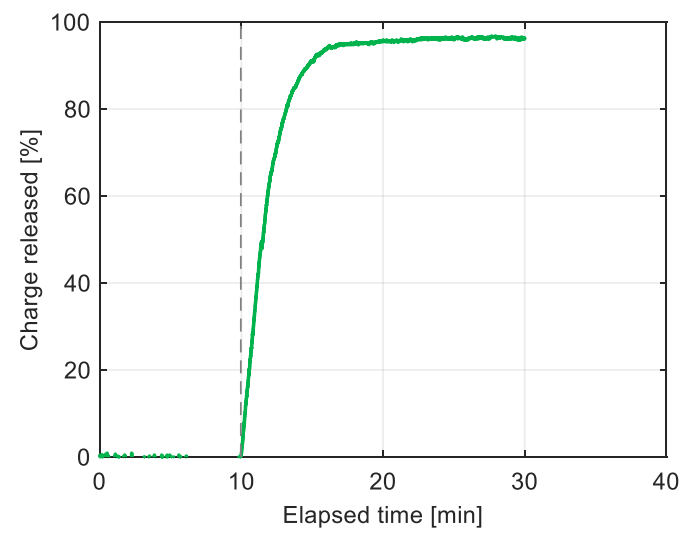

(b.)

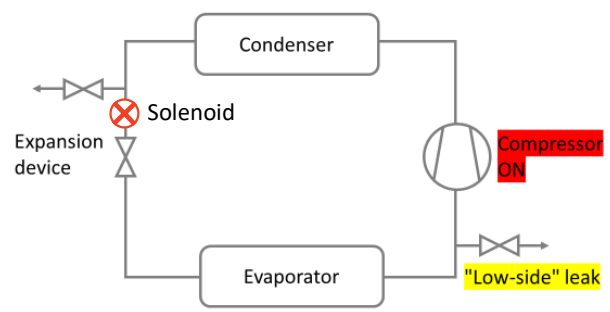

(d.)

Figure 56. (a.) High- and low-side pressure decay, (b.) percent charge released (c.) power consumption and (d.) system diagram for unit cooler test 137 (7.03 $\mathrm{mm}$ orifice) 


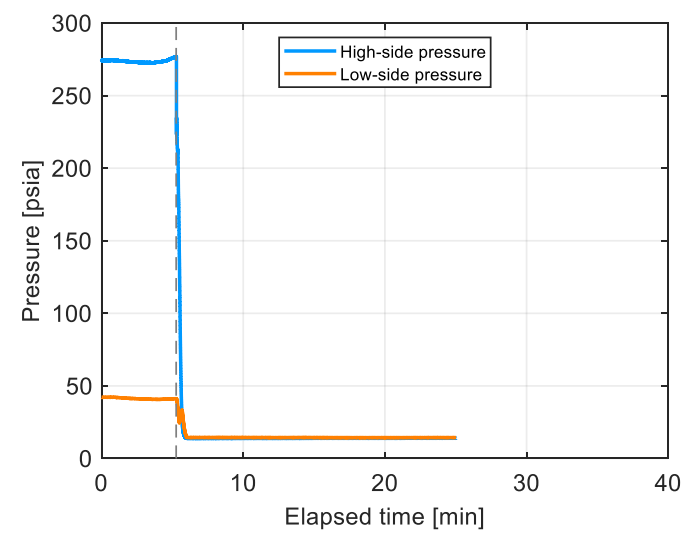

(а.)

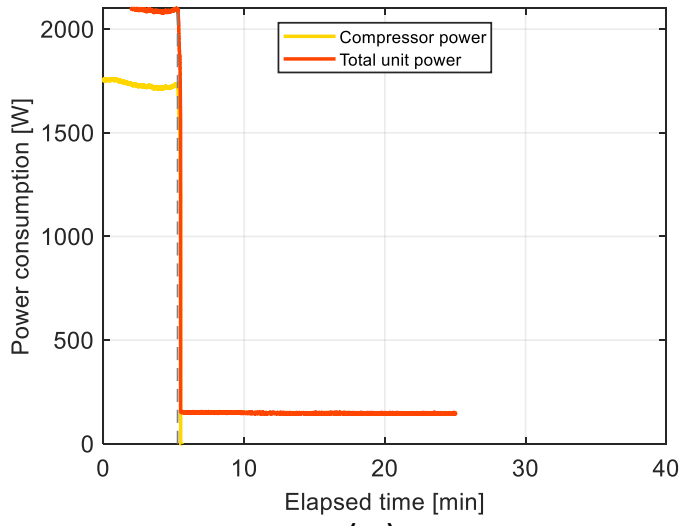

(c.)

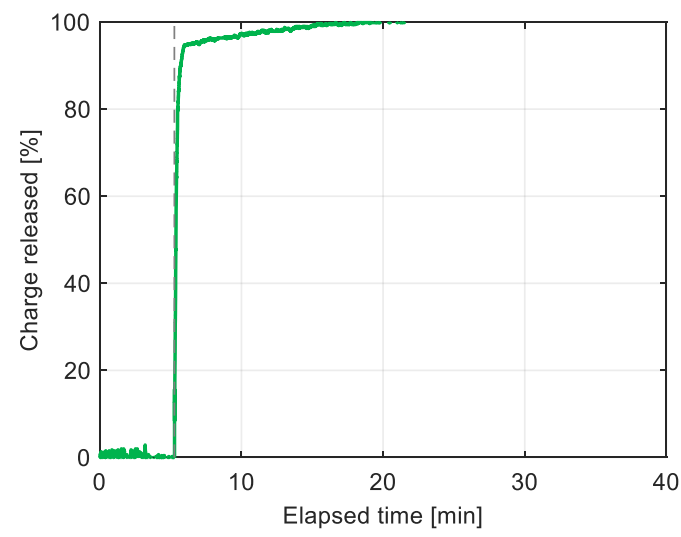

(b.)

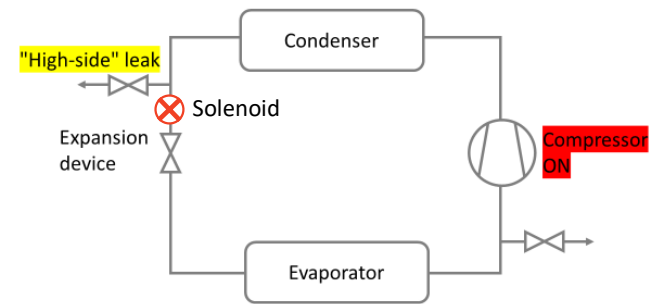

(d.)

Figure 57. (a.) High- and low-side pressure decay, (b.) percent charge released (c.) power consumption and (d.) system diagram for unit cooler test 138 ( $7.03 \mathrm{~mm}$ orifice) 


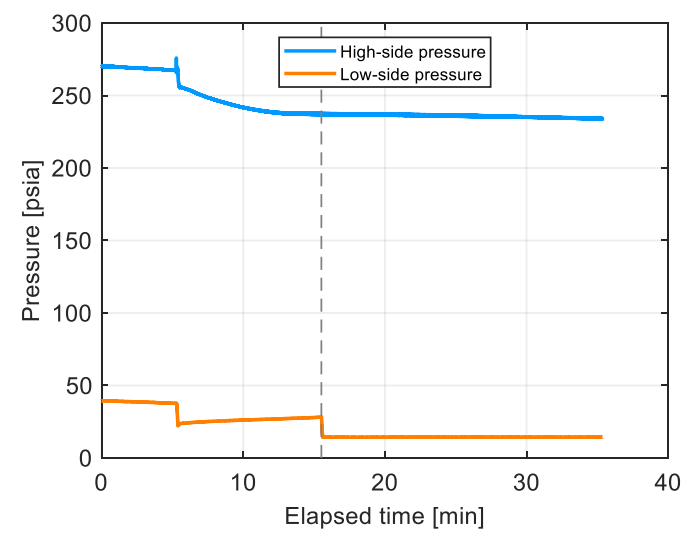

(а.)

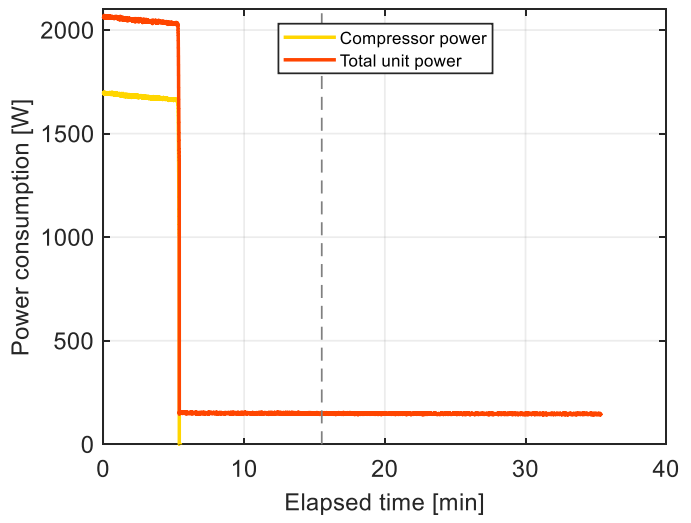

(c.)

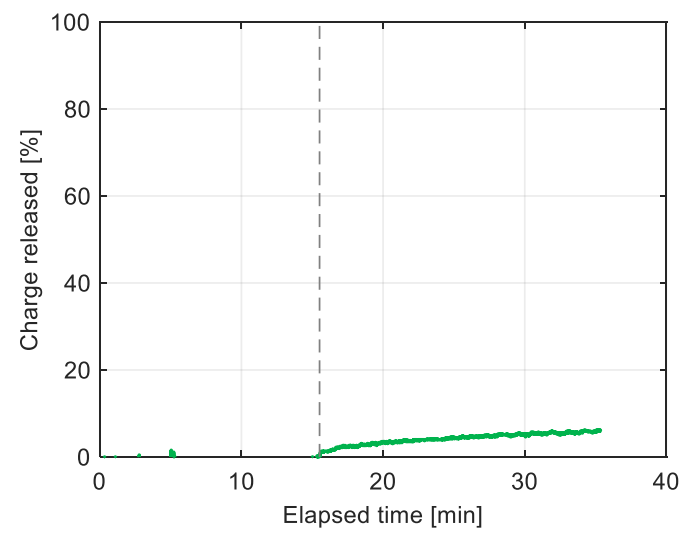

(b.)

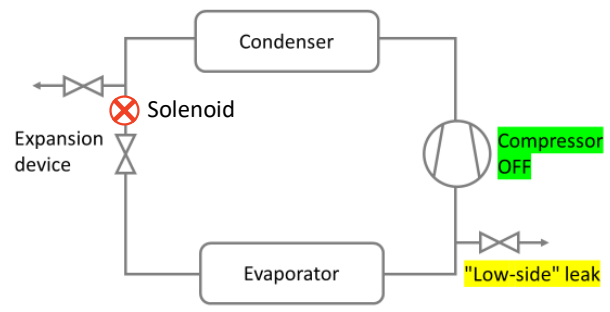

(d.)

Figure 58. (a.) High- and low-side pressure decay, (b.) percent charge released (c.) power consumption and (d.) system diagram for unit cooler test 139 ( $7.03 \mathrm{~mm}$ orifice) 


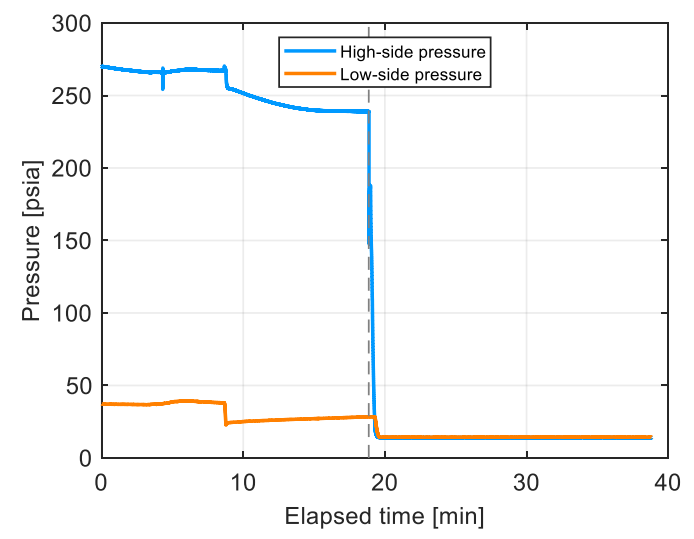

(а.)

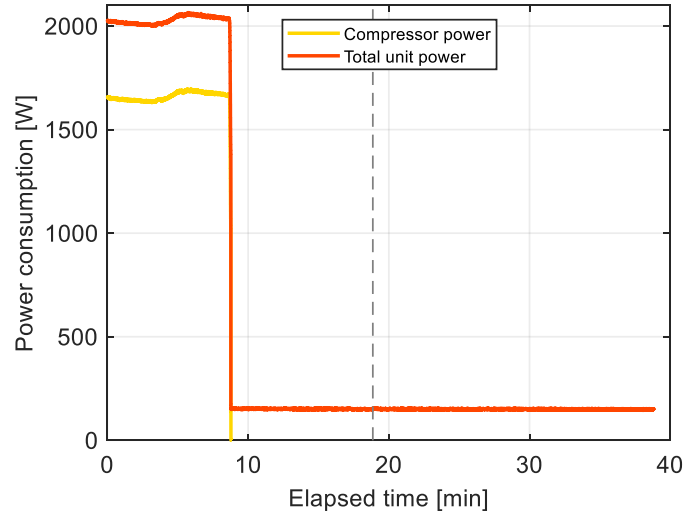

(c.)

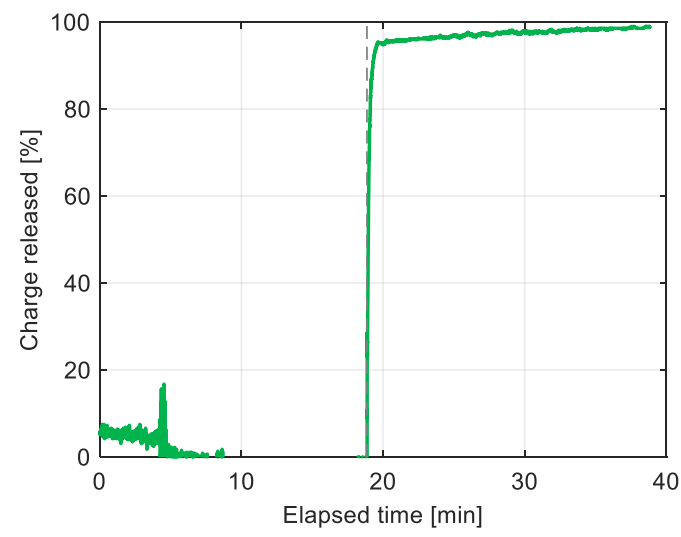

(b.)

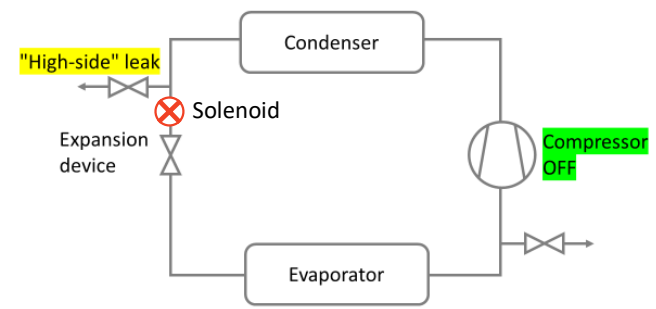

(d.)

Figure 59. (a.) High- and low-side pressure decay, (b.) percent charge released (c.) power consumption and (d.) system diagram for unit cooler test 140 ( $7.03 \mathrm{~mm}$ orifice) 


\subsection{ROOFTOP PACKAGED UNIT TEST RESULTS}

Figure 60 is a photo of the packaged 5-ton rooftop AC unit (RTU) showing the liquid and suction lines at the evaporator used as the leak points. Figure 61 shows the leak control automatic ball valve installed inside the RTU supply air outlet (leak orifice facing viewer).

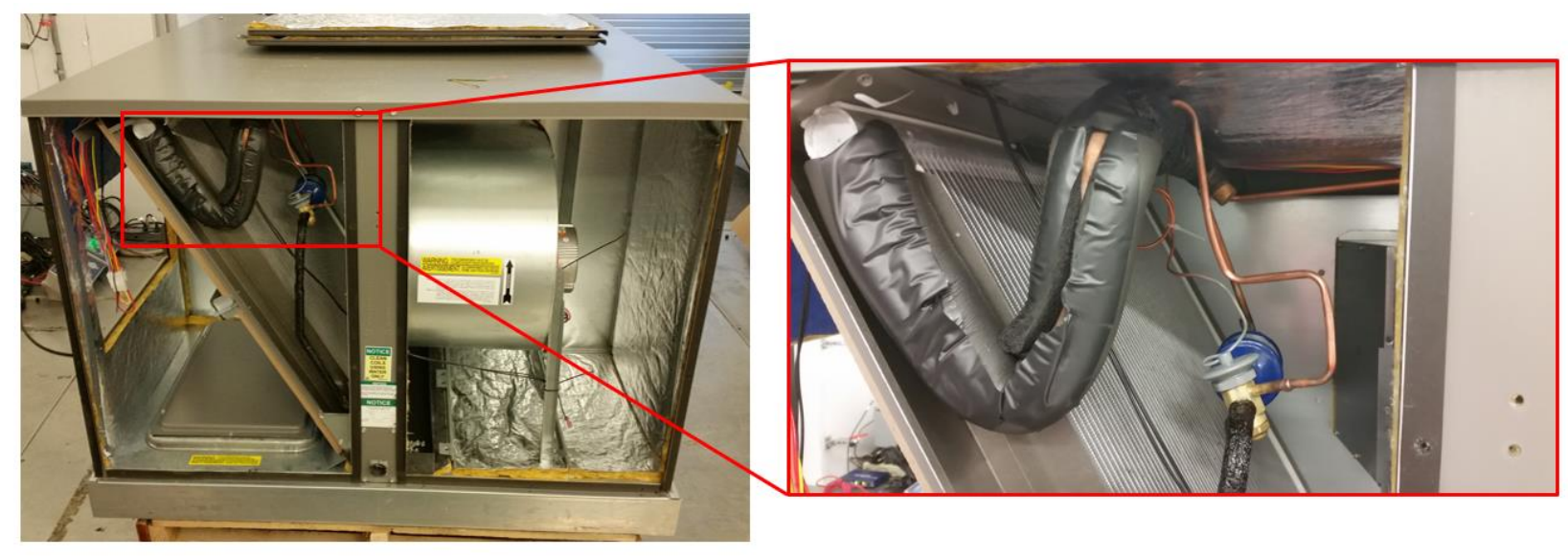

Figure 60. RTU test unit showing process tubes used as leak sources

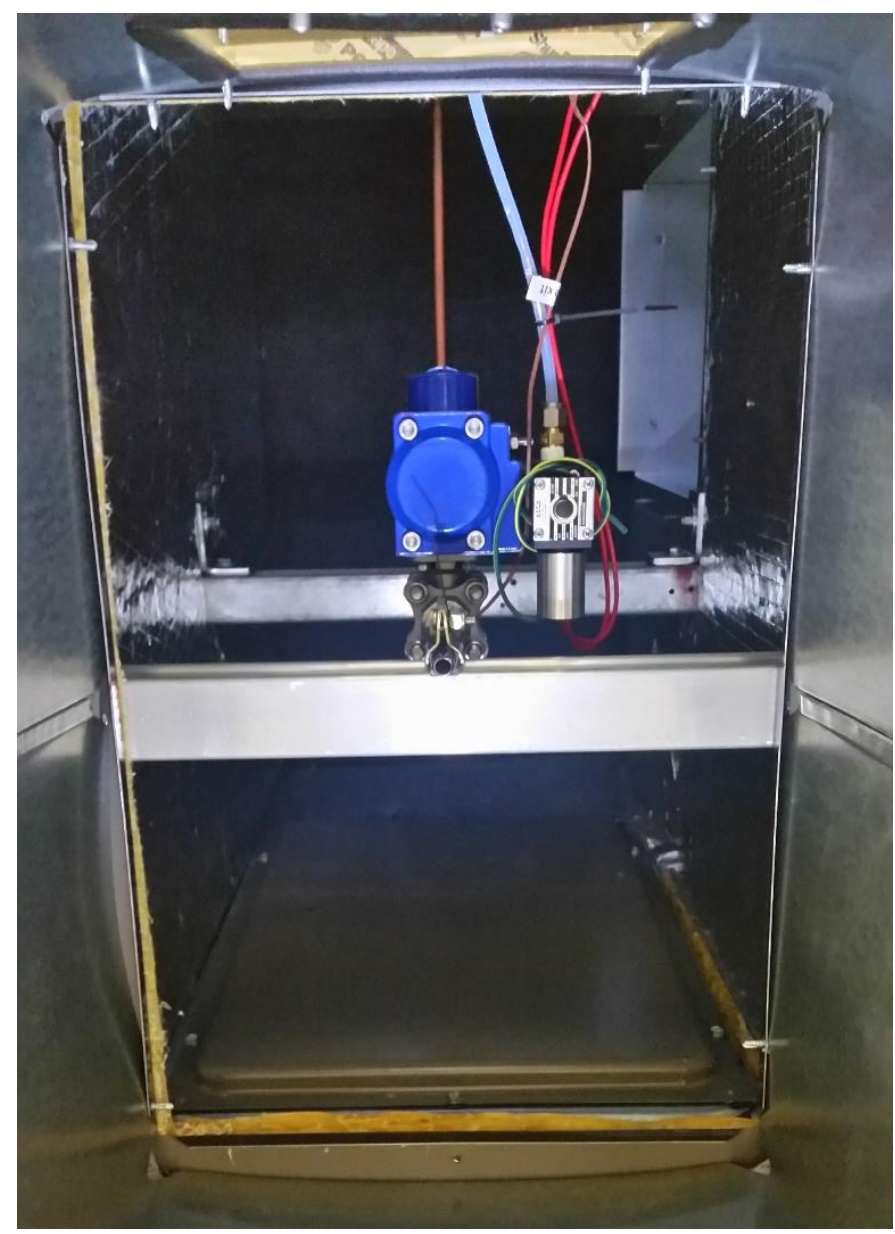

Figure 61. RTU leak control system installation 
For the low leak rate RTU tests $117-120$ a leak orifice diameter of 0.125 " $(3.175 \mathrm{~mm})$ was selected. This orifice size resulted in a leak time of $\sim 600 \mathrm{~s}$ ( $5 \mathrm{~min}$ ) to release $\sim 93 \%$ of the total RTU charge for test 119 (e.g., essentially the entire refrigerant release for the compressor off, low side leak, evaporator exit location). Figure 62 is a close-up photo of the leak release point with cap installed and 0.125 " hole drilled into the cap.

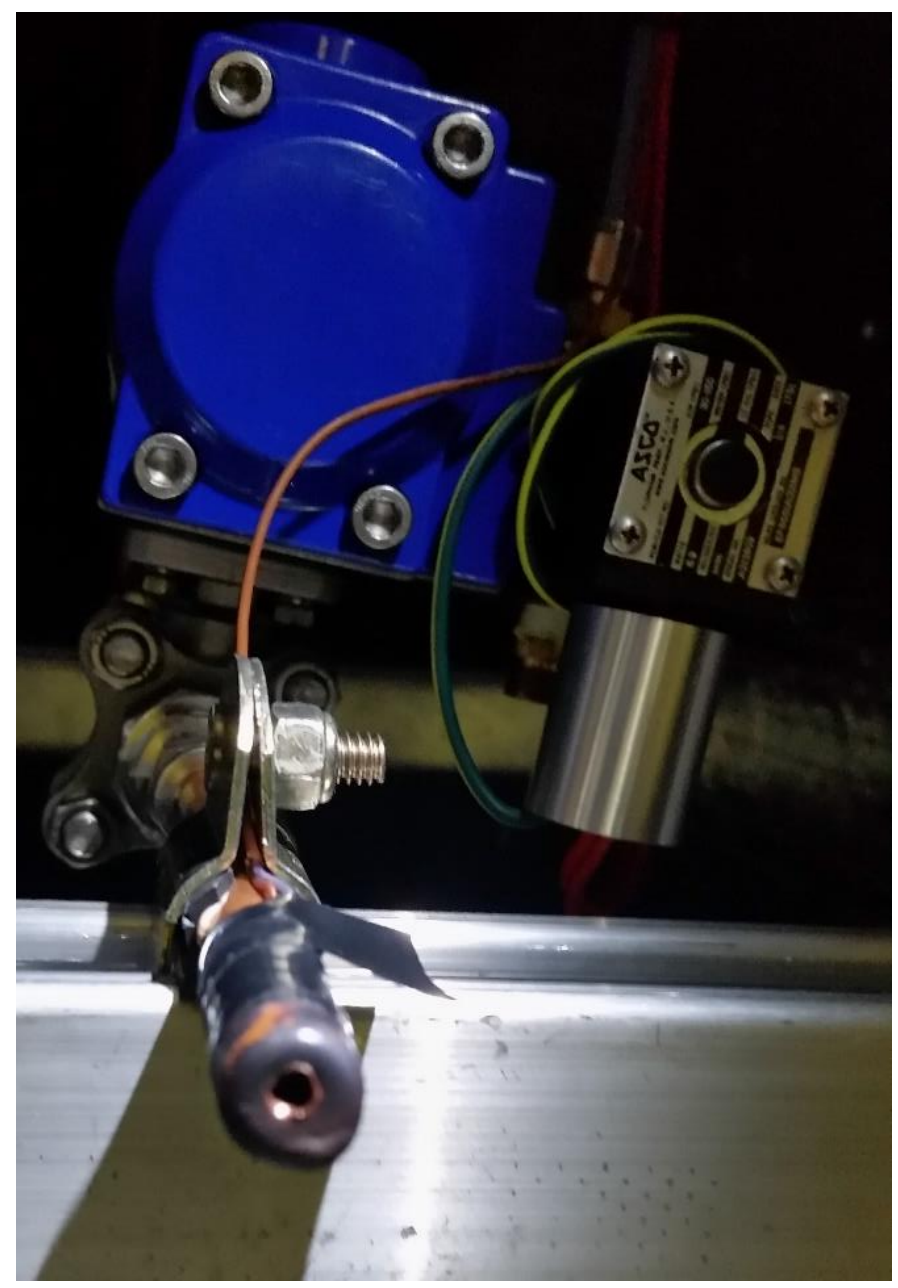

Figure 62. RTU leak release point with cap and 0.125 ” $(3.175 \mathrm{~mm})$ orifice for low leak rate tests

Results of tests to determine the impact of fan thrust on the unit weight data are given in Figure 63 . The ID blower thrust added about $0.22 \mathrm{lbs}(0.1 \mathrm{~kg})$ to the scale output while that of the OD fan and compressor added about an additional $2.5 \mathrm{lbs}(1.15 \mathrm{~kg})$ to the indicated weight. Data from the fan thrust tests were used to correct the refrigerant loss data from the leak tests. 


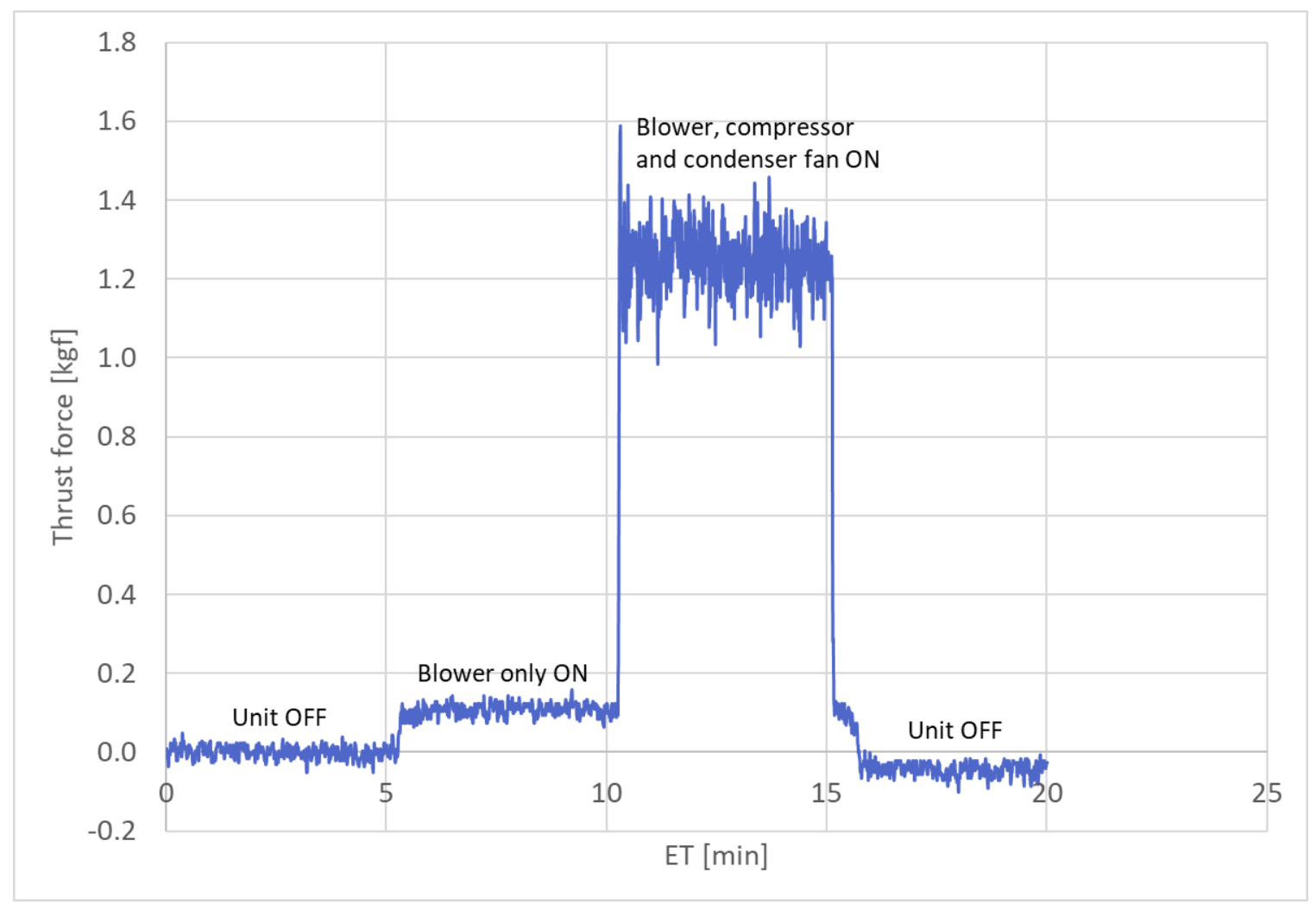

Figure 63. RTU fan thrust effect test results

Table 10 provides a summary of the RTU leak test results. Leak location, hole size, and compressor on/off status can be determined by referring to Figures 64-71. Due to the location of the leak release point inside the small supply air duct it was not possible to set up the oil capture pan for the RTU test series. Figures 64 - 71 provide graphical summaries of the normalized refrigerant loss data along with pressure decay vs. time for each test.

- All the RTU test results showed some refrigerant retention at the end of the 20-min test period, ranging from $3.3 \%$ to $12.1 \%$; generally, for the compressor "on" tests, more refrigerant was retained at test end for the corresponding compressor "off" tests (low side leak, lower rate tests 117 and 119 being the exceptions).

- For all of the compressor "on" tests, the compressor shut off shortly after the leak began (due to low pressure switch); the compressor (and condenser fan) attempted to restart one or a few times in each test (see the small inset charts in Figures 64, 65, 68 and 69 (b)).

- The compressor on, low-side leak tests showed the longest leak release times for both leak orifice sizes, and compressor on, high-side leak cases the shortest. The same general pattern held for the compressor off tests as well 
Table 10. RTU leak test results summary

\begin{tabular}{|c|c|c|c|c|c|}
\hline Test \# & $\begin{array}{c}\text { System } \\
\text { charge [lb] }\end{array}$ & $\begin{array}{c}\text { Total } \\
\text { charge } \\
\text { released } \\
{[\mathrm{lb}]}\end{array}$ & $\begin{array}{c}\text { Time to } \\
\text { release } \\
80 \% \text { of } \\
\text { total } \\
\text { charge [s] }\end{array}$ & $\begin{array}{c}\text { Average } \\
\text { leak rate } \\
\text { for 80\% } \\
\text { release } \\
{[\mathrm{lb} / \mathrm{min}]}\end{array}$ & $\begin{array}{c}\text { Charge left } \\
\text { in system } \\
{[\mathrm{lb}]}\end{array}$ \\
\hline 117 & 3.95 & 3.78 & 92.90 & 2.04 & 0.17 \\
\hline 118 & 3.95 & 3.47 & 30.50 & 6.21 & 0.48 \\
\hline 119 & 3.95 & 3.69 & 51.10 & 3.71 & 0.25 \\
\hline 120 & 3.95 & 3.69 & 33.40 & 5.67 & 0.27 \\
\hline 121 & 3.95 & 3.48 & 48.70 & 3.89 & 0.47 \\
\hline 122 & 3.95 & 3.56 & 18.00 & 10.52 & 0.39 \\
\hline 123 & 3.95 & 3.81 & 26.00 & 7.29 & 0.13 \\
\hline 124 & 3.95 & 3.78 & 19.40 & 9.76 & 0.17 \\
\hline
\end{tabular}

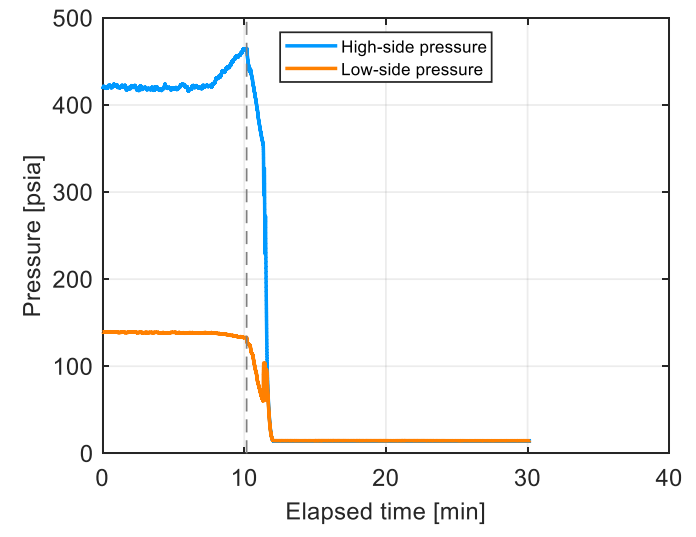

(a.)

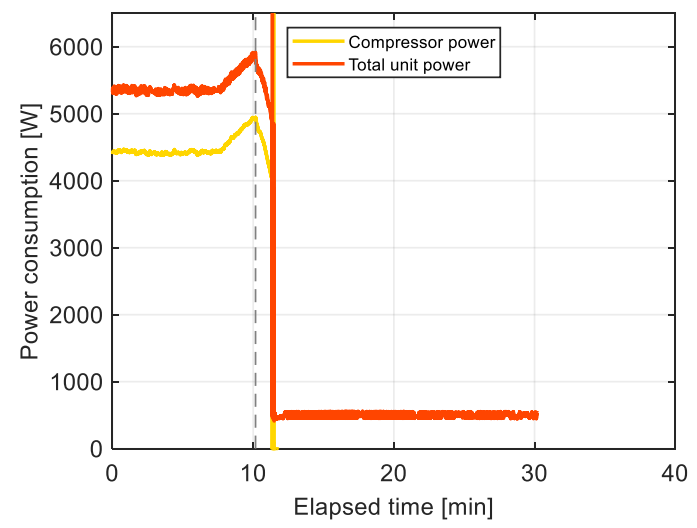

(c.)

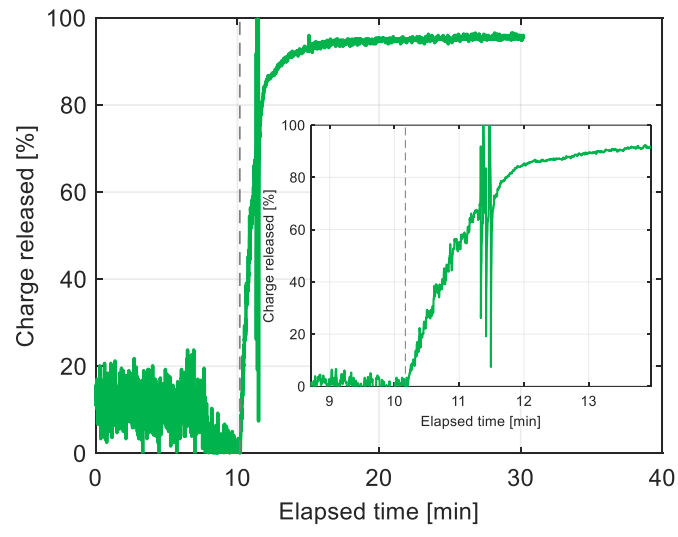

(b.)

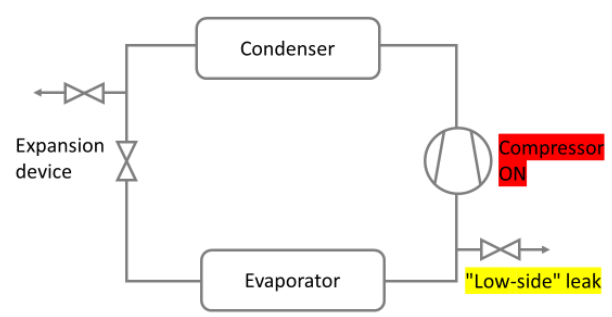

(d.)

Figure 64. (a.) High- and low-side pressure decay, (b.) percent charge released (c.) power consumption and (d.) system diagram for RTU test 117 (3.175 mm orifice) 


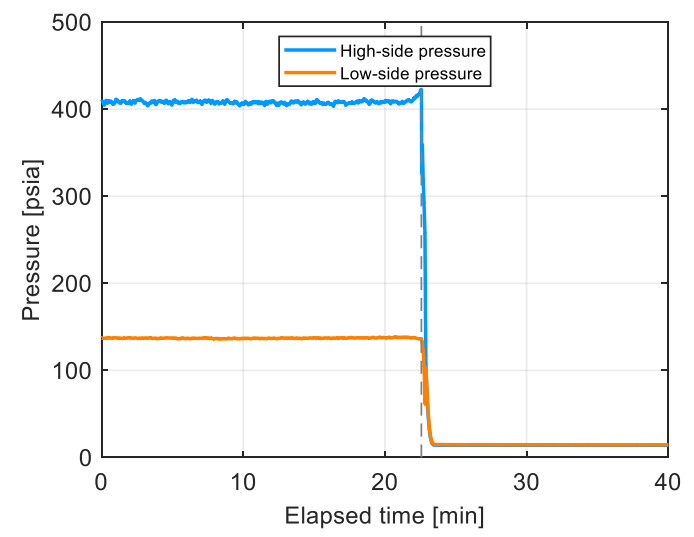

(a.)

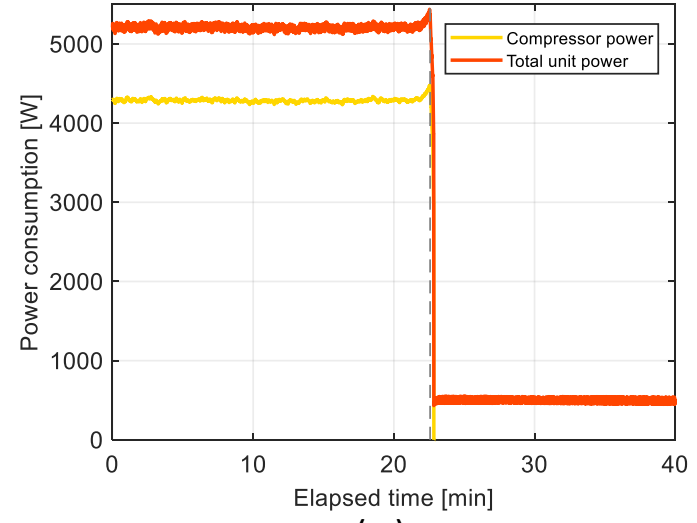

(c.)

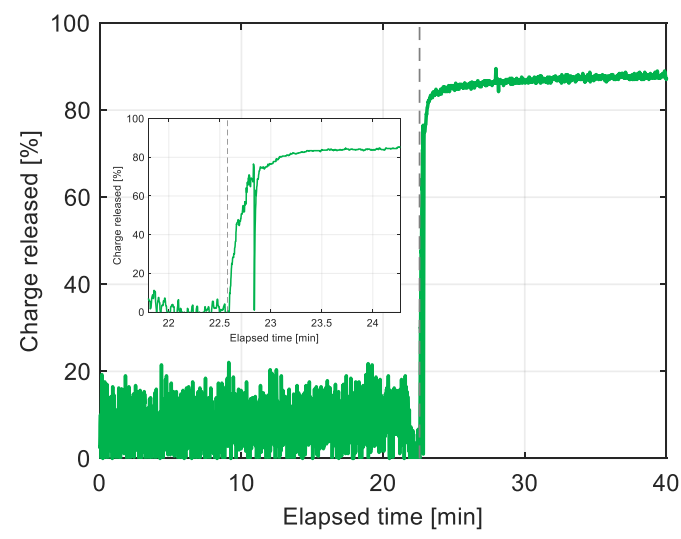

(b.)

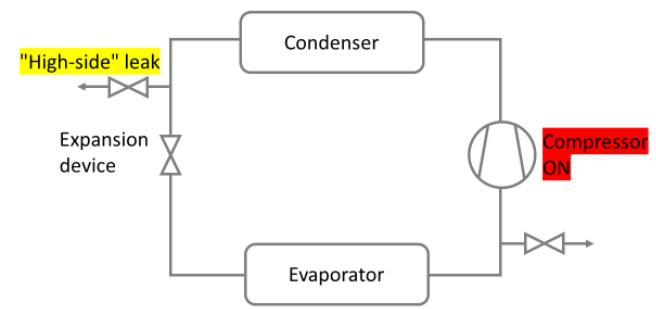

(d.)

Figure 65. (a.) High- and low-side pressure decay, (b.) percent charge released (c.) power consumption and (d.) system diagram for RTU test 118 ( $3.175 \mathrm{~mm}$ orifice) 


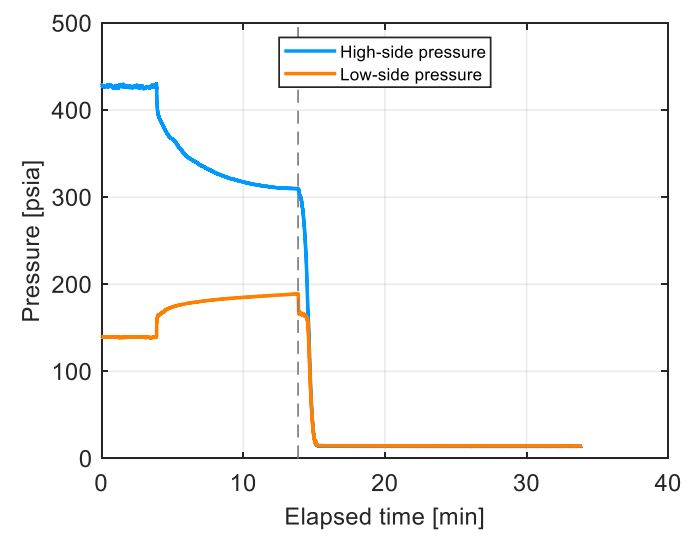

(а.)

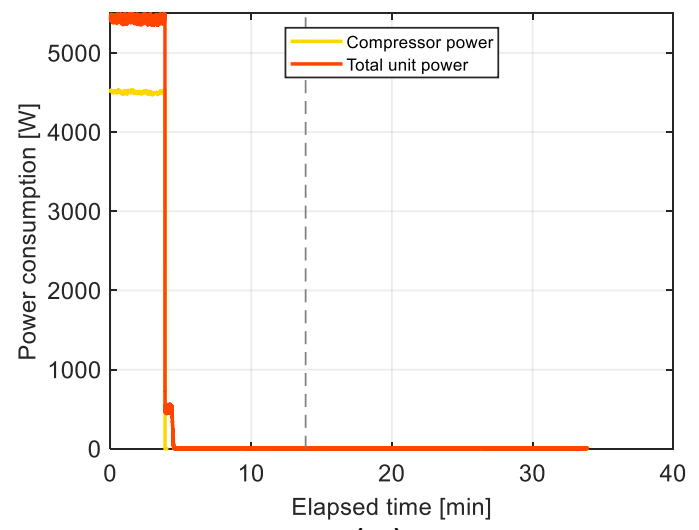

(c.)

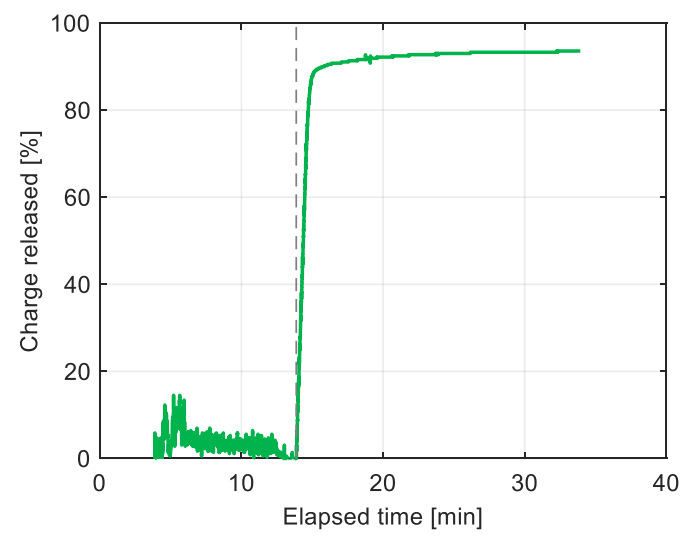

(b.)

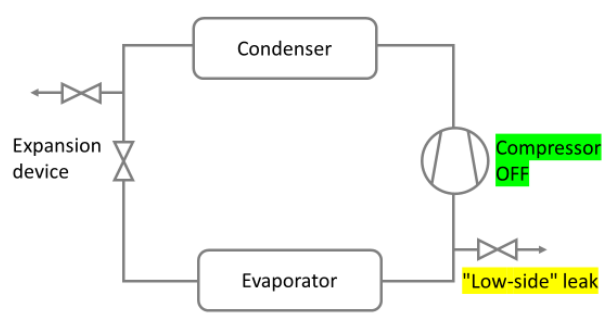

(d.)

Figure 66. (a.) High- and low-side pressure decay, (b.) percent charge released (c.) power consumption and (d.) system diagram for RTU test 119 (3.175 $\mathrm{mm}$ orifice) 


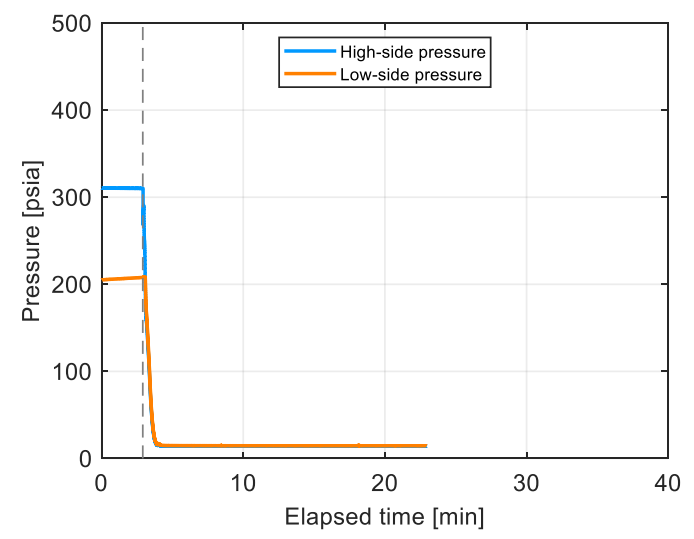

(а.)

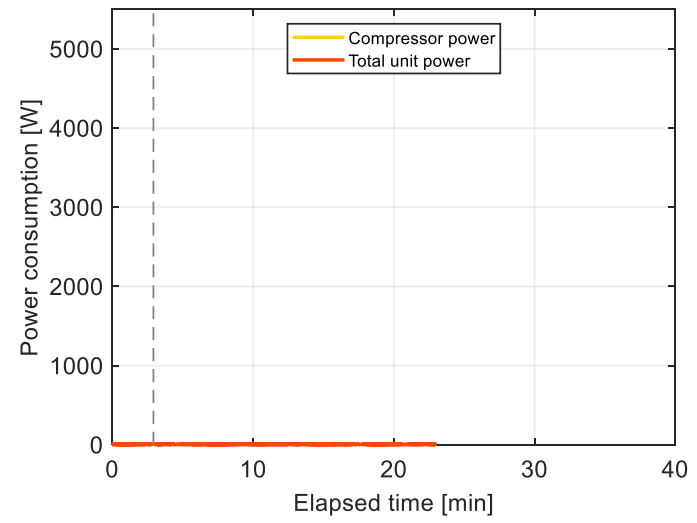

(c.)

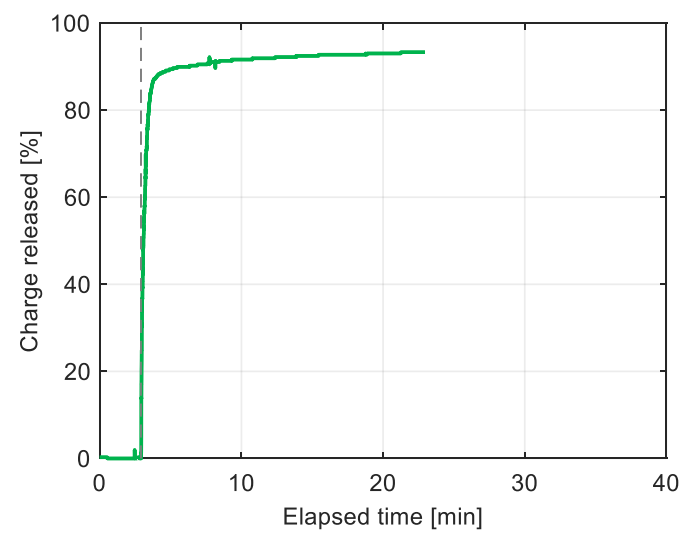

(b.)

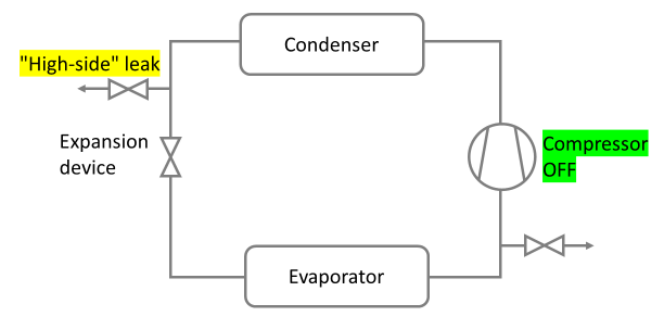

(d.)

Figure 67. (a.) High- and low-side pressure decay, (b.) percent charge released (c.) power consumption and (d.) system diagram for RTU test 120 ( $3.175 \mathrm{~mm}$ orifice) 


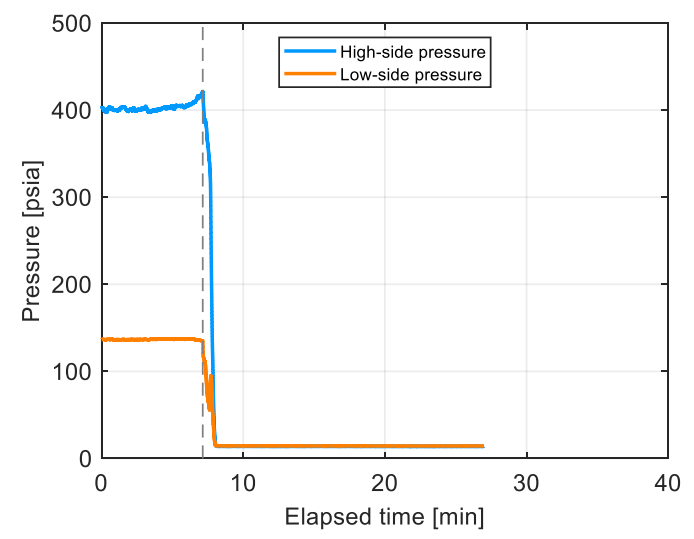

(а.)

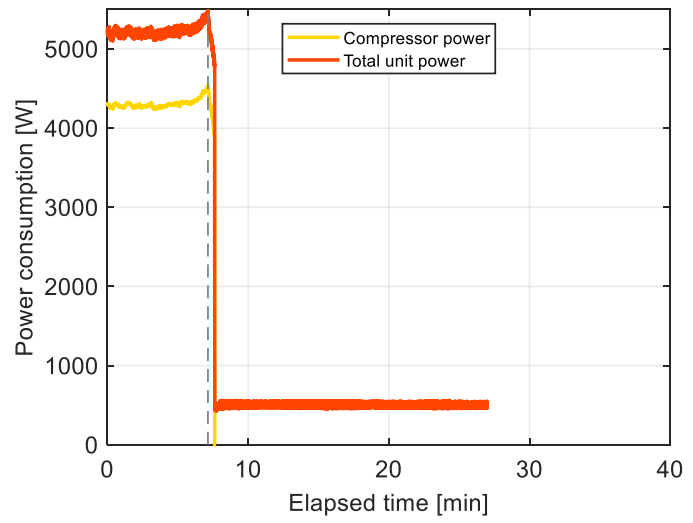

(c.)

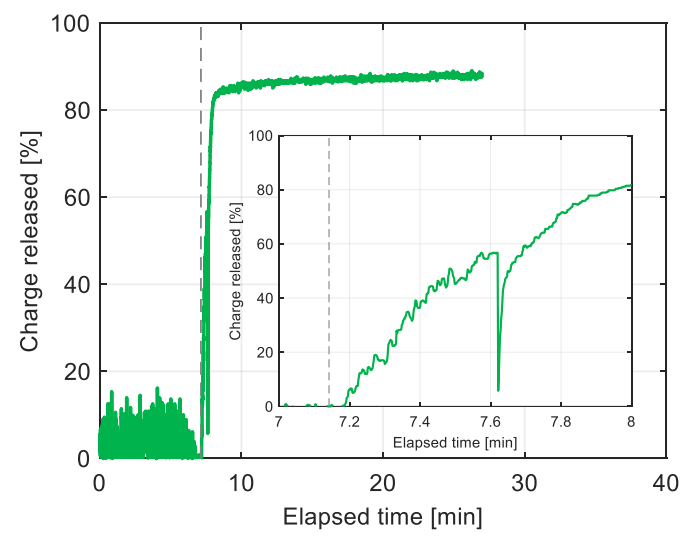

(b.)

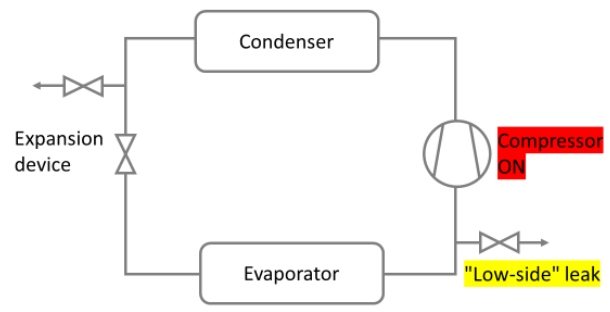

(d.)

Figure 68. (a.) High- and low-side pressure decay, (b.) percent charge released (c.) power consumption and (d.) system diagram for RTU test 121 (7.03 mm orifice) 


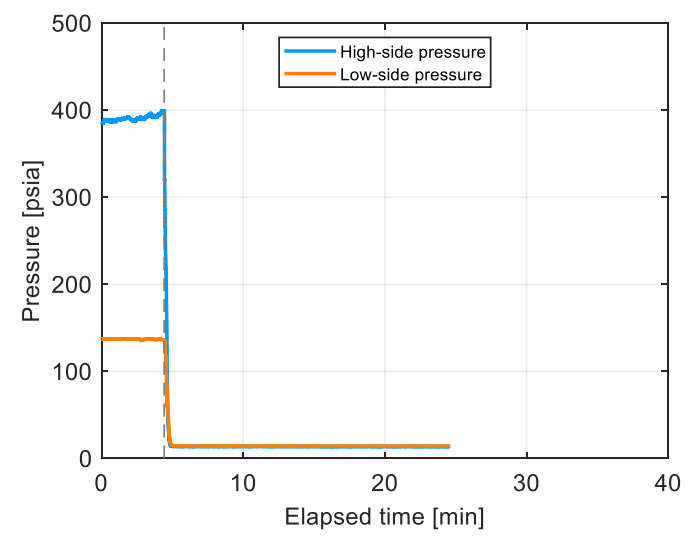

(а.)

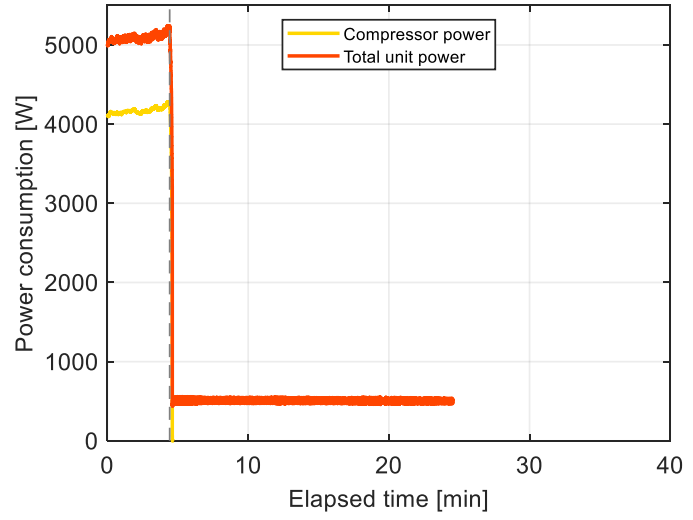

(c.)

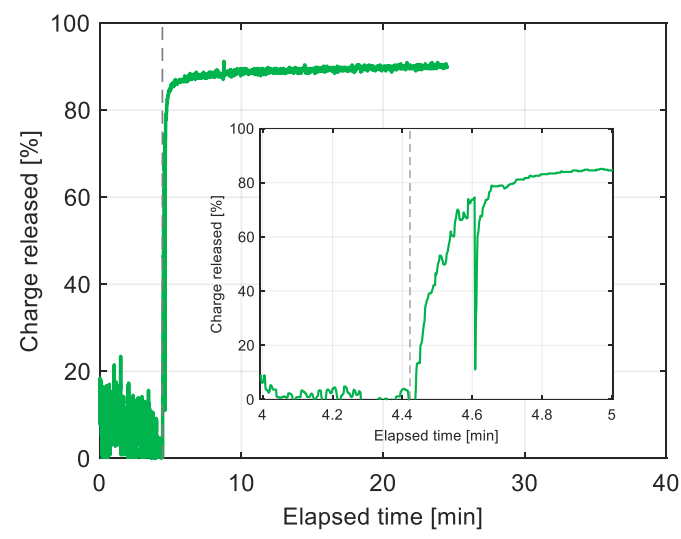

(b.)

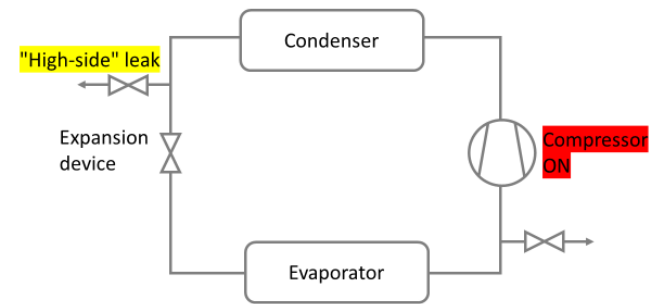

(d.)

Figure 69. (a.) High- and low-side pressure decay, (b.) percent charge released (c.) power consumption and (d.) system diagram for RTU test 122 (7.03 mm orifice) 


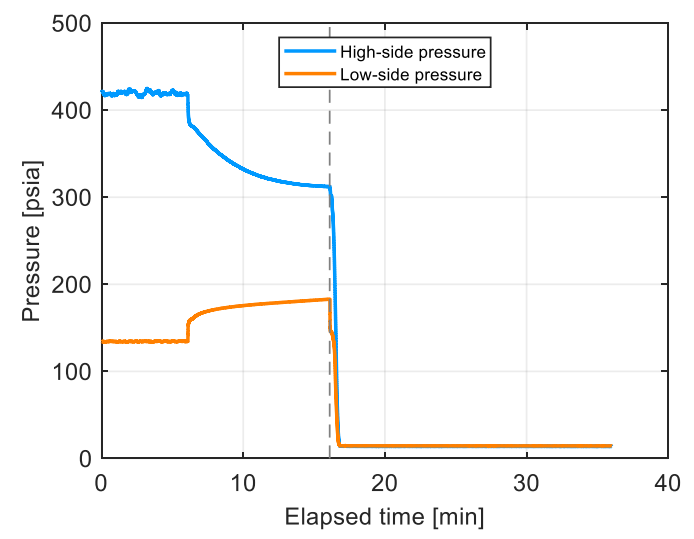

(а.)

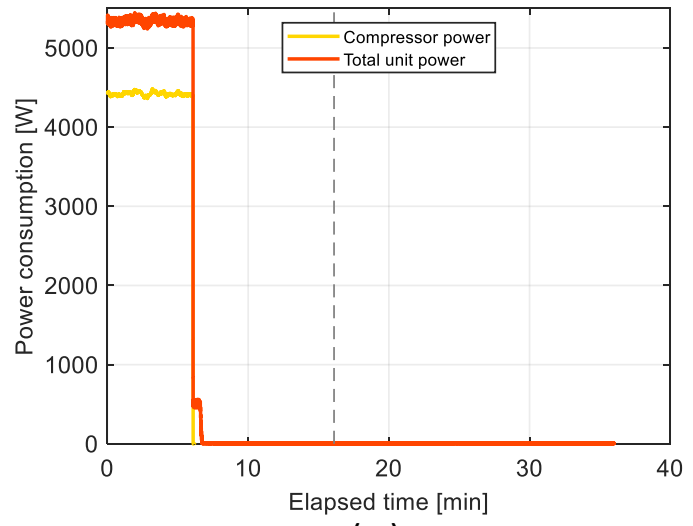

(c.)

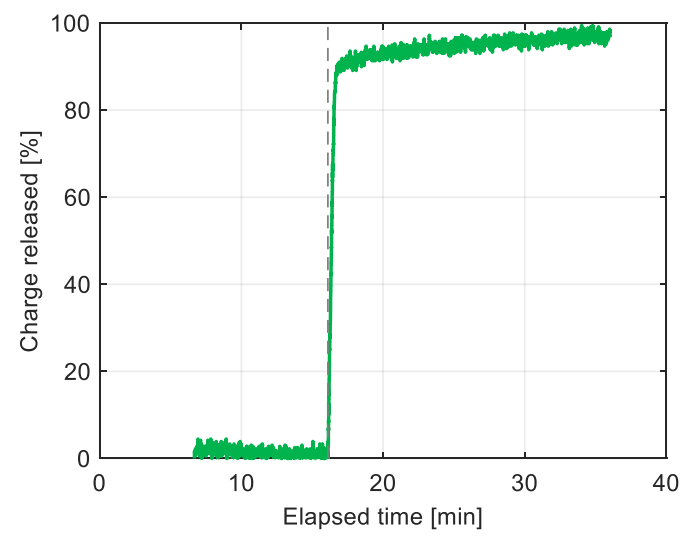

(b.)

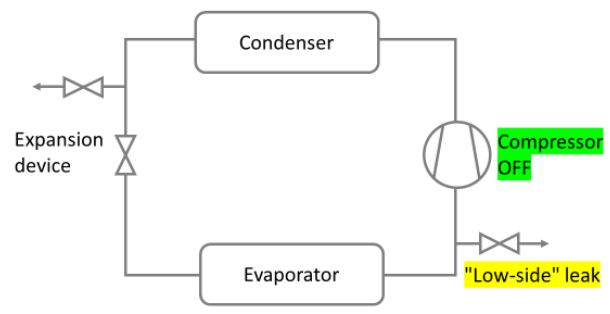

(d.)

Figure 70. (a.) High- and low-side pressure decay, (b.) percent charge released (c.) power consumption and (d.) system diagram for RTU test 123 (7.03 mm orifice) 


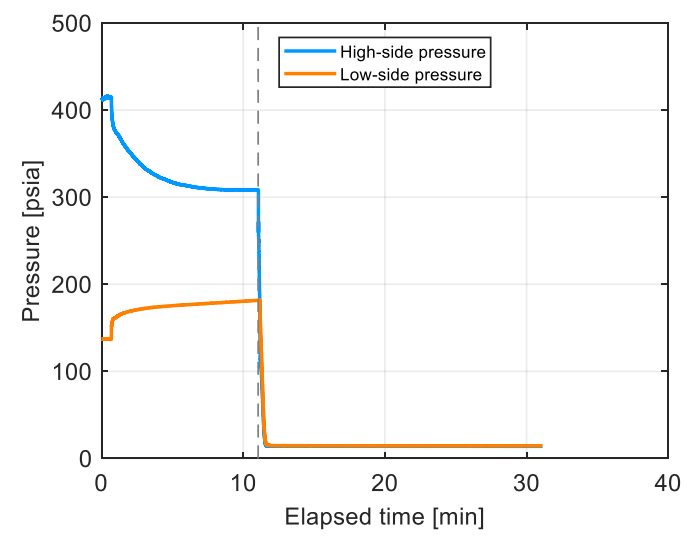

(а.)

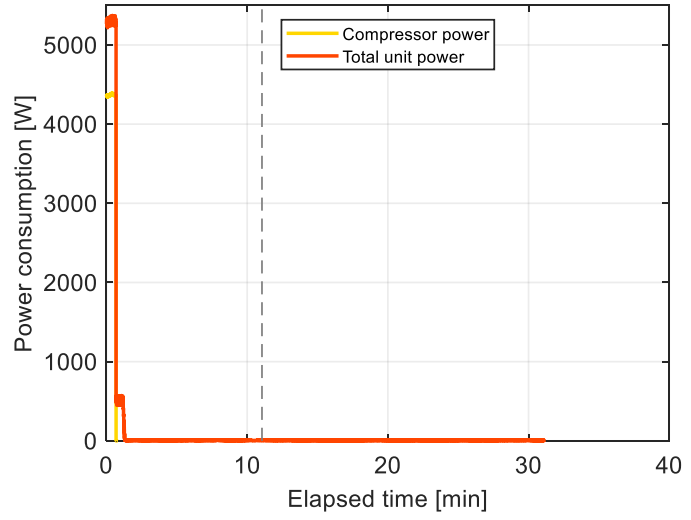

(c.)

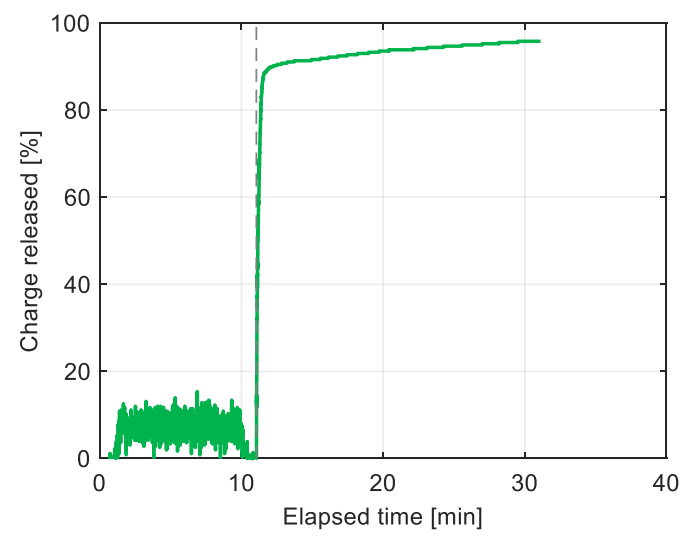

(b.)

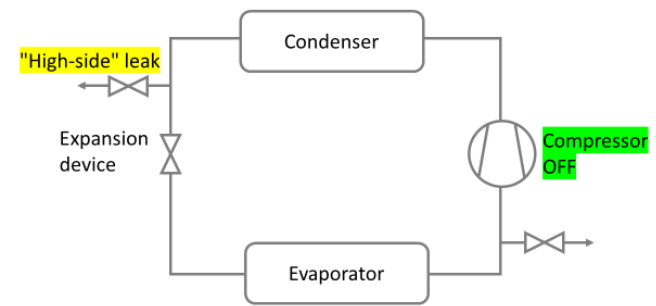

(d.)

Figure 71. (a.) High- and low-side pressure decay, (b.) percent charge released (c.) power consumption and (d.) system diagram for RTU test 124 (7.03 mm orifice) 


\section{LEAK QUALITY ESTIMATION}

\subsection{APPROACH}

An approach was developed for quantifying leak vapor quality for liquid release tests involving expansion of the released refrigerant into a closed volume. Initially we planned to use a flexible plastic bag as the closed "leak collection" container. However, due to problems with the bags expanding volume we switched to a 275-gallon (1041 1) capacity, rigid plastic tank (Figures 72 and 73). The tank would be weighed during the release and quality estimated based on the tank volume, mass of refrigerant released, and refrigerant properties. A general description of the data analysis approach is shown in Figure 74.

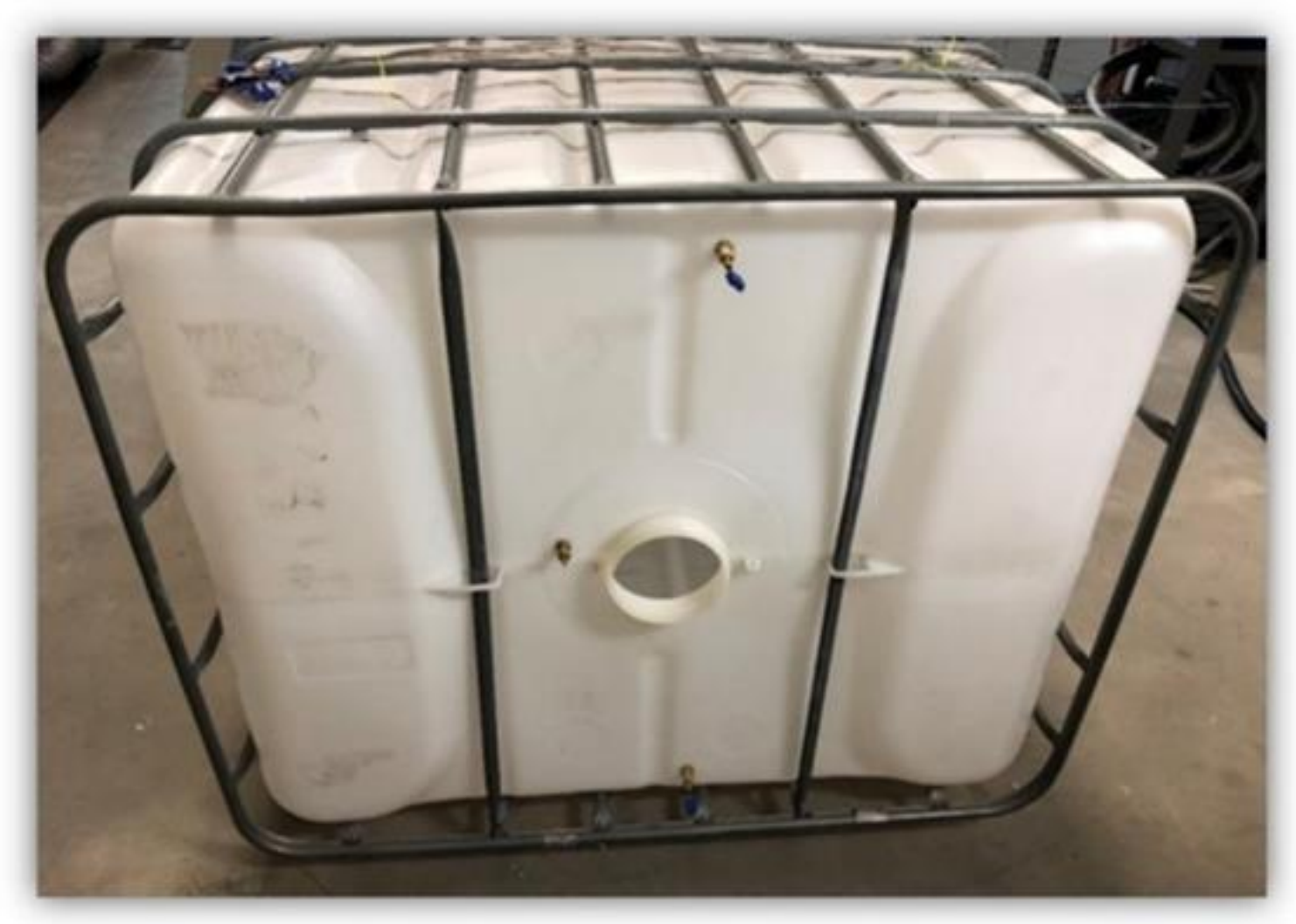

Figure 72. Tank used for leak quality estimation tests 


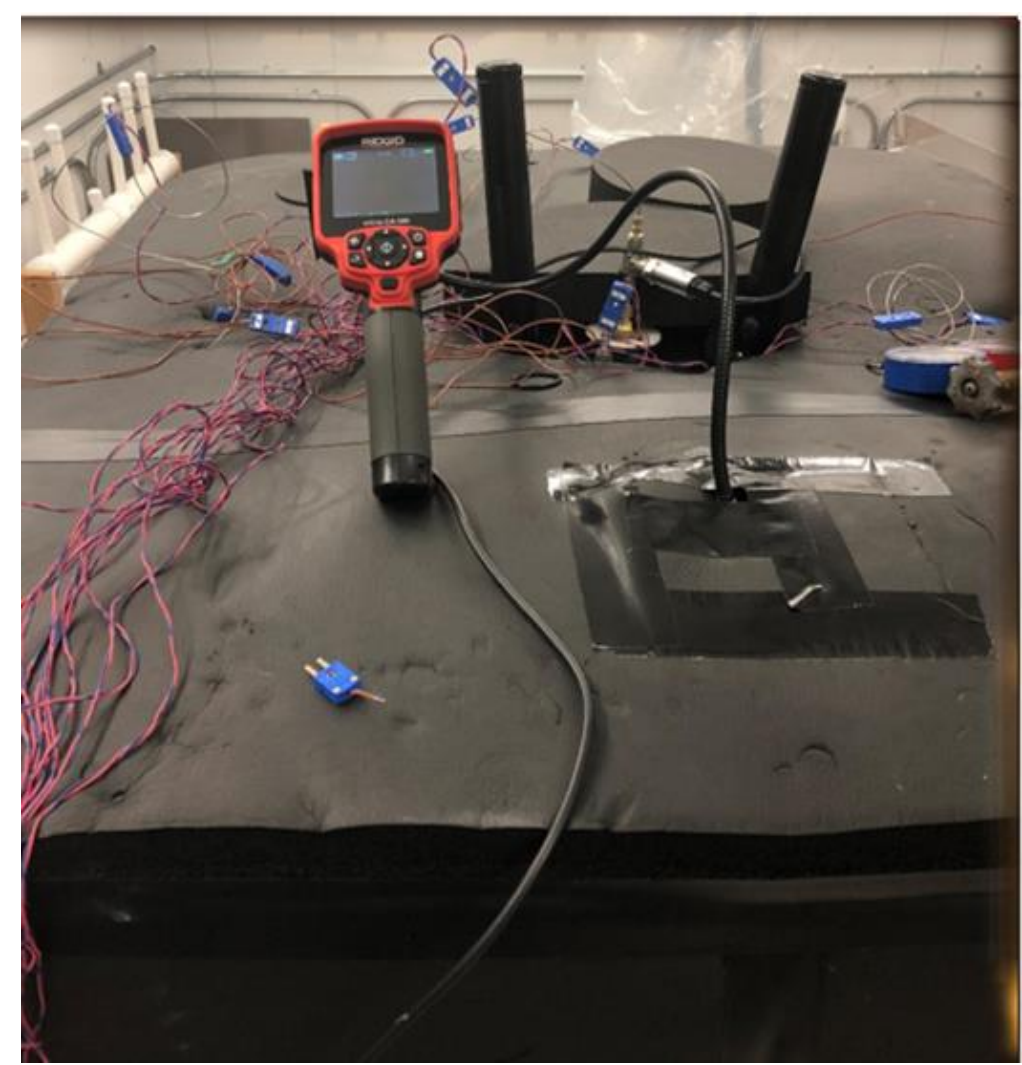

Figure 73. Tank instrumented and insulated

\section{BULK DENSITY \& P-v-T GAS MIXTURES}

Dalton's Law Additive Pressures [23]

$P_{\text {cont }}=\bar{P}_{\text {air }}+\bar{P}_{\text {ref }}$

$\bar{P}_{\text {ref }}=\frac{\eta_{\text {ref }}}{\eta_{\text {mix }}}\left(P_{\text {cont }}\right)=y_{\text {ref }} P_{\text {cont }}$

Amagats Law Additive Volumes [23]

$V_{\text {cont }}=\overline{V o l}_{\text {air }}+\overline{V o l}_{\text {ref }}$

$V o l_{\text {ref }}=\frac{\eta_{\text {ref }}}{\eta_{\text {mix }}}\left(\right.$ Vol $\left._{\text {cont }}\right)=y_{\text {ref }} V_{\text {ol }}$ cont

ㄷ $\bar{\rho}_{\text {ref }}=\frac{m_{\text {Ref }}}{y_{\text {Ref }} \text { Vol cont }}$

Q Quality in Container [24]

$x(t)_{\text {cont }}=\frac{\rho_{v}}{\rho_{v}-\rho_{L}}-\frac{\rho_{v}}{\bar{\rho}_{\text {ref }}}\left[\frac{\rho_{L}}{\rho_{v}-\rho_{L}}\right]$

IIf $\rho_{L} \gg \rho_{V}$ then to first order

$x(t)_{\text {cont }}=\frac{\rho_{v}}{\bar{\rho}_{\text {ref }}}$

\section{ENERGY BALANCE OF CONTAINER [23]}

口 Internal Energy \& Mass Vap/Liq

$U_{1}=\left[m_{f \text { vap }} \cdot u_{\text {vap }}+m_{f l i q} \cdot u_{\text {liq }}\right]_{1}$

$U_{2}=\left[m_{f \text { vap }} \cdot u_{\text {vap }}+m_{f l i q} \cdot u_{\text {liq }}\right]_{2}$

$$
h_{\text {Leak }}=\frac{U_{2}-U_{1}}{\left(m_{2}-m_{1}\right)}-\frac{\dot{Q}_{C V} \cdot \Delta t}{\left(m_{2}-m_{1}\right)}
$$

$\dot{Q}_{c v}=\dot{m}_{r e f} \cdot h_{f g}$

$$
\dot{m}_{r e f}(t)=\frac{m_{2}-m_{1}}{\Delta t}
$$

$$
x(t)_{\text {ref }}=\frac{\left[h_{\text {Leak }}-h_{L}\right]}{\left[h_{f g}\right]}
$$

Figure 74. Data analysis approach for leak quality estimation 


\subsection{TEST RESULTS}

Preliminary tests were conducted to help formulate and validate a testing procedure and an algorithm for predicting the quality of a refrigerant leak. A refrigerant charging cylinder containing R-134a served as the refrigerant source. The rigid plastic container held the leaked refrigerant while maintaining near atmospheric pressure. The container was instrumented with temperature and pressure sensors. A video device was used to observe the leak flow leaving the orifice (Figure 73). A flexible elastomeric thermal insulation was attached to all exterior surfaces of the container to retard heat gain and prevent condensation of water vapor in air near the exterior surfaces of the container. The refrigerant charging cylinder was placed on an electronic weigh scale to meter the amount of R-134a refrigerant manually leaked across a needle valve into the container for two leak flow rates: $0.5 \mathrm{~g} / \mathrm{s}$ and $5 \mathrm{~g} / \mathrm{s}(4 \mathrm{and} 40 \mathrm{lb} / \mathrm{hr})$. APPENDIX $C$ provides more description of the testing and calculation procedure. Briefly, calculation of the refrigerant enthalpy upstream the needle valve is based on computed P-v-T relations for the captured mixture of air, an ideal gas, and for R-134a, a real gas. The quality of refrigerant in the container was computed from the mass of captured air and R-134a and P-v-T relationships. An energy balance for flow entering the container was used to compute the enthalpy upstream the needle valve. The computed enthalpy is compared to the saturated liquid and vapor enthalpy of refrigerant in the weigh cylinder, Figure 75. The results show that the computed enthalpy based on P-v-T relationships for the container and a $1^{\text {st }}$ Law energy balance is consistent with thermodynamic principals.

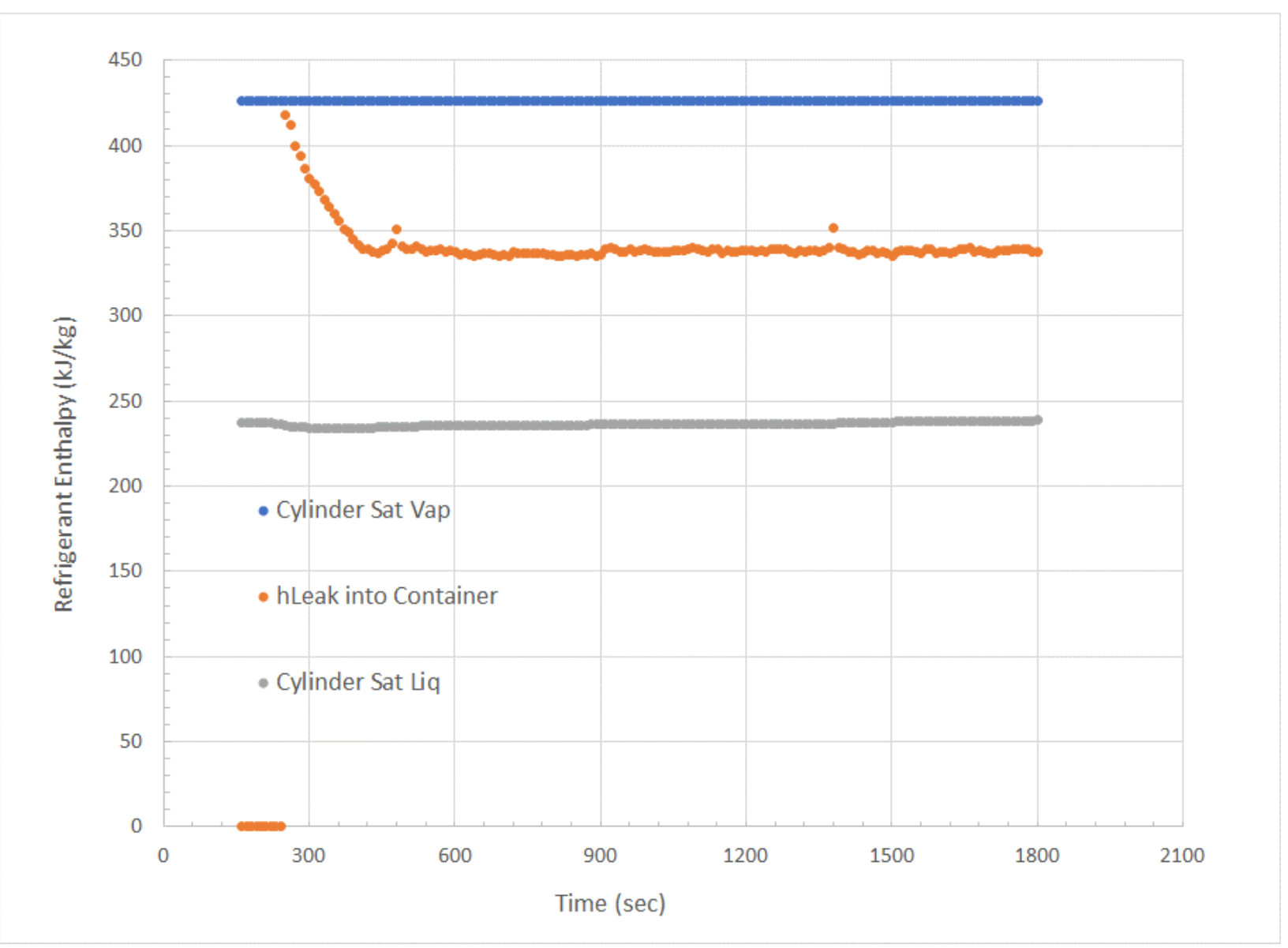

Figure 75. Leak quality estimates (in plastic container and refrigerant cylinder) for $0.5 \mathrm{~g} / \mathrm{s}$ leak

The refrigerant enthalpy in the container was found to be between the saturated vapor and liquid states in the refrigerant cylinder, which is consistent with an isenthalpic throttling process. Visual inspection of the 
leak showed it to start as a high-pressure vapor flow which transitioned more to a sputtering two-phase liquid and vapor flow. The data was reduced further using the equations outlined in Figure 74 for computing the refrigerant quality $\left[\mathrm{x}(\mathrm{t})_{\mathrm{ref}}\right]$ upstream the leak near the refrigerant cylinder, Figure 76 . At leak start the quality of the refrigerant is high, near a value of one, and gradually drops over the $1800 \mathrm{~s}$ duration of the test. There is also seen an increase in the quality of refrigerant within the container. For this test, liquid refrigerant was observed pooled on the bottom of the container. Measurement of the pooled liquid would be difficult. Therefore, an alternative approach using computed partial pressure of refrigerant and air was attempted for estimating the amount of saturated liquid refrigerant and vapor accumulating in the container. The computation for internal energy change in the container was based on quality estimates in the container, and the enthalpy entering the container was computed from an energy balance for the enclosed container. The overall pressure of the plastic tank rose slightly from 98.6 to $99.97 \mathrm{MPa}$ (14.3 to $14.5 \mathrm{psia}$ ). Therefore, the results were promising enough to attempt tests on the packaged 5-ton rooftop AC unit (RTU).

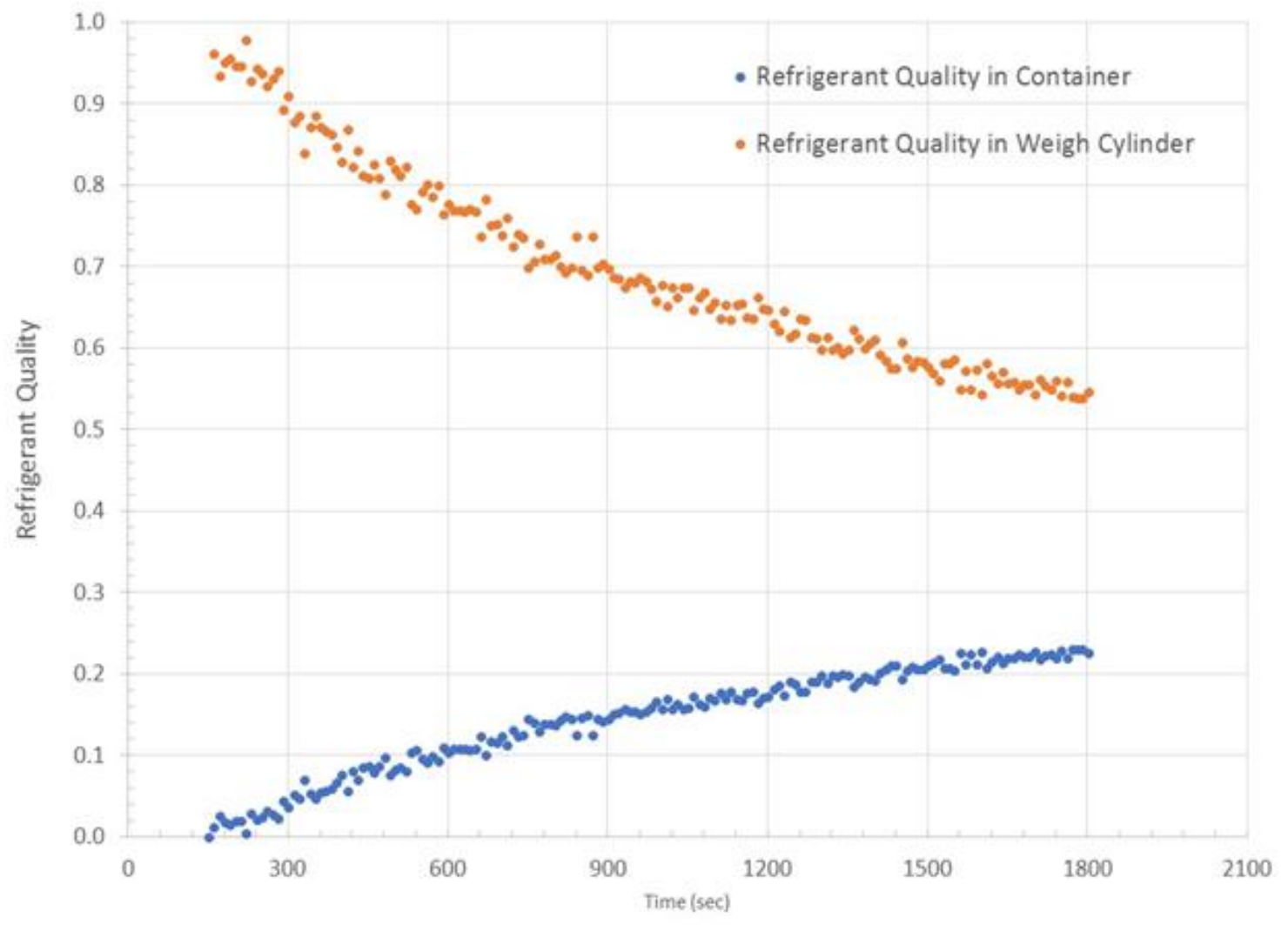

Figure 76. Leak quality estimates (in plastic container and refrigerant cylinder) for $0.5 \mathrm{~g} / \mathrm{s} \mathrm{leak}$

\subsection{TEST RESULTS FOR RTU UNIT}

The approach and procedure for quality estimation followed closely that used for the leak tests $117-124$, Table 2. Therefore, the existing setup (Figures 61 and 62) and the existing manifold for liquid and suction lines at the evaporator (Figure 60) were used. However, a smaller orifice of $1 \mathrm{~mm}$ was used to allow more time to observe the leakage of R-410A refrigerant while limiting the pressure increase in the finite volume container of 275-gallon (1041 1) capacity. It was important to maintain near atmospheric pressure in the container to best simulate a leak to the surrounding ambient. Leaks were initiated on the high-side (liquid 
line upstream expansion valve) and on the low-side (vapor line between evaporator and compressor suction). Tests were run with the RTU on and off. The weight of the RTU and the weight of the container were monitored with the same weigh scales used for Table 2 tests.

Leaking refrigerant from the low-side yielded a refrigerant quality of 1 for tests with the unit running. The refrigerant leaving the evaporator is superheated vapor and a reduction in refrigerant pressure across the orifice would cause the refrigerant state to remain outside and to the lower right side of the saturated refrigerant dome for R-410A. Therefore, the leak would remain a vapor with a quality of 1 .

Leaking from the low-side but with the RTU off did show a quality less than 1 over the leak interval. Figure 77 shows the total weight of the RTU (left ordinate scale) and of the container (right ordinate scale). The change in weight over time shows refrigerant movement to/from the RTU and the container. The RTU was run for several minutes to establish a steady-state operating condition like that conducted in Table 2 tests. The RTU and the outdoor chamber system were deenergized and after about $80 \mathrm{~s}$ the leak was initiated. The $80 \mathrm{~s}$ delay helped eliminate thrust effects of the chamber blower, compressor and fans on the weight scale for the RTU. The change in weight of the scale measuring the container was $0.49 \mathrm{~kg}$. The change in weight of the scale measuring the weight of the RTU was $0.65 \mathrm{~kg}$.

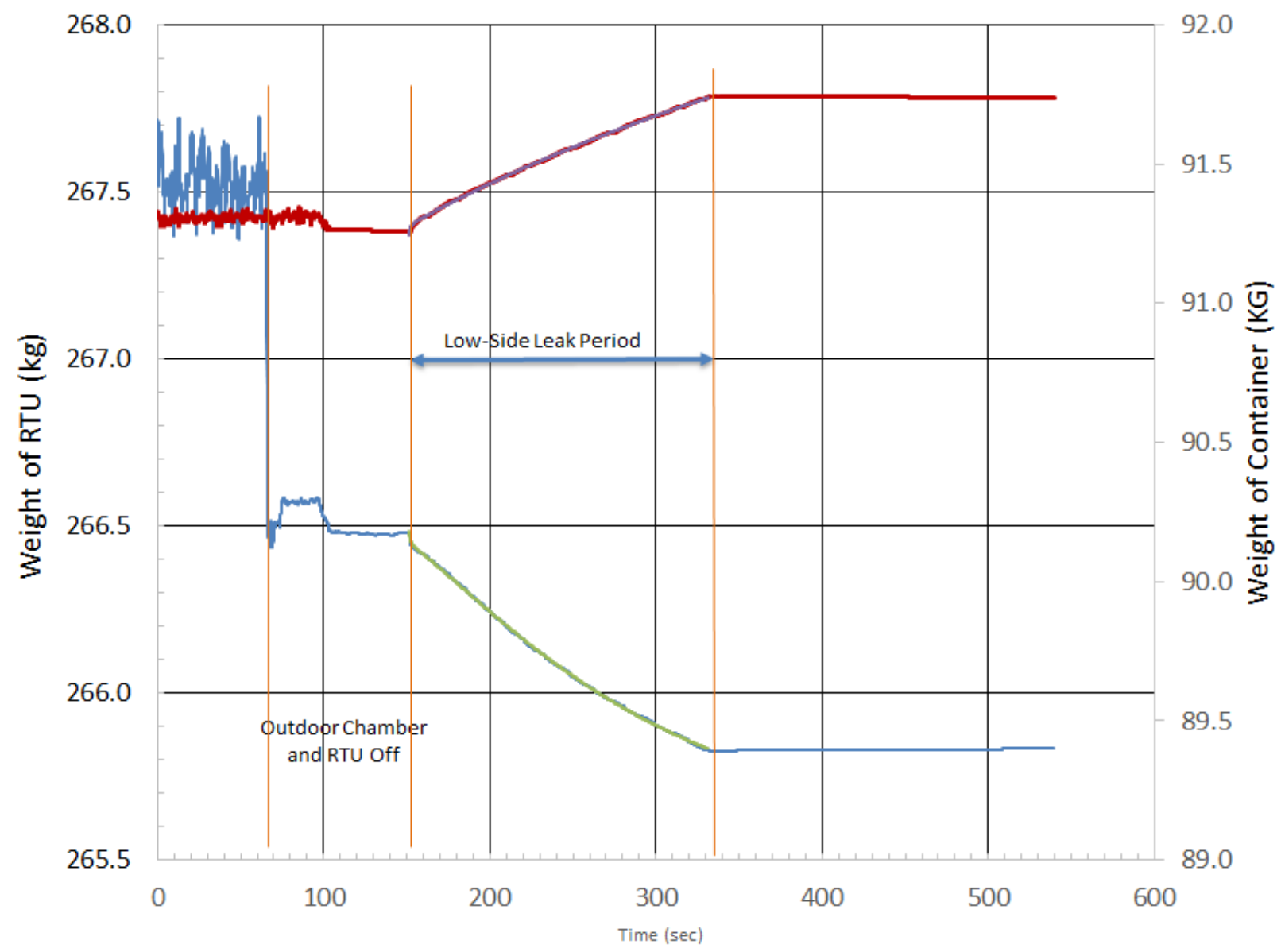

Figure 77. RTU and container weights showing the movement of refrigerant during the low-side leak with the unit turned off

Table A 1 in APPENDIX A lists the salient features of the floor weight scales used in the experiments. The scale recording weight of the RTU has a readability of $\pm 5 \mathrm{~g}$ while the scale used to weigh the container has a readability of $\pm 2 \mathrm{~g}$. The leak line attached to the container has a flexible section designed 
to help eliminate thrust vibration effects especially at the start of the leakage. However, this reading remained subject to some oscillation/vibration as noted in Figure 77. The scale associated with the RTU is affected by the thrust of the chamber blower and the RTU's compressor, fan and blower motors when they are operating. For tests when the RTU is off refrigerant weight data from the RTU scale was considered more stable and accurate and was used for the quality estimation computations described in Figure 74. However, if the RTU is running, data from container scale is considered more stable/accurate.

The quality of the refrigerant at the start of the leak was 1 and dropped steadily as time progressed, Figure 78. As noted above, with the unit running the low-side leak remained a superheated vapor throughout the test. Once the unit deenergizes, pressures equalize rapidly in about 1 to 2 minutes causing some high-side liquid refrigerant to equilibrate toward the low-side. The redistribution of refrigerant causes the drop in refrigerant quality shown in Figure 78, which appears to level out at a quality of about 0.85 .

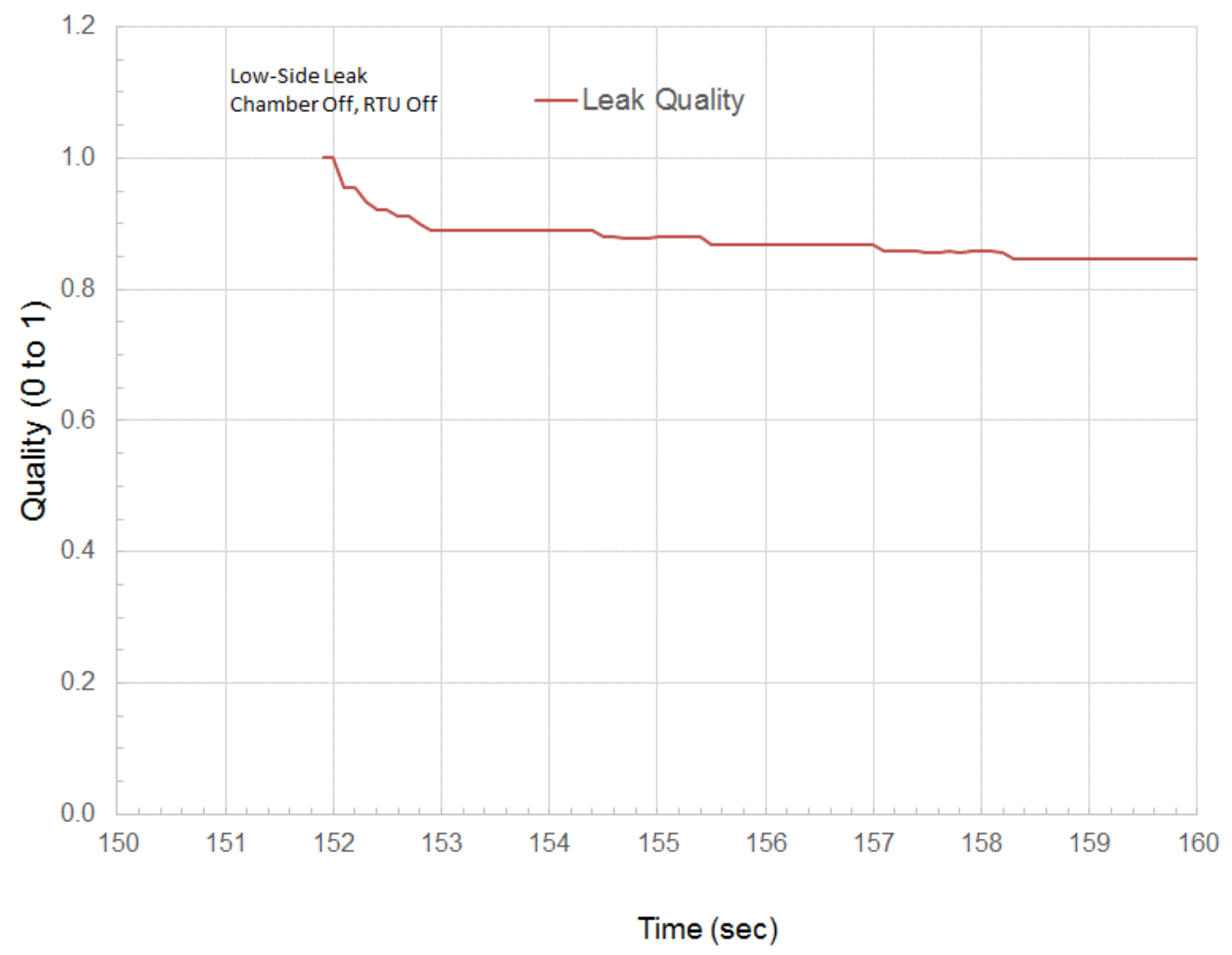

Figure 78. Leak quality estimates for low-side tests of the RTU turned off after running at steady-state

Testing continued with refrigerant leaked from the high-side of the RTU. Quality estimates were similar whether the RTU was on or off. Figure 79 shows the weights and redistribution of refrigerant once the leak is initiated with the RTU running. After about $60 \mathrm{~s}$ of refrigerant leakage the compressor started to cycle on/off as low-side pressure dropped. A low-side pressure switch stopped the unit, but the compressor and condenser fan attempted to restart as observed in Figure 79. The weight of the container was not affected by the cycling and allowed some measure of quality. 


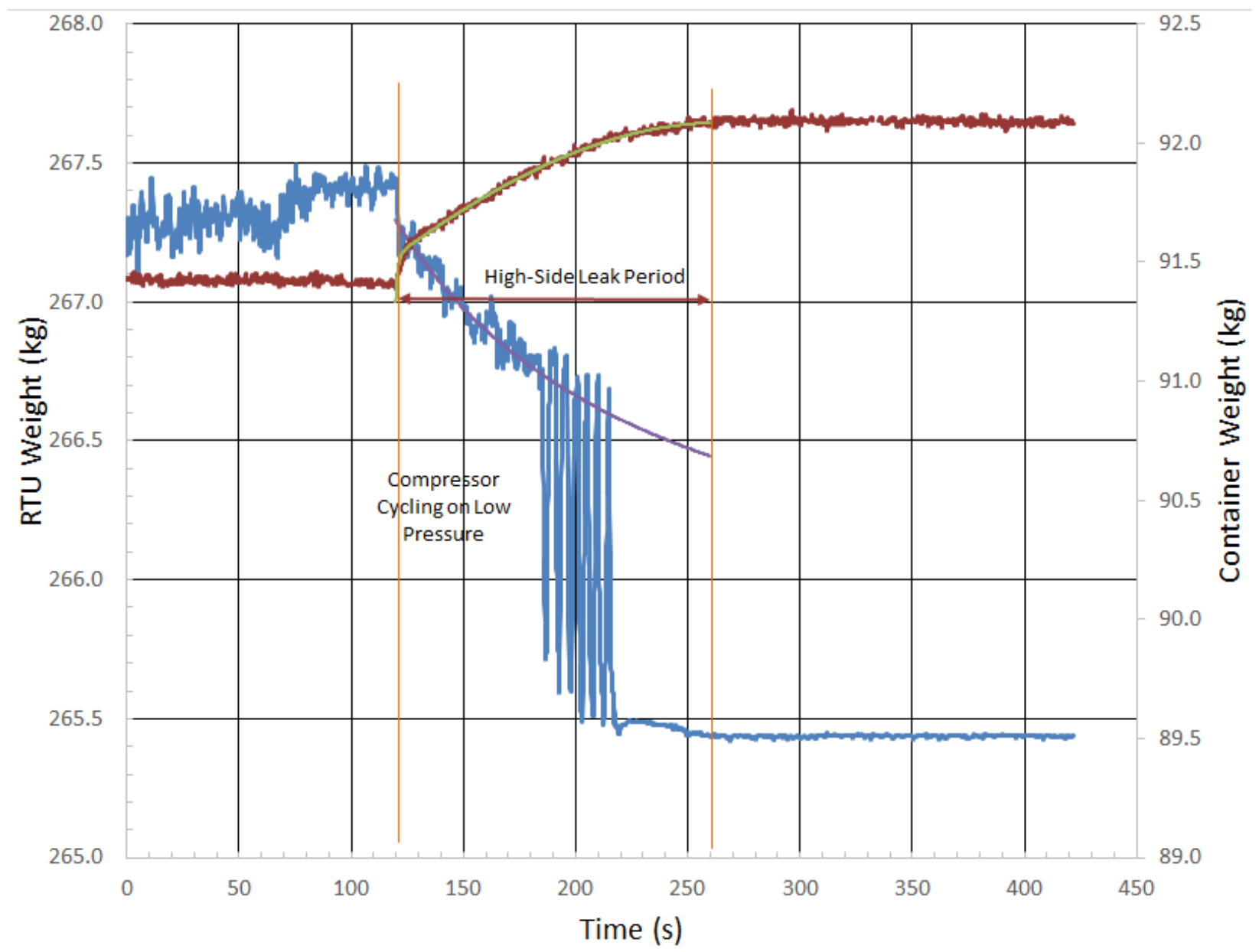

Figure 79. RTU and container weights showing the movement of refrigerant during the high-side leak with the unit running

The refrigerant quality starts at 1 but drops within seconds as liquid refrigerant is released from the highside of the liquid line. Within about $35 \mathrm{~s}$ the quality drops from 1 to 0 as refrigerant liquid fills the leak line and is released into the container, Figure 80. As stated earlier, similar quality trends occur for leakage from the high-side with the unit turned off. During the test the container pressure rose from $100 \mathrm{kPa}$ to $107 \mathrm{kPa}$ and remained constant for the duration of the test showing the container to be leak tight. 


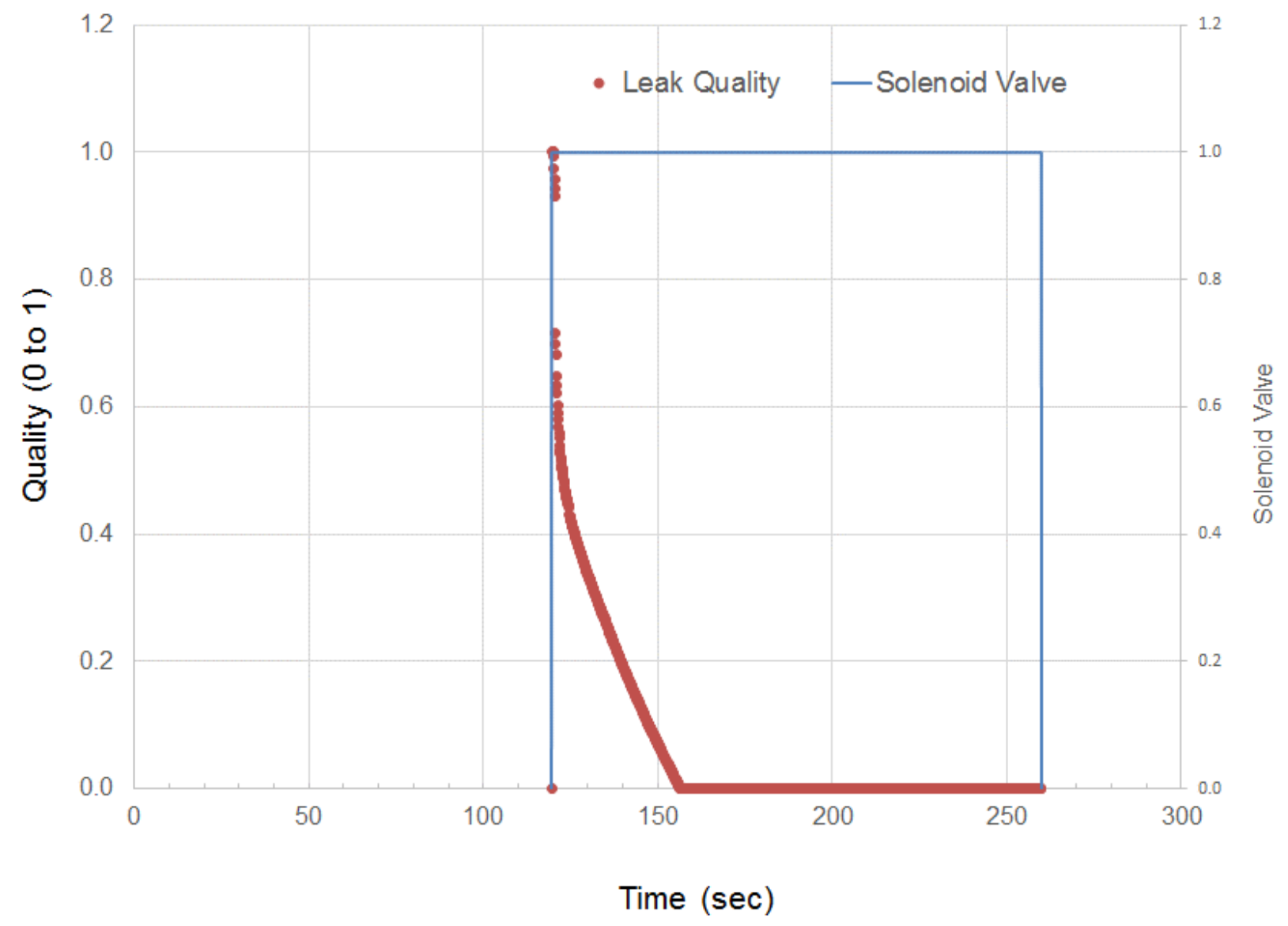

Figure 80. Leak quality estimates for high-side tests of the RTU running at steady-state 


\section{CONCLUSIONS AND SUMMARY}

The US Department of Energy (DOE) Building Technology Office (BTO) and AHRTI collaborated to sponsor an experimental study of refrigerant leak characteristics at ORNL; AHRTI project 9012. The original objectives were to conduct refrigerant leak testing under real life conditions (operating and static) to document the pressure decay rate and the mass flow rate of leaked refrigerant as a function of time. Estimates of the quality (vapor versus liquid) of the leaking refrigerant and oil escaping with the leak were also desired. The project involved imposing refrigerant leaks on five systems and conducting tests to obtain data to meet the project objectives. Systems chosen covered three air-conditioning (AC) applications (packaged terminal AC or PTAC, 3-ton residential split system AC, and 5-ton packaged rooftop AC or RTU) and two refrigeration applications (split system unit cooler, and standalone display case). AHRTI members donated the test systems used for the project. The systems were to be tested at two different leak rates (catastrophic high rate simulating full line break and a lower flow rate), two leak locations (high-pressure side and low-pressure side), and two operating conditions (compressor on or off).

Based on results from the leak tests for the split AC, PTAC, standalone display case, and RTU AC systems:

- The compressor on, high side release, larger orifice showed the fastest leak flow rate

- The compressor on, low side release, smaller orifice showed the slowest leak flow

- In general - with compressor on the high side leak rates are greater than the low side rates (higher pressure and density at the leak location); with the compressor off, high side leak rates are lesser than the low side rates (larger line size, less flow resistance to leak location on compressor suction line)

For the unit cooler system, the general test result trends were different. The refrigeration circuit for this system included a normally closed solenoid valve in the liquid line upstream of the thermostatic expansion valve (TXV). When the room temperature control thermostat is satisfied this valve closes isolating the evaporator. The system also uses a pump down cycle at thermostat shut down to move most of the refrigerant in the evaporator to the condensing unit. As a result, low side leaks with the unit compressor off resulted in only very small refrigerant loss (4\% of the charge for the low leak rate or smaller orifice case and $6 \%$ for the high leak rate case). Other general observations include:

- For the high side leaks, rates with compressor off are somewhat greater than for compressor on, opposite the trend seen with the other units tested

$\circ$ For compressor off tests, the liquid line solenoid valve is closed and the system pump down cycle had moved most of the refrigerant to the condensing unit; with the compressor on, the solenoid valve remained open and no pump down cycle occurred before the leak so less refrigerant was located in the high side of the system.

Additional highlights:

- $\quad$ Split AC system leak test results

○ Nearly all of the system charge was released (96-100\%) for all eight test scenarios

- For the compressor off and low side leak tests about $0.17 \mathrm{lb}(0.077 \mathrm{~kg})$ of oil is estimated to have been ejected with the refrigerant; there was no measurable oil leakage for any of the other tests. These were the only tests in which any measurable accumulation of oil was observed in the catch pan for any of the tests run.

- $\quad$ PTAC leak test results 
- $~ 100 \%$ of charge was released for all tests except the two compressor on tests with the smaller orifice size (for the low and high side leak locations, the PTAC retained $\sim 8 \%$ and $\sim 4 \%$ of the charge, respectively)

$\circ$ There was no measurable oil release during any of the tests

- Standalone display case leak test results

$\circ$ The only test condition to show $100 \%$ charge release was the compressor on, high side leak

○ All other tests showed 2-5\% charge retention

$\circ$ There was no measurable oil release during any of the tests

- Unit cooler leak test results (high leak rate)

○ No measurable oil release during any of the tests

- $\quad$ RTU AC leak test results

- No significant oil release observed during any of the tests (oil catch/weigh system not used for the RTU tests)

- All of RTU test results showed some refrigerant retention at the end of the 20-min test period, ranging from $3.3 \%$ to $12.1 \%$; generally, for the compressor "on," more refrigerant remained in the RTU at test end than for the corresponding compressor "off" tests (low side leak, lower rate tests (117 and 119) being the sole exception).

- No measurable oil release during any of the tests

- A testing procedure was developed, and an algorithm formulated that estimates the quality of a refrigerant leak upstream the point of leakage.

○ Proof-of-concept tests shows the procedure yields results consistent with thermodynamic principals for isenthalpic flow across a throttle

- Tests conducted on the RTU with a $\sim 1 \mathrm{~mm}$ leak orifice showed the following results:

- Low-side leak, unit on Vapor leak, quality $(x)=1$

- Low-side leak, unit off Two-phase leak, $x \sim 0.85$

- High-side leak, unit on Leak quality drops from 1 to 0 in $\sim 35 \mathrm{~s}$

- High-side leak, unit off Leak quality drops from 1 to 0 in $\sim 55 \mathrm{~s}$ 


\section{REFERENCES}

[1] IEC, 2016, IEC 60335-2-40:2016 Household and similar electrical appliances - Safety - Part 2-40: Particular requirements for electrical heat pumps, air-conditioners and dehumidifiers, International Electrotechnical Commission.

[2] UNEP, 2016, "The Kigali Amendment to the Montreal Protocol: HFC Phase-down," United Nations Environment Program OzonAction Fact Sheet, http://multimedia.3m.com/mws/media/1365924O/unepfact-sheet-kigali-amendment-to-mp.pdf.

[3] ASHRAE, 2016, ASHRAE 34-2016 - Designation and Classification of Refrigerants, American Society of Heating, Refrigerating and Air-Conditioning Engineers.

[4] ISO, 2014, ISO 817:2014 Refrigerants - Designation and Safety Classification, International Organization for Standardization.

[5] Clodic, D., and Cai, W., 1996, "Tests and Simulations of Diffusion of Various Hydrocarbons in Rooms from Air-Conditioners and Refrigerators," Proc. IIF - IIR Gustav Lorentzen Conference on Natural Working Fluids - Applications for Natural Refrigerants, Commissions B1, B2, E1 \& E2, Aarhus, Denmark.

[6] Kataoka, O., Ishida, S., Hirakawa, T., and Yoshizawa, M., 1999, "Experimental and numerical analyses of refrigerant leaks in a closed room," ASHRAE transactions, SE-99-19-02, p. 1151.

[7] Kataoka, O., Yoshizawa, M., and Hirakawa, T., 2000, "Allowable charge calculation method for flammable refrigerants," Proc. International Refrigeration and Air Conditioning Conference, Purdue University, West Lafayette, IN.

[8] ISO, 2014, ISO 5149 Refrigerating Systems and Heat Pumps: Safety and Environmental Requirements, International Organization for Standardization.

[9] ASHRAE, 2016, ASHRAE 15-2016 - Safety Standard for Refrigeration Systems, American Society of Heating, Refrigerating and Air-Conditioning Engineers.

[10] IEC, 2010, IEC 60335-2-24:2010 Household and Similar Electrical Appliances - Safety - Part 2-24: Particular Requirements for Refrigerating Appliances, Ice-cream Appliances and Ice makers, International Electrotechnical Commission.

[11] IEC, 2018, IEC 60335-2-40:2018 Household and Similar Electrical Appliances - Safety - Part 2-40: Particular Requirements for Electrical Heat Pumps, Air-conditioners and Dehumidifiers, International Electrotechnical Commission.

[12] IEC, 2010, IEC 60335-2-89:2010 Household and Similar Electrical Appliances - Safety - Part 2-89: Particular Requirements for Commercial Refrigerating Appliances with an Incorporated or Remote Refrigerant Unit or Compressor, International Electrotechnical Commission.

[13] UL, 2017, UL 60335-2-24:2017 Household and Similar Electrical Appliances - Safety - Part 2-24: Particular Requirements for Refrigerating Appliances, Ice-cream Appliances and Ice makers, Underwriters Laboratories. 
[14] UL, 2017, UL 60335-2-40:2017 Household and Similar Electrical Appliances - Safety - Part 2-40: Particular Requirements for Electrical Heat Pumps, Air-conditioners and Dehumidifiers, Underwriters Laboratories.

[15] UL, 2017, UL 60335-2-89:2017 Household and Similar Electrical Appliances - Safety - Part 2-89: Particular Requirements for Commercial Refrigerating Appliances with an Incorporated or Remote Refrigerant Unit or Compressor, Underwriters Laboratories.

[16] UL, 2010, UL 471 - Standard for Commercial Refrigerators and Freezers, Underwriters Laboratories.

[17] UL, 2009, UL 563 - Standard for Ice Makers, Underwriters Laboratories.

[18] Gandhi, P., Hunter, G., Haseman, R., and Rogers, B., 2017, "AHRI Project No. 9007: Benchmarking Risk by Whole Room Scale Leaks and Ignitions Testing of A2L Refrigerants," Prepared for AirConditioning, Heating and Refrigeration Technology Institute by Underwriters Laboratories LLC.

[19] IEC, 1997, IEC 60335-2-24:1997 Safety of Household and Similar Electrical Appliances - Part 2: Particular Requirements for Refrigerating Appliances and Ice makers, International Electrotechnical Commission.

[20] Zucker, R. D., and Biblarz, O., 2002, Fundamentals of Gas Dynamics - 2nd Ed., John Wiley \& Sons, Hoboken, NJ.

[21] ASHRAE, 2017, "2017 ASHRAE Handbook - Fundamentals," Section 6 - Materials, Chapter 30 Thermophysical Properties of Refrigerants, American Society of Heating, Refrigerating and AirConditioning Engineers.

[22] Munson, B. R., Young, D. F., and Okiishi, T. H., 2006, Fundamentals of Fluid Mechanics, John Wiley \& Sons, Inc, USA. 


\section{APPENDIX A. INSTRUMENTATION AND DAS}




\section{APPENDIX A. INSTRUMENTATION, DAS, AND TEST UNITS}

\section{INSTRUMENTATION AND DAS DETAILS}

\section{Refrigerant leak flow rate and total loss}

For the leak flow measurement, two high-precision floor weight scales were used to record the total mass of the test units vs. time during each test. The change in mass was correlated directly with the refrigerant loss. For the mass change of the leak "catch box" system, a third, lower-capacity scale was used.

Relevant specifications of the scales are given in Table A 1 below. The "outdoor unit" scale was used to weigh heavier components, such as the outdoor condensing units for the split AC and unit cooler, as well as the refrigerated display case and RTU. The "indoor unit" scale was used to weigh the indoor units for the split AC and unit cooler, as well as the PTAC unit. The outdoor and indoor scales were factorycalibrated, while the leak pan scale was calibrated on-site using precise weights; the calibration curve for the leak pan scale is shown in Figure A 1.

Table A 1. Scale specifications

\begin{tabular}{|c|c|c|c|c|c|}
\hline Scale & Make and model \# & $\begin{array}{l}\text { Maximum } \\
\text { capacity }\end{array}$ & Readability & $\begin{array}{l}\text { Base } \\
\text { size }\end{array}$ & Weighing terminal \\
\hline $\begin{array}{l}\text { Outdoor } \\
\text { unit scale }\end{array}$ & $\begin{array}{l}\text { Mettler Toledo } \\
\text { PFK988-C300 }\end{array}$ & $300 \mathrm{~kg}$ & $\begin{array}{l}\text { 60,000d non- } \\
\text { approved } \\
\quad \pm 5 \mathrm{~g}\end{array}$ & $\begin{array}{c}800 \mathrm{x} \\
1000 \\
\mathrm{~mm}\end{array}$ & $\begin{array}{l}\text { IND } 570 \text { with Ethernet/IP- } \\
\text { Modbus TCP Interface }\end{array}$ \\
\hline $\begin{array}{l}\text { Indoor unit } \\
\text { scale }\end{array}$ & $\begin{array}{l}\text { Mettler Toledo } \\
\text { PBK989-B120 }\end{array}$ & $120 \mathrm{~kg}$ & $\begin{array}{l}60,000 \mathrm{~d} \text { non- } \\
\text { approved } \\
\quad \pm 2 \mathrm{~g}\end{array}$ & $\begin{array}{c}400 \mathrm{x} \\
500 \mathrm{~mm}\end{array}$ & $\begin{array}{l}\text { IND570 with Ethernet/IP- } \\
\text { Modbus TCP Interface }\end{array}$ \\
\hline $\begin{array}{l}\text { Leak pan } \\
\text { scale }\end{array}$ & $\begin{array}{l}\text { Sartorius Midrics } \\
\text { MW1P1U-30ED-L }\end{array}$ & $30 \mathrm{~kg}$ & $\begin{array}{l}15,000 \mathrm{~d} \\
\pm 2 \mathrm{~g}\end{array}$ & $\begin{array}{c}400 \mathrm{x} \\
300 \mathrm{~mm}\end{array}$ & $\begin{array}{c}\text { Midrics Scale Indicator } \\
\text { MIS1 with } 4-20 \mathrm{~mA} \\
\text { output }\end{array}$ \\
\hline
\end{tabular}




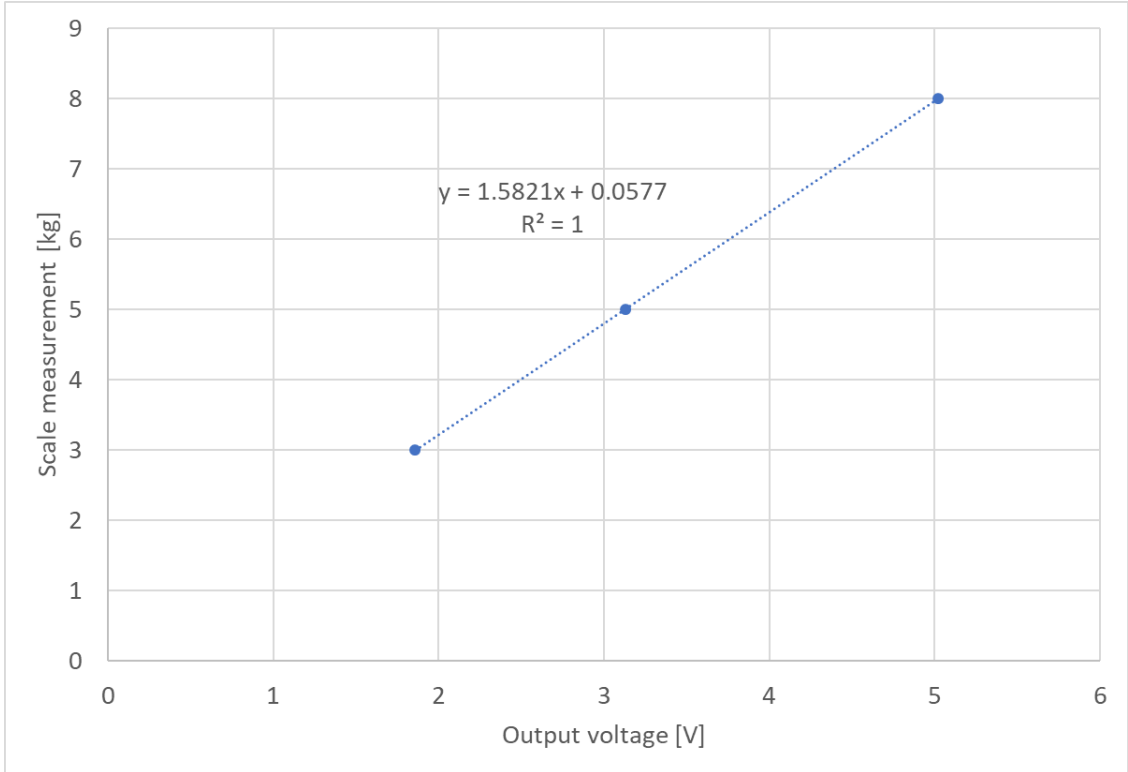

Figure A 1. Calibration curve for leak pan scale

\section{Refrigerant/oxygen concentration sensors}

As noted in Section 2.3, for measurement of refrigerant concentration in the test chamber during leak events, $12 \mathrm{O}_{2}$ deprivation sensors were used. Although not a direct refrigerant measurement, the approach has been used by Underwriter's Laboratories (UL) in a follow-on project to AHRTI-9007 [18] with reasonable accuracy. Relevant specifications of the $\mathrm{O}_{2}$ sensors are given in Table A 2. The sensors also had built-in type-K thermocouple for reference temperature measurement.

Table A 2. O2 sensor specifications

\begin{tabular}{|l|c|}
\hline Make and model & $\begin{array}{c}\text { Apogee }{ }^{\mathrm{SO}} \mathrm{SO}-220 \mathrm{Fast} \\
\text { Response } \mathrm{O}_{2} \text { sensor }\end{array}$ \\
\hline Measurement technique & $\begin{array}{c}\text { Gaseous } \mathrm{O}_{2} \\
\text { measurement, Galvanic } \\
\text { cell type }\end{array}$ \\
\hline $\begin{array}{l}\text { Response time (time required to } \\
\text { read 90\% of saturated response) }\end{array}$ & \begin{tabular}{c}
14 seconds \\
\hline Measurement range
\end{tabular} \\
\hline $\begin{array}{l}\text { Sensitivity (at sea level, } 101.3 \\
\text { kPa) }\end{array}$ & $\begin{array}{c}12-13 \mathrm{mV} \text { in } 21 \% \mathrm{O}_{2} \\
6.6 \mathrm{mV} \text { per } \% \mathrm{O}_{2}\end{array}$ \\
\hline Output at 0\% $\mathrm{O}_{2}$ & $0.01 \% \mathrm{O}_{2}$ \\
\hline Non-linearity & $\begin{array}{c}2 \% \text { of output at } 20.95 \% \\
\mathrm{O}_{2} \text { or } 0.2 \pm 0.1 \mathrm{mV}\end{array}$ \\
\hline Signal decrease per year & Less than $1 \%$ \\
\hline Oxygen consumption rate & $\begin{array}{c}6.3 \% \text { per year }(0.8 \mathrm{mV} \\
\text { per year) }\end{array}$ \\
\hline Operating environment & $\begin{array}{c}2.2 \mu \mathrm{mol} \mathrm{O}_{2} \text { per day at } \\
20.95 \% \mathrm{O}_{2} \text { and } 23^{\circ} \mathrm{C}\end{array}$ \\
\hline
\end{tabular}




\section{Visualization approach}

For general visualization of the leak events, five GoPro HERO5 Session ${ }^{\mathrm{TM}}$ cameras were mounted at different viewing locations. Table A 3 gives the general specifications of the cameras that were used. A snapshot of the views and camera angles for a typical test for the split AC are shown in Figure A 2. It is planned to make video files for all the tests available through the US DOE Office of Scientific and Technical Information (OSTI). A compressed file with all the video files will be uploaded to the OSTI site. Individual videos will have the following file naming convention:

$$
\begin{aligned}
& \text { "test-unit-name_test-number_camera-location.mp4" } \\
& \text { e.g., "Split-AC_test109_*.mp4 } \\
& \text { where * is } \\
& \text { - } \text { AboveLeak } \\
& \text { - } \text { BackLeft } \\
& \text { - } \text { BackRight } \\
& \text { - InLeakPan } \\
& \text { - } \text { Left }
\end{aligned}
$$$$
\text { e.g., "Split-AC_test109_*.mp4 }
$$

Table A 3. Nominal-speed camera specifications

\begin{tabular}{|l|c|}
\hline Make and model & GoPro HERO5 Session ${ }^{\mathrm{TM}}$ \\
\hline Photo & \\
\hline Video & $\begin{array}{r}\text { 10 MP/30 FPS burst/time lapse } \\
\text { 1440p 60 FPS } \\
\text { 1080p 90 FPS }\end{array}$ \\
\hline Waterproof & Yes \\
\hline $\begin{array}{l}\text { Sync capability } \\
\text { with other } \\
\text { cameras }\end{array}$ & Yes \\
\hline
\end{tabular}



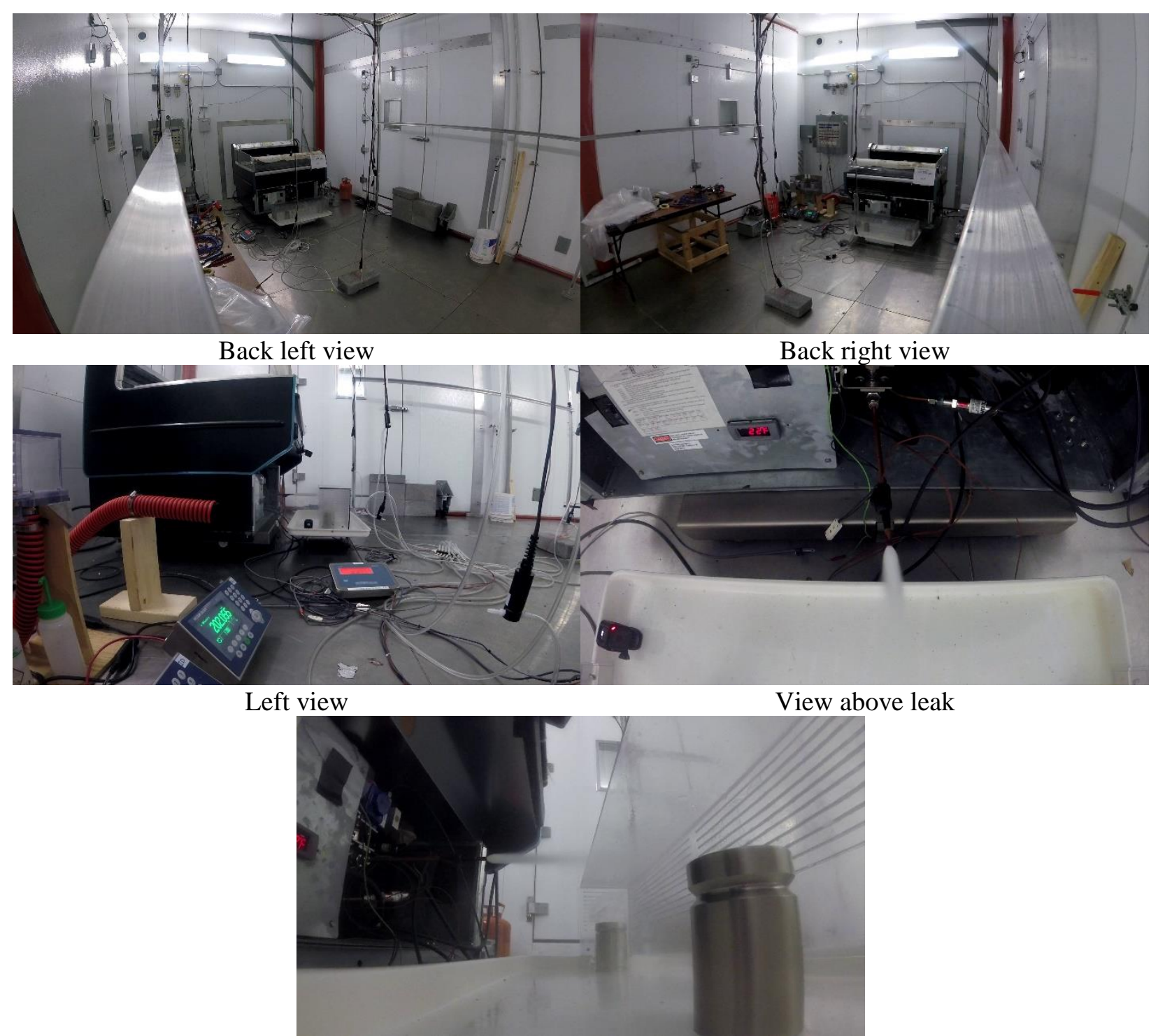

View from leak pan

Figure A 2. Snapshots of different camera angles captured during a typical display case test

\section{General sensors and controls}

Two separate data acquisition systems (DAS) were used. One was based on a PC connected to National Instruments hardware for very fast scanning $(10 \mathrm{samples} / \mathrm{sec})$ of the key leak parameters (scale readings, system pressures, temperatures at leak point, power for compressor and unit etc.). The main test chamber DAS was used for controlling and recording chamber ambient temperatures and system operation data.

Data acquisition hardware: Table A 4 shows the National Instruments hardware that was used for the fastscanning measurements and control. 
Table A 4. Data acquisition hardware specifications

\begin{tabular}{|c|c|c|}
\hline Chassis or module & Function & Specifications \\
\hline 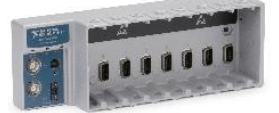 & Chassis & 8-Slot, USB CompactDAQ Chassis \\
\hline NI-9214 & Analog input - temperature & $\begin{array}{c}\text { 16-Channel, } 68 \mathrm{~S} / \mathrm{s} \text { Aggregate, } \pm 78 \\
\text { mV, Isothermal C Series } \\
\text { Temperature Input Module }\end{array}$ \\
\hline 09 & Analog input - voltage & $\begin{array}{l} \pm 10 \mathrm{~V}, 500 \mathrm{~S} / \mathrm{s}, 16-\text { Channel C } \\
\text { Series Voltage Input Module }\end{array}$ \\
\hline & Analog input - current & $\begin{array}{l}500 \mathrm{~S} / \mathrm{s}, \pm 20 \mathrm{~mA}, 16 \text {-Channel C } \\
\text { Series Current Input Module }\end{array}$ \\
\hline NI-9472 & Digital I/O & $\begin{array}{c}24 \text { V, 8-Channel (Sourcing Output) } \\
100 \text { s C Series Digital Module }\end{array}$ \\
\hline
\end{tabular}

Data acquisition software: National Instruments LabVIEW software was used to interface with the hardware, acquire data from sensors and generate control signals for the solenoid valve during leak events. A screenshot of the LabVIEW Virtual Instrument (VI) is shown in Figure A 3 for the unit cooler tests (minor changes were made to the control software for each equipment type). 


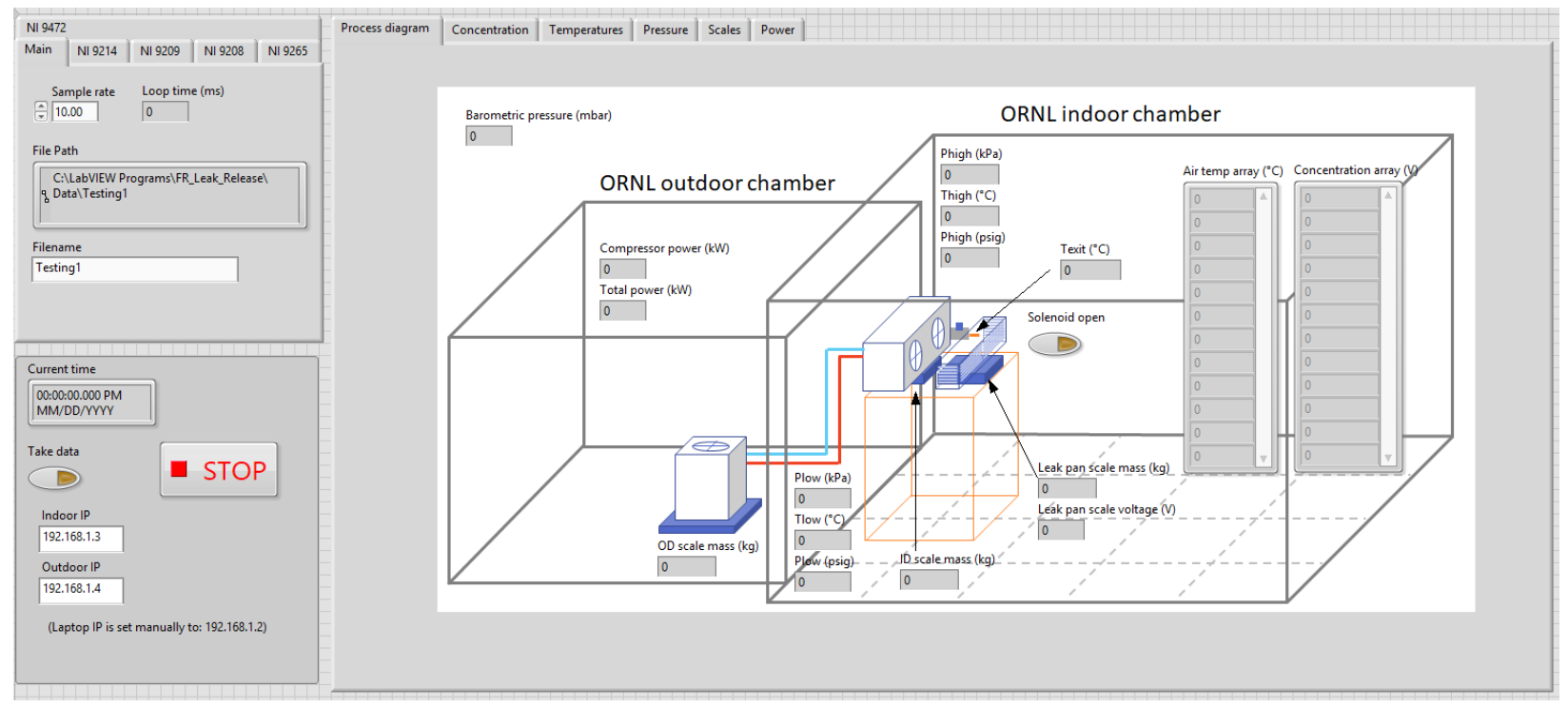

Figure A 3. Screenshot of NI LabVIEW VI used for unit cooler tests

Pressure transducers: Omega pressure transducers (MMA500C1P2D0T4A5CE) were used for measurement of refrigerant pressure on the high- and low-sides of the vapor compression cycles for all tests. The range was $0-500$ psia with a $4-20 \mathrm{~mA}$ output. The maximum measurement uncertainty was $\pm 0.05 \%$ of the full scale.

Temperature sensors: Omega type-T thermocouple probes (TMQSS-062U-6) were used for all temperature measurements (with the exception of type-K thermocouples built into $\mathrm{O}_{2}$ concentration sensors described above). The probes were 6" long and 0.0625 " in diameter, with ungrounded, stainlesssteel sheaths. The maximum measurement uncertainty was $\pm 0.5^{\circ} \mathrm{C}$.

Power measurement: Various transducers were used for power measurement, depending on the equipment being tested, maximum voltage and maximum power. In particular, two Ohio Semitronics Precision Watt transducers (AGW-006D and AGW-008D) were used in different configurations. These transducers had maximum power measurement capacities of up to $4 \mathrm{~kW}$, with the ability to increase the range by installing current transformers. The maximum measurement uncertainty was $\pm 0.2 \%$ of the reading.

Refrigerant release control systems: Three ball valves of nominal sizes of $1 / 4$ ", $1 / 2$ " and 5/16" were purchased for refrigerant release tests, as the different pieces of equipment required different leak diameters. All valves were full-port to minimize the flow resistance of the internal structure of the valve body to the refrigerant flow. All valves were actuated pneumatically for fast response. The same actuator (Parker 51-AC) was used for the 1/4" and the $1 / 2$ " valves, and a different one (OVC 052) was used for the $5 / 16$ " valve. Table A 5 below lists key specifications of each valve.

Table A 5. Refrigerant release valve specifications

\begin{tabular}{|c|c|c|c|c|}
\hline $\begin{array}{c}\text { Valve nominal } \\
\text { size }\end{array}$ & $\begin{array}{c}\text { Orifice } \\
\text { Diameter, } \\
\text { inches }\end{array}$ & $\mathrm{C}_{\mathrm{v}}$ & $\begin{array}{c}\text { Actuation } \\
\text { (opening) } \\
\text { time, seconds }\end{array}$ & $\begin{array}{c}\text { Model number } \\
\text { of the valve }\end{array}$ \\
\hline $1 / 4 "$ & 0.187 & 1.04 & 0.2 & Parker 4A-B6L \\
\hline $1 / 2 "$ & 0.406 & 6.42 & 0.2 & Parker 8A-B8L \\
\hline $5 / 16 "$ & 0.46 & Not listed & 0.25 & OVC 366FT \\
\hline
\end{tabular}




\section{TEST EQUIPMENT DETAILS}

Table A 6. Test systems used in this project

\begin{tabular}{|c|c|c|c|c|}
\hline $\begin{array}{l}\text { Test } \\
\text { unit }\end{array}$ & Manufacturer & Model number(s) & $\begin{array}{c}\text { Nameplate } \\
\text { charge }\end{array}$ & $\begin{array}{c}\text { Charge as } \\
\text { tested }\end{array}$ \\
\hline $\begin{array}{l}\text { Split } \\
\text { AC }\end{array}$ & Lennox & $\begin{array}{l}\text { OD unit: XC16S036- } \\
\text { 230-05 } \\
\text { ID blower: } \\
\text { CBA27UHE-036-230- } \\
\text { 6-01 }\end{array}$ & $\begin{array}{c}8 \mathrm{lb}, 6 \mathrm{oz} \\
(3.799 \mathrm{~kg}), \mathrm{R}- \\
410 \mathrm{~A}\end{array}$ & $\begin{array}{c}8.375 \mathrm{lb} \\
(3.799 \mathrm{~kg})\end{array}$ \\
\hline PTAC & Goodman & PTC123E00CXXXAB & $\begin{array}{c}33 \mathrm{oz}(0.93 \\
\mathrm{kg}), \mathrm{R}-410 \mathrm{~A}\end{array}$ & $\begin{array}{c}33.0 \mathrm{oz} \\
(0.93 \mathrm{~kg})\end{array}$ \\
\hline $\begin{array}{c}\text { Rooftop } \\
\text { AC }\end{array}$ & Rheem & RLPN-A060CK & $\begin{array}{r}63 \text { oz }(1.79 \\
\mathrm{kg}), \mathrm{R}-410 \mathrm{~A}\end{array}$ & $\begin{array}{c}63.1 \mathrm{oz} \\
(1.79 \mathrm{~kg}) \\
\end{array}$ \\
\hline $\begin{array}{c}\text { Display } \\
\text { Case }\end{array}$ & Heatcraft & MX1LC-04CUN & $\begin{array}{c}3.3 \mathrm{lb}(1.5 \\
\mathrm{kg}), \mathrm{R}-404 \mathrm{~A}\end{array}$ & $\begin{array}{c}3.3 \mathrm{lb}(1.5 \\
\mathrm{kg})\end{array}$ \\
\hline $\begin{array}{l}\text { Unit } \\
\text { cooler } \\
\text { system }\end{array}$ & Heatcraft/Bohn & $\begin{array}{l}\text { OD condensing unit: } \\
\text { BHT019165 } \\
\text { ID evaporator/cooler: } \\
\text { LET065 } \\
\end{array}$ & $\begin{array}{c}\mathrm{R}-404 \mathrm{~A}, \text { no } \\
\text { nameplate } \\
\text { charge shown }\end{array}$ & $\begin{array}{c}5 \mathrm{lb}(2.3 \\
\mathrm{kg})^{*}\end{array}$ \\
\hline
\end{tabular}

*testing charge determined using mfrs.' charging instructions 
APPENDIX B. EXPERIMENTAL PROCEDURE 


\section{APPENDIX B. EXPERIMENTAL PROCEDURES}

\section{FILENAME:}

TEST DESIGNATION AND DATE:

\section{Procedure for test with equipment $O N$}

1. Start DAS data

2. Make sure both chambers are running

a. Ambient Temperatures used will be $95 \mathrm{~F}+/-2 \mathrm{~F}$ for the "outdoor portion" and $75 \mathrm{~F}+/-2 \mathrm{~F}$ for the "indoor portion" of the equipment for $\mathrm{AC}$ units. For refrigeration units, $75 \mathrm{~F}+/-2 \mathrm{~F}$ shall be used.

3. Take a photo of the compressor oil level (whenever possible)

4. Turn equipment and blower $\mathrm{ON}$

5. Make sure instrument air is open

6. Make sure scales are reading fine

a. If errored out, lift equipment off the scale and zero it out

7. Start "taking data" from the VI

8. Place the GoPros and connect them up to the remote control

9. Check that ambient temperatures are within the requirements

a. When satisfied, stop the chambers

10. Start recording video (press the red button on remote controller)

11. Start release by opening the solenoid valve

12. After 5 minutes, stop video recording (press red button on remote controller)

13. Wait 20 minutes

14. Stop VI

15. Open the indoor chamber door and start venting fan

16. Start vacuum pump

17. Take a photo of the compressor oil level (whenever possible)

18. Save the video files and the data file in the shared folder

19. Highlight the completed test on the test matrix sheet in the indoor chamber

20. Turn off valve at leak 


\section{FILENAME:}

\section{TEST DESIGNATION AND DATE:}

\section{Procedure for test with equipment OFF}

1. Start DAS data

2. Make sure both chambers are running

a. Ambient Temperatures used will be $95 \mathrm{~F}+/-2 \mathrm{~F}$ for the "outdoor portion" and $75 \mathrm{~F}+/-2 \mathrm{~F}$ for the "indoor portion" of the equipment for AC units. For refrigeration units, $75 \mathrm{~F}+/-2 \mathrm{~F}$ shall be used.

3. Take a photo of the compressor oil level (whenever possible)

4. Turn equipment and blower $\mathrm{ON}$

a. After 10 minutes, turn the equipment OFF but leave the blower $\mathrm{ON}$

b. Start release 10 minutes after turning the equipment OFF

5. Make sure instrument air is open

6. Make sure scales are reading fine

a. If errored out, lift equipment off the scale and zero it out

7. Start "taking data" from the VI

8. Place the GoPros and connect them up to the remote control

9. Check that ambient temperatures are within the requirements

a. When satisfied, stop the chambers

10. Start recording video (press the red button on remote controller)

11. Start release by opening the solenoid valve

12. After 5 minutes, stop video recording (press red button on remote controller)

13. Wait 20 minutes

14. Stop VI

15. Open the indoor chamber door and start venting fan

16. Start vacuum pump

17. Take a photo of the compressor oil level

18. Save the video files and the data file in the shared folder

19. Highlight the completed test on the test matrix sheet in the indoor chamber

20. Turn off valve at leak

START TIME:

END TIME: 
FILENAME:

TEST DESIGNATION AND DATE:

Procedure for unit cooler test with equipment $\mathrm{ON}$

1. Start DAS data

2. Make sure both chambers are running

a. Ambient Temperatures used will be $95^{\circ} \mathrm{F}+/-2^{\circ} \mathrm{F}$ for the "outdoor portion" and $20^{\circ} \mathrm{F}+/-$ $2^{\circ} \mathrm{F}$ for the "indoor portion" of the equipment.

3. Take a photo of the compressor oil level (if possible)

4. Open the liquid line solenoid

5. Turn outdoor unit and indoor unit $O N$

6. Make sure instrument air is open

7. Make sure scales are reading fine

a. If errored out, lift equipment off the scale and zero it out

8. Start "taking data" from the VI

9. Place the GoPros and connect them up to the remote control

10. Check that ambient temperatures are within the requirements

a. When satisfied, stop the chambers

11. Start recording video (press the red button on remote controller)

12. Start release by opening the solenoid valve

13. After 5 minutes, stop video recording (press red button on remote controller)

14. Wait 20 minutes

15. Stop VI

16. Open the indoor chamber door and start venting fan

17. Start vacuum pump

18. Take a photo of the compressor oil level (whenever possible)

19. Save the video files and the data file in the shared folder

20. Highlight the completed test on the test matrix sheet in the indoor chamber

21. Turn off valve at leak

START TIME:

END TIME:

STARTED CAMERA:

STOPPED CAMERA: 
FILENAME:

TEST DESIGNATION AND DATE:

\section{Procedure for unit cooler test with equipment OFF}

1. Start DAS data

2. Make sure both chambers are running

a. Ambient Temperatures used will be $95^{\circ} \mathrm{F}+/-2^{\circ} \mathrm{F}$ for the "outdoor portion" and $20^{\circ} \mathrm{F}+/-$ $2^{\circ} \mathrm{F}$ for the "indoor portion" of the equipment.

3. Take a photo of the compressor oil level (if possible)

4. Open the liquid line solenoid

5. Turn outdoor unit and indoor unit $O N$

a. After 10 minutes, turn both the indoor and outdoor units OFF

b. Close the liquid line solenoid

c. Start release 10 minutes after turning both the indoor and outdoor units OFF

6. Make sure instrument air is open

7. Make sure scales are reading fine

a. If errored out, lift equipment off the scale and zero it out

8. Start "taking data" from the VI

9. Place the GoPros and connect them up to the remote control

10. Check that ambient temperatures are within the requirements

a. When satisfied, stop the chambers

11. Start recording video (press the red button on remote controller)

12. Start release by opening the solenoid valve

13. After 5 minutes, stop video recording (press red button on remote controller)

14. Wait 20 minutes

15. Stop VI

16. Open the indoor chamber door and start venting fan

17. Start vacuum pump

18. Take a photo of the compressor oil level

19. Save the video files and the data file in the shared folder

20. Highlight the completed test on the test matrix sheet in the indoor chamber

21. Turn off valve at leak

START TIME:

END TIME:

STARTED CAMERA:

STOPPED CAMERA: 
APPENDIX C. LEAK QUALITY ESTIMATION

C-1 


\section{APPENDIX C. LEAK QUALITY ESTIMATION}

Quality estimation tests used two high-precision floor weight scales to record the total mass of the RTU test unit and a plastic container as function of time during a refrigerant leakage. The change in mass was correlated directly with the movement of refrigerant. Relevant specifications of the scales are given in Table A 1. The "outdoor unit" scale was used to weigh the RTU. The "indoor unit" scale was used to weigh the 275-gallon (1041 l) capacity, rigid plastic container (Figures 72 and 73). The outdoor and indoor scales were factory-calibrated, Table A 1 . Table C 1 lists a brief synopsis of results for the quality estimation tests. The "Total Pressure Drop" columns in Table C 1 represent the change in high-side pressure (drop) and low-side pressure (rise) inside the unit during the refrigerant release period. A leak orifice diameter of $\sim 1 \mathrm{~mm}$ was used to prevent pressure inside the container from rising too quickly during the test.

Table C 1. Salient Results of Quality Estimation Tests

\begin{tabular}{|c|c|c|c|c|c|c|c|}
\hline \multirow[b]{2}{*}{ Test } & \multirow[b]{2}{*}{$\begin{array}{c}\text { Leak } \\
\text { Period }\end{array}$} & \multicolumn{2}{|c|}{ Total Pressure Drop in RTU } & \multirow{2}{*}{$\begin{array}{c}\text { Container } \\
\text { Pressure at } \\
\text { End of leakage }\end{array}$} & \multirow{2}{*}{$\begin{array}{c}\text { Cont. R- } \\
410 \mathrm{~A} \\
\text { Weight } \\
\text { increase }\end{array}$} & \multirow{2}{*}{$\begin{array}{l}\text { RTU R- } \\
410 \mathrm{~A} \\
\text { Weight } \\
\text { decrease }\end{array}$} & \multirow[b]{2}{*}{$\begin{array}{c}\text { Leak } \\
\text { Quality }\end{array}$} \\
\hline & & High-Side & Low-Side & & & & \\
\hline & $\mathrm{sec}$ & $\mathrm{kPa}$ & $\mathrm{kPa}$ & $\mathrm{kPa}$ & $\mathrm{kg}$ & $\mathrm{kg}$ & 0 to 1 \\
\hline $\begin{array}{l}\text { Low-Side, } \\
\text { RTU Off }\end{array}$ & 180 & 1452.9 & 793.5 & 101.94 & 0.49 & 0.65 & $\sim 0.85$ \\
\hline $\begin{array}{l}\text { Low-Side } \\
\text { RTU On }\end{array}$ & 180 & 124.2 & 270.2 & 100.36 & 0.22 & 0.36 & 1.0 \\
\hline $\begin{array}{l}\text { High-Side } \\
\text { RTU Off }\end{array}$ & 112.6 & 1375.6 & 363.4 & 107.44 & 0.82 & 0.73 & $\begin{array}{l}\text { Drops } \\
\text { from } \sim 1 \\
\text { to } 0.0 \\
\text { within } \\
\sim 55 \mathrm{~s}\end{array}$ \\
\hline $\begin{array}{l}\text { High-Side } \\
\text { RTU On }\end{array}$ & 140.0 & 2116.9 & 383.5 & 106.9 & 0.75 & 0.85 & $\begin{array}{l}\text { Drops } \\
\text { from } \sim 1 \\
\text { to } 0.0 \\
\text { within } \\
\sim 35 \mathrm{~s}\end{array}$ \\
\hline
\end{tabular}

The plastic container was instrumented with temperature and pressure sensors. Stainless steel sheathed Type T copper-constantan thermocouples were used to measure the refrigerant temperatures at several locations in the container. A sensor was placed mid-height in the container directly in line with the $1 \mathrm{~mm}$ orifice spraying leaked refrigerant in the container. Other thermocouples were also placed mid-height to the left and right side and to the back of the container. These 4 measures were averaged to yield a bulk refrigerant temperature inside the container. Another thermocouple was placed on the container floor for detecting liquid refrigerant that might pool if the leak were liquid. Two absolute pressure transducers were installed on the container. The one transducer measured the absolute pressure of the container and had a pressure measurement range of 0 to $344.7 \mathrm{kPa}$ ( 0 to $50 \mathrm{psia})$. The second transducer measured the refrigerant pressure just of upstream the $1 \mathrm{~mm}$ orifice. The second transducer sensed the pressure for both high-side and low-side leaks and had a pressure measurement range of 0 to $3447.4 \mathrm{kPa}$ ( 0 to $500 \mathrm{psia}$ ). A video device was also used to observe the leak flow exiting the orifice (Figure 73). High- and low-side temperatures and pressures were already in place on the RTU and were also recorded during the leak tests. 
A flexible elastomeric thermal insulation was attached to all exterior surfaces of the container to retard heat gain and prevent condensation of water vapor in air near the exterior surfaces of the container. The condensation of water would confound the measure of refrigerant leaked into the container.

\section{TEST PROCEDURE AND FORMULATION OF ALGORITHM}

The MAXLAB environmental chamber was conditioned similarly to tests conducted in Table 2 to allow for an ambient temperature difference between the ID and OD rooms of $11.1^{\circ} \mathrm{C}\left(\sim 20^{\circ} \mathrm{F}\right)$. A vacuum pump was attached to the plastic container to remove any R-410A from previous testing and to bring the container pressure down to slightly below atmospheric pressure; surrounding atmospheric pressure being about $98.6 \mathrm{kPa}$ (14.3 psia). Afterwards, the vacuum pump was shut-off from the container by closing a ball valve. Data collection was initiated but the leak was not immediately introduced. The RTU was deenergized and about $90 \mathrm{~s}$ passed to allow the weigh scales to steady before opening the leak port, Figure C 1 .

Note that several seconds of container pressure and bulk temperature data were used after the RTU deenergized and the leak not energized to compute the mass of air held by the container. The mass of air remained fixed during the leakage period. The number of moles of air were computed and added to the number of moles of R-410A as it leaked into the container. On command, the data acquisition system (DAS) initiated the leak and monitored all data at a $0.1 \mathrm{~s}$ interval. Over the leak interval the weigh scale for the RTU showed a refrigerant loss of $0.73 \mathrm{~kg}(1.6 \mathrm{lb})$ while the container weight scale container showed a refrigerant gain of $0.82 \mathrm{~kg}(1.8 \mathrm{lb})$, Figure $\mathrm{C} 1$. We feel that the differences are most likely due to differing thrust effects on the scale readings. As discussed in Section 4 of the report, the weight measure used to compute quality estimates differed depending on the operating state of the RTU. If the RTU was on, the container measurement was felt to be more accurate (less subject to thrust noise) and was used. With the RTU off, the RTU scale was felt to be more accurate so it was used. Both Dalton's Law of Additive pressures [23] and Amagat's law of additive volumes [23] were used with the molar mass fraction to compute the partial pressures and partial volumes of R-410A and air in the container. Given these values the bulk density of R-410A was computed from Equation 1 as:

$$
\bar{\rho}_{\text {ref }}=\frac{m_{\text {ref }}}{\left[y_{r e f} \cdot V o l_{\text {cont }}\right]}
$$

where

$$
y_{\text {ref }}=\frac{\eta_{\text {ref }}}{\eta_{\text {ref }}+\eta_{\text {air }}}
$$

is the mole fraction of refrigerant in the refrigerant and air mixture. A relationship was derived for the quality of refrigerant [24] in the container which takes the form:

$$
x(t)_{\text {cont }}=\frac{\rho_{v}}{\left(\rho_{v}-\rho_{L}\right)}-\frac{\rho_{v}}{\bar{\rho}_{\text {ref }}}\left[\frac{\rho_{L}}{\rho_{v}-\rho_{L}}\right]
$$

If the saturated liquid density is much greater than the saturated vapor density, then to first order the quality simplifies to: $x(t)_{\text {cont }}=\frac{\rho_{v}}{\bar{\rho}_{\text {ref }}}$. Calculation of the container quality (Equation 2) allows one to estimate the liquid and vapor content of the refrigerant released through the orifice. Measuring the amount of liquid pooling on the bottom of the container is too difficult and intrusive on the container and most likely leading to greater error than observed using Equation 2. The approach using the quality in the container was selected because of its simplicity leading hopefully to better accuracy of the quality 
estimate. Next an energy balance for the container was formulated much like the charging of a vessel. The balance takes the form:

$$
h_{\text {Leak }}=\frac{(U)_{2}-(U)_{1}}{\left(m_{2}-m_{1}\right)}-\frac{\dot{Q}_{c v} \cdot \Delta t}{\left(m_{2}-m_{1}\right)}
$$

where:

$$
\begin{array}{rc}
\text { internal energy } \mathrm{U}_{1} \text { at time } \mathrm{t} & U_{1}=\left[m_{f \text { vap }} \cdot u_{\text {vap }}+m_{f \text { liq }} \cdot u_{\text {liq }}\right]_{1} \\
\text { internal energy } \mathrm{U}_{2} \text { at time } \mathrm{t}+\Delta \mathrm{t} & U_{2}=\left[m_{f \text { vap }} \cdot u_{v a p}+m_{f \text { liq }} \cdot u_{\text {liq }}\right]_{2} \\
& m_{1} \\
\text { mass of refrigerant in container at time } \mathrm{t} & m_{2} \\
\text { mass of refrigerant in container at time } \mathrm{t}+\Delta \mathrm{t} & \dot{Q}_{c v}=\dot{m}_{r e f} \cdot h_{f g} \\
\text { heat transfer due to flashing of refrigerant } & \dot{m}_{\text {ref }}=\frac{m_{2}-m_{1}}{\Delta t} \\
\text { mass flow of refrigerant entering container } &
\end{array}
$$

The throttling process is assumed isenthalpic with minimal heat loss across the orifice and therefore the enthalpy $h_{\text {Leak }}$ represents the enthalpy upstream the throttle. It can be used in Equation 4 to compute the quality of the refrigerant as:

where

$$
x(t)_{\text {ref }}=\frac{\left[h_{\text {Leak }}-h_{\text {sat liq }}\right]}{h_{f g}}
$$

$h_{\text {sat liq }}$ enthalpy based on pressure of R-410A measured in the RTU

$h_{f g} \quad$ change in enthalpy saturated vapor to saturated liquid based on pressure in the RTU

Computations using Equations 1 through 4 are displayed in Figure C 2. Refrigerant weight measurement for this test came from the RTU scale because the unit was off and there was some thrust effect being

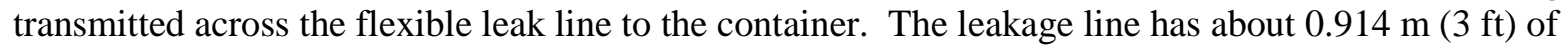
travel from the RTU's evaporator coil to the $1 \mathrm{~mm}$ orifice in the container. This line is open to the atmosphere of the container until the solenoid energizes and allows the flow of refrigerant through the line to the orifice. Quality starts at 1 all vapor but within $1 \mathrm{~s}$ drops to 0.8 and in less than a min becomes all liquid (i.e., quality of 0). These results are very similar to those shown in Figure 80 for a high-side leak with the RTU running while leaking refrigerant.

As the leak progressed the container pressure was closely monitored so that the container would not exceed atmospheric conditions. A pressure relief valve on the container was set at $110 \mathrm{kPa}$ (16 psia) as a safety. Figure $\mathrm{C} 3$ shows the change in container pressure caused by a refrigerant leak introduced from the high-side with the RTU running. The container pressure rose from 100 to $107.4 \mathrm{kPa}$ (14.5 to 15.6 psia). After the solenoid valve closed, the container pressure remained steady for about 3 min showing the container leak tight. 


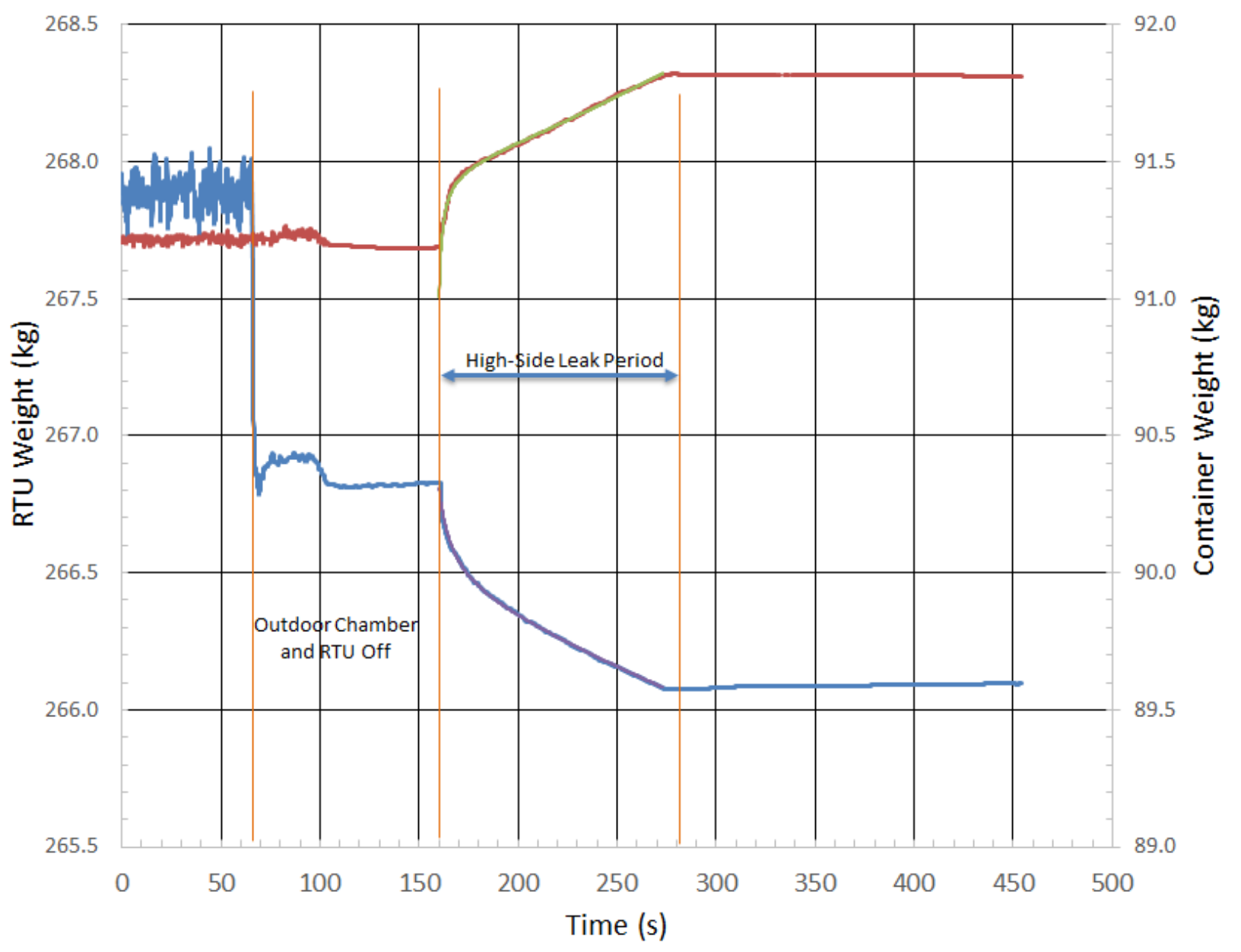

Figure C 1. Container and RTU weights measured during refrigerant leaking from the high-side with the RTU deenergized 


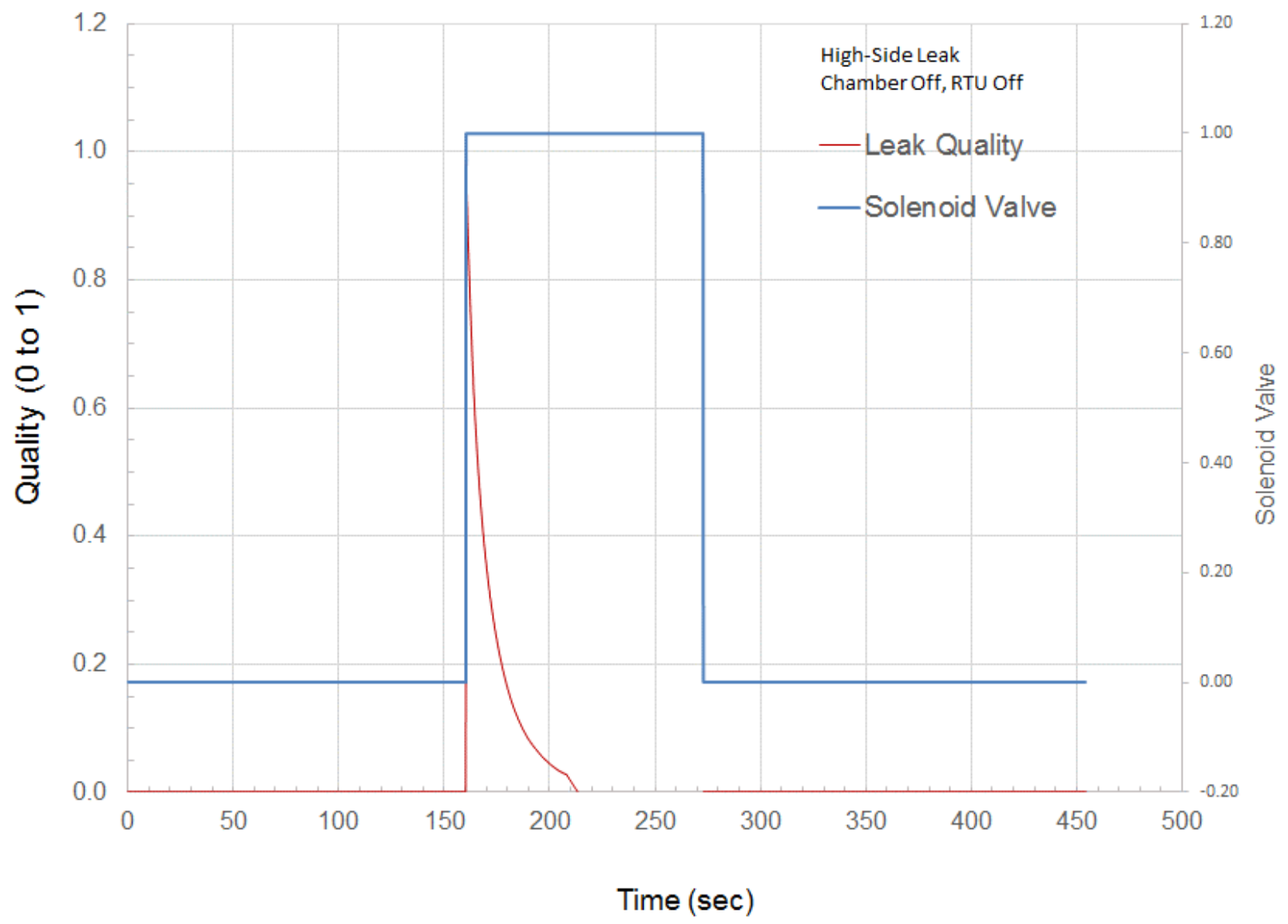

Figure C 2. Refrigerant quality computed upstream the orifice during refrigerant leaking from the high-side with the RTU deenergized 


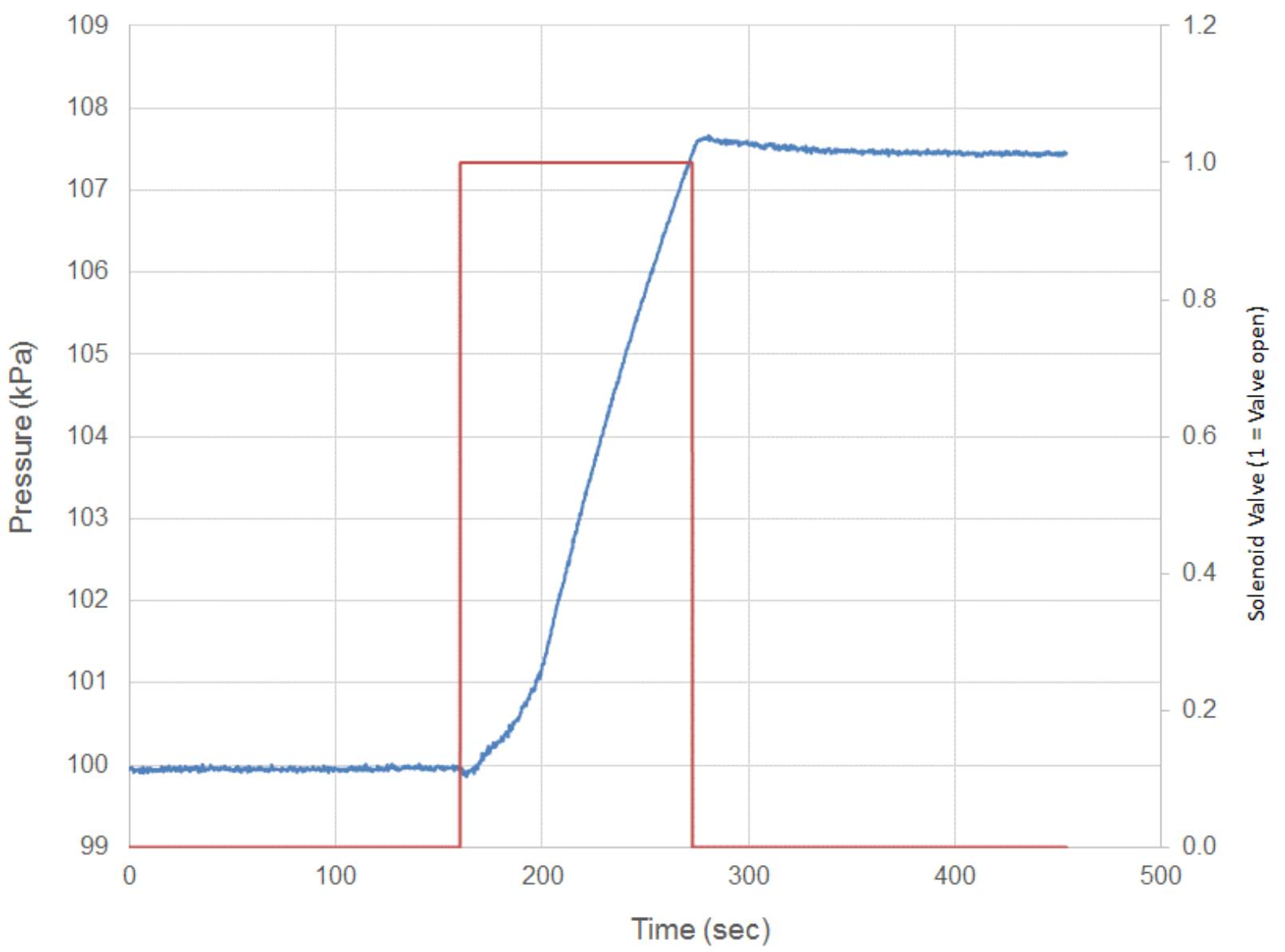

Figure C 3. Container pressure measured during refrigerant leaking from the high-side with the RTU deenergized 